\title{
Lunar Remote Sensing and Measurements
}

GEOLOGICAL SURVEY PROFESSIONAL PAPER 1046-B

Prepared on behalf of the

National Aeronautics and Space Administration

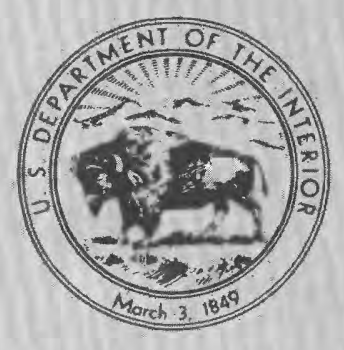




\section{Lunar Remote Sensing and Measurements}

By H. J. MOORE, J. M. BOYCE, G. G. SCHABER, and D. H. SCOTT

A P O L L O $15-17$ O R B I T A L I N V E S T I G A T I O N S

GEOLOGICAL SURVEY PROFESSIONAL PAPER 1046-B

Prepared on behalf of the

National Aeronautics and Space Administration

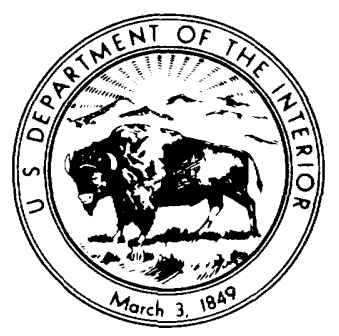

UNITED STATES GOVERNMENT PRINTING OFFICE, WASHINGTON : 1980 


\title{
UNITED STATES DEPARTMENT OF THE INTERIOR
}

CECIL D. ANDRUS, Secretary

\section{GEOLOGICAL SURVEY}

H. William Menard, Director

\author{
Library of Congress Cataloging in Publication Data \\ United States. Geological Survey. \\ Lunar remote sensing and measurements. \\ (Apollo 15-17 orbital investigations) (Geological Survey professional \\ paper ; 1046-B) \\ Bibliography: p. B70-B78. \\ Supt. of Docs. no.: I 19.16:1046-B \\ 1. Moon-Remote sensing, 2. Project Apollo. I. Moore, Henry J. \\ II. Title. III. Series. IV. Series: United States. Geological Survey. \\ Professional paper ; 1046-B. \\ QB591.U54 $1979 \quad 559.9^{\prime} 1 \quad 79-607805$
}

For sale by the Superintendent of Documents, U.S. Government Printing Office Washington, D.C. 20402

Stock Number 024-001-03265-1 


\section{CONTENTS}

Abstract

Introduction

Acknowledgments

Apollo orbital results

Ages of lunar plains, by J. M. Boyce and H. J. Moore

Review of methods of estimating relative ages ........

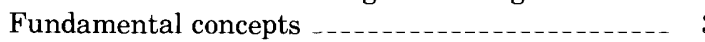
Rapid method for determining relative ages -..-- 5 Pitfalls in determining relative ages _-_-_-_-_ 6

Relative ages of lunar plains _._._._._._._. 8

Correlation of relative ages with radiometric ages _... 9

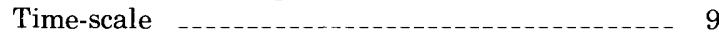
Cratering rate with time _._._._._._._._._._. 11

Comparison of relative ages with other remotely sensed data

Geologic map units

Regolith thickness _._.

Bistatic-radar results

Discussion _-_._-_._. 14

Early major events _..._. 15

Cratering rate

Maria_...._. 18

Western maria _-_- 18

Lunar gravity and tectonics, by D. H. Scott _-__-_-_ 18

Methods of analysis and application

Gravity and geologic structure _._._._. 21

Summary and conclusion

Lunar magnetism, by G. G. Schaber _............ 22

Orbital magnetic data

Lunar surface and sample magnetic data _._._._._._- 23

Origin of lunar magnetism _._._._. 23

Geologic analysis and significance of lunar NRM _-_-_ 27

Orbital geochemistry, by H. J. Moore _._._._._._._._._. 29

X-ray fluorescence spectrometry ______ 29

Description -..._. 29

Results _.

Gamma-ray spectrometry

Description …_. 31
Apollo orbital results-Continued

Orbital geochemistry, by H. J. Moore-Continued

Gamma-ray spectrometry-Continued

Results

Discussion --_-

Bistatic radar, by H. J. Moore _..._._._. 34

Comparison of radar roughness with lunar terrain _._- 34

Correlation with geologic map units_..._-_._-_._-_- 37

Correlation with infrared eclipse temperatures ___._. 37

Slope-probability distribution

Discussion _..._. 40

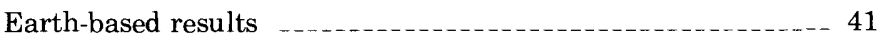

Reflection of solar radiation with wavelengths from $0.3 \mu \mathrm{m}$ to $2.2 \mu \mathrm{m}$, by G. G. Schaber

Photometry and polarization of sunlight

Color -_-_-_- 43

Spectral reflectivity -_-_-_-_-_- 43

Spectral response and chemical composition _._____- 47

Comments -................. 51

Reflection of radar waves from earth-based stations, by G. G. Schaber and H. J. Moore _... 52

Radar maps _._.

Echoes and lunar features

Laboratory studies

Discussion _- 58

Infrared eclipse temperatures, by H. J. Moore --_-_-_-_- 61

Eclipse temperatures and lunar features _._._._._. 61

Causes of high infrared eclipse temperatures _-_._- 64

Discussion - 65

A basis for extrapolation -

Duration of volcanic activity _-___ 66

Early cratering history before 3.84 b.y. ago _________-_ 66

Lunar multiringed basins and the provenance of lunar

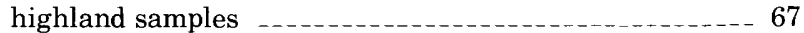

Regional and local chemical variations 68

Variation of physical properties and roughness of lunar surface - 69

References cited _._. 70

\section{ILLUSTRATIONS}

1. Cumulative frequency distributions of craters for three ages of surfaces

2. Relationships between $D_{L}, K$, and $C_{s}$

3. Comparison of the observed and predicted ratio of unshadowed to shadowed craters as a function of crater diameter

4. Ratio of unshadowed to shadowed craters as a function of diameter for floors of Albategnius and Meton

5. Effects of photograph resolution on the determination of relative ages

6. Errors in measurement of crater diameter as a function of sun elevation angle

7. Sample area necessary to establish $D_{s}$

8. Histograms of relative ages of lunar plains 
10. Comparison of relative ages and radiometric ages and incremental flux of objects producing small craters 11

11. Size frequency distribution of craters on flanks of North Ray crater (Apollo 16)

12. Correlation between median regolith thickness and relative age of surface

13. Bistatic-radar roughness and relative ages _._.

14. Size frequency distributions of craters for selected lunar areas

15. Topographic profile of Theophilus .

16. Topographic and gravity profiles through Montes Secchi

17. Maps showing magnetic anomalies _..

18. Diagram showing Apollo 15 laser altimeter data

19. Map showing Apollo 15 and 16 gamma-ray results

20. Graph showing reflection coefficient for single orbit of $0.5-\mathrm{keV}$ electron data obtained at high rate from the

Apollo 16 subsatellite

21-24. Maps showing:

21. Aluminum-silicon intensity ratios for the lunar near side from the Apollo 15 and $16 \mathrm{X}$-ray fluorescence experiments _...

22. Concentrations of five elements from the Apollo 15 and 16 gamma-ray spectrometer experiments ...... 32

23. Hand-calculated root-mean-square slopes along the Apollo 14 bistatic-radar experiment subspecular track 35

24. Machine-calculated root-mean-square slopes along the Apollo 15 and 16 bistatic radar experiment subspecular tracks

25-32. Graphs showing:

25. Comparison of average S-band and VHF root-mean-square slopes for selected geologic map units along the

26. Comparison of average S-band root-mean-square slopes and albedos for selected geologic units along the Apollo 14, 15, and 16 bistatic-radar tracks

27. Comparison of S-band root-mean-square slopes and average infrared eclipse temperatures for selected

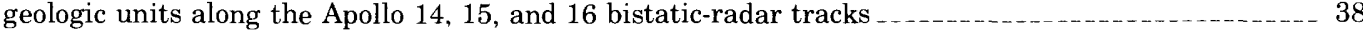

28. Bistatic-radar and photogrammetry slope-probability distributions of the normal type for highlands near Vitruvius

30. Bistatic-radar and photogrammetry slope-probability distribution of the complex type for highlands near Glaisher

31. Comparison of algebraic standard deviations estimated from slope-probability distributions measured by radar- and machine-calculated root-mean-square slopes _......... 40

32. Polarization of light of the Moon

33. Composite color-difference photograph of the Moon 34-40. Graphs showing:

34. Normalized spectral reflectivity for selected lunar surfaces $\ldots$

35. Relative spectral reflectivity for a series of background mare and highland areas

36. Relative spectral reflectivity for selected craters in lunar maria and highlands

37. Spectral reflectance for several common minerals

38. Position of short-wavelength absorption band plotted against long-wavelength band for Apollo samples _.. 48

39. Spectral reflectivity of glass made from 12063 whole-rock powder

40. Plot of titanium oxide percentage in bulk lunar soils as a function of $0.400 \mu \mathrm{m}$ to $0.565 \mu \mathrm{m}$ slope

41. Maps of polarized and depolarized 3.8-cm radar echoes from the Moon

42. Maps of polarized and depolarized 70-cm radar echoes from the Moon

43. Graphs showing comparison of polarized and depolarized echoes of $3.8-\mathrm{cm}$ and $70-\mathrm{cm}$ radar

44. Map showing infrared eclipse temperatures, albedos, and $3.8-\mathrm{cm}$ and $70-\mathrm{cm}$ radar depolarized echoes along the Apollo 14 bistatic-radar track

45. Map showing 3.8-cm and 70-cm radar depolarized echoes along the Apollo 15 and 16 bistatic-radar tracks _._._. 60

46. Picture showing scaled infrared eclipse temperatures of lunar near side

47. Map showing infrared eclipse temperatures and albedos along the Apollo 15 and 16 bistatic-radar tracks

48. Graph showing average infrared eclipse temperatures and albedos of maria, highlands, and selected craters along the Apollo 14, 15, and 16 bistatic-radar tracks 
TABLES

TABLE

1. Comparison of results from relative age measurements $\left(D_{L}\right)$, net accomulated flux $(K)$, and upper limiting size $\left(C_{s}\right) \quad \begin{array}{r}\text { Page } 6 \\ \text { B.- }\end{array}$

2. Diameters of craters measured stereoscopically and monoscopically, and measurement error -

8

3. Relative ages of lunar plains and some craters

4. Relative ages of Apollo landing sites and radiometric ages of rocks returned from the Apollo landing sites

9

5. Calculated incremental fluxes for small craters during the last 3.9 billion years

6. Comparison of regolith thickness and relative age of surface $\left(D_{L}\right)$

7. Aluminum-silicon intensity ratios associated with fourth order trend surface residuals and selected lunar features $\ldots 31$

8. Concentrations of five elements from the Apollo 15 and 16 gamma-ray spectrometer experiments

9. Comparison of machine-calculated rms slopes, hand-calculated rms slopes, and algebraic standard deviations estimated from slope-probability distributions _._.

10. List of selected craters and areas in Apollo zone with relatively high eclipse temperatures for general area 


\title{
LUNAR REMOTE SENSING AND MEASUREMENTS
}

\author{
By H. J. Moore, J. M. Boyce, G. G. Schaber, and D. H. Scott
}

\section{ABSTRACT}

Remote sensing and measurements of the Moon from Apollo orbiting spacecraft and Earth form a basis for extrapolation of Apollo surface data to regions of the Moon where manned and unmanned spacecraft have not been and may be used to discover target regions for future lunar exploration which will produce the highest scientific yields. Orbital remote sensing and measurements discussed include (1) relative ages and inferred absolute ages, (2) gravity, (3) magnetism, (4) chemical composition, and (5) reflection of radar waves (bistatic). Earth-based remote sensing and measurements discussed include (1) reflection of sunlight, (2) reflection and scattering of radar waves, and (3) infrared eclipse temperatures. Photographs from the Apollo missions, Lunar Orbiters, and other sources provide a fundamental source of data on the geology and topography of the Moon and a basis for comparing, correlating, and testing the remote sensing and measurements.

Relative ages obtained from crater statistics and then empirically correlated with absolute ages indicate that significant lunar volcanism continued to 2.5 b.y. (billion years) ago-some 600 m.y. (million years) after the youngest volcanic rocks sampled by Apollo- and that intensive bombardment of the Moon occurred in the interval of 3.84 to 3.9 b.y. ago. Estimated fluxes of crater-producing objects during the last $50 \mathrm{~m} . y$. agree fairly well with fluxes measured by the Apollo passive seismic stations.

Gravity measurements obtained by observing orbiting spacecraft reveal that mare basins have mass concentrations and that the volume of material ejected from the Orientale basin is near 2 to 5 million $\mathrm{km}^{3}$ depending on whether there has or has not been isostatic compensation, little or none of which has occurred since 3.84 b.y. ago. Isostatic compensation may have occurred in some of the old large lunar basins, but more data are needed to prove it.

Steady fields of remanent magnetism were detected by the Apollo 15 and 16 subsatellites, and the lunar dipole field was revised to no more than $6 \times 10^{19}$ gauss. High-resolution mapping of fields of weak remanent magnetism (to 0.1 gamma) was made possible by the Apollo plasma and energetic-particle experiment. Although the causes of remanent magnetism are poorly understood, correlations with geologic units suggest the results may ultimately have farreaching significance to lunar history. Maria are much less structured by strong surface magnetic anomalies than the highlands. The strongest anomalies are associated with ejecta of farside basins, plains materials filling pre-Imbrian craters, and other old Imbrian to pre-Imbrian units. The high remanent fields could be due to cooling of ejecta units in an ancient magnetic field, lunar regolith maturity, extensive reworking and disruption of a magnetized layer, or simply surface roughness.

Orbital geochemical experiments have shown that lunar high- lands have larger $\mathrm{Al}: \mathrm{Si}$ ratios and smaller $\mathrm{Mg}: \mathrm{Si}$ ratios than maria. These two ratios are inversely related on a regional basis. With the exception of fresh craters, albedo and $\mathrm{Al}: \mathrm{Si}$ ratios vary directly, showing that compositional differences as well as exposure of fresh materials are responsible for high albedos. Statistically treated data show that geologic contacts and compositional boundaries are concentric and can be roughly matched. Some craters on mare material have penetrated the mare fill, bringing highland-type materials to the surface. Natural radioactivity from thorium, potassium, and uranium is inversely correlated with elevation. Mare regions are enriched in iron, titanium, and magnesium relative to the highlands.

Orbital bistatic-radar results provide estimates of surface roughness at two scale lengths (about $30 \mathrm{~m}$ and $250 \mathrm{~m}$ ), which agree with visual estimates of roughness. The dielectric constant of the lunar surface, where sampled, is uniform to $13-\mathrm{cm}$ radar and near 3 . Slope frequency distributions measured by the radar vary and may be logarithmic, gaussian, or complex in form.

Study of sunlight reflected from the lunar surface proved to be accurate in predicting the microscale physical properties of the lunar surface, and also the spectral character of the reflected light reveals differences in color related to chemical composition and maturation of the lunar regolith. Color-difference photographs reveal boundaries between highland and mare units as well as boundaries of units within the maria and highlands. Spectral reflectance data show that map units have unique spectral characteristics: (1) fresh mare craters are different from fresh highland craters, (2) mature maria are different from mature highlands, and (3) units within the maria vary. Spectral reflectances of returned samples correlate with those derived from Earth-based telescopes.

Lunar depolarized echoes of radar signals from Earth are affected by the physical and chemical properties of the lunar surface. Although the properties affecting the echoes are only partly understood, lunar surfaces can be classified by their echoes. Depolarized echoes from lunar maria are typically weaker than those from highlands. Young craters have echoes that are much stronger than average. Some areas with low albedos have echoes that are much weaker than average.

Infrared eclipse temperatures separate the Moon's features into two major groups: maria which are relatively warm and highlands which are relatively cool. Superposed on this general pattern are "hot spots" which coincide with young craters and "cold spots" which coincide with dark mare-like materials. With the exception of hot and cold spots, infrared eclipse temperatures are inversely correlated with albedo. High eclipse temperatures are the result of blocky and relatively coarse grained regoliths. 
Extrapolation of remote sensing and measurements indicate five problems that could be resolved by selecting proper sites and experiments for future exploration: (1) the duration of volcanic activity on the Moon, (2) early cratering history of the Moon before 3.85 b.y. ago, (3) the characteristics of multiringed basins and the provenance of lunar highland samples, (4) high-resolution regional and local chemical variations, and (5) variations of physical properties and roughness of the lunar surface. The first problem can be resolved by collecting samples from western maria where the combined evidence from remotely measured relative ages, infrared eclipse temperatures, and photogeologic evidence indicate that very young maria are present. The second and third problems could be resolved by a landed-sample return mission to a relatively young lunar basin such as Orientale where the basin and ejecta units are well preserved. This mission should be combined with orbital and surface gravity measurements to determine if isostatic equilibrium was achieved in early lunar history. The fourth problem can best be resolved with highresolution orbital geochemical experiments like those of Apollo combined with spectral reflectances measured from orbit. The last problem could be resolved with a set of suitably designed experiments on a polar orbiting spacecraft, such as a bistatic-radar experiment measuring quasi-specular and diffuse echoes, an infrared experiment measuring the thermal responses of lunar surfaces under a variety of insolation conditions, a high-resolution imaging experiment, and a photometry experiment.

\section{INTRODUCTION}

This paper is one of four separate chapters summarizing Apollo 15-17 orbital investigations; it summarizes those data from remote sensing which extend the results from the Apollo landed missions to other parts of the Moon and indicates some unresolved lunar problems. This is done in two parts: (1) results from the Apollo orbital experiments and photography which are confined to areas beneath the orbits of the spacecraft and (2) results from terrestrial observations, which are confined to the Earth-facing side of the Moon. The results reported were obtained as part of NASA (National Aeronautics and Space Administration) Experiment S-222 (Photogeology-Apollo 15-17), which started in March 1972 and ended December 1975.

Samples returned by the Apollo missions to the Moon have shown that the Moon was differentiating in the interval from 4.55 billion years (b.y.) ago (Papanastassiou and Wasserburg, 1975) to 4.35 b.y. ago (Lugamair and others, 1975). Possibly during this interval, and subsequently from about 4.0 b.y. ago to 3.84 b.y. ago, the Moon was bombarded by a massive flux of both large and small bodies producing huge basins and craters (Turner and Cadogan, 1975; Tera and others, 1974). Radiometric ages of mare basalts show that outpourings of lava followed the formation of the huge basins and craters during the interval from 3.84 to 3.15 b.y. ago (Turner and Cadogan, 1975; Papanastassiou and Wasserburg, 1971a, b; Wasser- burg and Papanastassiou, 1971; Nyquist and others, 1975).

This general framework, supplied by the returned samples, has been expanded using remote measurements from orbiting spacecraft and Earth. Ages of the outpourings of lava extend to more recent times than indicated by the returned samples, and lunar surfaces not sampled by Apollo can be related to and contrasted with the Apollo landing sites using remotely sensed data, many yielding results that are truly remarkable. Measured accelerations of spacecraft in orbit such as Lunar Orbiter, Lunar Module Ascent Stages, Apollo subsatellites, and Command and Service Modules have provided data on the lunar gravity field, and Apollo laser altimetry and metric quality photographs have provided data on lunar topography which, when combined with the orbital results, yield the relation between the center of mass and center of figure of the Moon. Information on the lunar magnetic field has also become available. Apollo orbital geochemical experiments have produced a wealth of information on the chemical composition of lunar surfaces along the orbital ground tracks.

As remarkable as the other Apollo orbital experiments, although less dramatic, are the bistatic-radar experiments, which produced estimates of the roughness of lunar surfaces that agree with visual impressions of roughness seen in lunar photographs and images. The relative dielectric constants of surfaces along the radar subspecular tracks were also measured. Terrestrial observations have been used to predict correctly some characteristics of the lunar surface; these observations form a basis for extrapolating Apollo surface results to other areas of the Moon, and for elucidating problem areas for future lunar exploration.

\section{ACKNOWLEDGMENTS}

Results reported in this paper are based on work performed by the U.S. Geological Survey as part of NASA Experiment S-222 (Photogeology-Apollo 15-17; NASA contract T-1167B) on behalf of the National Aeronautics and Space Adminstration. The authors thank S. N. Hardee and J. Dixon of the Johnson Spacecraft Center, Houston, Tex., for their support and assistance in the experiment. Data along the Apollo bistatic radar ground tracks were furnished by G.L. Tyler (Apollo Bistatic Radar Experiment), T. W. Thompson of the Jet Propulsion Laboratories, Pasadena, Calif. $(70-\mathrm{cm}$ Earth-based radar echoes and infrared eclipse temperatures), and S. H. Zisk of the Haystack Observatory, Lexington, Mass. (3.8-cm Earth-based radar echoes). 


\section{APOLLO ORBITAL RESULTS}

\section{AGES OF LUNAR PLAINS}

By J. M. Boyce and H. J. Moore

Volcanism and outpourings of volcanic flows on the Moon continued to at least 2.5 b.y. ago-some 600 m.y. after the youngest mare basalts sampled by Apollo (Papanastassiou and Wasserburg, 1971a) were formed, and two distinct episodes of intensive bombardment of the lunar surface occurred about 3.84 b.y. and 3.9 b.y. ago. These results, determined from orbit, represent important advances in and substantial contributions to understanding of the geologic history of the Moon. They are based on a crater-morphology technique of obtaining relative ages of lunar plains (Soderblom and Lebofsky, 1972) that were empirically converted to absolute ages from returned samples (Soderblom and Boyce, 1972).

Apollo photographs taken from orbit (National Space Science Data Center, 1971a through 1974; Aeronautical Chart and Information Center, 1971, 1972; and Defense Mapping Agency, 1972, 1973) and Lunar Orbiter images (National Space Science Data Center, 1969) provide the necessary information to determine relative ages. Here, results from 472 areas of lunar plains are discussed along with other results. Previously, relative ages were correlated with color differences of mare surfaces (Soderblom and Lebofsky, 1972). This correlation indicated three stages of mare formation: (1) an early stage of mare materials with relatively large blue reflectances and high titanium content, (2) an intermediate stage of materials with relatively large red reflectances and low titanium content, and (3) a late stage of mare materials with relatively large blue reflectances and high titanium content. Relative ages of large lunar craters such as Copernicus and Aristarchus also were determined. Many highland light plains photographed by Apollo 16 were found to be the same relative age, older than the maria and younger than surfaces related to the event that formed the Imbrium basin. The uniform relative ages were attributed to the event producing the Orientale basin, and a curve for converting relative ages to absolute ages was presented (Soderblom and Boyce, 1972). Older highland plains corresponding in age to the Imbrian event were discovered, and crater frequency distributions within the Orientale basin and on its ejecta were found to be the same as those of the extensive plains photographed by Apollo 16 (Boyce and others, 1974). Relative ages have also substantiated superposition relations determined for the Imbrian flows (Schaber, 1973) and flows near Delisle and Diophantus
(Wilhelms, 1980). Maps showing the distribution of relative ages of lunar maria and highland plains appear in the literature and later in this section (Boyce and Dial, 1973; Boyce and others, 1975).

\section{REVIEW OF METHODS OF ESTIMATING RELATIVE AGES}

\section{FUNDAMENTAL CONCEPTS}

There are three fundamental concepts required to understand the techniques of estimating relative ages: (1) Craters are continuously produced by impacts on the lunar surface with a size-frequency distribution extending from very small craters to very large craters, and there are many more small craters than large ones, (2) craters are eroded and destroyed by subsequent impacts, with the chief effect being erosion of larger craters by impacts producing smaller craters, and (3) lunar surfaces reach a steady-state condition in which craters below a certain size are destroyed as rapidly as they are produced. In addition, requirements of measurement and sampling must be met. The concepts, requirements, and a brief description of methods for estimating relative ages appear belows.

Continuous production of craters by impacts with the lunar surface producing a frequency distribution of craters is a fact established by Apollo (Duennebier and others, 1975; Morrison and others, 1972) as well as previous studies (see for example, Shoemaker, 1965). Lunar data indicate that crater frequency distributions directly reflecting the crater production curve are of the form

$$
N=K D^{\alpha}
$$

where

$N$ is the cumulative number of craters per unit area on a surface with diameters equal to or larger than $D$,

$K$ is the net accumulated flux, which increases with relative age of the surface,

$D$ is the crater diameter, and

$\alpha$ is an exponent with a value near -3.0 for the range of sizes of craters considered here (Soderblom and Lebofsky, 1972; Neukum and others, 1975a; Moore, 1964).

Primary craters are produced by objects from space and secondary craters by ejecta from primary craters. The relative importance of the two kinds of craters is a matter of debate. Some authors indicate secondary craters are dominant over some ranges of sizes (Soderblom, 1970a; Shoemaker, 1965), and others indicate conditions where primary craters are dominant 
(Gault, 1970; Moore, 1964). Idealized crater frequency distributions are illustrated in figure 1.

Regardless of the primary or secondary origin of the craters, young surfaces have fewer craters than older ones. The net accumulated fluxes for three surfaces $\left(K_{1}\right.$, $K_{2}, K_{3}$ in fig. 1) increase with their relative ages. Crater frequency distributions reflecting the relative ages of surfaces have the form of equation (1) and are only valid for the larger sizes of craters, because theoretical considerations show that the area occupied by small craters produced by primary impacts alone exceeds the area of the surface on which they are produced within a short time (Moore, 1964; Shoemaker, 1965; Marcus, 1970; and Soderblom, 1970a). Thus, subsequent impacts must destroy previously formed craters. Erosion of larger craters by smaller ones is the chief mechanism of crater destruction (Soderblom, 1970a), although infilling by deposition of ejecta (Marcus, 1970; Moore, 1964; Soderblom, 1970a) also occurs. This erosion and infilling destroy small craters as rapidly as they are produced so that the surface reaches a steady state (below a limiting crater size) in which the general appearance of the cratered surface remains the same although the details are continually changing. Because the erosion occurs at a fine scale by the production of craters in the steady-state size range (Shoemaker and others, 1969a, b), the surface has been saturated with craters many times over. Thus, statistical errors produced by swarms of secondary or primary impacts are averaged out. The erosion model used for most estimates of relative age in this section (Soderblom, 1970a) is valid for craters with interior slopes of about $8^{\circ}$ to $25^{\circ}$. Slopes steeper than about $25^{\circ}$ erode partly by slumping and sliding, whereas slopes less than about $8^{\circ}$ are degraded by overlap of craters and superposed ejecta blankets.

Steady-state frequency distributions of craters on lunar surfaces are well established (Gault, 1970, Shoemaker and others, 1969b; Trask, 1966.) In general, the steady-state distribution for lunar plains can be represented by an equation of the form

$$
M=C D^{-2},
$$

where

$M$ is the cumulative frequency of craters per unit area with diameters larger than $D$ and

$C$ is a parameter that varies with the manner in which craters are destroyed and the physical properties of the surface (Moore, 1964; Marcus, 1970; Soderblom, 1970a; Morrison and others, 1972 ); its value is near $10^{10.9}$ craters- $\mathrm{m}^{2} / 10^{6} \mathrm{~km}^{2}$ for most lunar plains (Trask, 1966; Moore, 1964).

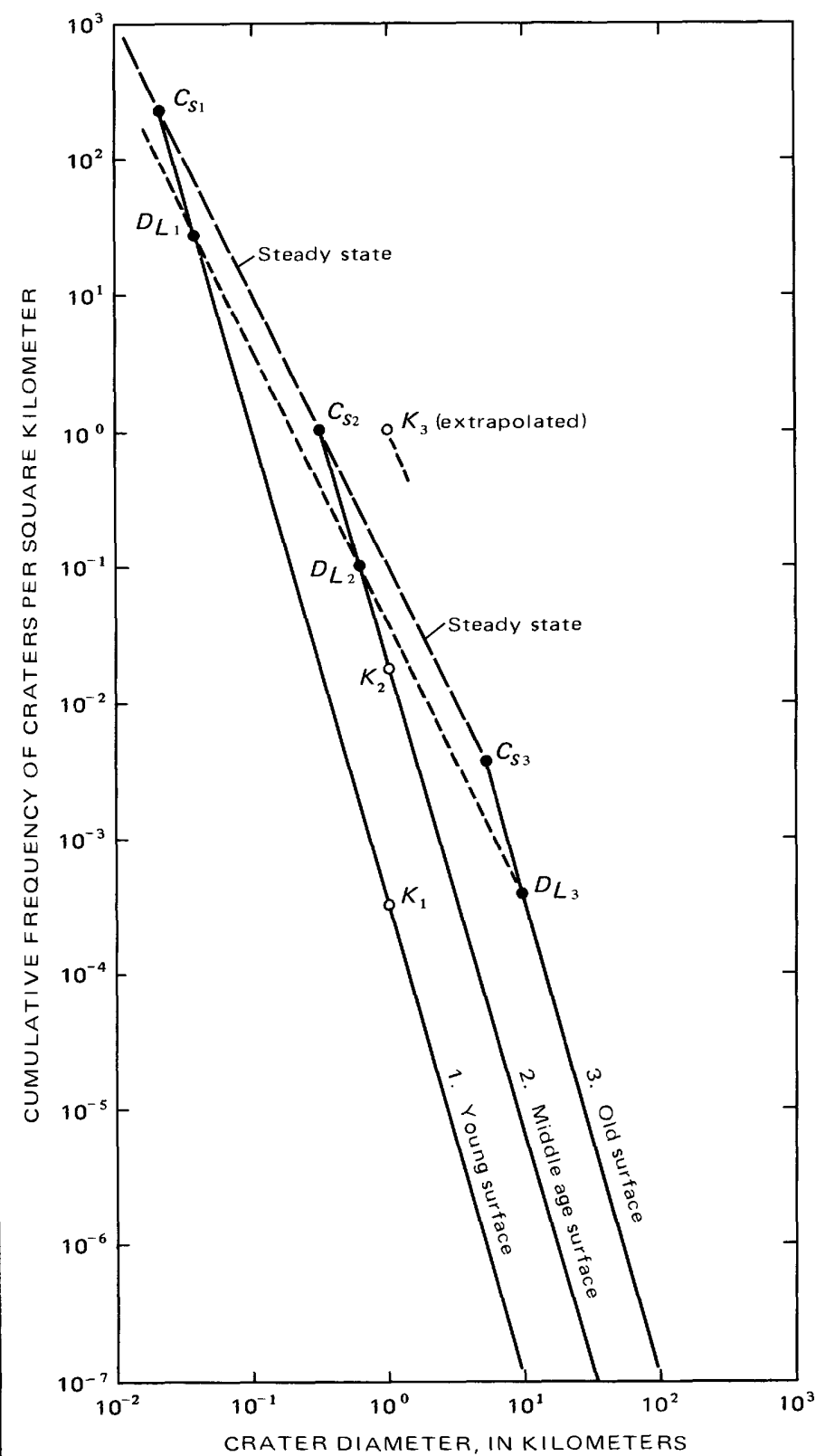

FIGURE 1.-Hypothetical cumulative frequency distributions of craters for three ages of surfaces. Distribution for each surface is composed of two parts, a steady-state distribution and a crater production distribution. Crater production distribution of young surface joins steady-state distribution at $C_{s 1}$; largest crater eroded to an interior slope angle of $1^{\circ}$ is $D_{L 1}$; net accumulated flux ( $K$ in equation 1 ) is $K_{1}$. Crater production distribution of middle age surface joins steady-state distribution at $C_{\mathrm{s} 2}$; largest crater eroded to an interior slope angle of $1^{\circ}$ is $D_{L 2}$; net accumulated flux is $K_{2}$. Crater production distribution of old surface joins steady-state distribution at $C_{s 3}$; largest crater eroded to an interior slope angle of $1^{\circ}$ is $D_{L 3}$; net accumulated flux is $K_{3}$. Note diameters corresponding to $C_{s 1}, C_{s 2}$, and $C_{s 3}$ increase with age of surface, diameters of $D_{L 1}$, $D_{L 2}, D_{L 3}$ also increase with age of surface, and cumulative frequencies corresponding to $K_{1}, K_{2}$, and $K_{3}$ increase with age of surface. 
Although the exponent on $D$ is minus two for most lunar surfaces, other values are possible where crater destruction is the result of thermal creep on steep slopes, seismic erosion, and blanketing (see for example Marcus, 1970), and the form of the crater production frequency distribution may alter this exponent (Moore, Lugn, and Newman, 1974). The technique is not applied where there is evidence that the conditions imposed by equations (1) and (2) are not met.

In any event, for lunar plains, equations (1) and (2) join at a point with the same frequency and diameter (fig. 1). The upper limiting crater diameter at which this join occurs is called $C_{s}$ (Shoemaker and others, $1969 \mathrm{a}, \mathrm{b}) . C_{s}$ increases with the relative age of the surface $\left(C_{s 1}, C_{s 2}, C_{s 3}\right.$ in fig. 1$)$ and thus the net accumulated flux. Below the upper limiting crater diameter (in the steady state), the relative frequencies of craters of any given size with the same morphology or state of preservation are the same (Trask, 1971; Moore, 1971a, 1964; Soderblom and Lebofsky, 1972), and so the cumulative frequency of craters eroded with a given interior slope angle (or greater) lies on a line parallel to the steadystate curve in figure 1 . The diameter of craters eroded to an interior slope angle of $1^{\circ}$ has been termed $D_{L}$ (Soderblom and Lebofsky, 1972) and intersects the crater frequency distribution at a diameter larger than $C_{s}$ (fig. 1). Like $C_{s}, D_{L}$ increases with the relative age $\left(D_{L 1}\right.$, $D_{L 2}, D_{L 3}$ in fig. 1) of the surface.

\section{RAPID METHOD FOR DETERMINING RELATIVE AGES}

One procedure for establishing relative ages of lunar surfaces is to determine $D_{L}$. In practice, the maximum diameter $\left(D_{s}\right)$ of craters is estimated from those with interior slopes eroded to the appropriate sun elevation angle $\left(S_{s}\right)$ by the accumulated flux. All craters larger than $D_{s}$ have shadows because their interior slope angles are equal to or greater than the sun elevation angle. Craters smaller than this size are shadowed or unshadowed. The ratio of unshadowed to shadowed craters is zero for craters larger than $D_{s}$ but finite for craters smaller than $D_{s}$ and constant within the steady state. The value of $D_{s}$ may be determined rapidly by finding the largest unshadowed crater in an image and the smallest diameter at which all craters are clearly shadowed (Soderblom and Lebofsky, 1972). This procedure yields lower and upper bounds for $D_{s}$. The value of $D_{L}$ is then computed using the crater erosion model of Soderblom (1970a):

$$
D_{L}=\left[\frac{\ln \left(S_{i} / S_{s}\right)}{\ln \left(S_{i} / \tan 1^{\circ}\right)}\right]^{1 / 2} D_{s}
$$

where $S_{i}$ is the initial interior slope angle of the crater (taken as $30^{\circ}$. Thus, there are three tests of the validity of the technique if $\alpha=-3$ : (1) the value of the net accumulated flux ( $K$ in equation 1 ) should be directly proportional to the largest crater eroded to an interior slope angle of $1^{\circ}\left(D_{L}\right)$ for the same surface, (2) the join between the steady-state distribution and the crater frequency distribution, $C_{s}$, should be directly proportional to $D_{L}$, and (3) the ratio of shadowed to unshadowed craters for different sun elevation angles should satisfy equation (3). Additionally, $K$ and $C_{s}$ should be directly proportional to each other. These tests are reasonably well met. As shown in figure 2 and table 1 , (1) $D_{L}$ and $K$ are directly proportional (Soderblom and Boyce, 1972, (2) $C_{s}$ and $K$ are directly proportional, but the values of $C_{s}$ for Surveyor 1 and 6 are too small, and (3) $D_{L}$ and $C_{s}$ are directly proportional, but $C_{s}$ values for Surveyors 1 and 6 are too small. The deviations for $C_{s}$ values for Surveyors 1 and 6 are the result of the constant for the steady-state curve used in calculating $C_{s}$; here the value of $C$ in equation (2) is near $10^{11}$ rather than $10^{10.9}$ (Shoemaker and others, 1969b). The values of $C_{s}$ should be nearer to

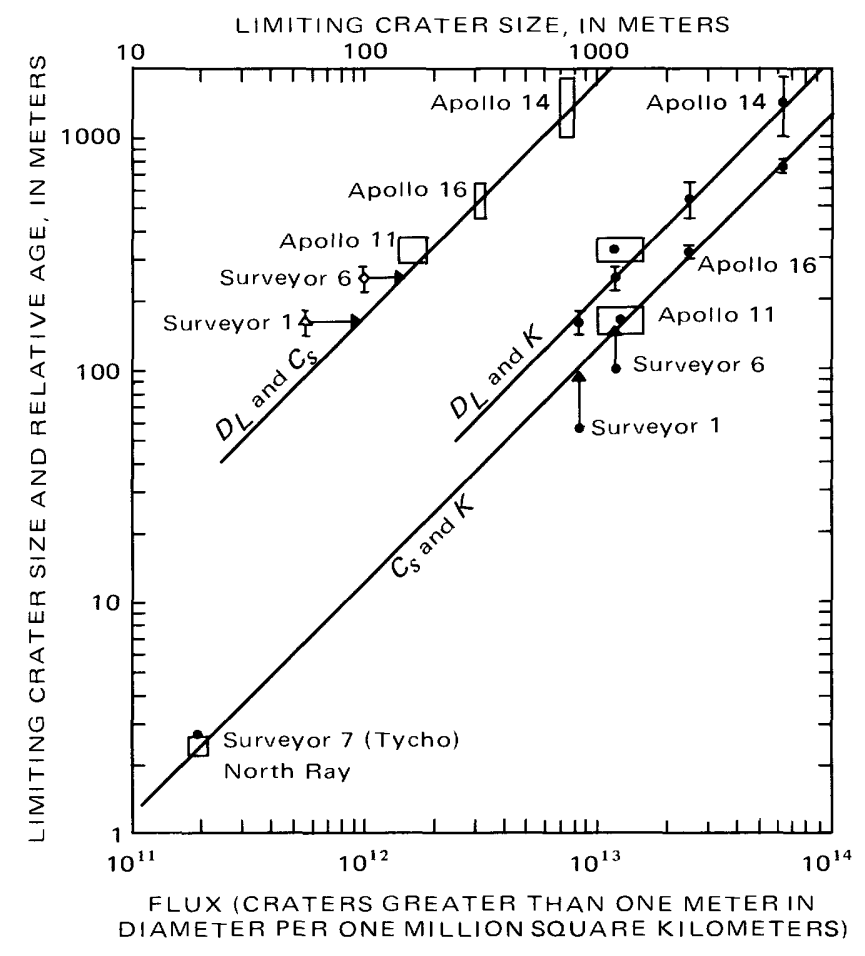

Figure 2.-Relations between $D_{L}$ (diameter of largest crater the interior wall of which has been eroded below $1^{\circ}$ ), $K$ (integrated impact flux determined from crater counts), and $C_{s}$ (limiting crater size). Arrows indicate $C_{s}$ values expected for corresponding $D_{L}$ values for Surveyors 1 and 6 data points and direction to upperbound $D_{L}$ values for Apollo 14. Boxes represent ranges in estimates for Apollo 11 and 16. Vertical bars indicate ranges in estimates for $D_{L}$ and $C_{s}$. 
TABLE 1.-Comparison of results from relative age measurements $\left(D_{L}\right)$, net accumulated flux $(K)$, and upper limiting size $\left(C_{s}\right)$

\begin{tabular}{l} 
Location \\
\hline
\end{tabular}

94 and 147 for Surveyors 1 and 6 respectively on the basis of $D_{L}$ values.

Finally, the ratio of unshadowed to shadowed craters matches the expectations of the crater erosion model (Soderblom, 1970a) as shown in figures 3 and 4. The erosion model predicts:

$$
\begin{array}{ll}
P=0 & \text { when } D>D_{\mathrm{s}} \\
P=\left(D_{s} / D\right)-1 & \text { when } D_{s}>D>D_{c} \\
P=\left(D_{s} / D_{c}\right)-1 & \text { when } D_{c}>D
\end{array}
$$

where

$P$ is the ratio of unshadowed to shadowed craters,

$D_{s}$ is the diameter of the largest crater with interior slopes eroded to the sun angle, and

$D_{c}$ is the theoretical diameter of the largest crater eroded to slope angles beyond recognition; $D_{c}$ is the same as $C_{s}$.

\section{PITFALLS IN DETERMINING RELATIVE AGES}

Estimates of relative ages of surfaces cannot be made indiscriminately. Initial surfaces must have been flat and featureless where the conditions imposed by equation (1) have been met. Ages in the rugged highlands, for example, cannot be determined by this method. Craters in areas that are blanketed by ejecta or other deposits may have an eroded and degraded appearance and will give erroneous results. Areas of blanketing are avoided by using geologic mapping techniques and recognizing the effect of ejecta blankets on crater morphology and the size frequency distribution of craters (Hartmann and Wood, 1971; Boyce and others, 1974).

The assumption that all circular craters from $100 \mathrm{~m}$ to $2,000 \mathrm{~m}$ in diameter had the same initial shape de-
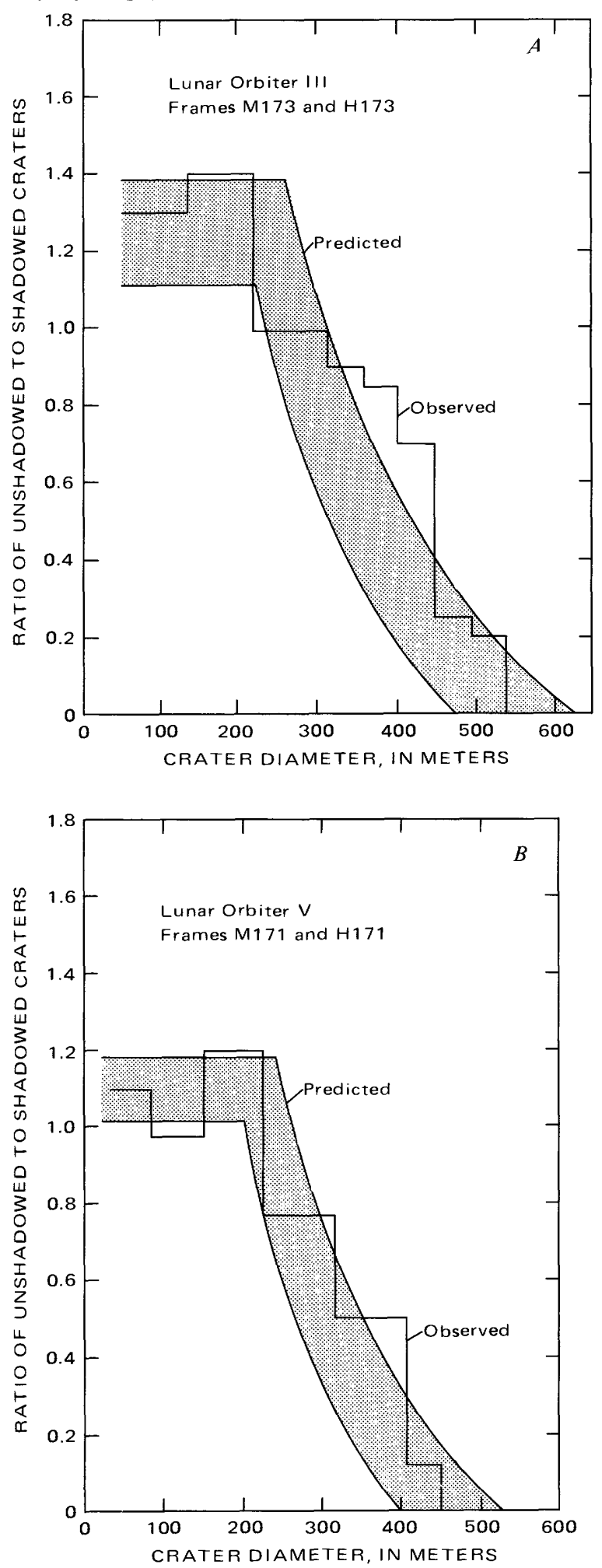

Figure 3.-Comparison of observed and predicted ratio of unshadowed to shadowed craters as a function of crater diameter. The Lunar Orbiter frames V-H171 and IIIH173 cover the same area in Oceanus Procellarum but were taken at different sun elevation angles $\left(S_{s}\right): A$, sun angle is $21^{\circ} ; B$, sun angle is $15^{\circ}$. The shaded areas represent the regions of acceptable fit of the theoretical model to the data. (After Soderblom and Lebofsky, 1972.) 


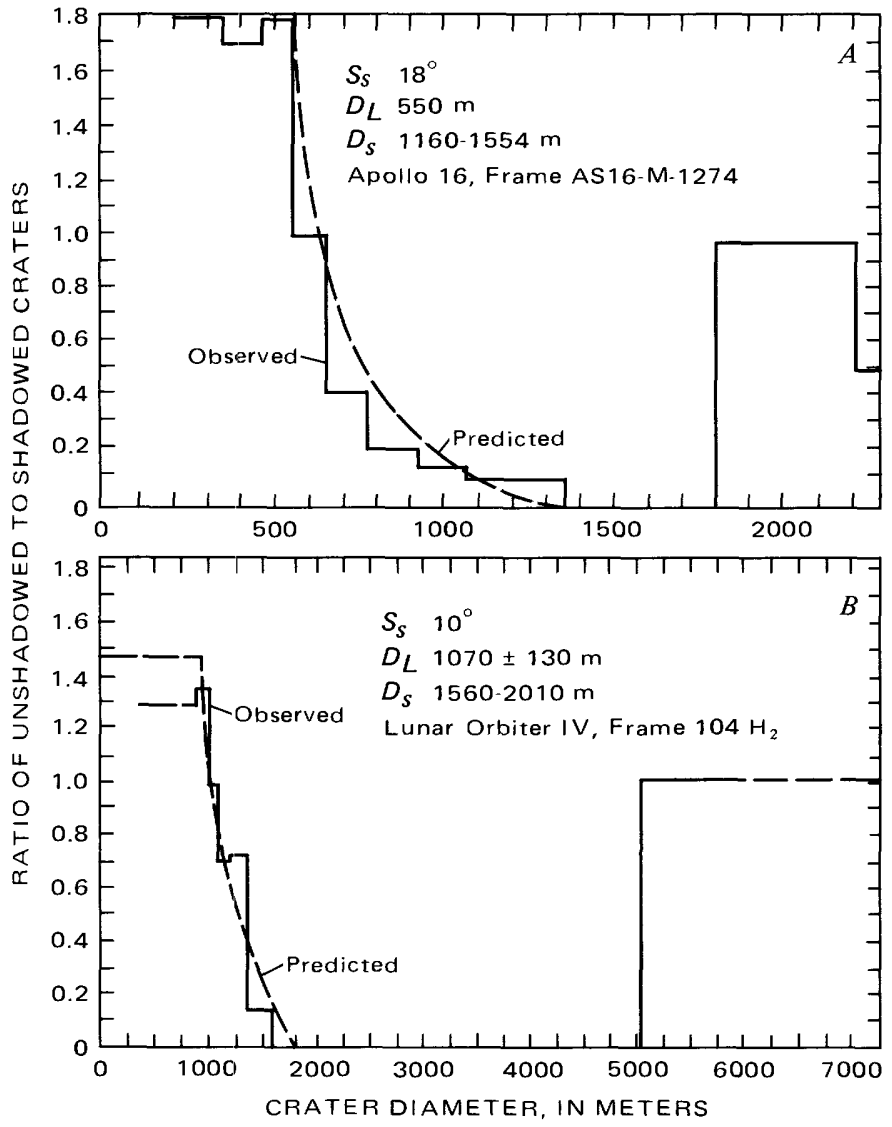

FIGURE 4.-Ratio of unshadowed to shadowed craters as a function of diameter for floor of Albategnius, $A$, and floor of Meton, $B$. Bumps in observed values at about $1,800 \mathrm{~m}$ for Albategnius and $5,000 \mathrm{~m}$ for Meton reflect old partially buried craters. Dashed line represents best fit of theoretical model of Soderblom and Lebofsky (1972). $S_{s}$, sun elevation angle; $D_{L}$, relative ages; $D_{s}$, maximum diameter. (After Boyce and others, 1974.)

serves some comment. Some support for this assumption is found in the data of Pike (1974), where leastsquares regressions to data on craters indicate that depths of craters between about $80 \mathrm{~m}$ and $10 \mathrm{~km}$ across are directly proportional to crater diameters. On the other hand, craters deviating from a simple form, such as concentric craters, flat-floored craters, and craters with central peaks, do exist in the size range of $10 \mathrm{~m}$ to $500 \mathrm{~m}$ and are particularly abundant in Oceanus Procellarum (Quaide and Oberbeck, 1968). Generally speaking, these craters are smaller than $D_{s}$ and have little or no effect on the results. Irregularly shaped craters that may have had initially low slopes, such as dimple craters (Greeley, 1970; Kuiper, 1965), and swarms of secondary craters (Oberbeck and others, 1972) are identifiable, and areas where they occur are avoided.

Proper measurements are essential to the technique of estimating relative ages. There are four ingredients for proper measurement: (1) Shadowed and unshadowed craters must be distinguished, (2) image res- olution must be good enough to show clearly craters in the size range of interest, (3) diameter measurements must be reasonably accurate, and (4) the area sampled must be sufficiently large. Photographs used for estimates of relative ages are well processed and present few problems in identification of shadowed and unshadowed craters within the limits of error expressed in the reported $D_{L}$ values. For the sun elevation angles $\left(8^{\circ}-25^{\circ}\right)$ and images used in this study, image contrast is marked between the shadow and illuminated parts of clearly shadowed craters. Moderate-resolution Lunar Orbiter images (about $30 \mathrm{~m}$ ) are checked against high-resolution Lunar Orbiter images (1-3 m) of the same craters to verify that shadowed and unshadowed craters are properly identified.

Boyce and others (1975) showed experimentally that consistent $D_{L}$ values or relative ages can be obtained if the resolution of the image is 0.15 times $D_{L}$ or better. (Here, resolution is the size of the smallest crater that can be identified in the photograph or image. The data are summarized in Boyce and others, 1975, and in figure 5.) Thus, it is important that crater frequency distributions be used for relative age measurements when the resolution criterion cannot be satisfied. Such conditions occur at North Ray crater at Apollo 16, the crater Tycho, and the light mantle at the Apollo 17 site. The results above not only show the relation between resolution and $D_{L}$, but they also substantiate the erosion model (Soderblom, 1970a), because the $D_{L}$ val-

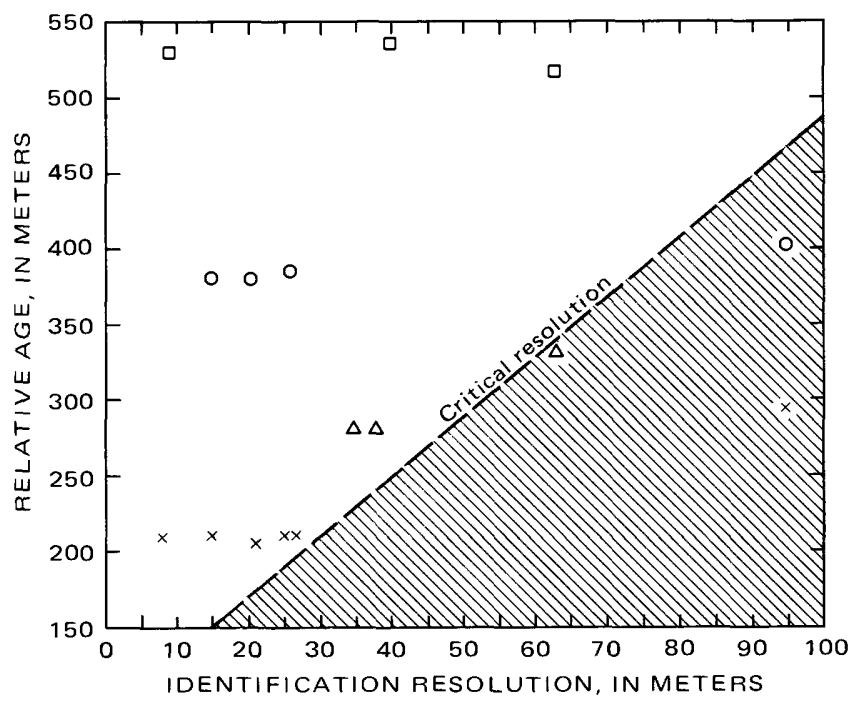

FigurE 5.-Effects of photograph resolution on determination of $D_{L}$ (relative age). Dashed line represents approximate location of critical resolution $\left(\simeq 0.15 D_{L}\right)$. For resolutions better than $0.15 D_{L}$ (left of dashed line), relative age measurements for a particular unit are constant; at lower resolutions (diagonal lines), measurements become inconsistent. $\times$, Mare Serenitatis; $\Delta$, Eastern Mare Cognitum; $o$, dark mantle west of Apollo 17 landing site; $\square$, floor of Fra Mauro. (After Boyce and others, 1975.) 
ues calculated from $D_{s}$ remain constant over the predicted range of sun elevation angles.

Diameters of craters reported here have been measured monoscopically on photographs taken with sun elevation angles between $8^{\circ}$ and $25^{\circ}$. Although some workers argue that monoscopic measurements may be as much as 20 percent in error (Young, 1975), our monoscopic measurements are less than 5 percent off compared to stereoscopic measurements at these low sun elevation angles (fig. 6; table 2). Thus, monoscopic techniques are entirely suitable and well within the error limits of reported $D_{L}$ values. Furthermore, regional studies require monoscopic measurements because most of the usable images of the Moon are monoscopic.

Minimum sizes of sample areas required for a reasonable estimate of relative ages are a function of relative ages of the surfaces and sun elevation angles because the area should include more than ten measured craters with diameters equal to $D_{s}$ (Soderblom

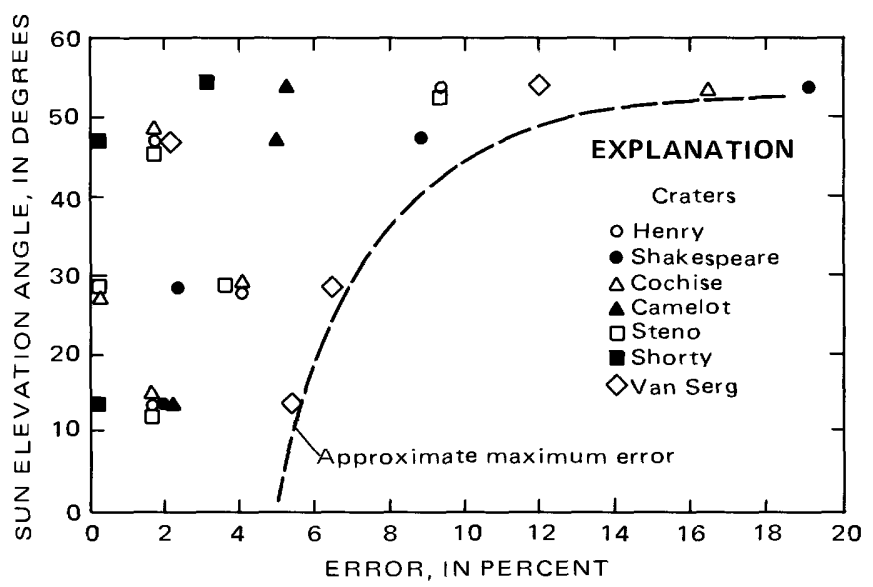

Figure 6.-Errors in measurement of crater diameter as a function of sun elevation angle (see table 2).

TABLE 2.-Diameters of craters measured stereoscopically and monoscopically, and measurement error

\begin{tabular}{|c|c|c|c|c|c|c|}
\hline \multirow{3}{*}{ Crater } & \multicolumn{6}{|c|}{ Diameter $(\mathrm{m})$ and error (percent) with $\mathrm{S}-2$ as standard } \\
\hline & \multicolumn{4}{|c|}{ Monoscopic } & \multicolumn{2}{|c|}{ Stereoscopic } \\
\hline & M-1 ${ }^{1}$ & M- $2^{2}$ & $\mathbf{M}-3^{3}$ & M-4 $\mathbf{4}^{4}$ & S-1 & S- -2 \\
\hline $\begin{array}{l}\text { Henry } \\
\text { Shakespeare } \\
\text { Cochise } \\
\text { Camelot } \\
\text { Steno } \\
\text { Shorty } \\
\text { Van Serg }\end{array}$ & $\begin{array}{r}-583-1.7 \\
-625+1.9 \\
-583-1.7 \\
-667+2.0 \\
-583-1.7 \\
-1120.0 \\
-87-5.4\end{array}$ & $\begin{array}{r}569-4.0 \\
596-2.3 \\
569-4.0 \\
650-0.6 \\
596+0.5 \\
108-3.6 \\
98+6.5\end{array}$ & $\begin{array}{r}583-1.7 \\
667+8.8 \\
583-1.7 \\
625-4.9 \\
583-1.7 \\
113+0.9 \\
90-2.2\end{array}$ & $\begin{array}{c}538-9.3 \\
496-19.1 \\
496-16.4 \\
620-5.2 \\
538-9.3 \\
108-3.6 \\
81-12.0\end{array}$ & $\begin{array}{r}583-1.7 \\
606-1.1 \\
583-1.7 \\
650-0.6 \\
583-1.7 \\
107-4.5 \\
93+1.1\end{array}$ & $\begin{array}{r}593 \\
613 \\
593 \\
654 \\
593 \\
112 \\
92\end{array}$ \\
\hline \multicolumn{7}{|c|}{$\begin{array}{l}{ }^{1} \text { Apollo metric photograph AS17-M-0597, sun } 13^{\circ} \text { above local horizontal. } \\
{ }^{2} \text { Apollo metric photograph AS17-M-1500, sun } 28^{\circ} \text { above local horizontal. } \\
{ }^{3} \text { Apollo metric photograph AS17-M-2086, sun } 47^{\circ} \text { above local horizontal. } \\
\text { Appllo metric photograph AS15-M-1113, sun } 54^{\circ} \text { above local horizontal. } \\
\text { "Apollo panoramic photographs AS17-P-9557 and AS17-P-9559 both with sun } 53^{\circ} \text { above } \\
\text { local horizontal. } \\
\text { "Apollo panoramic photographs AS17-P-2309 and AS17-P-2314 both with sun } 15^{\circ} \text { above } \\
\text { local horizontal. }\end{array}$} \\
\hline
\end{tabular}

and Lebofsky, 1972). Large areas are required for high sun elevation angles and old surfaces (Boyce and others, 1975, Fig. 7). When large areas are required for adequate sampling, care must be taken to avoid sampling mixtures of units with different ages by using careful mapping; otherwise, the tendency is to obtain the relative age of the oldest unit in the area of the image (Soderblom and Lebofsky, 1972).

In summary, the crater morphology technique of establishing relative ages yields good results within the limits discussed. Problems arising from the presence of blanketed terrain and mixtures of geologic units can generally be recognized and solved. Areas with craters for which the model does not apply can be identified. When resolution will not permit an estimate of $D_{L}$, crater frequency distributions must be obtained. $D_{L}$ can be calculated as 1.7 times $C_{s}$ from the intersection of the measured crater frequency distribution (equation 1) and the empirically determined steady-state distribution (equation 2).

\section{RELATIVE AGES OF LUNAR PLAINS}

Three major subdivisions of relative ages are indicated in a frequency histogram of relative ages for

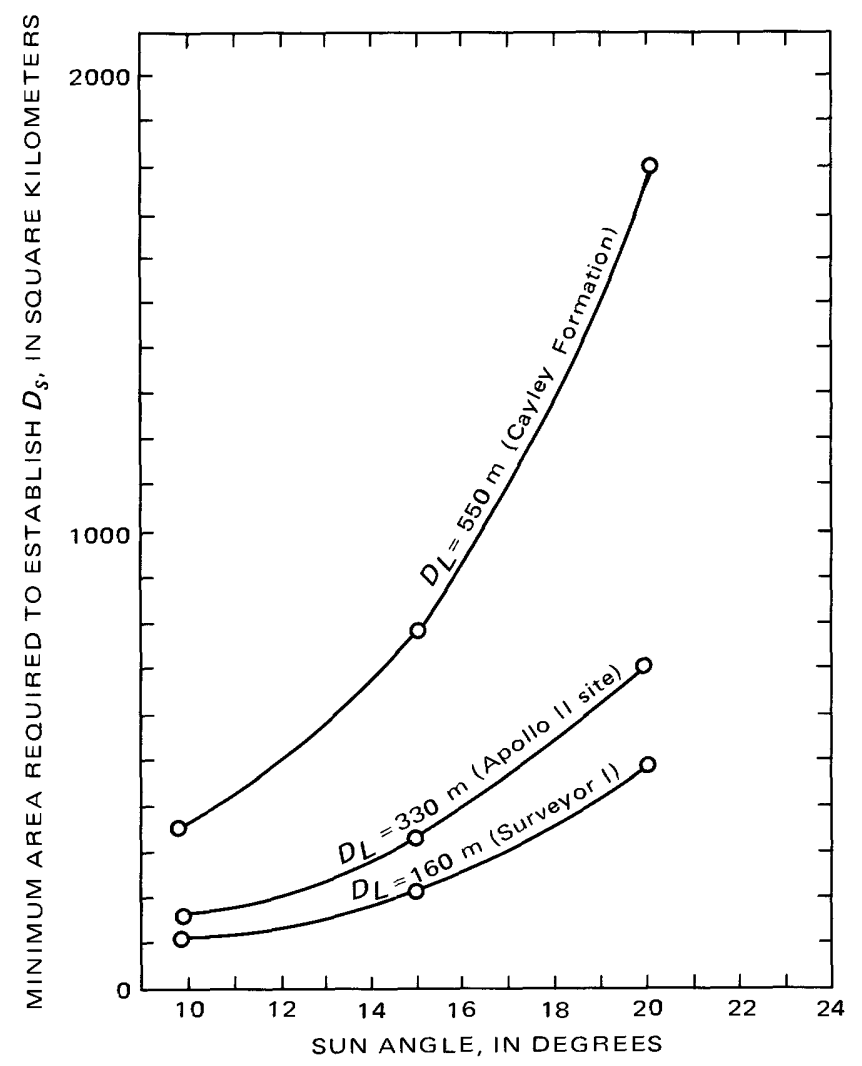

FIGURe 7.-Sample area necessary to establish $D_{s}$ (maximum diameter of craters). $D_{L}$, relative ages. (From Boyce and others, 1975.) 
lunar plains (fig. 8, table 3): (1) young mare plains, (2) light plains of intermediate age, and (3) old light plains. The latter two are confined to the highlands. A fourth group of ages representing very young craters such as Tycho, Aristarchus, and Copernicus (Soderblom and Lebofsky, 1972) can be added, and mare plains can be further subdivided, although somewhat arbitrarily, into five units corresponding to troughs and flexures in the histogram. Data on relative ages are listed in Boyce and others (1975).

From figure 8 it may be seen that a substantial fraction of mare plains have younger relative ages than the Apollo 12 landing site. Large expanses of mare plains that are younger than those of Apollo 12 occur in Oceanus Procellarum. This indicates that mare volcanism continued to more recent times than at Apollo 12.

The geographic distribution of surfaces with the same relative ages is substantially the same as that reported previously (fig. 9; Soderblom and Boyce, 1972; Boyce and Dial, 1974; Boyce and others, 1974). More recent work (Boyce and Dial, 1975; Boyce, 1976) gives a clearer picture. Light plains of intermediate age scattered across the entire lunar highlands have the same relative age as the ejecta or Hevelius Formation of the Orientale basin. Old light plains are less frequent than

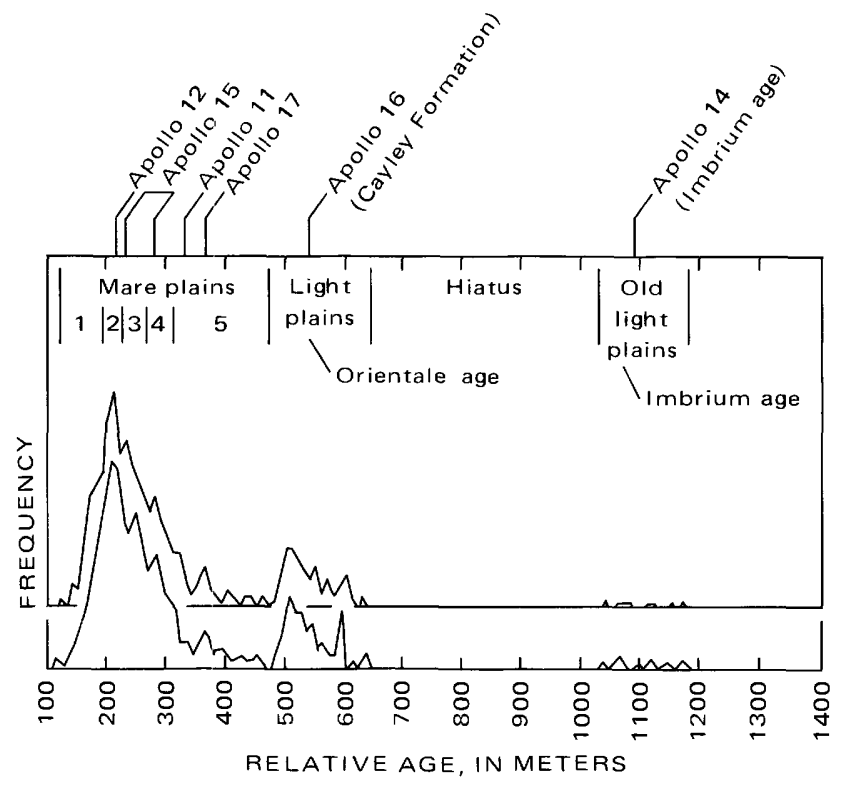

Figure 8.-Histograms of relative ages of lunar plains. Lower histogram represents frequencies in intervals of $117-127 \mathrm{~m}$, etc.; upper histogram represents frequencies in interval 122-132 m, etc. Note frequency modes near 210 (mare plains), 510 (light plains of intermediate age), and 1,100 (old light plains). Hiatus represents short interval of normal activity between the major basin-forming events (Orientale and Imbrium). Mare plains may be subdivided into five subunits based on minor modes and flexures in histograms (table 3 ).
TABLE 3.-Relative ages of lunar plains and some craters

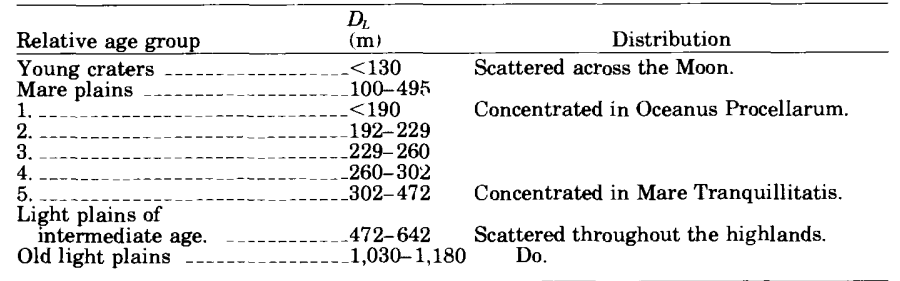

the young light plains, but they are also scattered across the lunar highlands. The relative ages of mare plains tend to decrease westward. The youngest mare plains are concentrated in Oceanus Procellarum and the oldest in Mare Tranquillitatis. Relative ages of plains vary within the maria. Relatively young plains occur within Mare Imbrium and Mare Serenitatis where they are more or less centrally located.

\section{CORRELATION OF RELATIVE AGES WITH RADIOMETRIC AGES}

TIME SCALE

An approximate time scale for lunar events can be established by comparing relative ages $\left(D_{L}\right)$ of the Apollo and Luna landing sites with ages of returned rocks and interpretations of the provenance of some samples collected by Apollo (Shoemaker, 1970; Soderblom and Lebofsky, 1972; Soderblom and Boyce, 1972; Boyce, 1975). Such a correlation can be made independently of the erosion model provided the crater flux has changed in a well-behaved way with time and has been uniformly distributed across the Moon. Relative ages ( $D_{L}$ values) are plotted against radiometric ages in figure 10, and values used are listed in table 4 with the appropriate references. Radiometric ages for the old light plains are taken as 3.9 b.y., and those for the light plains are taken as 3.85 b.y. (see Tera and others, 1974). Stratigraphic relations between the highland plains and mare units (Wilhelms and McCauley, 1971) indicate these light plains must be older than the oldest mare basalts, which are about 3.84 b.y. (Nyquist and others, 1975; Turner and Cadogan, 1975). Plotted points for the Apollo 17, 11, and 12 sites appear well behaved, but the relative age for Apollo 15 appears to be too old when compared to the smooth curve in figure 10 . Thus, the relative age reported (Soderblom and Lebofsky, 1972) may represent an older unit at the Apollo 15 site. A more recent relative age for Apollo 15 is lower and in agreement (Boyce and others, 1975). For two of the points shown in figure 10, Copernicus and Tycho, somewhat speculative interpretations are required. Rock 12013 is presumably from Copernicus because rays from Copernicus streak 


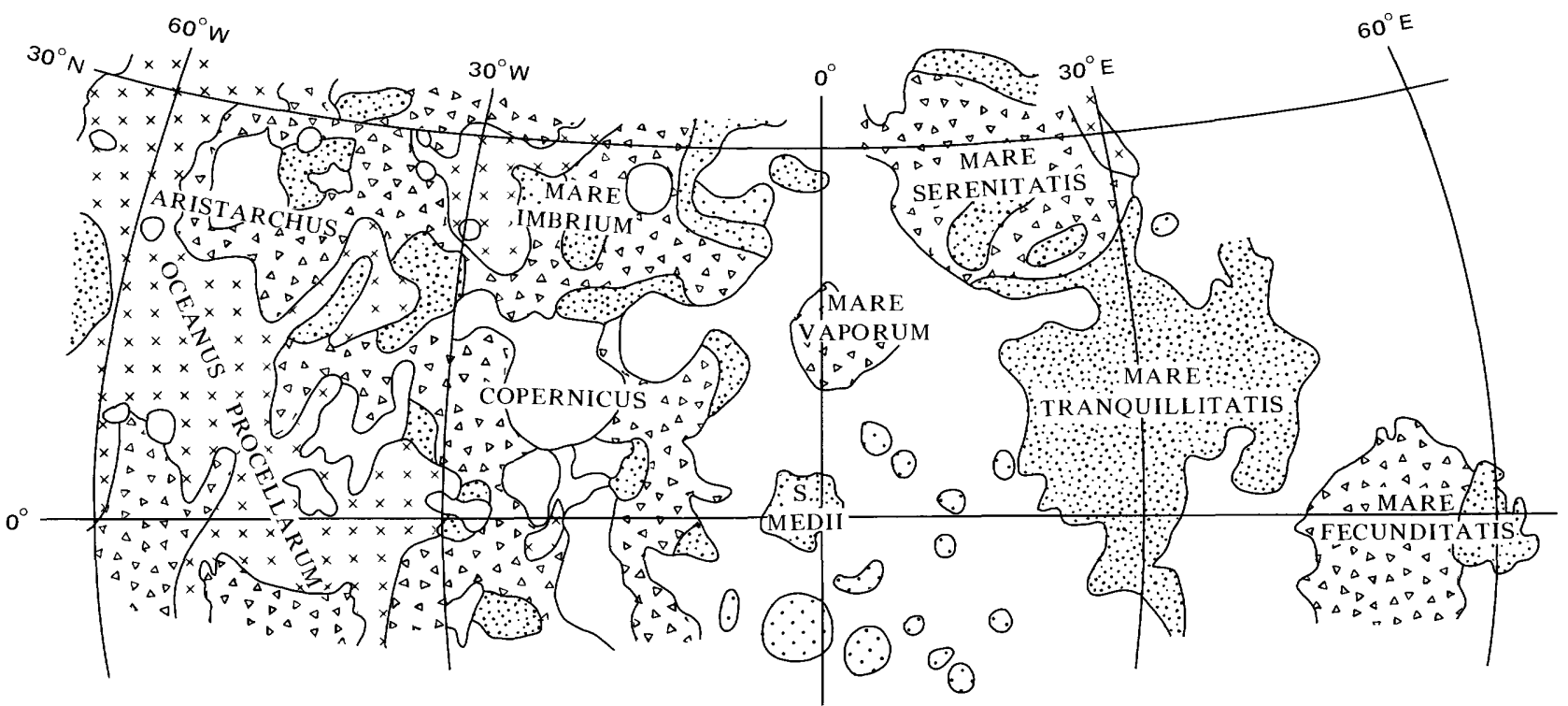

EXPLANATION

$\times \times D_{L}$ less than 190 meters

$\because \because D_{L} 472-642$ meters
@ण $D_{L}$ 191-261 meters

$\because D_{L} 261-472$ meters

\section{500 KILOMETERS \\ APPROXIMATE SCALE}

FIGURE 9.-Distribution of relative ages $D_{L}$ of lunar plains in the "Apollo zone" (after Boyce, 1976).

TABLE 4.-Relative ages of Apollo landing sites and radiometric ages of rocks returned from the Apollo landing site

\begin{tabular}{|c|c|c|c|c|}
\hline Location & Geologic unit & $\begin{array}{l}\text { Relative } \\
\text { age }\end{array}$ & $\begin{array}{l}\text { Radiometric } \\
\text { age }\end{array}$ & References \\
\hline Apollo 14 & $\begin{array}{l}\text { Fra Mauro } \\
\text { Formation }\end{array}$ & $1,400 \pm 400$ & 3.9 b.y. & $\begin{array}{l}\text { Tera and others (1974). } \\
\text { Papanastassiou and Wasserburg (1971b). } \\
\text { Soderblom and Boyce (1972). }\end{array}$ \\
\hline Apollo 16 & $\begin{array}{l}\text { Formation } \\
\text { Foyley }\end{array}$ & $\begin{array}{l}540 \pm 90 \\
----\end{array}$ & $\begin{array}{l}3.85 \text { b.y. } \\
>3.84 \pm 0.12 \text { b.y. } \\
>3.78 \pm 0.05 \text { b.y. }\end{array}$ & $\begin{array}{l}\text { Tera and others (1974). } \\
\text { Papanastassiou and Wasserburg (1972). } \\
\text { Turner and Cadogan (1975). } \\
\text { Soderblom and Boyce (1972). }\end{array}$ \\
\hline $\begin{array}{l}\text { Apollo } 17 \\
\text { Apollo } 11\end{array}$ & Mare Material _. & $\begin{array}{l}-365 \pm 30 \\
-330 \pm 40\end{array}$ & $\begin{array}{l}3.68 \pm 0.18 \text { b.y. } \\
3.59 \pm 0.05 \text { b.y. }\end{array}$ & $\begin{array}{l}\text { Nyquist and others (1975); and this report. } \\
\text { Papanastassiou and Wasserburg (1970). } \\
\text { Soderblom and Lebofsky (1972). }\end{array}$ \\
\hline Apollo 15 & $-\mathrm{do}_{-}$ & $\begin{array}{l}280 \pm 40 \\
230 \pm 30\end{array}$ & $3.28 \pm 0.04$ b.y. & $\begin{array}{l}\text { Papanastassiou and Wasserburg (1973). } \\
\text { Soderblom and Lebofsky (1972). }\end{array}$ \\
\hline Apollo 12 & 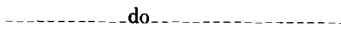 & $215 \pm 45$ & $3.16 \pm 0.09$ b.y. & $\begin{array}{l}\text { Papanastassiou and Wasserburg (1971a) } \\
\text { Soderblom and Lebofsky (1972) }\end{array}$ \\
\hline (Apollo 12) & _-_._Copernicus & $100 \pm 30$ & $0.85 \pm 0.1$ b.y. & $\begin{array}{l}\text { Silver (1971); Soderblom and Lebofsky } \\
\text { (1972). }\end{array}$ \\
\hline Apollo 16 & North Ray & -3.7 to 4.6 & \multirow{3}{*}{$\begin{array}{l}48.9 \pm 1.7 \mathrm{~m} . \mathrm{y} . \\
\text { and }>30 \mathrm{~m} . \mathrm{y} . \\
50-128 \mathrm{~m} . \mathrm{y}\end{array}$} & $\begin{array}{l}\text { Marti and others }(1973) \text {; Kirsten and others } \\
\text { (1973), this report }\left(D_{l} \text { taken as } 1.7 \times C_{s}\right) \text {. }\end{array}$ \\
\hline Apollo 17 & $\begin{array}{l}\text { Light mantle } \\
\text { (avalanche interpreted } \\
\text { to have been produced } \\
\text { by Tycho ejecta). }\end{array}$ & 3.4 to 6.8 & & $\begin{array}{l}\text { Leich and others (1975, light mantle): } \\
\text { Hutcheon and others (1974; Boulder } 2 \\
\text { Sta. 2); Muehlberger and others (1973). }\end{array}$ \\
\hline & Tycho & $\approx 4.7$ & & $\begin{array}{l}\text { Shoemaker and others }(1969), D_{L} \text { taken as } \\
1.7 \times C_{s} \text {. }\end{array}$ \\
\hline
\end{tabular}



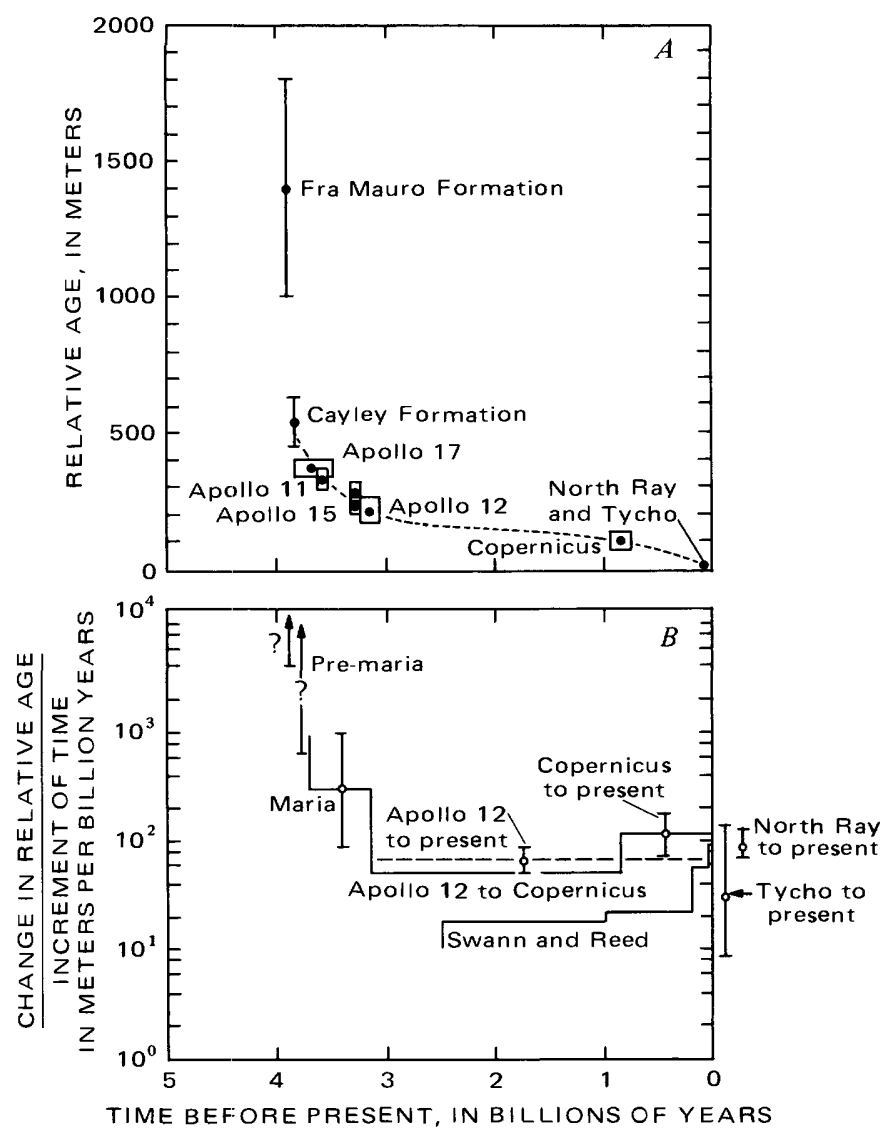

Figure 10. $-A$, Comparison of relative age determinations made from orbital photography and radiometric ages determined from Apollo samples. Small range of $D_{L}$ for Cayley plains indicates a short period for their formation. $B$, Incremental flux of objects producing small craters estimated from relative ages and radiometric ages determined from Apollo samples. Error bars on both relative ages and radiometric ages indicate flux may have been nearly constant for more than 3.5 b.y., but flux may have been relatively low during the interval of 0.85 to 3.15 b.y. ago. Flux was clearly high between 3.85 and 4.0 b.y. ago. Results of Swann and Reed (1974) included for comparison.

cross the general area of the Apollo 12 landing site (Silver, 1971). An argument for a genetic and temporal relation between the light mantle at Apollo 17 and Tycho has been presented by a number of authors (Muehlberger and others, 1973; Howard, 1973; Lucchitta, 1975). Crater counts on the light mantle yield a $C_{s}$ of 2-4 and an age of about 100 m.y. for the age of the light mantle and lend support for the contemporaneity of Tycho and the light mantle (Muehlberger and others, 1973). The $D_{L}$ value of $13 \pm 5 \mathrm{~m}$ reported in Muehlberger and others (1973) is probably invalid because the resolution and sun elevation angle of the photographs used will not permit a reliable estimate of $D_{L}$. An estimate of $D_{L}$ compatible with the data and erosion model is 1.7 times $C_{s}$ or 3.4 to $6.8 \mathrm{~m}$. Such a $D_{L}$ would reduce the estimate of age to roughly 50 m.y.
Krypton exposure ages at Boulder 1, Station 2, of $53 \pm 3$ m.y. (Leich and others, 1975; Arvidson and others, 1975) place a lower boundary on the age of the light mantle because the boulder is superposed on it. Argon exposure ages of rocks collected at Station 3 on the light mantle are $195 \pm 5$ m.y. (Crozaz and others, 1974) and 110 to 160 m.y. (Turner and Cadogan, 1975). Lucchitta (1977) believes that the crater Camelot with exposure ages of $80 \mathrm{~m} . \mathrm{y}$. (Turner and Cadogan, 1975), 118-128 m.y. (Horn and others, 1975), and 71.7 \pm 1.8 m.y. (Crozaz and others, 1974) is older than those craters interpreted to be secondary impact craters from Tycho, because Camelot is more subdued and eroded than the secondary craters. This would place the age of the light mantle and Tycho between 50 and 128 m.y.

Crater counts on the ejecta blanket of North Ray from the crater rim to roughly one-half crater radius from the rim, obtained from Apollo 16 Panoramic Camera photographs, can be fairly well described by equation (1) (fig. 11), and calculations of $K$ and $C_{s}$ for North Ray using $\alpha=-3$ in equation (1) and equation (2) are $1.72-2.12 \times 10^{11}$ craters $/ 10^{6} \mathrm{~km}^{2}$ and 2.2 to $2.7 \mathrm{~m}$, respectively. Again, the resolution of the photograph is too poor for an estimate of $D_{L}$, which should be near 3.7 to $4.6 \mathrm{~m}$ or 1.7 times $C_{s}$. The absolute age of North Ray is widely accepted as $48.9 \pm 1.7 \mathrm{~m} . \mathrm{y}$. (Marti and others, 1973), but smaller ages (near 30 m.y.) have been reported (Kirsten and others, 1973).

\section{CRATERING RATE WITH TIME}

An incremental impact-flux history (fig. 10B) for relatively small craters can be derived in terms of $\Delta D_{L} / \Delta t$ from the cumulative curve shown in figure 10 . The large flux during the interval from about 3.9 to 3.84 b.y. ago is consistent with previous results (Soderblom and Boyce, 1972; Shoemaker, 1970; Soderblom and Lebofsky, 1972; Neukum and others, 1975b) and much larger than that during the interval from 3.68 to 3.16 b.y. ago. These results when combined with the histograms of figure 8 indicate that two major craterforming events, separated by a short hiatus, occurred early in lunar history. For ages less than 3.15 b.y. (Apollo 12), the incremental frequency is not well understood. Computed incremental frequencies using the error bars yield mixed results (tables 4 and 5), but best-guess estimates suggest an increase in flux during the last billion years. When the uncertainties for the data point represented by Copernicus are considered, the argument for such an increase in flux seems somewhat weak. Neukum and others (1975b) combine data on terrestrial craters to indicate an increase in flux of large craters (in contrast to the small craters considered here) during the last billion years. This postulate needs further study using lunar data. 


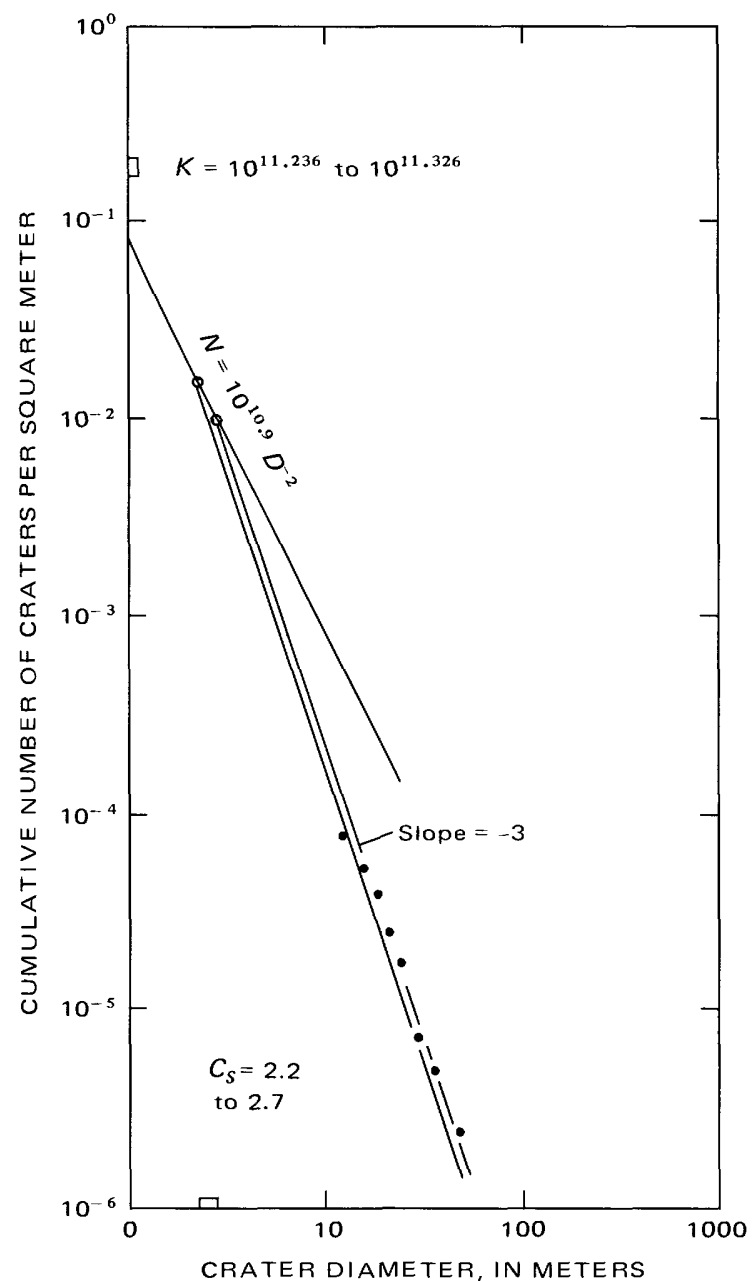

FIGURE 11.-Frequency distribution of craters on flanks of North Ray crater (Apollo 16) from rim to about one-half crater radius from rim.

TABLE 5.-Calculated incremental fluxes for small craters during the last 3.9 billion years

\begin{tabular}{|c|c|c|}
\hline Time interval & $\begin{array}{l}\text { Incremental flux } \\
\text { and estimate range }\end{array}$ & $\begin{array}{l}\text { Values of } D_{l} \text { and } \\
\text { age used }\end{array}$ \\
\hline North Ray to present & $\begin{array}{l}85 \mathrm{~m} / \mathrm{b} \cdot \mathrm{y} \\
\text { ( } 76 \text { to } 153 \text { ) }\end{array}$ & $\begin{array}{l}4.2 \mathrm{~m}, 49 \mathrm{~m} . \mathrm{y} . \\
(3.7 \mathrm{~m}, 49 \mathrm{~m} . \mathrm{y} . \text { and } \\
4.6 \mathrm{~m}, 30 \mathrm{~m} . \mathrm{y} .)\end{array}$ \\
\hline Tycho-Light Mantle to present & (27 to 136$)$ & $\begin{array}{l}4.7 \mathrm{~m}, 89 \mathrm{~m} . \mathrm{y} \\
(3.4 \mathrm{~m}, 128 \mathrm{~m} . \mathrm{y} \\
\text { and } 6.8 \mathrm{~m}, 50 \mathrm{~m})\end{array}$ \\
\hline Copernicus to present & $\begin{array}{l}118 \mathrm{~m} / \mathrm{b} . \mathrm{y} \\
\quad(70 \text { to } 173)\end{array}$ & $\begin{array}{l}100 \mathrm{~m}, 0.85 \text { b.y. } \\
(70 \mathrm{~m}, 0.95 \text { b.y. and } \\
130 \mathrm{~m}, 0.75 \text { b.y. })\end{array}$ \\
\hline Apollo 12 to present & $\begin{array}{l}68 \mathrm{~m} / \mathrm{b} . \mathrm{y} \\
(52 \text { to } 85)\end{array}$ & $\begin{array}{l}215 \mathrm{~m}, 3.16 \text { b.y. } \\
(170 \mathrm{~m}, 3.25 \text { b.y. and } \\
260 \mathrm{~m}, 3.07 \text { b.y. })\end{array}$ \\
\hline Apollo 17 to Apollo 12 & $\begin{array}{r}288 \mathrm{~m} / \mathrm{b} . \mathrm{y} . \\
\quad(89 \text { to } 978)\end{array}$ & $\begin{array}{l}215 \mathrm{~m}, 3.16 \text { b.y. and } \\
365 \mathrm{~m}, 3.68 \mathrm{~b} . \mathrm{y} . \\
(260 \mathrm{~m}, 3.07 \mathrm{b.y} \text {. and } \\
335 \mathrm{~m}, 3.86 \text { b.y.: } \\
170 \mathrm{~m}, 3.27 \text { b.y. and } \\
395 \mathrm{~m}, 350 \text { b.y. }\end{array}$ \\
\hline
\end{tabular}

An argument for an increase in impact flux in more recent times has been given by Swann and Reed (1974). Their increment flux (shown in fig. 10B) may be converted to $\Delta D_{L} / \Delta t$ using the relation

$$
\Delta K=\delta \Delta D_{L},
$$

where $\delta=4.8 \times 10^{10}$, and using equation (1) with $\alpha=$ -3 . The results are lower than expected when compared with the other results. This may reflect the fact that many craters have been destroyed and were not counted because the craters counted extend well into the steady-state sizes, and others could have been missed because of illumination conditions.

\section{COMPARISON OF RELATIVE AGES WITH OTHER REMOTELY SENSED DATA}

Relative ages correlate, with some qualifications, with other remotely sensed data: (1) geologic map units, (2) regolith thickness estimates, and (3) bistatic-radar surface roughness estimates. These are briefly discussed below.

\section{GEOLOGIC MAP UNITS}

In a broad way, the sequence of formation of lunar plains units determined from relative ages is in agreement with relative ages based on geologic criteria such as superposition, intersection, and degree of modification (Shoemaker and Hackman, 1962; Wilhelms and McCauley, 1971; Wilhelms, 1980). Highland geologic plains units are older than mare units by both relative age dating techniques $\left(D_{L}\right.$ values) and geologic techniques. Ejecta from craters such as Tycho, Copernicus, and Aristarchus are also found to be younger than the maria using both techniques. Relative ages of highland plains fall into an older group and younger group. Generally those mapped as preImbrian plains (Wilhelms and McCauley, 1971) correspond to the older relative ages, and those mapped as Imbrian plains (Wilhelms and McCauley, 1971) correspond to younger relative ages. These results are internally consistent with the hypothesis that the "crater age clocks" of pre-Imbrian surfaces were reset by the Imbrian event and that Imbrian surfaces were reset by the Orientale event if the resetting of the crater age clocks was accomplished by a nondeposition process such as seismic erosion (Schultz and Gault, 1974). On the other hand, the results are inconsistent if thick deposits of primary ejecta produced the new surfaces (Chao and others, 1975) or thick deposits of secondary and tertiary crater ejecta produced the new surfaces (Oberbeck, Hörz, and others, 1975). If this second postulate is true, both groups of plains are Imbrian. Within the mare plains, particularly good correlations between relative ages and geology are found in Mare Imbrium, Oceanus Procellarum, and Mare Serenitatis. The Imbrium flows are clearly superposed on other flows, and their relative ages $\left(D_{L}\right.$ values) are clearly 
younger than the subjacent flows (Schaber, 1973). Similar results are found for the young flows inundating Delisle (Wilhelms, 1980). The mare materials of Oceanus Procellarum are clearly superposed on those around Montes Agricola, just north of the Aristarchus Plateau, and in complete agreement with the $D_{L}$ values for the two geologic units (Zisk and others, 1975, 1977; Boyce, 1975). Within Mare Serenitatis, part of the dark annulus has an older relative age than the material within the basin-a result consistent with geologic mapping (Boyce and Dial, 1973; Howard and others, 1973). Finally, both relative crater ages and geologic mapping show that Copernicus is younger than Eratosthenes and both are younger than the surrounding maria (Shoemaker and Hackman, 1962; Soderblom and Lebofsky, 1972).

\section{REGOLITH THICKNESS}

Regolith thicknesses should increase with net accumulated flux and $D_{L}$ or relative age (Shoemaker and others, 1960b; Soderblom and Lebofsky, 1972). Four methods for estimating regolith thicknesses that are independent of crater frequency distributions and relative ages are (1) analyses of crater morphologies (Oberbeck and Quaide, 1967, 1968; Moore and others, 1975; Quaide and Oberbeck, 1968, 1969), and their ejecta (Wolfe and others, 1975), (2) active seismometry (Kovach and others, 1971, 1972; Duennebier and others, 1974), (3) excavations in thin regoliths (Shoemaker and others, 1969a), and (4) bistatic radar (Tyler, 1968). The crater morphology technique, which is affected by photographic resolution (Moore and others, 1975), shows that young mare surfaces in Oceanus Procellarum tend to have thin regoliths (fig. 12 , table 6 ), but some estimates seem to be at odds with the expectations. These anomalous estimates are discussed below. Regolith thicknesses estimated from active seismometry indicate that the regolith at the older Apollo 16 site is thicker than that at the younger Apollo 17 site, whereas the regolith at the oldest site, Apollo 14, is relatively thin (fig. 12). Excavations by the Surveyor 7 surface sampler indicate the regolith on the flank of Tycho is very thin, as it should be. Although difficult to correlate with relative ages, the Ex-

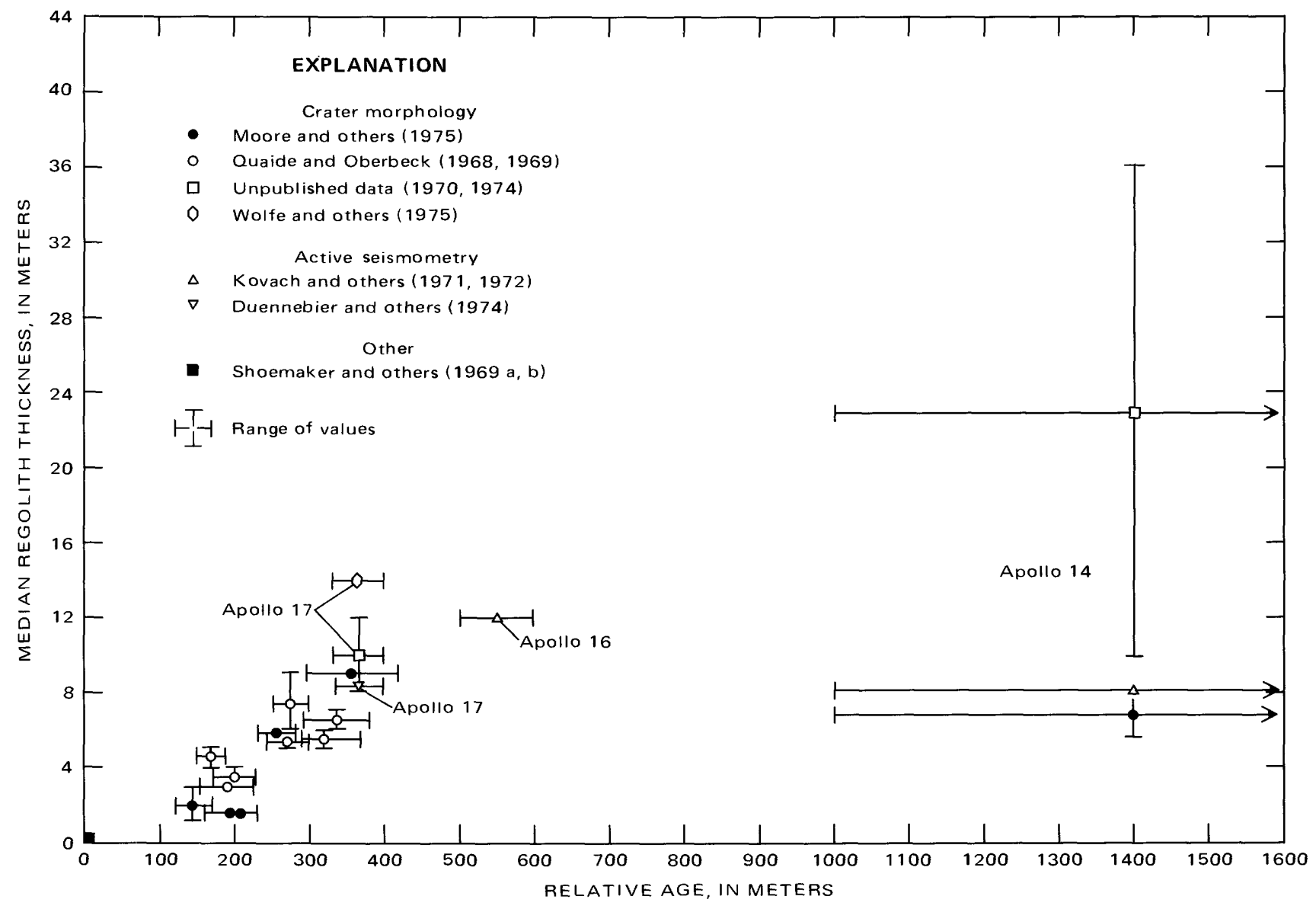

FIGURE 12.-Correlation between median regolith thickness and relative age of surface. 
TABLE 6.-Comparison of regolith thickness and relative age of surface $\left(D_{L}\right)$

\begin{tabular}{|c|c|c|c|}
\hline & $\begin{array}{l}\text { Median } \\
\text { regolith } \\
\text { thickness } \\
\text { (m) }\end{array}$ & $\begin{array}{c}D_{L} \\
(\mathrm{~m})\end{array}$ & Reference \\
\hline \multicolumn{4}{|c|}{ Crater morphology ${ }^{1}$} \\
\hline $\begin{array}{l}\text { Oceanus Procellarum: } \\
2^{\circ} \mathrm{N}, 34^{\circ} \mathrm{W} \\
2^{\circ} \mathrm{N}, 43^{\circ} \mathrm{W} \\
3^{\circ \mathrm{S}}, 37^{\circ} \mathrm{W} \\
4^{\circ \mathrm{S}}, 3^{\circ} \mathrm{W} \\
2^{\circ} \mathrm{N}, 42^{\circ} \mathrm{W} \\
1^{\circ} \mathrm{S}, 20^{\circ} \mathrm{W} \\
3^{\circ} \mathrm{S}, 44^{\circ} \mathrm{W} \\
1^{\circ \mathrm{c}} 0^{\circ} \mathrm{W}\end{array}$ & $\begin{array}{l}1-3 \\
1.5 \\
1.5 \\
3 \\
4-5 \\
5.5-6 \\
9-6 \\
3-4\end{array}$ & $\begin{array}{l}145 \pm 25 \\
205 \pm 25 \\
195 \pm 35 \\
190 \pm 40 \\
170 \pm 20 \\
255 \pm 25 \\
355 \pm 60 \\
200 \pm 30\end{array}$ & $\begin{array}{l}\text { Moore and others (1975). } \\
\text { Do. } \\
\text { Do. } \\
\text { Quaide and Oberbeck (1969). } \\
\text { Do. } \\
\text { Moore and others (1975) } \\
\text { Do. } \\
\text { Quaide and Oberbeck (1968) }\end{array}$ \\
\hline $\begin{array}{l}1^{\circ} \mathrm{S}, 20^{\circ} \mathrm{W} \\
\text { Sinus Medii: } \\
04^{\circ} \mathrm{N}, 1^{\circ} \mathrm{W} \\
0.4^{\circ} \mathrm{N}, 1^{\circ} \mathrm{W}\end{array}$ & $\begin{array}{l}5-6 \\
6-9\end{array}$ & $\begin{array}{l}280 \pm 20 \\
275 \pm 25\end{array}$ & Do. \\
\hline $\begin{array}{l}\text { Mare Tranquillitatus: } \\
0.7^{\circ} \mathrm{N}, 24^{\circ} \mathrm{E} \\
26^{\circ}, 34^{\circ} \mathrm{E}\end{array}$ & $\begin{array}{l}5-6 \\
6-7\end{array}$ & $\begin{array}{l}320 \pm 50 \\
335 \pm 45\end{array}$ & $\begin{array}{l}\text { Quaide and Oberbeck (1969). } \\
\text { Do. }\end{array}$ \\
\hline $\begin{array}{l}\text { Fra Mauro: } \\
\text { Apollo } 14 \text { site } \\
\text { Apollo } 17 \text { site }\end{array}$ & $\begin{array}{l}10-36 \\
5.6-8 \\
8-12 \\
14\end{array}$ & $\begin{array}{r}1,400 \pm 40 \\
1,400 \pm 40 \\
365 \pm 35 \\
365 \pm 35\end{array}$ & $\begin{array}{l}\text { Moore, unpub. data (1970). } \\
\text { Moore and others (1975). } \\
\text { Moore, unpub. data (1974). } \\
\text { Wolfe and others (1975). }\end{array}$ \\
\hline \multicolumn{4}{|c|}{ Active seismometer } \\
\hline $\begin{array}{l}\text { Apollo } 14 \text { site } \\
\text { Apollo } 16 \text { site } \\
\text { Apollo } 17 \text { site }\end{array}$ & $\begin{array}{l}8.2 \\
-12 \\
-<8.5\end{array}$ & $\begin{array}{r}1,400 \pm 400 \\
550 \pm 50 \\
365 \pm 35\end{array}$ & $\begin{array}{l}\text { Kovach and others }\{1971\} \text {. } \\
\text { Kovach and others (1972). } \\
\text { Duennebier and others (1974). }\end{array}$ \\
\hline \multicolumn{4}{|c|}{ Excavation } \\
\hline Tycho, Surveyor 7 & $-0.02-0.15$ & $\approx \overline{4.7}$ & Shoemaker and others $(1969 \mathrm{a}, \mathrm{b})$. \\
\hline \multicolumn{4}{|c|}{ Imbrium flows ${ }^{2}$} \\
\hline $\begin{array}{l}\text { Older surface } \\
25^{\circ} \mathrm{N} ., 2^{\circ} \mathrm{W} . \\
\text { On flows. } \\
\text { On flows } \\
\text { On flows.... }\end{array}$ & $\begin{aligned} & 5 \\
&-10 \\
&-8 \\
&- 7.5\end{aligned}$ & $\begin{array}{r}=250 \\
200 \pm 20 \\
160 \pm 20 \\
180 \pm 40\end{array}$ & Moore and others (1975). \\
\hline
\end{tabular}

${ }^{1}$ Estimates of regolith thicknesses made using Lunar Orbiters II and III high-resolution photographs. Orbiter IV photographs which have companble rolutions. These points not plotted in figure 12 because resolution affects thickness estimates (see Moore and others, 1975).

plorer 35 bistatic-radar experiment indicates considerable variation in thickness of the regolith.

Some regolith thickness estimates are puzzling. The estimates at the Apollo 14 landing site using active seismometry $(8.2 \mathrm{~m})$ and some crater morphology studies $(5.6-8 \mathrm{~m})$ are much lower than that predicted by the regolith-crater model of Shoemaker (Shoemaker and others, $1969 \mathrm{~b}$ ). Here a median regolith thickness of $35 \mathrm{~m}$ (and a range of about $20-200 \mathrm{~m}$ ) would be expected instead of 6 to $8 \mathrm{~m}$. A thick median regolith is in keeping with buried craters greater than $500 \mathrm{~m}$ across at the Apollo 14 site, South Triplet, a central peak crater $90 \mathrm{~m}$ across, and early estimates of regolith thickness (10-36 m, H. J. Moore, unpub. data, 1970). Estimates of the regolith thickness at the Apollo 17 site vary, less than $8.5 \mathrm{~m}$ (active seismometry), 8-12 m (crater morphology), and $14 \mathrm{~m}$ (crater ejectamorphology). Regolith thicknesses on the Imbrium flows measured using the crater morphology technique are greater $(8-10 \mathrm{~m})$ than on the surface on which they are superposed $(5 \mathrm{~m})$ and are comparable to the thickness of the flows (Moore and Schaber, 1975) rather than the regolith on the flows. Indeed, relative age data indicate that the regolith on the Imbrium flows should be near $2-4 \mathrm{~m}$.

\section{BISTATIC RADAR RESULTS}

With time, the lunar plains should become rougher because the number of craters increase with continued meteoroid impacts. If craters on lunar plains are the chief factor producing surface roughness, one would expect a positive correlation between relative age and independent estimates of surface roughness. This is the case. The bistatic-radar experiment (Howard and Tyler, 1971, 1972a, 1972b; and Tyler and Howard, 1973), which is discussed more fully below, provides independent estimates of surface roughness at two scale lengths. Two wavelengths were used, $13 \mathrm{~cm}$ (Sband) and $116 \mathrm{~cm}$ (VHF), which measure surface roughness at scale lengths between 10 and 250 wavelengths, or scale lengths comparable to or less than most $D_{L}$ values reported.

Surface roughness obtained from simple measures of radar echo broadening are expressed as root-meansquare (rms) slopes, which increase with increasing roughness of the surface. Correlations of the rms slopes with relative ages along and near the bistatic-radar subspecular tracks for Apollo 14, 15, and 16 (Moore and others, 1975,1976 ) show they are directly related, although there is considerable scatter (fig. 13). The missions are plotted separately because of differences in roughness estimates between missions.

The large amount of scatter in the results (fig. 13) may be the result of experimental error for both the radar and relative ages, contribution to surface roughness other than craters, and unknown causes.

\section{DISCUSSION}

Relative ages of lunar plains and craters yield four significant results: (1) Two major events, accompanied by the production of a large number of craters, reset the crater-age clocks of many surfaces over the entire Moon prior to 3.84 b.y. ago; (2) the flux of objects producing relatively small craters (less than $1 \mathrm{~km}$ ) was relatively higher between 3.2 and 3.84 b.y. ago than it was after 3.2 b.y. ago, and the flux of objects producing relatively small craters may have increased slightly in the interval from 1 b.y. ago to the present; (3) outpourings of lava to produce the dark mare plains of the Moon extended to more recent times than indicated by samples returned from the Moon; and (4) great expanses of young mare plains are found on the west limb of the Moon in Oceanus Procellarum and in western Mare Imbrium, whereas expanses of old plains are found in Mare Tranquillitatis near the east limb of the Moon. 

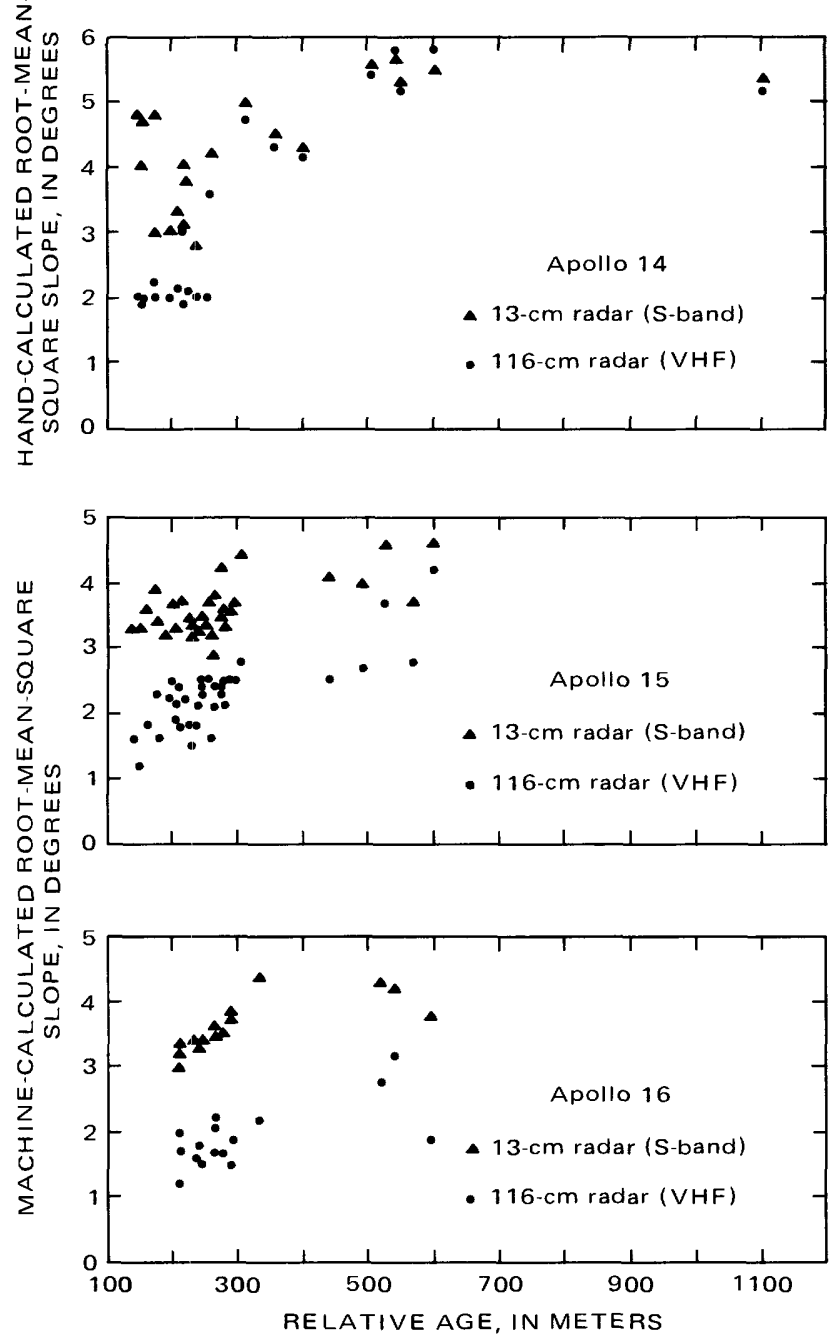

Figure 13.--Bistatic-radar roughness (root-mean-square slopes) and relative ages of units along and near the Apollo 14, Apollo 15, and Apollo 16 subspecular tracks.

\section{EARLY MAJOR EVENTS}

There are a number of questions related to the two major events, represented by $D_{L}$ values near $540 \mathrm{~m}$ and above $1,000 \mathrm{~m}$, that occurred before $3.84 \mathrm{~b} . \mathrm{y}$. ago. The first question is in regard to time: Do the relative ages actually represent two contemporaneous events or two episodes of penecontemporaneous events? Radiometric ages representing metamorphism of lunar highland samples indicate the events occurred within a relatively short interval of time from 4.0 to 3.85 b.y. ago (Tera and others, 1974, Turner and Cadogan, 1975), and stratigraphic relations - the superposition of mare material on light plains-show that the last major event occurred before the formation of the maria, thus confirming that the events occurred within a short interval of time. Within the limits of measurement, relative ages can be interpreted as representing two distinct events occurring at one time within a few hours or days or so. The hiatus in relative ages between $D_{L}$ values about $600 \mathrm{~m}$ and above $1,000 \mathrm{~m}$ indicates a period of normal, very low activity. On the other hand, the limits of measurement of relative age are so large that they may represent episodes lasting tens of millions of years; but the period of normal activity remains. The time the last episode ceased is fixed to a small interval between mare formation and the formation of the formation of the Orientale basin. Additional evidence for the synchronous occurrences of at least two major events is found in comparisons of crater frequency distributions obtained by independent observers (fig. 14). Crater frequency distributions obtained for basin-related geologic units within the Orientale basin (Ulrich and Saunders, 1968; Neukum and others, 1975) are the same as those for the ejecta on the flank of the Orientale basin (Boyce and others, 1974). These crater frequency distributions for Orientale are nearly the same as those for light plains of intermediate age (Cayley plains) far distant from the Orientale basin and its ejecta (Grudewicz, 1974-light plains near Hyginus Rille and mantled ones on the Aristarchus Plateau; Neukum and others, 1975-light plains of the Apollo 16 site; Boyce and others, 1974-light plains in Albategnius, Ptolemaeus, and those of the Apollo 16 site). Frequency distributions of craters smaller than 3 to $5 \mathrm{~km}$ on the flanks of the Imbrium basin in the Montes Apenninus (Neukum and others, 1975a) are similar to those for Orientale and light plains of intermediate age, and frequencies of craters larger than 3-5 $\mathrm{km}$ are relatively higher than those of Orientale. This suggests that the degraded appearance of parts of the Imbrium ejecta and local partial resetting of the crater age clocks in the Montes Apenninus could have been due to the Orientale event, which destroyed craters smaller than 3 to $5 \mathrm{~km}$ but not the larger ones.

The crater frequency distribution for the Fra Mauro Formation (Neukum and others, 1975b; Boyce and others, 1974; Soderblom and Boyce, 1972; Swann and others, 1971) matches the distributions of the widely scattered old light plains in Meton (Boyce and others, 1974). Although scarce, they could represent vestiges of evidence offered by craters for the Imbrium event.

Some crater frequency distributions may indicate other earlier events on the Moon. The distribution in Albategnius is one such example (fig. 14). Here, the frequency distribution of craters greater than $2.3 \mathrm{~km}$ exceeds that for the Fra Mauro Formation and indicates an older surface for which craters smaller than about $1.4 \mathrm{~km}$ were obliterated and the crater-age clock was reset at the time the Orientale basin formed. Evidence for this older surface and still older ones are seen in the histograms comparing the ratio of unshadowed 


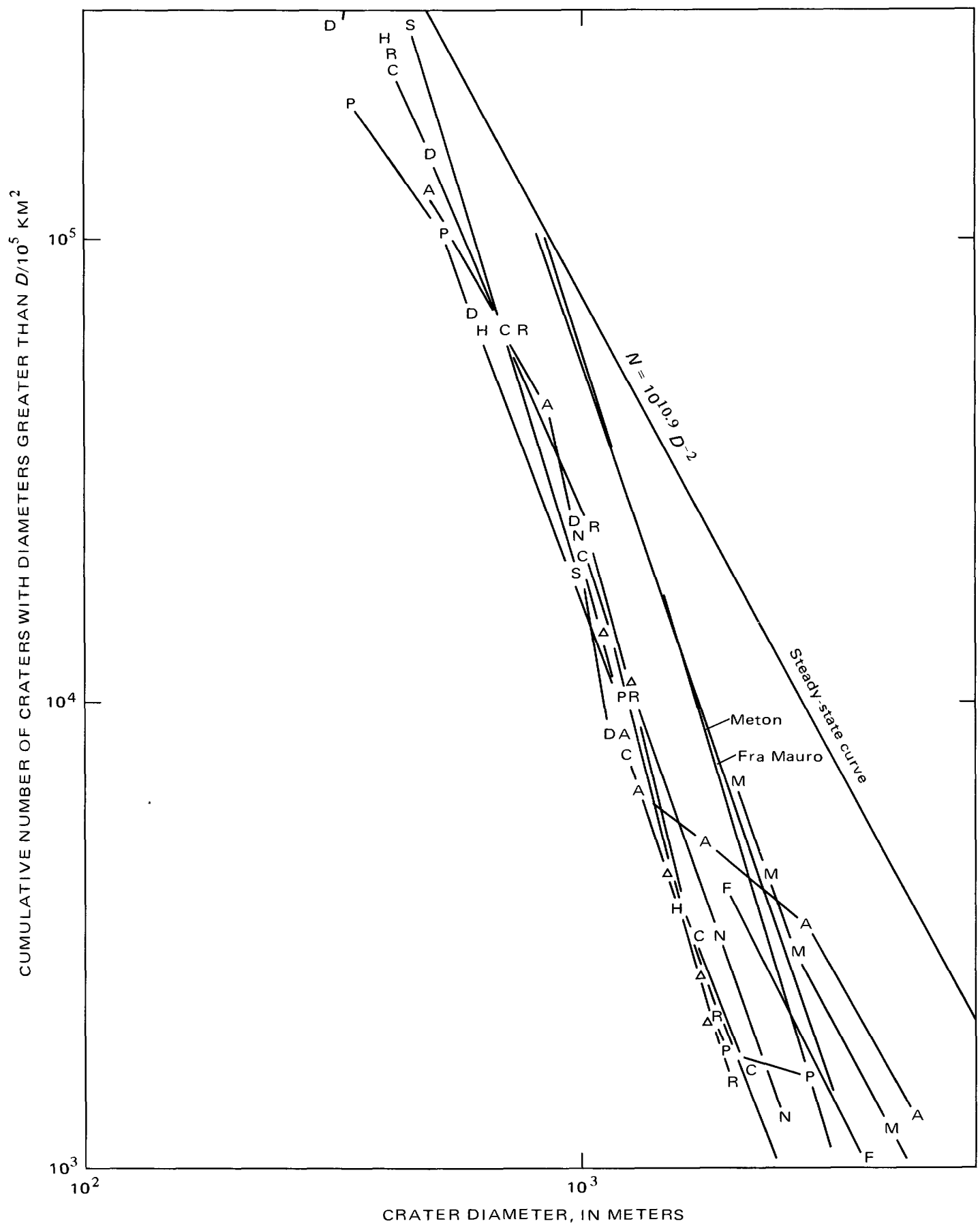

FIGURE 14.-Size frequency distributions of craters for selected lunar areas: Montes Rook Formation (R), central light plains material of Orientale (C), Apollo 16 landing site (D, N, $\Delta$ ), Vallis Schröteri Formation (S), Hyginus light plains (H), Fra Mauro Formation at the Apollo 14 site (indicated by leader, F), floor of Albategnius (A), floor of Ptolemaeus (P), floor of Mendeleev (M), and floor of Meton (indicated by leader). Data are from Ulrich and Saunders (R, C, 1968), Grudewicz (S, H, 1974), Boyce and others (Fra Mauro, Meton, 1974), and Neukum and others (1975a) (N, $\Delta$, and F). Steady-state curve after Trask (1966). Curves for younger Cayley-age light plains $(\mathrm{S}, \mathrm{H}, \mathrm{D}, \mathrm{N}, \Delta, \mathrm{A}$, and $\mathrm{P})$ are similar to Orientale $(\mathrm{R}, \mathrm{C}$,) and very different from Imbrium ejecta (F, Fra Mauro) and older light plains (M, Meton). Bends in curves of Albategnius and Ptolemaeus at about $2-3 \mathrm{~km}$ are interpreted to reflect old partially buried craters. Error bars excluded for clarity. 
to shadowed craters (fig. 4) where, for Albategnius, a mode occurs at diameters near $1.8 \mathrm{~km}$. Still larger craters are preserved in Meton (fig. $4 B$ ) and Mendeleev (Neukum and others, 1975a).

A second question is what caused the major events. There are a number of possibilities for resetting the crater age clocks represented by $D_{L}$ values near $540 \mathrm{~m}$ and above $1,000 \mathrm{~m}$ in the interval from about 4.0 to 3.84 b.y. ago, some of which are:

A. Exogenic

1. Tidal interactions between the Moon and Earth giving rise to seismic erosion or tectonism.

2. Anomalously large episodic increases in the flux of objects producing primary impact craters.

3. Some unknown cosmic event.

B. Endogenic

1. Lunar seismic erosion or tectonism and volcanism.

C. Exo-endogenic

1. Tectonism or seismic erosion generated by the impacts producing the large basins.

2. Anomalously large momentary increases in flux of objects ejected from the large basins producing secondary impact craters that erode and smooth pre-existing terrain.

3. Dynamic deposition of ejecta from large basins producing thick deposits that smooth preexisting topography - such deposits are clearly continuous around the basin margins to, on the average, 2.38 basin radii from the basin center and are probably discontinuous beyond.

Of these possibilities, the exo-endogenic ones appear to be the most likely, and all three possibilities in this category almost certainly contributed to some degree. Seismic erosion induced by tidal interactions between the Moon and Earth seems unlikely because such interactions would probably affect the entire Moon and would not permit the preservation of the scattered old light plains in some places but not in others. Anomalously large episodic increases of the flux of objects producing primary craters is possible but unlikely because of the hiatus. Although there is weak evidence for changes in flux from 3.84 to 3.16 b.y. ago (figs. 8,10 ), no hiatus is observed in this interval. Additionally, the preservation of the scattered old plains in some places but not in others is difficult to explain with this process. Evidence for extensive endogenic tectonism and volcanism from about 4.0 to 3.84 b.y. ago is practically nonexistent. Indeed, evidence for extensive fracturing and faulting of the Orientale and Imbrium ejecta blan- kets is scarce, and most highland rocks sampled by Apollo are shock-metamorphosed nonvolcanic rocks. Thus, at this time, exo-endogenic processes are the best mechanisms to account for the relative-age data.

Exo-endogenic processes offer an explanation for the data on relative ages and crater frequency distributions that is consistent with other photogeologic evidence. Dynamic deposition of ejecta from basins that smooth preexisting topography and reset the craterage clocks has certainly occurred near the rims of the larger basins (Moore and others, 1974, Chao and others, 1973, 1975). It is also demonstrable that ejecta producing large secondary craters has produced new surfaces (Oberbeck, Hörz, and others, 1975). Less certain are the roles of seismic erosion (Schultz and Gault, 1974), dynamic deposition of ejecta from the basins producing continuous layers at very large distances (Chao and others, 1973, 1975), small secondary impact craters produced by basin ejecta that form smooth surfaces underlain by mixtures of ejecta and local materials (Oberbeck, Hörz, and others, 1975), and fluting and furrowing by the impact of concentrations of ejecta as far distant as the antipodes of the basins (Moore and others, 1974). The contributions to the formation of smooth plains cannot be separated at this time. Photogeologic evidence does support the hypothesis that ejecta from Imbrium produced fluting and furrowing at the antipode of Imbrium near Mare Ingenii, where Imbrian age furrows and flutes are subparallel to one another, regardless of the magnitude and orientation of local slopes. The seismic erosion model may be least likely because it is difficult to imagine how some areas, such as in Mendeleev and Meton, could have escaped the pervasive effects predicted (Schultz and Gault, 1974), whereas nearby plains did not. The known irregular patterns of ejecta from craters and basins permit the survival of local areas.

\section{CRATERING RATE}

The flux of objects producing small craters clearly decreased after 3.15 b.y. ago, and calculations using the reported $D_{L}$ values and ages (without considering the error bars) indicate a decrease in flux to the time the crater Copernicus formed. Subsequently the flux increased somewhat. The relatively large flux from 3.68 to 3.16 b.y. ago is probably real because calculated fluxes are large for smaller intervals throughout that interval. Assuming the worst possible errors, calculations indicate that the flux could have been nearly constant from the time of mare formation to the present. Our estimates of the flux for North Ray are consistent 
with Apollo results from the passive seismic experiment (Dunnebier and others, 1975), for which estimate errors are just as severe as ours. An order of magnitude estimate of compatibility between the flux of objects determined by us for North Ray and the estimate from the passive seismometer can be calculated. Ranger VIII struck the lunar surface with a kinetic energy of about $10^{16.14} \mathrm{ergs}$, producing a crater about $13 \mathrm{~m}$ across (Moore, 1968). Assuming diameter is proportional to the cube root of the energy of the object producing the crater, neglecting the effect of angle of impact, and using a velocity of $15 \mathrm{~km} / \mathrm{s}$ (Zook, 1975), we calculate the mass of an object producing a crater $1 \mathrm{~m}$ across to be $5.6 \mathrm{~g}$. When the mass is substituted in the preferred equation derived from the passive seismometer data (Duennebier and others,1975), the flux becomes $10^{-1.964}$ craters $/ \mathrm{km}^{2}$ yr. Since North Ray is about 50 m.y. old, the predicted net accumulated flux for North Ray becomes $10^{11.74}$ craters $/ 10^{6} \mathrm{~km}^{2}$. This value is somewhat larger than the measured values for North Ray of $10^{11.236}$ to $10^{11.326}$, but it is within a factor of 3 . The mass of a meteor traveling at $15 \mathrm{~km} / \mathrm{s}$ that is required to produce a $1 \mathrm{~m}$ crater $(14 \mathrm{~g})$, estimated from data on missile impact craters (Moore, 1976, 1971b), and the same type of calculations as above yield a net accumulated flux of $10^{10.79}$ craters $/ 10^{6} \mathrm{~km}^{2}$. This is smaller than the lower value of $K$ for North Ray but is within a factor of 3. From the foregoing discussion it is apparent that calculations could be made to yield better agreement between the passive seismic preferred estimates of the flux and the measured one.

Scaling laws for impact crater formation that result in crater frequency distributions for which the cumulative frequency is proportional to the inverse cube of the diameter (equation 1) can be satisified for conditions of constant projectile velocity by

$$
D^{3} \propto \mathrm{m}^{1.13}
$$

Such a result suggests that scaling laws developed from studies of missile impact craters (Moore, 1976) might be more appropriate for small lunar craters than those produced by experimental impacts with sand in the laboratory (Oberbeck, 1970; Cook and Mortensen, 1967).

\section{MARIA}

Outpourings of lava to produce the dark mare plains of the Moon extended to more recent times than indicated by samples returned from the Moon. The exact duration is difficult to determine because of the errors in $D_{L}$ values and the general flattening of the $D_{L}$-time curve after 3.16 b.y. (see also Neukum and others, $1975 \mathrm{~b})$. For example, $D_{L}$ values of $180 \pm 30$ could repre- sent ages of 3.15 to 2.5 b.y., although the midpoint corresponds to 2.65 b.y. When this error is combined with the errors in both radiometric age $(3.16 \pm 0.09$ b.y. and $D_{L}(215 \pm 45)$ for Apollo 12, the possibility of overlap is clear. On the other hand, the consistent repetition of low relative ages or $D_{L}$ values in Oceanus Procellarum gives a strong indication that there is, in fact, young mare material there that may have formed as recently as about 2.5 b.y. ago, some 0.6 b.y. after the Apollo 12 mare basalts. Other evidence supports this conclusion: (1) Infrared eclipse temperatures (Shorthill, 1973), which are discussed below, are uniformly large in Oceanus Procellarum, suggesting the presence of large concentrations of rocks and thin regoliths which would be expected for young maria; (2) Lunar Orbiter images show a large number of blocky craters in Oceanus Procellarum; (3) analyses of craters imaged by Surveyor 1 indicate that the regolith is, in fact, thin compared to that in other maria (Shoemaker and others, 1969b); and (4) the bistatic-radar results indicate smoother, less cratered surfaces in Oceanus Procellarum than in other maria (Moore and others, 1976).

\section{WESTERN MARIA}

The occurrence of vast expanses of young mare materials in Oceanus Procellarum is an important observation but the reason for their occurrence there is not understood. The surfaces of the maria in Oceanus Procellarum are higher than those of earlier formed maria elsewhere on the Moon (Head, 1976). Larger hydrostatic heads of deeper magma sources would be expected in a lunar crust that thickens with time, but the reason why earlier formed maria at lower elevations were not also flooded by younger lava is not certain. It seems that some additional factors, perhaps inhomogeneities in the lunar crust or structural factors, were involved.

\section{LUNAR GRAVITY AND TECTONICS}

\section{By D. H. ScotT}

Among the most interesting and significant results of the lunar space program was the discovery of large positive gravity anomalies on the Moon and their association with circular maria. The mass concentrations or "mascons" responsible for the gravity anomalies were first revealed during doppler tracking of spacecraft in the Lunar Orbiter missions by Müller and Sjogren (1968) of the Jet Propulsion Laboratory. In effect, the spacecraft acted as an accelerometer, responding to mass variations on the Moon by changes in velocity along its orbital path. The orbits, however, did not approach closer than $100 \mathrm{~km}$ to the lunar surface in the 
early missions and consequently afforded inadequate resolution for the gravitational definition of many small to moderate-size topographic and geologic features. For example, the gravity response of a crater such as Copernicus showing a negative anomaly of -57 milligals (Sjogren and others, 1974a) at $20 \mathrm{~km}$ spacecraft altitude would only have a value of about -8 milligals at $100 \mathrm{~km}$ altitude. Moreover, the much smaller anomaly at the higher altitude would be dispersed over a radial distance several times as great. During the later Apollo missions, nearside perilune altitudes were lower, and relatively minor features such as some small craters, mare ridge systems, and certain mountain chains appeared as "free-air" gravity anomalies. The gravity data together with accurate elevations established by laser and radar altimetry together with photogrammetric methods have shown that many structures of basin size and smaller are not isostatically compensated. The large basins, however, have probably passed through cycles of combined isostatic and hydrostatic changes ranging from (1) an uncompensated negative stage when first formed, through (2) a period of equilibrium resulting from updoming of the mantle and basalt flooding, followed by (3) an overly compensated positive stage as basalt filling progressed and the crust stiffened enough to maintain the load. These stages are illustrated by the Orientale basin. The smooth mare-filled central part of Orientale basin is a positive anomaly, whereas the rough outer floor of the basin is strongly negative. In all other lunar near-side basins the basalt filling has progressed much farther than at Orientale, and the negative anomaly associated with the depression has virtually disappeared. These basins are large mascons. Yet, for the most part, gravity variations over large regions of the Moon are relatively mild compared with Earth, and equilibrium generally prevails (Kaula, 1975).

The following discussion will describe methods used in the analysis of gravity data, some of the results obtained from these methods, and relations between gravity anomalies and tectonic features, mostly on the near side of the Moon.

\section{METHODS OF ANALYSIS AND APPLICATION}

The gravity field at any particular point depends upon the mass distribution around the point. It is a direct function of the incremental masses and an inverse function of the squares of the distances of the incremental masses from the point. Thus, topography and rock units with varying densities produce variations in the gravity field or anomalies. The magnitudes of the anomalies produced by rock units, neglecting topography and distance between observer and the surface, are a function of density, depth, size, and shape of rock units below the surface. Ambiguities in the interpretation of gravity anomalies result from the innumerable variations possible in these characteristics. In some places, however. the shape of a gravity anomaly, revealed either by contours or profile, may provide constraints on the depth and configuration of the causative mass. This is true for many of the positive anomalies associated with the mascon basins. For example, the flat top of the gravity profile for the Nectaris Basin mascon and the break in slope on the gravity profile across Mare Serenitatis together with the circular outlines of the anomalies indicate nearsurface, disk-shaped structures (Sjogren and others, 1972a, b). Using the shapes of the anomalies, Sjogren and his co-workers (1972a) have shown that the mass distribution and hence thickness of the nearside mascons is quite uniform; their thickness may range from about $2.7 \mathrm{~km}$ to $8 \mathrm{~km}$ depending on whether the original basin was isostatically compensated or not.

In other areas, gravity observations obtained at different spacecraft altitudes have been useful in determining the size of the source mass with less ambiguity than from single level data alone (Scott, 1974). The variables of density, thickness, depth of a thin cylindrical or disk-shaped object such as a mascon, for example, are effectively eliminated from the computations provided differences in orbital altitudes are large relative to body thickness.

All large craters on the near side as well as the Orientale basin on the west limb of the Moon are associated with negative free-air gravity anomalies (Sjogren and others, 1974b, c). Where topographic control is poor, as at Orientale, the gravity data can be used to estimate the mass deficiency of the cavity and thus, indirectly, obtain an approximation of the amount of material ejected (Scott, 1974). In areas where topographic maps are reliable, theoretical or Bouguer gravity values due to the cavity can be calculated from crater geometry. The difference between the observed (free-air) and theoretical gravity (Bouguer) values is a measure of the anomalous gravity (Bouguer anomaly) attributable to either a mass deficiency or a mass excess associated with the crater. A negative anomaly implies a mass deficiency unaccounted for by the crater void; it might result from a lens of brecciated material beneath the crater floor having a relatively low bulk density (Innes, 1961). A positive anomaly indicates a mass excess and could be caused by basalt flows on the crater floor or uplift of relatively dense subsurface material reflecting some degree of isostatic adjustment. Many nearside craters ranging in age from Copernican to pre-Nectarian show little or no Bouguer 
anomaly; observed and theoretical gravity are nearly equal (Sjogren and others, 1972a; Scott, 1974). It follows that these lunar craters, like the mascon basins, are not in isostatic equilibrium. The lunar crust must have been sufficiently thick or rigid to support their negative load since early in lunar history. These stresses amount to more than $800 \mathrm{~kg} / \mathrm{cm}^{2}$ for the mascons associated with the circular basins (Sjogren and others, $1974 \mathrm{~b}$ ) and about $-900 \mathrm{~kg} / \mathrm{cm}^{2}$ for a young crater such as Theophilus, described below.

This type of analysis is presently restricted to areas covered by the LTO series 1:250,000-scale maps, or to selected craters whose geometry has been well established by photogrammetric studies. An example of the application of the 1:250,000-scale maps to gravity studies is shown using the crater Theophilus. Only half of this crater is presently covered by the large-scale maps (LT0077D2 and LT078C1), but its total volume is probably reliably extrapolated as photographs show Theophilus to be nearly circular in outline and symmetrical in shape. A representative schematic topographic profile across the crater is shown in figure 15 . The cavity has a depth of $3 \mathrm{~km}$ with respect to the terrain beyond the raised crater rim material; its volume is $13,723 \mathrm{~km}^{3}$ after subtraction of the space occupied by the central peak. In order to determine the gravity effect of this void, the dimensions of a disk or cylinder having an equal volume are calculated. The radius of this disk, having a thickness equal to the depth of Theophilus $(3 \mathrm{~km}$ ), is $38.2 \mathrm{~km}$. From these data, and assuming a crustal density of $3.0 \mathrm{~g} / \mathrm{cm}^{3}$ (Warren and Anderson, 1972), a peak gravity value of about -180 milligals is obtained for the mass deficiency. This closely compares to an observed (filter corrected) value of -184 milligals at spacecraft altitudes of $22-23 \mathrm{~km}$ (W. L. Sjogren, oral commun., 1976). Thus, the new, more accurate and detailed elevation control from the large-scale topographic maps together with observed gravity results suggest that Theophilus, like other lunar craters, has undergone little if any isostatic adjustment.

As previously mentioned, gravity data can be used in some places to estimate the volume of craters and basins where topographic control is poor (Scott, 1974).

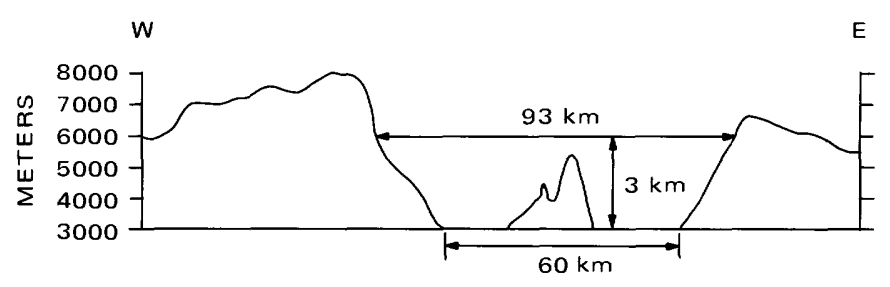

FIGURE 15.-Topographic profile of Theophilus.
The Orientale basin on the west limb of the Moon is a good example of the application of orbital gravity results to volume and mass estimates in the absence of adequate topographic data. As Orientale is relatively young (middle Imbrian) and well preserved morphologically, it is the prototype of all lunar multiringed basins. For this reason a large amount of study has been directed toward the geology of the basin, the thickness and areal distribution of its ejecta blanket, and the mechanics of its formation (Head, 1974; Howard and others, 1974, Moore and others, 1974; Scott and others, 1977). Volume estimates are important to these studies; they were made by calculating the mass deficiency from gravity data obtained by Apollo 15 and Apollo 16 subsatellites (Scott, 1974). Two methods were used for the computations and are briefly summarized here. The first method employed a set of surface mass points (Sjogren and others, 1974b) which were calculated to produce the observed residual accelerations of the spacecraft. The sum of the negative mass points was believed to correspond to the minimum amount of material ejected from the basin. In the second method, gravity profiles across a part of the basin were visually adjusted to remove the distorting effect of the central mascon. The negative anomaly value remaining more nearly reflected the mass (and volume) deficiency of the present basin, about $2 \times 10^{6}$ $\mathrm{km}^{3}$, than the first method using mass points. Other approximations of the volume of the basalt plug or dike swarms intruding the central part of Orientale are about $3 \times 10^{6} \mathrm{~km}^{3}$. Thus the total volume of the original cavity, equivalent to the amount of material ejected, may have been about $5 \times 10^{6} \mathrm{~km}^{3}$.

Sjogren and others (1974a) have developed a more sophisticated approach in the reduction of Apollo 17 gravity results. This method uses a dynamic solution in which real data and data simulated from a model are identically processed. It is an iterative procedure; the model, an assemblage of point masses, is progressively improved to obtain a best fit of simulated accelerations with real accelerations. The method seems to provide the most accurate estimations of mass as it accounts for vertical components of gravity, spacecraft altitudes, and filtering effects. Volume determinations of craters made from high-quality topographic maps together with accurate mass estimates obtained from dynamic solutions of gravity data could provide reliable bulk densities of the lunar crustal rocks.

Several attempts at lunar gravity data reduction using a template method to obtain residual gravity values have been made but without noticeable success. Residuals were calculated from the difference between the observed gravity at a point and the average value of the observed gravity within a large area around the 
point. In effect this is a filtering process which tends to enhance small gravity deviations that otherwise might be obscured by large regional variations. When this method was applied to lunar gravity maps, however, no significant anomalies were disclosed. This failure probably results from a combination of the following: (1) Spacecraft altitudes are so high over most areas that minor variations in the gravity field due to local or shallow sources are effectively filtered out. (2) Spacing of gravity control lines is too great for the effective use of residual templates having radii less than the line spacing, that is, small enough to amplify anomalies associated with such features as rilles, ridges, volcanic centers, and some craters. Another residual procedure involves the visual adjustment of observed gravity profiles to smooth continuous curves approximating regional slopes. Departures from the regional curve are due to local effects, and the magnitude of these anomalies can be measured. This method was used in the analysis of the gravity profile across Montes Secchi (fig. 16).

\section{GRAVITY AND GEOLOGIC STRLCTURE}

On a broad scale, the near side of the Moon shows positive gravity values except for a region extending around the central highlands in a broad semicircular arc (Sjogren, 1974, plate I). This generally negative region consists of large basalt-filled areas within Maria Fecunditatis, Tranquillitatis, and Nubium as well as the highlands north of Mare Vaporum including a part of the Montes Apenninus and the highlands around Rima Hyginus and Rima Ariadaeus. As the negative anomalies include both high and low terrain, they are not simply related to the Bouguer effect, and their cause is not clear. The largest of these anomalies, in Mare Nubiurn, has a value of less than -40 milligals. It is centered along the northwest extension of Rupes Recta, a large fault scarp transecting Imbrium mare materials and having a vertical displacement of $410 \mathrm{~m}$ (Holt, 1974). The present scarp is believed to be relatively young but probably represents recurrent movement along an older fault. Possibly this area has been undergoing uplift in repeated adjustments toward equilibrium which it has not yet reached. On a smaller scale, major mare ridge systems such as those in Oceanus Procellarum show positive gravity anomalies, whereas large rilles, except for Hyginus and Ariadaeus as noted above, have no noticeable gravity response (Scott and others, 1975). The linear rilles are believed to be grabens formed by extension of the lunar crust. The absence of associated gravity anomalies indicates that these structures have not produced any substantial lateral discontinuities in crustal density distribu- tion. Aside from the mascons associated with multiringed basins, the largest positive anomaly on the lunar near side occurs over Rupes Altai, the great fault scarp forming the outer ring of the Nectaris Basin (Sjogren, 1974, plate I; Rowan, 1971). Although the scarp rises more than $1,000 \mathrm{~m}$ above the basin floor, it is ridgelike in profile, and its height decreases to about one-half within about $10-20 \mathrm{~km}$ of its crest line. Thus, the average difference in elevation on either side of Rupes Altai is estimated to be about $500 \mathrm{~m}$. The magnitude of the positive gravity anomaly attributed to the uplift is difficult to ascertain because of the large adjacent mascon associated with the Nectaris basin. However, a gravity difference of about 60 milligals appears to be a reasonable estimate from Sjogren (1974, plate I). The calculated gravity effect of a fault with $500 \mathrm{~m}$ vertical offset is about 63 milligals, using the formula $\Delta g=2 \pi \gamma \sigma t$ (Nettleton, 1940) and a density $(\sigma)$ of 3.0 $\mathrm{g} / \mathrm{cm}^{3}$. If the fault extends to and, in like degree, displaces mantle material of density contrast $0.3 \mathrm{~g} / \mathrm{cm}^{3}$, then 6.3 milligals should be added to the calculated gravity. This would increase the total anomaly to nearly 70 milligals but well within the probable range of the measured or observed value. Here again, isostatic adjustment appears to be nil.

Gravity and topographic profiles constructed across the Montes Secchi, a highland ridge between Mare Fecunditatis and Mare Tranquillitatis, are shown at reduced scale in figure 16. Elevations increase to the northwest about $1,200 \mathrm{~m}$ between the two maria, but local relief of the Montes Secchi is only about $500 \mathrm{~m}$. Gravity also increases northwest to the Montes Secchi, which have a residual value of about 15 milligals above the regional. The anomaly is somewhat oval in outline (Sjogren and others, 1974b, fig. 7) and so may be approximated by a disk for theoretical computations. The dimensions of this disk, having the same volume as that calculated for the near-spherical segment of the

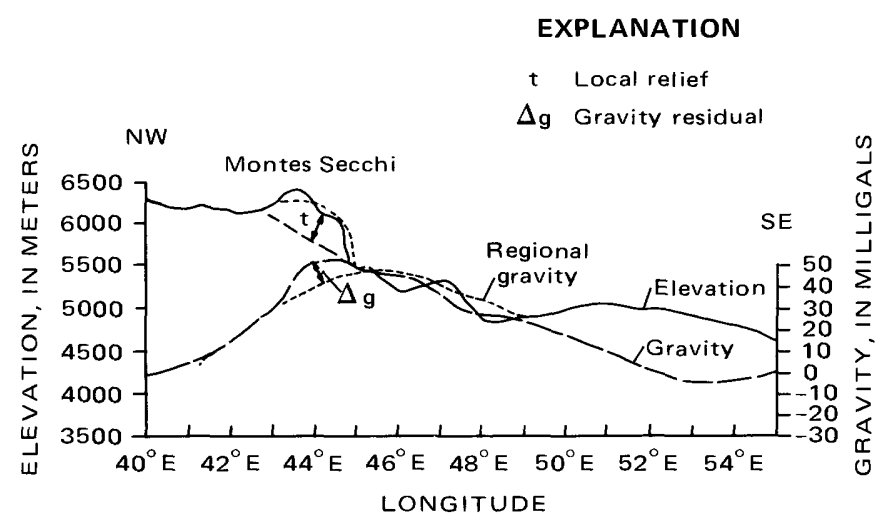

FIgURE 16.-Topographic and gravity profiles through Montes Secchi. 
Montes Secchi in figure 16, are: radius $30 \mathrm{~km}$, thickness $250 \mathrm{~m}$. Assuming a spacecraft altitude of $15 \mathrm{~km}$ (Sjogren and others, 1974b, fig. 1) and density of 3.0 $\mathrm{g} / \mathrm{cm}^{3}$, no isostatic compensation appears to exist.

Recent studies of long-term perturbations in the orbits of lunar satellites has resulted in gravity maps of the far side (Ferrari, 1975; Ananda, 1975). These maps generally show negative anomalies to be associated with multiringed basins; thus they represent mass deficiencies rather than mascons. This difference is attributed to the topographic asymmetry of the Moon, with the higher parts of the far side being unfilled by the hydrostatic flow of mare basalts (Ferrari, 1975). Although the details of the gravity field on the far side is known only within broad limits, calculations of the Bouguer anomaly for the Mendeleev (Ferrari, 1975) and Hertzsprung basins (Scott and others, 1977) indicate that a large amount of isostatic compensation may have taken place. As these basins contain little or no mare basalt, their approach to a state of equilibrium reflects deep-seated uplift of more dense material, probably the mantle. This uplift is indicated on the floor of the Orientale basin by concentric and radial fissures attributed to updoming before the extrusion of mare basalts (Scott and others, 1977).

\section{SUMMARY AND CONCLUSION}

The first large mass concentrations on the Moon were discovered during the early Lunar Orbiter flights. The resolution of these mascons was enhanced by the lower altitude Apollo missions, and others were found as well. Aside from the basin-associated mascons, many other structures on the Moon including large craters and positive relief features such as Rupes Altai and Montes Secchi are not isostatically compensated. Over broad areas, however, lunar gravity relief is smali compared with that of Earth.

Gravity observations obtained at different heights above the lunar surface have been useful in reducing the number of assumptions for determining the shape of buried masses. Also, the large-scale LTO series maps with their excellent topgraphic control allow accurate volume calculations of selected features and hence their probable mass and resulting gravity anomaly value. Reliable elevations together with a refined method of reducing gravity data developed after the last Apollo missions should yield good estimates of bulk densities of lunar rocks. In those areas where topographic data is poor, such as at Orientale, gravity results give acceptable estimates of crater volume that provide constraints for ejecta distribution studies.

Although all large craters on the near side of the Moon are negative gravity anomalies, some high areas are also negative and the cause is not everywhere apparent. Mare ridge systems are generally positive, but many rilles show no gravity effect.

On the lunar farside, preliminary calculations indicate that isostatic compensation of large basins may be further advanced, but more accurate data are needed to pursue these studies. In the future, low-altitude polar orbiters operating in conjunction with subsatellites may provide this information.

\section{LUNAR MAGNETISM}

\section{By Gerald G. Schaber}

The discovery of stable components of natural remanent magnetization (NRM) in Apollo 11 samples (Doell and others, 1970; Helsley, 1970; Nagata and others, 1970; Runcorn and others, 1970; Strangway and others, 1970) was one of the most unexpected and scientifically important findings of the Apollo program. Before Apollo, magnetometers aboard Luna 10 (Dolginov and others, 1966) and Explorer 35 (Sonett and others, 1967) obtained no evidence of a global lunar magnetic field, implying a value of less than $10^{23}$ gauss $\mathrm{cm}^{3}$ for the lunar dipole. This value is five orders of magnitude less than that for the geomagnetic dipole (Fuller, 1974).

Lunar surface magnetometers placed on the Moon starting with Apollo 12 monitored surprisingly high local surface fields of up to several hundreds of gammas (Dyal and others, 1970, 1972). These high fields are thought to be caused by remanent magnetization of local rocks. The size, distribution, and magnitude of the anomalies were further defined by the magnetometers carried on the Apollo 15 and 16 subsatellites. These experiments provided an additional surprise by revealing steady remanent fields associated in part with surface features and detectable at heights of approximately $100 \mathrm{~km}$ (Coleman and others, 1971, 1972). The Apollo subsatellite magnetometer data also revised downward the present lunar dipole field to a maximum of $6 \times 10^{19}$ gauss.

An electron scattering technique for high-resolution mapping of the lunar remanent magnetic field was developed by Lin and others $(1975 \mathrm{a}, \mathrm{b})$. Using low-energy electrons from $14 \mathrm{keV}$ to $0.5 \mathrm{keV}$, they showed that extremely weak remanent fields (to 0.1 gamma) can be mapped with a resolution of about $15 \mathrm{~km}$ to $40 \mathrm{~km}$.

In the present discussion, I will concentrate on the geologic relations of available lunar magnetic data and will not detail the physics of lunar orbital, lunar surface, or lunar sample magnetic data beyond the point necessary for a basic geologic comprehension. The reader is referred to an excellent summary article by Fuller (1974). 
ORBITAL MAGNETIC DATA

The first indication of geologically important variations in the lunar magnetic field came from the Apollo 15 and 16 subsatellite magnetometer data that revealed stronger fields and more variability in the remanent magnetic fields over the far-side highlands than over the near-side maria. In addition, strong magnetic anomalies were found associated with or near large far-side craters such as Milne, Gargarin, Pavlov, Van de Graaff, and old basins such as Korolev and Hertzsprung (Coleman and others, 1971, 1972). The strongest and most obvious feature found in the magnetic records was correlated reasonably well with the crater Van de Graaff (fig. 17). Attention has focused on the Van de Graaff anomaly because of its larger magnitude and the fact that it is the central anomaly of a group of anomalies distributed somewhat symmetrically about $180^{\circ}$ longitude. In addition, this group of magnetic anomalies correlates well with a topographic low measured by the Apollo 15 laser altimeter (Roberson and Kaula, 1972) and a region of high gamma-ray emission (Arnold and others, 1972b) (figs. 18, 19). It was concluded that the Van de Graaff magnetic anomaly is related to a major depression centered at $180^{\circ}$ longitude, perhaps representing an old, unfilled basin of which there is no surface trace.

Lin and others (1975b) have presented preliminary results of an electron scattering technique to detect and measure weak and small-scale lunar magnetic fields. The technique makes use of the fact that solar and interplanetary charged particles are easily scattered in moving to a region of increased magnetic field strength as they approach the Moon. The particles, in effect, provide a probe along the external magnetic field line down to the lunar surface which is sensitive to increases in field strength along its path. If no surface magnetization is present, the particles are guided by the external magnetic field into the lunar surface, where they are absorbed (except for less than 5 percent which are Coulomb backscattered from the surface material). If remanent magnetization is present, the total field strength increases as the particles enter the region of remanent magnetization. A fraction of the particles scatter back with an intensity that increases with the strength of the total surface field.

All of the remanent field regions found by the Apollo subsatellite magnetometers (Coleman and others, 1971,1972 ) were found to scatter the electrons strongly (over 50 percent). In addition, a number of new regions of remanent magnetization were found using the higher resolution electron scattering technique. Magnetic scattering effects have been observed for electrons by the Apollo 15 and 16 Particles and Field Subsatellites, with most observations being made with 14
$\mathrm{keV}$ electrons (Lin and others, 1975b). A limited amount of high-resolution data were also collected using the lower energy $0.5 \mathrm{keV}$ electrons (Lin and others, 1975b) (fig. 20).

\section{LUNAR SURFACE AND SAMPLE MAGNETIC DATA}

Starting with the Apollo 12 mission, lunar surface magnetometers observed surprisingly high NRM (natural remanent magnetism) ranging from a low of 6 gammas at the Apollo 15 site to a high of 313 gammas at the Apollo 16 site (Dyal and others, 1970, 1972). These fields are known to be due to remanent magnetism of the lunar crust because as the Moon orbits the Earth, it encounters a variety of magnetic environments, including a zero-source-field region that permits separation of the induced and remanent fields.

In order to better understand the nature and origin of the lunar surface NRM, extensive magnetism studies of the Apollo samples have been reported (Runcorn and others, 1970; Nagata and others, 1970, 1971, 1972, 1973, 1975; Pearce and others, 1972, 1973, 1974; Griscom and others, 1972; Collinson and others, 1972). An NRM of between $10^{-3}$ and $10^{-7}$ gauss $\mathrm{cm}^{3} \mathrm{~g}^{-1}$ has been reported in the samples of breccia which carry the strongest and most stable NRM.

These studies have confirmed that the most important ferromagnetic constituent is metallic iron, in some cases alloyed with a few percent of nickel or cobalt. Other ferromagnetic and ferrimagnetic phases have been reported, but iron and iron-nickel alloys predominate (Duller, 1974). The soils and breccias contain from a few tenths of a percent to 1 percent by weight metallic iron, but the feldspar-poor mare basalts contain only about one-tenth this amount. In both the soil and unmetamorphosed breccia, the iron is predominantly in the form of extremely fine (about $100 \mathrm{~A}$ ) single domain particles and spherules, which occur in impactgenerated glass. They appear to increase in content with maturity of the surface (Pearce and others, 1974). In well-annealed breccia the iron is somewhat coarser and multidomain. The high abundance of almost pure iron in breccias and fines is most likely to be the product of breakdown of fayalite, ulvospinel, ilmenite, and other minerals by severe meteoritic impact (Nagata and others, 1974).

\section{ORIGIN OF LUNAR MAGNETISM}

The NRM of the samples strongly argues for the existence of ancient fields on the order of $10^{3}$ to $10^{4}$ gammas in which they acquired their magnetization, and the variability of the sample NRM fields (ranging from hundreds of gammas to an oersted-10,000 gam- 

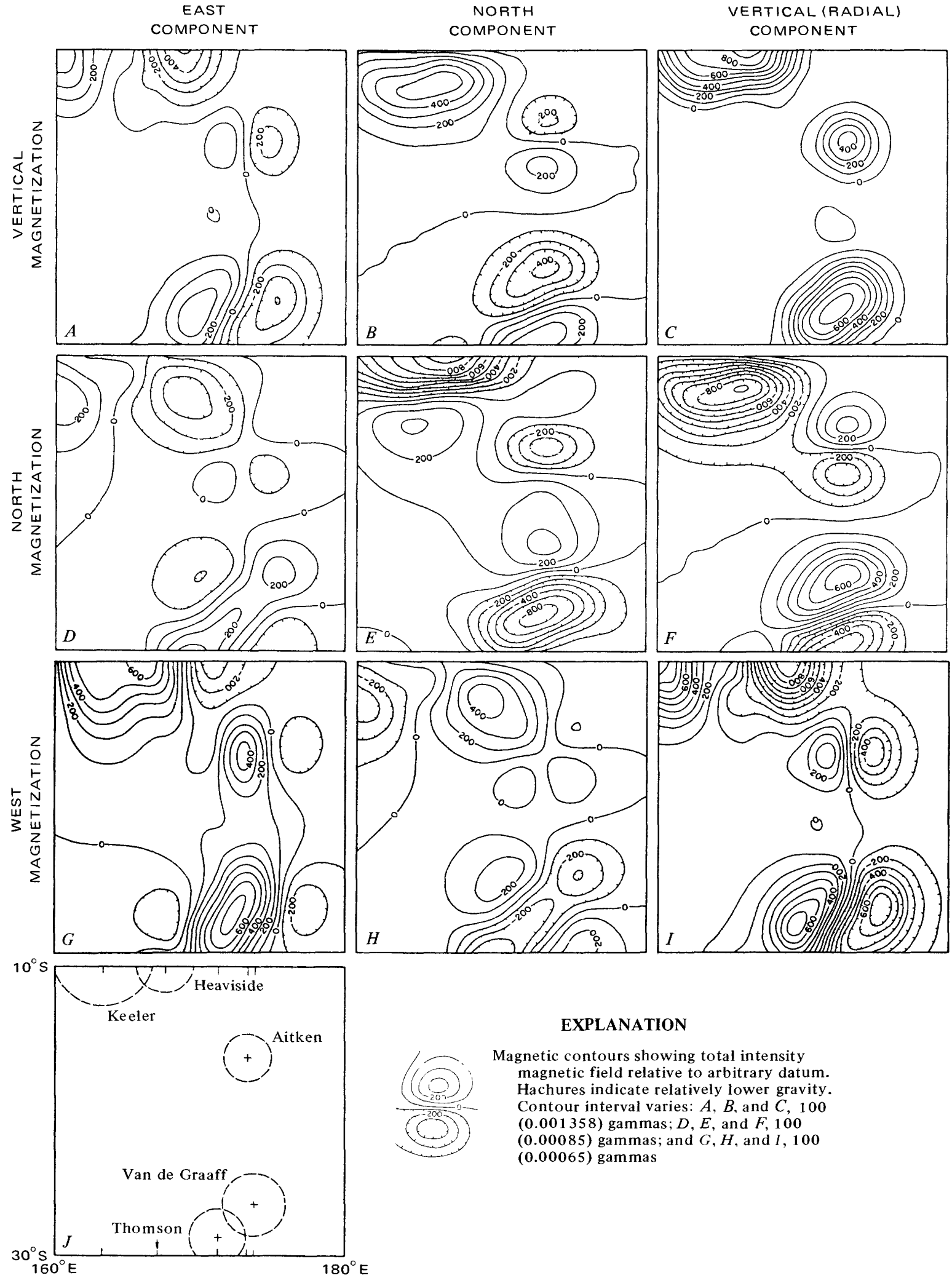

\section{EXPLANATION}

Magnetic contours showing total intensity magnetic field relative to arbitrary datum. Hachures indicate relatively lower gravity. Contour interval varies: $A, B$, and $C, 100$ $(0.001358)$ gammas; $D, E$, and $F, 100$ (0.00085) gammas; and $G, H$, and $I, 100$ $(0.00065)$ gammas

FIgURE 17.--Magnetic anomalies calculated for bodies $1 \mathrm{~km}$ thick and magnetized at a level of $3 \times 10^{4} \mathrm{emu} / \mathrm{cm}^{3} . J, \mathrm{index}$ map showing location of craters in area of magnetic anomalies. (After Strangway and others, 1975b.) 

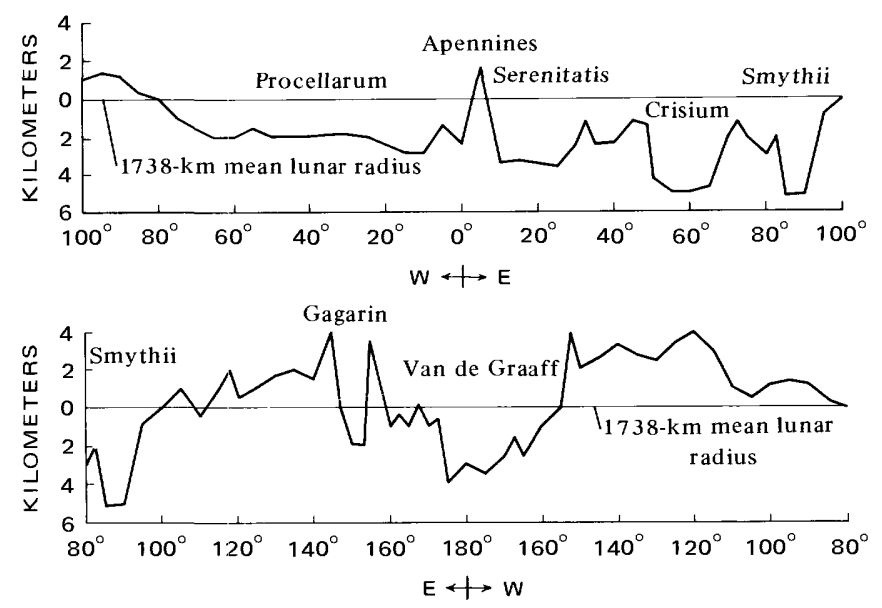

FIgURE 18.-Apollo 15 laser altimeter results (from Roberson and Kaula, 1972).

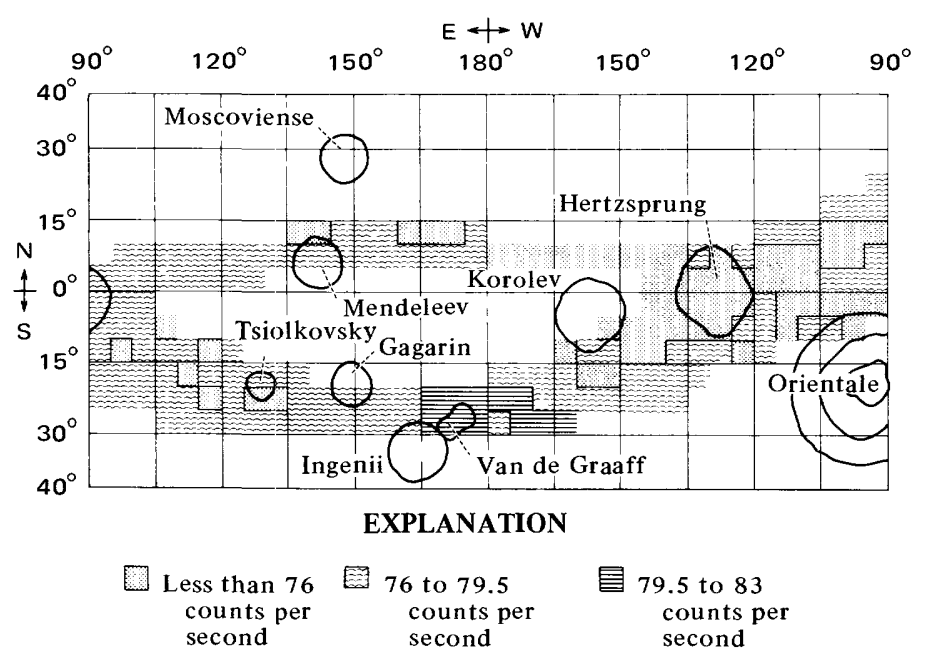

FIgURE 19.-Apollo 15 and 16 relative gamma-ray emission intensities for lunar radioactive elements (from Arnold and others, 1972b). One degree of latitude is $30 \mathrm{~km}$.

mas) suggests a complex origin of these fields. The surface fields observed by the Apollo surface magnetometers revealed coherent sources of remanent magnetization on the lunar surface, whereas the Apollo subsatellite data give evidence of an at-depth homogeneous magnetization of the lunar crust on a scale even greater than that suggested by the surface fields (Fuller, 1974). It is not yet clear whether a single explanation will account for all aspects of these phenomena or whether multiple explanations will be necessary.

Many theories to date require a planet-wide field that induced the observed magnetization of the rocks and has since disappeared. Such a field has been attributed to external fields such as the solar wind or the terrestrial field; and to internal origin, such as the proposed lunar dynamo (Nagata and others, 1972; Runcorn and others, 1971). Additional models have also been proposed that assume that the whole Moon, or a large part of it, was magnetized early in its history to give rise to a primitive remanent field that is recorded in the lunar rocks. Later still the primitive remanent field is thought to have been thermally demagnetized (Urey and Runcorn, 1973).

The origin of the large variability in lunar NRM has also been attributed to transient local fields generated by high-energy impacts (Dunn and others, 1972; Nagata and others, 1970; Cisowski and others, 1972).

The defenders of the lunar dynamo hypothesis, led by Runcorn (1975) and Collinson and others (1975), report measurements of paleointensities of the lunar field for samples of various ages, leading to the conclusion that the ancient lunar surface field had a strength of 1.2 oersteds some 4.5 b.y. ago-a value nearly three times the strength of the Earth's present surface equatorial field. Opponents of this model argue that the lunar magnetism is a manifestation of purely local, surface effects such as impact processes, and that no global dynamo-driven ancient lunar field need be present. This school draws its strength from a number of observations: (1) Apollo subsatellite magnetometer measurements (Russell and others, 1974, 1975) and subsatellite electron scattering observations (McCoy and others, 1975) show that the lunar surface is magnetized with a variety of intensities and scale lengths in an apparently chaotic manner; (2) analysis of moonquakes (Nakamura and others, 1974) and lunar electromagnetic sounding (Sonett and others, 1971) rule out the existence of a metallic lunar core larger than $350 \mathrm{~km}$ in radius-thus for a lunar dipole surface field of 1.2 oersteds the core surface field must have exceeded 150 oersteds, an impossibly large value; (3) the remanence mechanisms which can operate on the lunar surface are greater in number than those found in classical terrestrial rock magnetism (Wasilewski, 1974), and so the usual paleointensity methods may not be applicable (Fuller, 1974; Hoffman and Banerjee, 1975 ) and the lunar field intensities of Collinson and others (1975) may be suspect; and (4) "ground truth" results of the lunar portable surface magnetometer (Dyal and others, 1970, 1972) confirm the small scale sizes and variable intensities and directions of the lunar surface fields.

Dunn and others (1972) have suggested that there may be at least two processes effective in generating shock-associated remanent magnetization. First, there may be remanence produced during the actual shock, and second, there may be remanence produced during 


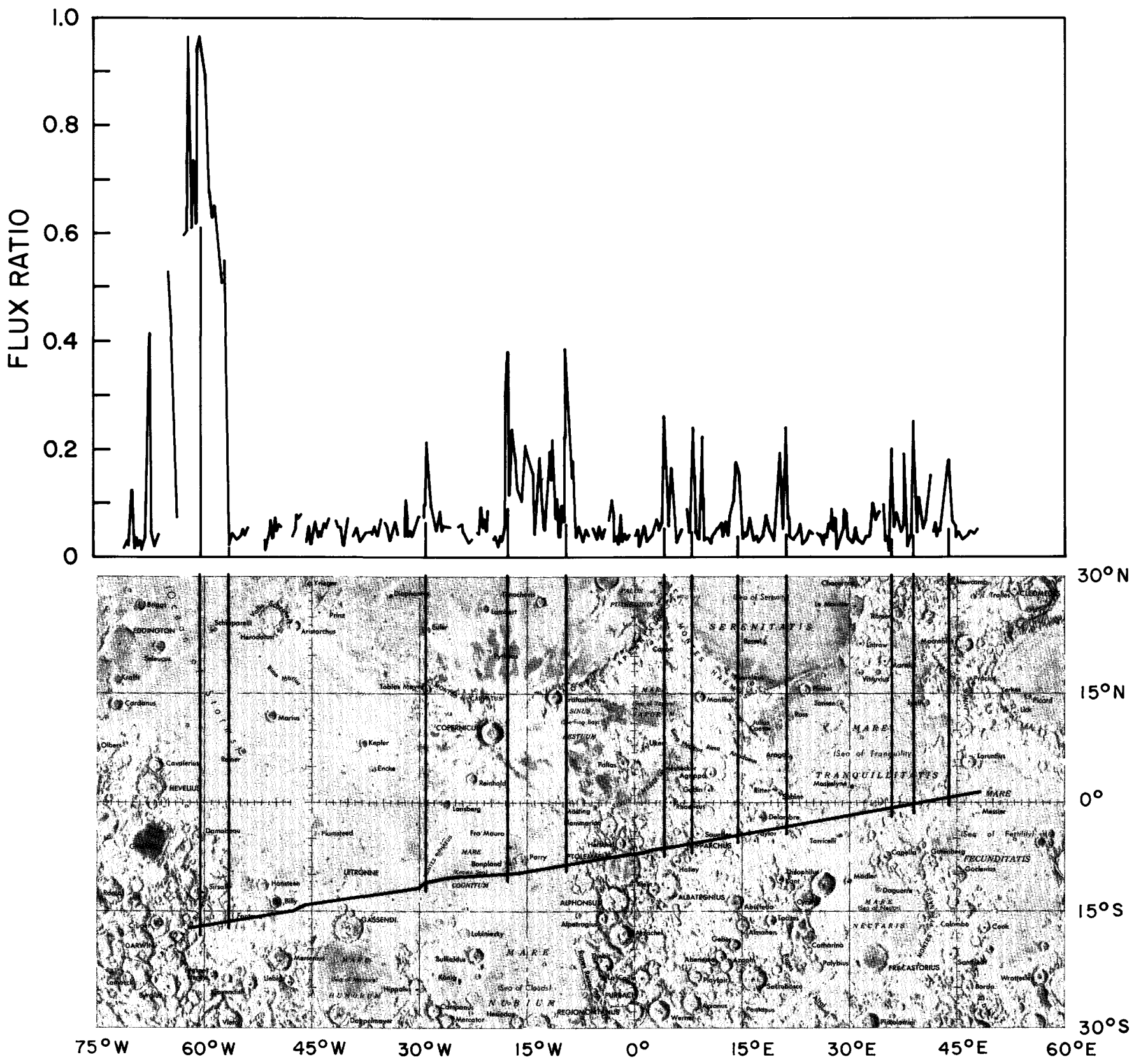

FIGURE 20.-Reflection coefficient for a single orbit of $0.5-\mathrm{keV}$ electron (gyroradius about $7 \mathrm{~km}$ in the $10 y$ magnetotail field) data obtained at high rate from Apollo 16 subsatellite. Track of intersection of projected magnetic field and lunar surface shown below. Surface magnetic features smaller than $10 \mathrm{~km}$ in size predominate and appear to be related to geologic features. Coulomb backscattered flux which forms the background is uniform and about 5 percent (from Lin and others, 1975a). One degree of latitude is $30 \mathrm{~km}$.

the post-shock cooling. The fields generated during the shock phase of impact may be the result of several mechanisms, including thermal instabilities (Tidman and Shanny, 1974) and chemical discontinuities (Tidman, 1974) in the vaporized material. In the post-shock phase, an ejecta blanket cooling below the Curie point of iron $\left(770^{\circ} \mathrm{C}\right)$ in the presence of a magnetic field will acquire a thermo-remanent magnetization.

A simple argument by Lin and others (1975a) dem- onstrates that impact shock processes could account for the range in magnitude of the observed lunar NRM. They considered a spherical meteroid of radius $R$, mean density $\rho$, and impact velocity $V$ striking the lunar surface. The energy $E$ and the power $P$ per unit area are given by:

$$
\begin{gathered}
E \simeq 2 / 3 R V^{2} \\
P \simeq 2 / 3 V^{3}
\end{gathered}
$$

For a typical lunar impact with $\rho=3.0 \mathrm{~g} / \mathrm{cm}^{3}, R=10$ 
$\mathrm{m}$, and $V=10 \mathrm{~km} / \mathrm{s}$, one finds the $E=2 \times 10^{12}$ joules $/ \mathrm{m}^{2}$ and $P=2 \times 10^{15}$ watts $/ \mathrm{m}^{2}$. These energy and power densities equal or exceed the levels commonly used in experiments on the interaction of focused laser light with solid matter, in which spontaneous magnetic fields of 10-10000 oersteds are usually found (Stamper and others, 1971; McKee and others, 1974). Although scaling effects must be considered when comparing the laser microexplosion with a cratering impact, it is clear that the same physical processes must occur in the two situations when the energy and power per unit area are equally high (Lin and others, 1975a).

Magnetic studies of the 22-24-km-diameter Ries Basin impact structure in Germany (Dennis, 1971) and the 1,200-m-diameter Meteor Crater in Arizona (Regan and Hinze, 1975) have also shown evidence of substantial impact-related NRM. For the Ries structure, Pohl and Angenheister (1969) found that the average total magnetization $\left(+50 \times 10^{-5}\right.$ oersted) of the suevite around the crater is more than an order of magnitude greater than that of unaltered basement rocks. The strong magnetization of the suevite suggests crystallization of new magnetite during the melting process, requiring local temperatures of at least $1,400^{\circ} \mathrm{C}$. Cooling past the Curie point $\left(580^{\circ} \mathrm{C}\right)$ must have taken place shortly after the suevite was deposited. Detailed petrographic investigations reported by Dennis (1971) indicate peak shock pressures and temperatures in excess of $600 \mathrm{~kb}$ and $2,000^{\circ} \mathrm{C}$.

The origin of the complex lunar remanent fields is not understood at the present time, but several observations can be made: (1) whether ancient dynamo or primitive fossil magnetic fields were present or not, some local transient field effects (such as impact events) are required to account for the very high fields recorded in certain rocks, (2) the fossil fields, if present early in lunar history, could be used to explain some of the anomaly fields observed by the lunar surface magnetometer and Apollo subsatellite magnetometers (Fuller, 1974).

\section{GEOLOGIC ANALYSIS AND SIGNIFICANCE OF LUNAR NRM}

Careful definition of the surface magnetic fields can lead to a variety of far-reaching conclusions about the Moon's modes of evolution and about its origin. The origin of the remanent magnetization may have a direct bearing on lunar thermal models. For example (Lin and others, 1975a), no current thermal model that adequately accounts for the chemical compositions and ages (Apollo 12 and 15 basalts are youngest at about $3.3-3.2$ b.y.) of the returned lunar samples and the present physical state of the Moon provides for either a lunar dynamo or a permanently magnetized Moon that became fully demagnetized later than about 3.0 b.y. ago. Even the coolest of thermal models (Hubbard and Minear, 1975) predicts a demagnetized lunar interior by 3.5 b.y. ago.

Understanding the Moon's magnetic features will require detailed knowledge of the magnetic fields at the Moon's surface on a spatial scale similar to that used for photogeology, crater studies, spectral reflectance studies and some orbital geochemical studies. The ability to correlate magnetic studies with cratering events, for example, is very desirable in light of the current interest in impact magnetization.

Geologic analyses of Apollo subsatellite magnetometer data have indicated a great variety in the size and magnitude of surface magnetic anomalies related in some cases to surface features such as large craters and basins (Coleman and others, 1971, 1972). Strangway and others $(1975 \mathrm{a}, \mathrm{b})$ have recently looked at the magnetic anomalies in the region of the craters Van de Graaff (fig. 17), Keeler, Aitken, Thompson, and Heaviside and determined that the magnetic field perturbations are caused by breccias in the crater floors that have settled in place and cooled from a temperature of $800^{\circ} \mathrm{C}$, acquiring a remanence in the presence of an ancient field. They suggest that these breccias have not been excessively reworked since their deposition. They further hypothesize that the light-colored plains materials present in many crater floors are the source of at least some of the orbital anomalies.

A preliminary geologic evaluation of the Apollo 16 subsatellite electron scattering data (Lin and others, 1975a) has shown the technique to be extremely sensitive to the presence of terra breccias which appear to be carrying the major part of the lunar NRM as verified by the magnetic studies of the lunar samples. As was the case for the subsatellite magnetometer data, the electron scattering technique showed the near-side maria to be much less structured by strong surface magnetic anomalies than the far-side terrae. The most intense near-side field observed by the electron scattering data was on the western shore of Oceanus Procellarum (long $56^{\circ} \mathrm{W}$. to $65^{\circ} \mathrm{W}$. at lat $16^{\circ} \mathrm{S}$.) mapped as Imbrian and Nectarian rough terrain (Scott and McCauley, 1975). This perturbation is best seen on the high-resolution $0.5 \mathrm{keV}$ electron scattering map shown in figure 20. The Van de Graaff anomaly, recognized in the subsatellite data, was also confirmed by the electron scattering technique.

Strong natural remanent field anomalies were also found to be associated with the outer hummocky ejecta (not necessarily the basin structure) of the far-side basins Orientale, Hertzsprung, Korolev, Mendeleev, and two recently recognized very old basin structures at lat $18^{\circ} \mathrm{N}$, long $176^{\circ} \mathrm{E}$., and lat $2^{\circ} \mathrm{N}$., long $112^{\circ} \mathrm{E}$. 
(Abul Wafa region). The latter two basins are so degraded that no ejecta blanket has been recognized. The geologic materials giving highly structured and strong remanent fields on the lunar far side are Nectarian basin materials (undifferentiated); Nectarian basin materials (lineated); Nectarian terrain (undifferentiated); Imbrian-Orientale rough mountain and hummocky rim materials and Nectarian-preNectarian terra (Scott and McCauley, 1975; Wilhelms and El-Baz, 1975).

The near-side NRM field anomalies found by the electron scattering technique were all associated with various types of terra materials and terra plains materials of pre-Imbrian or Imbrian age such as Imbrian hilly and pitted terrain; Imbrian plains; pre-Imbrian rough mountain terrain; Imbrian and pre-Imbrian terrain and pre-Imbrian crater materials (from Wilhelms and McCauley, 1971). All maria including Imbrian and Eratosthenian materials were found to have greatly reduced remanent field values with fewer and much less intense amplitude variations characteristic of the older highlands. Additional regions of increased remanent magnetization on the near side include: (1) the southern part of the Riphaeus Mountains mapped as Imbrian and pre-Imbrian terra; (2) the region just south of the craters Perry and Bonpland, mapped as Imbrian plains filling pre-Imbrian crater materials; (3) the floor of Hipparchus mapped as Imbrian plains; (4) the regions southwest and southeast of Delambre where the orbital track of the Apollo 16 subsatellite crosses Imbrian irregular crater materials thought to be secondaries from the Imbrian event; and (5) the terra peninsula on the southeastern rim of Mare Tranquillitatis composed of Imbrian and pre-Imbrian terra, Imbrian hilly and pitted materials, pre-Imbrian rough mountain terrain, and Imbrian plains. Two geologically important observations have emerged from initial photogeologic analysis of the Apollo subsatellite magnetometer and electron scattering data. First is the distinct enhancement of NRM associated with the older breccia terranes; second is the enhancement associated with some large craters and basin materials. There is evidence that the magnetic characteristics of the lunar rocks are related to their iron content and petrologic type (Gosé and others, 1972) and that lunar soil iron ratio $\mathrm{Fe}^{0} / \mathrm{Fe}^{++}$is in turn associated with soil maturity (Pearce and others, 1974).

There are large areas of the Moon that have less than 0.1 gamma remanent magnetic fields. Photogeologic comparison of weakly magnetic regions with those of normal or enhanced magnetic fields should provide important clues to the origin of such diverse fields. The areas of very weak magnetic field may have been extensively reworked after the time when there was a strong global magnetic field. Alternatively, perhaps these are regions where an extensive, intact magnetized layer at depth has not been highly cratered to produce leakage of strong magnetic fields. A uniformly magnetized sheet of infinite extent has no outside magnetic field. However, there are "edge" effects, that is, leakage of magnetic lines at regions of magnetic field perturbance such as at the edge of craters and mare boundaries (Collinson and others, 1975). A major question to be answered is how deep is the source of the NRM. Although most lunar maria exhibit greatly reduced NRM relative to the terra breccias, there are exceptions. A shallow mare region southeast of the crater Parry (at lat $10^{\circ} \mathrm{S}$, long $9^{\circ}-14^{\circ} \mathrm{W}$.) appears to have a high NRM, the source of which is perhaps below the mare fill. A very strong NRM is observed for the Cayley plains just to the west of this mare area in the region of the craters Parry and Bonpland (south of the crater Fra Mauro) (see fig. 20). The source of magnetic anomalies, such as that associated with the Van de Graaff features, have been estimated to be as great as $10 \mathrm{~km}$ deep (Coleman and others, 1972).

In an important recent observation, Srnka (1975), using Apollo laser altimetry, showed a definite correlation between surface slope and lunar limb compressions in the solar wind determined by the Apollo subsatellite. He found (1) that areas containing large sunset-facing slopes are significantly favored as limb compression source regions and (2) that magnetic anomalies correlate with rms slope (roughness). Srnka suggests that the probable causes are (1) plasma heating by energetic photoelectron emission from steep terrain illuminated at the terminator or (2) plasma deflection by remanent fields selectively enhanced at sunset-facing slopes by electrostatic depositional remanent magnetization (eDRM) of lunar fines.

One of the present controversies in lunar geology is related to the modes of deposition and a real distribution of ejecta from the large impact basins (Oberbeck, 1975; Morrison and Oberbeck, 1975; Eggleton and Schaber, 1972; Moore and others, 1974). The main contention lies in estimating the percentage of basinrelated deposits attributable to excavation of pre-basin materials by the basin secondaries and the amount of mixing of this material with primary basin ejecta. The relation of observed remanent magnetic field anomalies with basin rim deposits (as discussed above) and basin-related smooth plains materials (for example, the Cayley Formation) may provide significant new data to be used in resolving this controversy. It may be insignificant whether the basin-related anomalies in NRM are caused at the time of basin impact or are the result of primitive internal or external 
fields. It is possible that the NRM and thus the iron content of the primary basin ejecta are sufficiently different from that of secondary crater ejecta that they could be independently recognized.

The geologic significance of obtaining higher resolution NRM data for the entire Moon cannot be overemphasized. The available data indicated that a correlation between such data and detailed surface geology does exist, but it is as yet poorly understood. Recognition of the Moon's remanent magnetic field stands as one of the Apollo program's major findings, and a careful investigation of the variations in this field should provide the lunar and planetary science community with exciting new data relating to the early history of the solar system.

\section{ORBITAL GEOCHEMISTRY}

By H. J. Moore

The Apollo orbital geochemical experiments are truly remarkable in both concept and results. Between the X-ray fluorescence and gamma ray spectrometer experiments, the amounts of aluminum, silicon, magnesium, iron, titanium, thorium, and potassium were estimated from the orbiting Command and Service Modules for areas on the Moon where no spacecraft have landed. These estimates will remain an important set of information for future plans for lunar surface exploration.

\section{X-RAY FLUORESCENCE SPECTROMETRY}

\section{DESCRIPTION}

X-ray fluorescence spectrometers were carried aboard the Command and Service Modules of Apollo 15 and 16 (Adler and others, 1972a, b, c, d, e). The characteristic energy distributions and intensities of secondary or fluorescent X-rays produced by the interaction of solar X-rays with the lunar surface were measured by the spectrometers so that results were confined to the sunlit lunar surface. Measurements were limited to the K-shell spectra of the elements $\mathrm{Mg}, \mathrm{Al}$, and $\mathrm{Si}$ because of the special nature of the solar flux. Elements heavier than Si are not appreciably excited by the solar flux and elements lighter than $\mathrm{Mg}$ are inefficiently detected. Results are reported as intensity and (or) concentration ratios $\mathrm{Al} / \mathrm{Si}$ and $\mathrm{Mg} / \mathrm{Si}$. Intensity ratios vary with solar activity (Adler and others, 1972c), so care must be taken in interpreting results reported as intensity ratios in terms of concentration ratios. For nearly constant solar activity, concentration ratios are approximately linearly related to intensity ratios (compare tables 17-I and 17-II in Adler and others, 1972a; fig. 19-2 and tables 19-II in Adler and others, 1972b; and see table 1 in Adler and others, 1972c).

Concentration ratios from returned lunar samples are used to calibrate the intensity ratios corresponding to the landing sites. Concentration ratios computed elsewhere rely on this empirical calibration and on theoretically derived relations between the solar flux, intensity ratios of the secondary flux, and concentration ratios. Observed concentration ratios of the crossover points of Apollo 15 and 16 agree within 10 percent, and those for the Apollo 16 landing site area agree well with those of samples returned by Apollo 16 (Adler and others, 1973).

The areas sampled are large. The instantaneous viewing area at one-half peak response of the instrument collimator is 110 by $110 \mathrm{~km}$ at an orbital altitude of $110 \mathrm{~km}$ (Adler and others, 1972c), which translates to 3.6 degrees longitude at the equator. Data were accumulated in intervals of 8 to 64 seconds corresponding to 11.5 to $92.2 \mathrm{~km}$ along the ground track. Thus, the spatial resolution may be taken approximately as $110 \times 122 \mathrm{~km}$ to $110 \times 200 \mathrm{~km}(3.6 \times 4.0$ degrees to $3.6 \times 6.7$ degrees) depending on the duration of accumulation, but contributions from peripheral areas are present. Thus, the areas sampled often exceed the areas of individual geologic map units, and so the analytical results include mixtures. This does not mean that small units cannot be detected. Most of the instrument response comes from an area $60 \times 60 \mathrm{~km}$, and sizes of residuals from trend surface analyses (Podwysocki and others, 1974) indicate features as small as about 30 to $60 \mathrm{~km}$ can be detected.

\section{RESULTS}

Initial results (fig. 21) from the X-ray fluorescence experiment, despite the low resolution, are important (Adler and others, 1973, 1972c):

1. Lunar highlands have larger $\mathrm{Al} / \mathrm{Si}$ values and smaller $\mathrm{Mg} / \mathrm{Si}$ values than the maria, and these two ratios vary inversely on a regional basis. This result shows, when combined with samples collected by the Apollo missions, that the lunar crust has differentiated into gabbroic anorthosites (highlands) and feldspathic basalts (maria).

2 . The highland crust is broadly similar over large areas, and $\mathrm{Al} / \mathrm{Si}$ values measured from orbit for the Descartes landing area (includes Apollo 16 landing site) are large and comparable to those on the far side. This suggests that samples collected at the Apollo 16 landing site are similar to the rocks of the far side.

3 . $\mathrm{Al} / \mathrm{Si}$ values vary directly with albedo on a regional basis, although there are notable exceptions such as fresh craters. This result shows that compo- 
崩

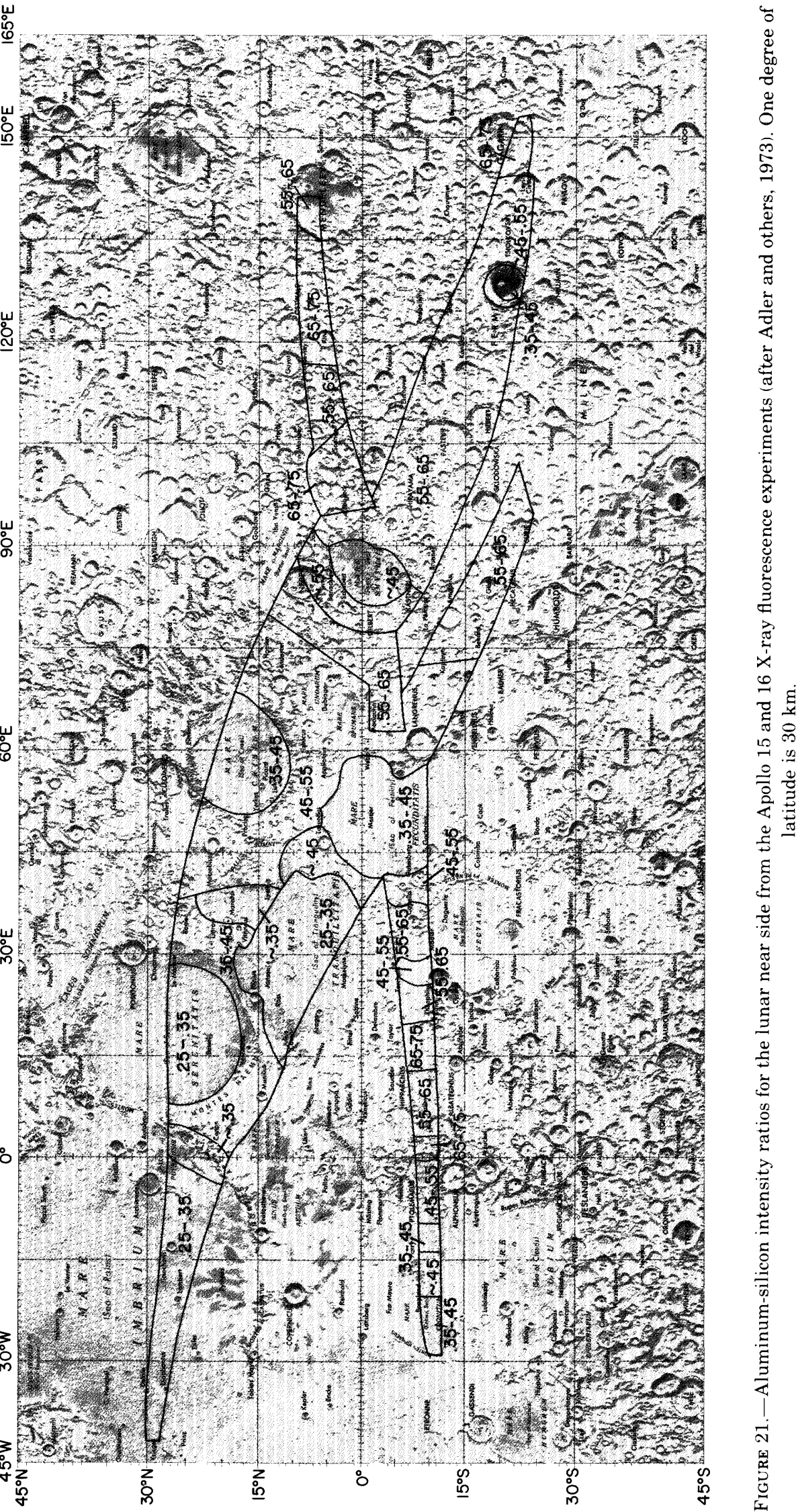


sitional differences as well as exposure of fresh materials by impact cratering and mass wasting are responsible for the high albedos of lunar surfaces.

Trend surface analysis (Podwysocki and others, 1974) and sliding averages (Andre and others, 1975; Hallam and others, 1974) of the Serenitatis-LittrowTranquillitatis region of the Moon have produced refined results. Trend surface contours conform, in a general way, to mare-highland boundaries (Podwysocki and others, 1974), and contours based on residuals from the trend surface conform in a more detailed way with geologic contacts (Hallam and others, 1974). It is clear, however, that the mapping resolution is in no way as good as that achieved using images and photographs. Trend surface residuals (Hallam and others, 1975; Podwysocki and others, 1974) associated with small lunar features such as craters are of particular interest because the results provide information on the type of material ejected from the crater. $\mathrm{Al} / \mathrm{Si}$ intensity ratios for selected features are listed in table 7 , where it may be seen that some mare impact craters have apparently excavated more aluminous materials $(\mathrm{Al} / \mathrm{Si}$ intensity $>0.95$ ), indicating that thin units of mare material overlie more aluminous material_probably highland material.

\section{GAMMA-RAY' SPECTROMETRY}

\section{DESCRIPTION}

The gamma-ray spectrometer experiment was conducted from the Command Service Modules of Apollo missions 15 and 16 (Arnold and others, 1972a, 1972b). Gamma rays from natural radioactive potassium-40 and daughters of thorium and uranium as well as emitted gamma rays resulting from the interaction of galactic cosmic rays with the surface materials of the Moon are recorded by the spectrometer aboard the orbiting spacecraft. The gamma rays are separated by their energies and their intensities measured. After subtraction of the known continuum from the observed spectrum of galactic cosmic rays, a line spectrum results from which the amounts of potassium, thorium, uranium, magnesium, iron, and titanium can be determined. In practice, the amounts of these elements are calibrated with Apollo data on chemical compositions of returned samples. Surface data from Apollo missions and the agreement between Apollo 15 and 16 results at the ground-track crossover points lead to a good prediction of the radioactivity of the surface materials at the Apollo 16 site. The resolution of the system is approximately $2.5^{\circ}$ on the lunar surface, or 75 $\mathrm{km}$. Some data are integrated to cover much larger areas.
TABLE 7.-AllSi intensity ratios associated with fourth-order trend surface residuals and selected lunar features

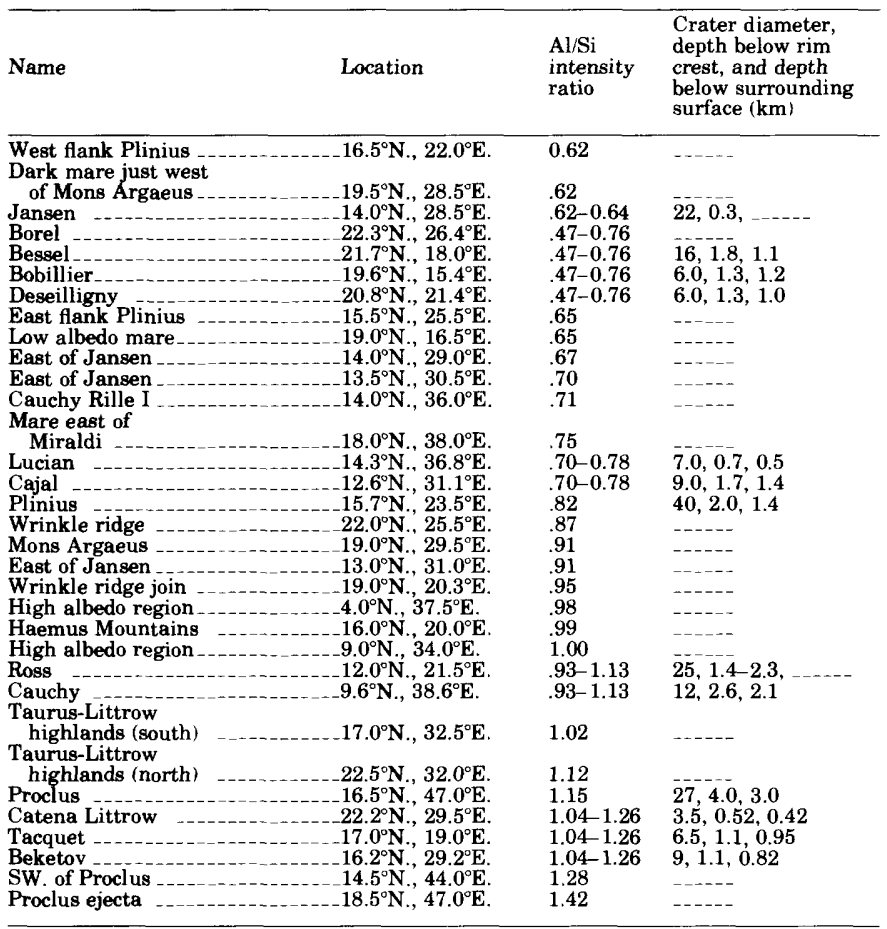

RESULTS

Natural radioactivity generally correlates with other Apollo lunar data (Trombka and others, 1973). Natural radioactivity is inversely correlated with mean elevation. Elevated regions of the lunar far side have low natural radioactivity. Relatively large radio activities were measured near the Van de Graaff depression of the far side. Highest natural radioactivities were recorded just south of the Fra Mauro landing area, at the crater Archimedes, and near the Crater Aristarchus. Western maria in Mare Imbrium and Oceanus Procellarum were relatively radioactive. Aluminum-silicon ratios are also inversely correlated with natural radioactivity.

Subsequent analyses of the gamma-ray spectrometer data have yielded surface concentrations of iron, magnesium, titanium, thorium, and potassium at the sacrifice of spatial resolution (Metzger and others, 1974). The large size of the areas to which the concentrations apply are of little use for detailed geologic studies, but they do yield valuable information on the grand scale. Some of the results available at this time are shown in figure 22 and listed in table 8.

The chief results of the gamma-ray spectrometer are summarized below after Metzger and others (1974). First, mare regions are enriched in iron, titanium, and to a lesser degree magnesium relative to the highlands. Concentrations of radioactive elements tend to be 
남

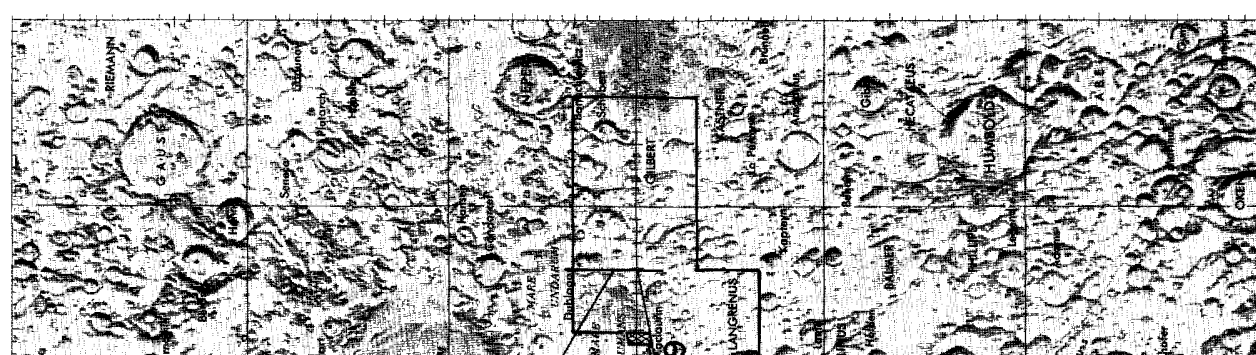

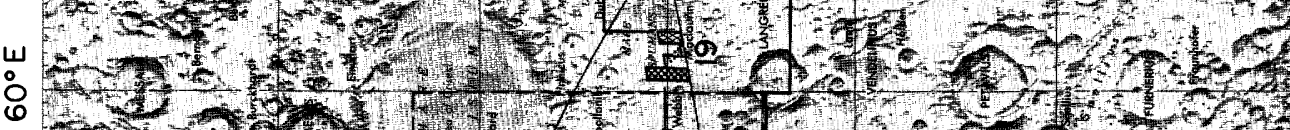

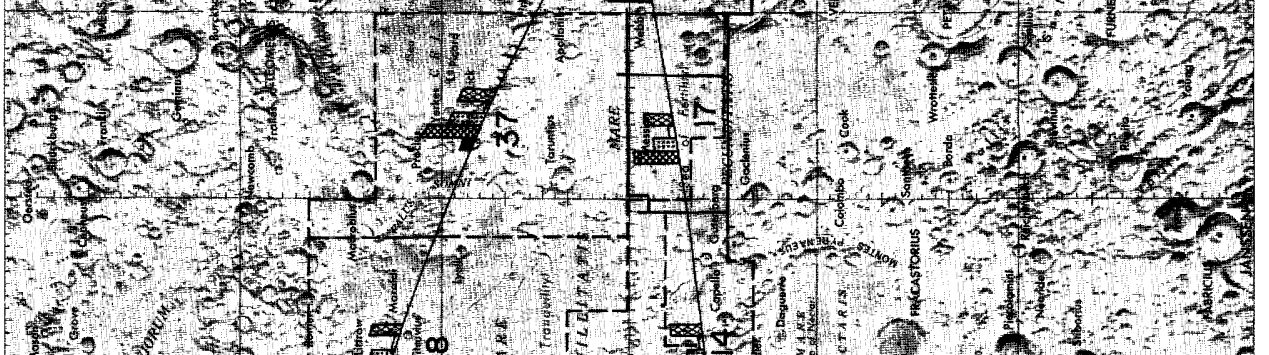
W

$\stackrel{\circ}{\circ}$

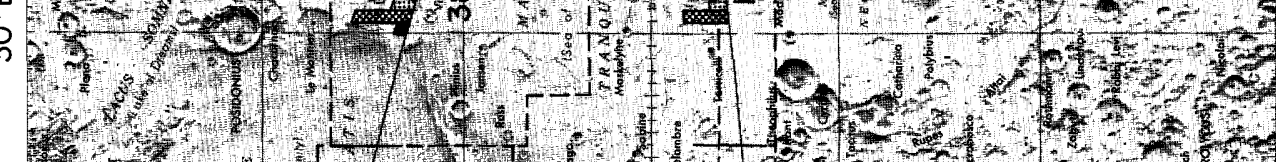

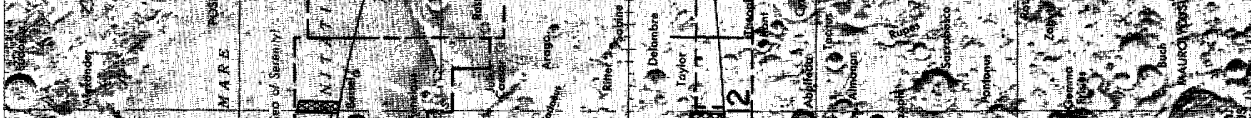

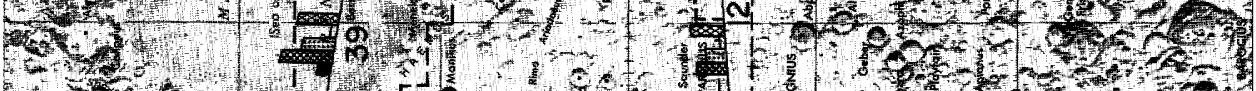

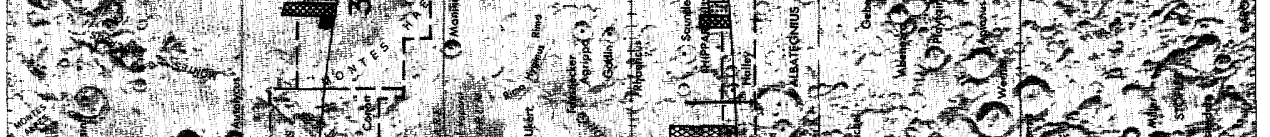

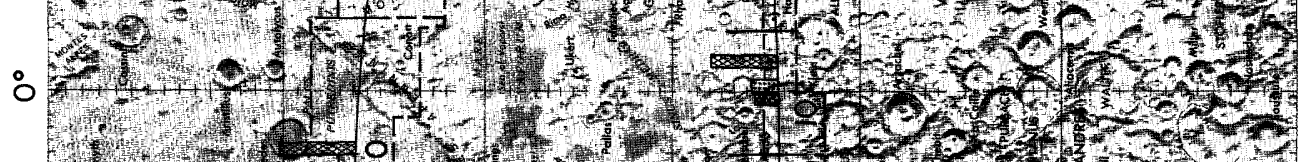
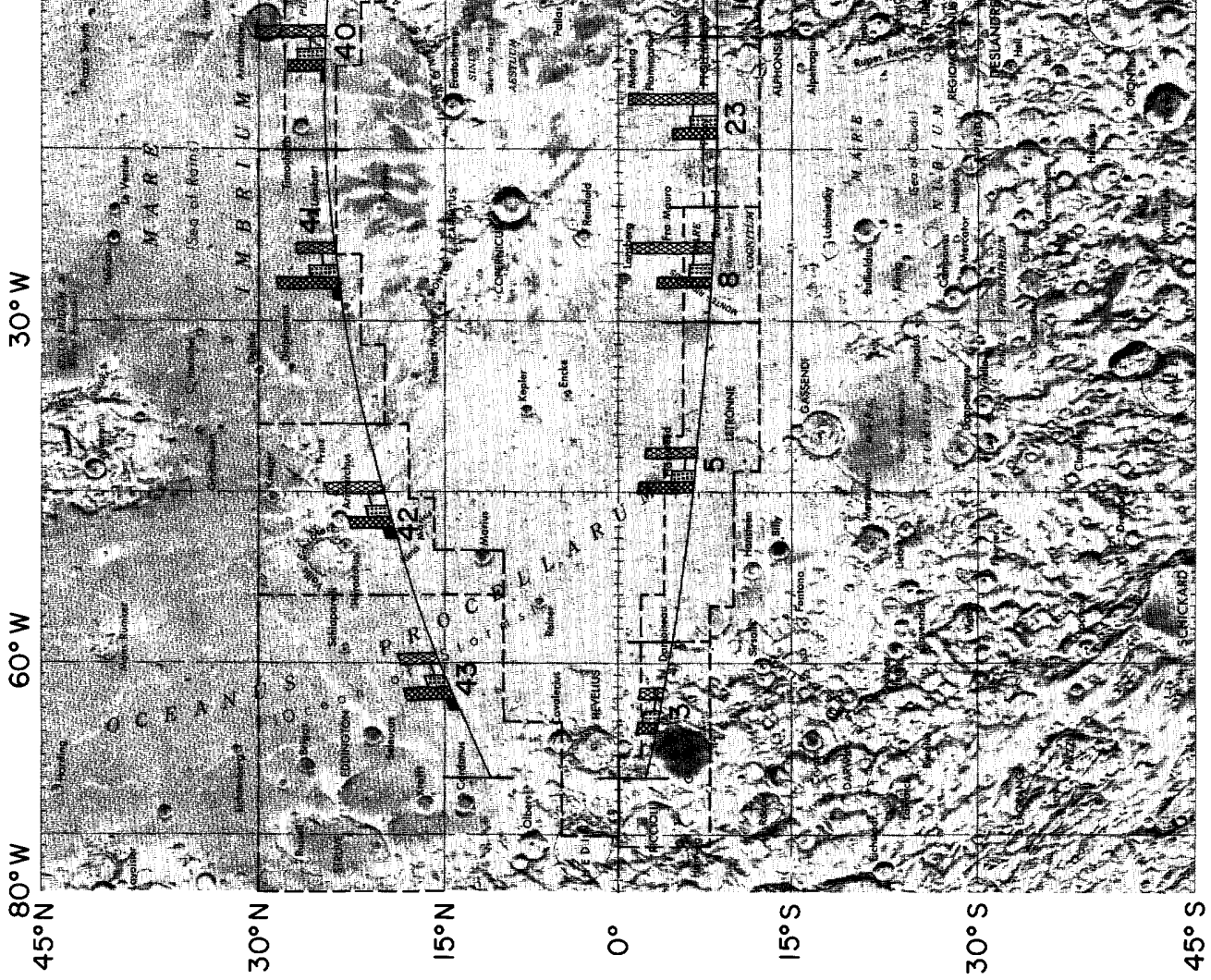

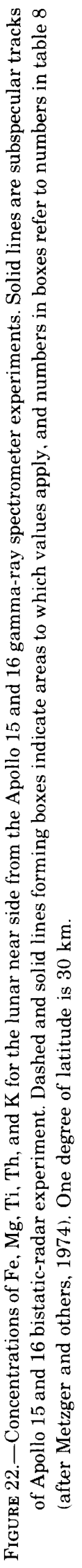


TABLE 8.-Concentrations of five elements from the Apollo 15 and 16 gamma-ray spectrometer experiments

\begin{tabular}{|c|c|c|c|c|c|c|c|}
\hline & $\begin{array}{l}\text { Region } \\
\text { number } \\
\text { (Metzger and } \\
\text { others, 1974) }\end{array}$ & $\begin{array}{l}\text { Longitudinal } \\
\text { bounds of } \\
\text { sample area }\end{array}$ & $\underline{\mathrm{Fe}}$ & $\frac{\mathrm{Mg}}{\text { percent }}$ & $\mathrm{Ti}$ & $\begin{array}{r}\text { Th } \\
(\mathrm{ppm})\end{array}$ & $\begin{array}{r}\mathbf{K} \\
(\mathrm{ppm})\end{array}$ \\
\hline \multicolumn{8}{|l|}{ Apollo mission 15: } \\
\hline Mare Fecunditatis & 37 & $60^{\circ} \mathrm{E} ., 42^{\circ} \mathrm{E}$. & 11.3 & 7.0 & 2.2 & 1.2 & 1,400 \\
\hline Mare Tranquillitatis - & ${ }^{-1} 38$ & $42^{\circ} \mathrm{E} ., 21^{\circ} \mathrm{E}$. & $(12.1)$ & $(4.8)$ & (2.9) & 1.7 & 1,200 \\
\hline Mare Serenitatis & 39 & $21^{\circ} \mathrm{E}, 6^{\circ} \mathrm{E}$ & 10.7 & 6.6 & 2.6 & 2.3 & 1,700 \\
\hline Archimedes & 240 & $6^{\circ} \mathrm{E} ., 15^{\circ} \mathrm{W}$ & 8.4 & 6.3 & .8 & 6.8 & 3,100 \\
\hline Mare Imbrium & -41 & $15^{\circ} \mathrm{W} ., 39^{\circ} \mathrm{W}$. & 13.6 & 6.2 & 1.4 & 5.8 & 1,700 \\
\hline Aristarchus - & -242 & $39^{\circ} \mathrm{W} ., 54^{\circ} \mathrm{W}$ & 9.6 & 4.9 & 2.2 & 6.9 & 2,500 \\
\hline Oceanus Procellarum N & 43 & $54^{\circ} \mathrm{W} ., 81^{\circ} \mathrm{W}$ & 10.5 & 4.6 & 2.0 & 3.9 & 1,700 \\
\hline \multicolumn{8}{|l|}{ Apollo mission 16: } \\
\hline Eastern near side highlands & 19 & $83^{\circ} \mathrm{E} ., 55^{\circ} \mathrm{E}$. & 8.6 & 4.5 & -..- & 1.3 & 980 \\
\hline Mare Fecunditatis & 17 & $55^{\circ} \mathrm{E}, 4^{\circ} \mathrm{E}$. & 9.0 & 4.6 & & 2.1 & 1,100 \\
\hline Capella-Theophilus & -14 & $44^{\circ} \mathrm{E} ., 21^{\circ} \mathrm{E}$. & 9.0 & 3.5 & - n-..- & 1.5 & 1,300 \\
\hline Central near side highlands & 12 & $21^{\circ} \mathrm{E}, 5^{\circ} \mathrm{E}$ & 5.9 & 4.0 & ..... & 2.1 & 1,400 \\
\hline Ptolemaeus-Albategnius -... & ${ }^{2} 10$ & $5^{\circ} \mathrm{E} ., 5^{\circ} \mathrm{W}$ & 4.6 & 5.2 & -..-- & 5.0 & 2,700 \\
\hline Fra Mauro. & 223 & $5^{\circ} \mathrm{W} ., 20^{\circ} \mathrm{W}$ & 9.7 & 5.7 & - - - - & 10.5 & 3,900 \\
\hline Mare Cognitum & 8 & $20^{\circ} \mathrm{W}, 3^{\circ} \mathrm{W}$ & 12.1 & 4.9 & $-\ldots-\ldots$ & 8.4 & 3,600 \\
\hline Oceanus Procellarum $\mathrm{S}_{-}$ & & $30^{\circ} \mathrm{W}, 58^{\circ} \mathrm{W}$ & 12.2 & 3.6 & $\ldots . .$. & 2.4 & 1,100 \\
\hline \multirow{2}{*}{\multicolumn{8}{|c|}{ Apollo mission 15 : }} \\
\hline & & & & & & & \\
\hline Western far side highlands & 44 & $81^{\circ} \mathrm{W}, 1^{\circ} 168^{\circ} \mathrm{W}$ & 5.7 & 3.5 & 1.5 & .4 & 950 \\
\hline Van de Graaff & .34 & $168^{\circ} \mathrm{W}, 168^{\circ} \mathrm{E}$. & 7.7 & 3.8 & .1 & 2.3 & 1,600 \\
\hline Eastern far side highlands & 35 & $168^{\circ} \mathbf{E} ., 82^{\circ} \mathbf{E}$ & 6.5 & 4.5 & 1.3 & 1.0 & 940 \\
\hline
\end{tabular}

'Values in parentheses are "ground truth" data used to normalize concentrations for these elements in all

'Region of apparent depressed neutron flux; iron concentration may be a few percent higher than indicated.

greater in the maria than in the highlands with a notable exception, the region of Van de Graaff (table 8). Potassium and thorium concentrations near Van de Graaff are as high as typical maria; iron concentrations are between maria and highland concentrations, but titanium concentrations are the lowest indicated along the entire Apollo 15 zone. About 5 percent of material like granitic rock 12013 added to the highland soil at Van de Graaff could produce the observed radioactivity. The highlands are not uniform: (1) iron and thorium concentrations are higher in eastern regions than western ones, and (2) some regions (table 8) have depressed thermal neutron fluxes and appear to have high concentrations of KREEP (potassium, rare earth elements, and phosphorus).

\section{DISCUSSION}

If the details required for careful geologic analyses are to be obtained, much higher resolution of the geochemically sampled areas is necessary. Residuals from trend surface analyses certainly improve the detection resolution of the X-ray fluorescence data, and such studies should continue. Of particular interest are the craters and their ejecta, which can yield information on the uppermost layers of the Moon (Hallam and others, 1975). If the magnitude of intensity ratios assigned to the residuals are correct, the thickness of basalt in Mare Tranquillitatis near Cauchy and Ross can be no greater than about $2.0 \mathrm{~km}$, whereas Lucian and Cajal excavated chiefly basalts from depths no greater than $1.2 \mathrm{~km}$ (Hallam and others, 1975, and C. G. Andre, written commun., 1975). In Mare
Serenitatis, the intensity ratios indicate that basalt extends to depths of more than $1 \mathrm{~km}$, and around the margin intensity ratios indicate that high-alumina highland materials were brought to the surface by Catena Littrow, Tacquet, and Beketov from depths less than $0.4,0.9$, and $0.8 \mathrm{~km}$, respectively.

More detailed analyses such as those above with the goal of deciphering basin ejecta would be of interest.

Currently, gamma-ray spectrometer data are being analyzed further with the hope of producing results with higher resolution. Some of the integrated resolution cells, such as the Aristarchus and Archimedes regions, include a wide variety of terrains and geologic map units. Indeed, high-resolution data show that the very large concentrations of natural radioactivity (Trombka and others, 1973) coincide with the crater Aristarchus and its southern flank, but such fine detail is lost in the large regions (fig. 22) which include diverse geologic units of the Aristarchus Plateau such as rilles, highland materials, and mare materials as well as young crater materials. Thus, the concentrations reported must correspond to the equivalent of mechanical mixtures. Mixing of samples must also be compounded by the omnidirectional sampling of the gamma-ray spectrometers as well as mechanical mixing by meteor impacts.

High concentrations of potassium and thorium generally occur in regions of low elevation (Metzger and others, 1974), but regions with both high potassium and thorium and depressed thermal neutron fluxes are, with the exception of the Grimaldi region, associated with regions that contain Imbrium ejecta or reexcavated Imbrium ejecta. Aristarchus probably reexca- 
vated Imbrium ejecta (Zisk and others, 1977) and the Fra Mauro, Ptolemaeus, and Archimedes regions contain Imbrium ejecta. Thus, it is entirely possible that the Imbrium impact event excavated in part KREEP. rich materials.

\section{BISTATIC RADAR}

\section{By H. J. Moore}

Bistatic-radar experiments produced some of the finest scientific results of all the Apollo orbital science experiments. Most significantly, slope-probability distributions were derived from the radar echoes which agree in form with those obtained using Apollo panoramic camera photographs and photogrammetric techniques. The experiments were conducted during Apollo missions 14, 15, and 16 (Howard and Tyler, 1971, 1972a, b; Tyler and Howard, 1973). In the experiments, transmissions from orbiting Command Service Modules were received on Earth after reflection from the lunar surface. Two wavelengths were used simultaneously $-13 \mathrm{~cm}$ and $116 \mathrm{~cm}(2287.5 \mathrm{MHz}$, S-band, and $259.7 \mathrm{MHz}, \mathrm{VHF}$ ). The data provide a sampling of lunar surface roughness at two different scales, because scattering from the lunar surface is dependent on wavelength. The longer wavelength measurements sample at larger scale lengths than the shorter wavelength measurements.

The echo spectrum is broadened according to the roughness or slope probability distribution of the surface slopes ${ }^{1}$ as expressed through the doppler shift (Howard and Tyler, 1971). Lunar slope-probability distributions may be inferred directly from the bistaticradar data (Parker and Tyler, 1973; Moore and Tyler, 1974). Single estimates of surface roughness may also be obtained from echo broadening in two ways. The first is called machine-calculated root-mean-square (rms) slope and is obtained from the equivalent area bandwidths (Tyler and Howard, 1973) based on an objective measure of peak power spectral density and total signal power. The second is called handcalculated rms slope and is obtained by graphically measuring the bandwidth at the one-half power points of the echo spectrum (Tyler and others, 1973). The rms slope is equivalent to the algebraic standard deviation of a slope-probability distribution with an algebraic mean of zero.

The data on rms slopes correspond to averages over resolution cells varying between about 10 and $20 \mathrm{~km}$ in diameter depending on the surface roughness. The

\footnotetext{
'Slopes considered here are unidirectional-that is, the angles formed by the local horizontal and the intersection of the surface with a vertical plane or parallel vertical planes. In contrast, adirectional slopes are the maximum angles between the surface at a point and the local horizontal.
}

data on slope-probability distributions represent about 28 combined resolution cells of echo spectra and cover a span of about two degrees in longitude along the subspecular track (figs. 23 and 24). At the present time, the scale length of roughness measured is understood only in a general way. The best empirical estimate of the horizontal surface scales corresponding to the slope measurements is about 250 wavelengths (Tyler and others, 1971), or about $32 \mathrm{~m}$ for the S-band radar and $290 \mathrm{~m}$ for the VHF radar. Theoretical considerations place the scale length between 10 to 100 wavelengths and the first Fresnel zone (G. L. Tyler, oral commun., 1975). For the S-band radar, this corresponds to scale lengths between 1.3 to $13 \mathrm{~m}$ and $335 \mathrm{~m}$. For the VHF radar, this corresponds to scale lengths between 11.6 to $116 \mathrm{~m}$ and $1000 \mathrm{~m}$.

Results vary systematically for each mission because of experimental conditions and techniques unrelated to the terrain traversed along the subspecular ground tracks (Moore and others, 1975, 1976). In particular, (1) machine-calculated rms slopes for the VHF radar of Apollo 14 are commonly larger than the handcalculated rms slopes, and (2) machine-calculated rms slopes for the VHF radar of Apollo 16 are uniformly low compared to Apollo 14 and 15 VHF rms slopes (Moore and others, 1976). S-band rms can be compared from mission to mission to a good approximation, although Apollo $14 \mathrm{rms}$ slopes tend to be slightly larger than those of the other two missions.

The subspecular ground track of the Apollo 14 bistatic-radar experiment covers a thin strip across the near side of the Moon from a point southwest of Langrenus (about lat $12^{\circ} \mathrm{S}$., long $45^{\circ} \mathrm{E}$.) to about lat $9^{\circ} \mathrm{N}$., long $70^{\circ} \mathrm{W}$. (fig. 23). In the western part the ground track traverses chiefly maria; in the central and eastern parts it traverses chiefly highlands. The Apollo 15 track covers an arcuate strip across the near side of the Moon from $1.68^{\circ} \mathrm{N} ., 70^{\circ} \mathrm{E}$. to just south of Archimedes (at $24.76^{\circ} \mathrm{N} ., 5.04^{\circ} \mathrm{W}$.) and west to $11.06^{\circ} \mathrm{N} ., 70.02^{\circ} \mathrm{W}$. (fig. 24). The western part of the track traverses Oceanus Procellarum and Mare Imbrium. To the east, the track crosses Montes Apenninus, Mare Serenitatis, and then chiefly highlands. The Apollo 16 track is similar to the Apollo 14 track. It begins north of Langrenus (at $0.21^{\circ} \mathrm{S}$., $70^{\circ} \mathrm{E}$.) and ends at $2.42^{\circ} \mathrm{S}$., $70.04^{\circ} \mathrm{W}$. (fig. $24)$. The western part covers chiefly maria, and the eastern part covers chiefly highlands except at the extreme east in Mare Fecunditatis.

\section{COMPARISON OF \\ RADAR ROUGHNESS WITH LUNAR TERRAIN}

Root-mean-square (rms) slopes for all three missions and at both wavelengths correlate with lunar terrain. As shown in figures 23 and 24, rms slopes are relatively large over the highland areas and relatively 
岁

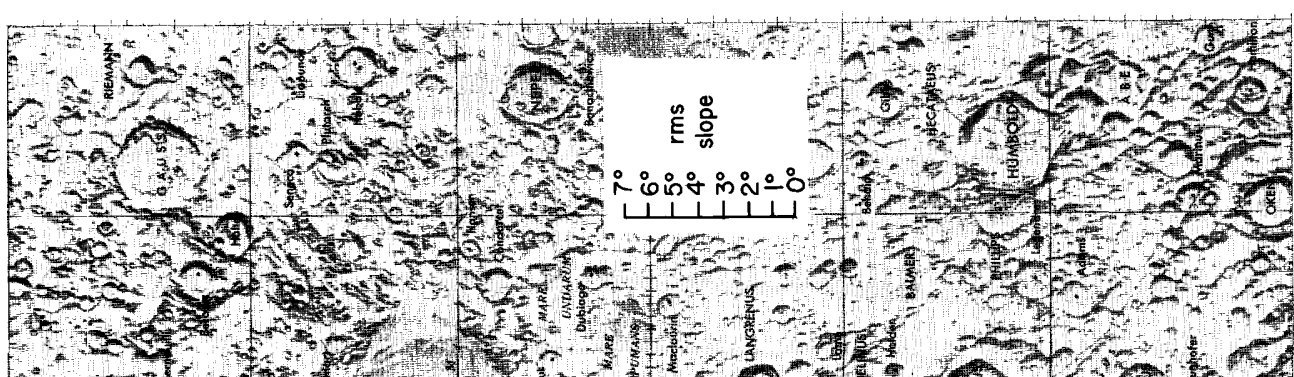
:

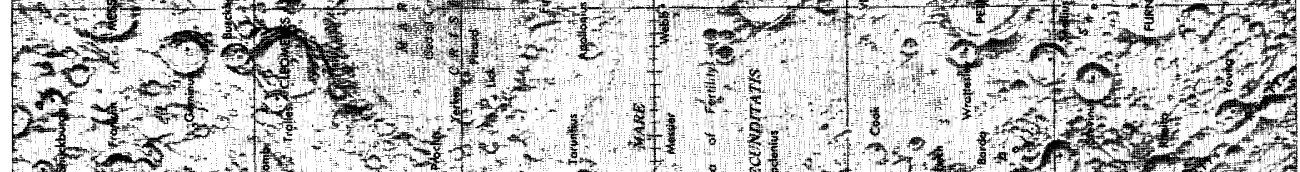

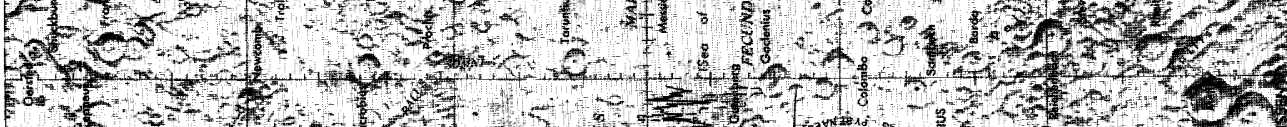

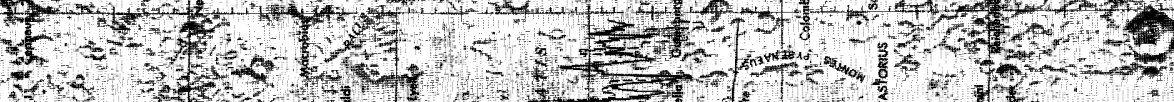

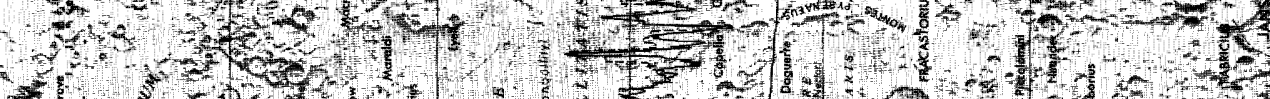

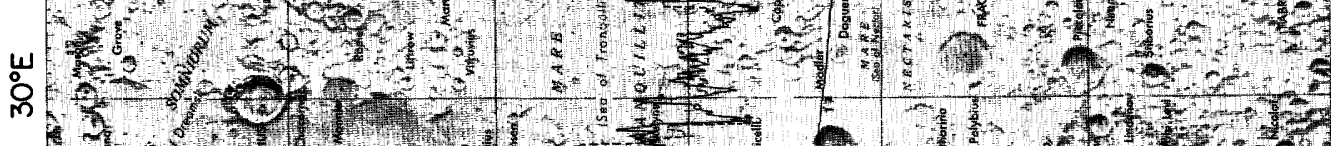

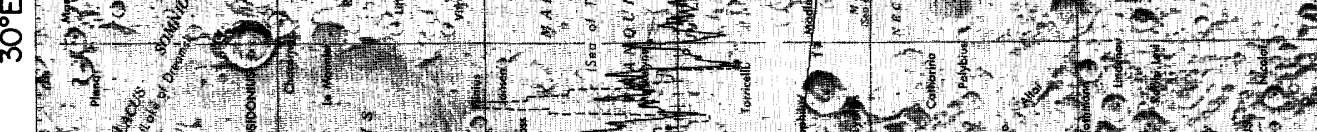

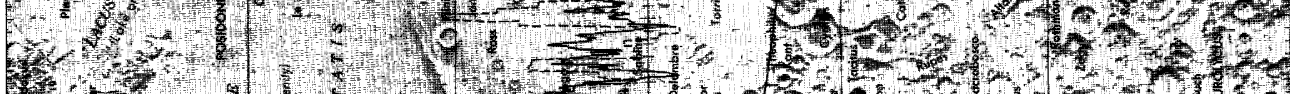

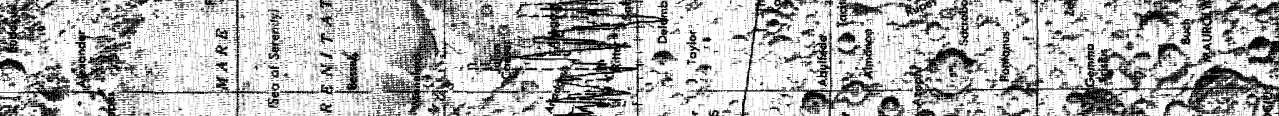

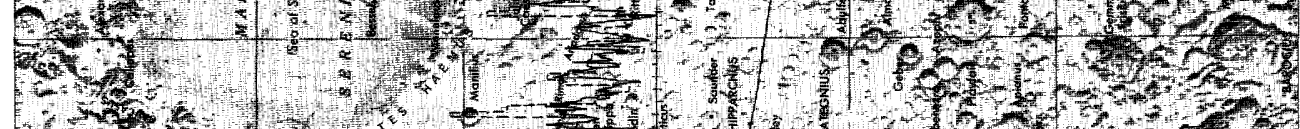

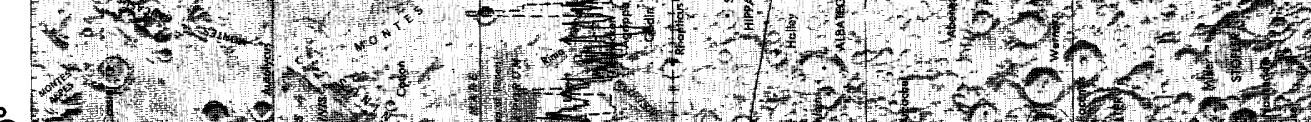

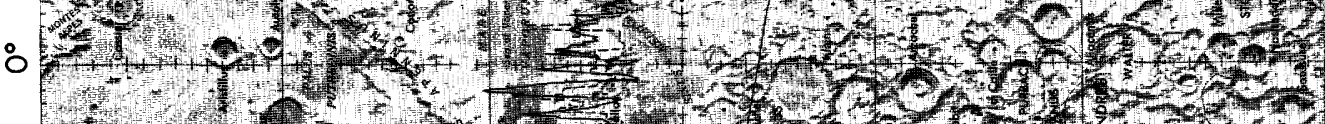

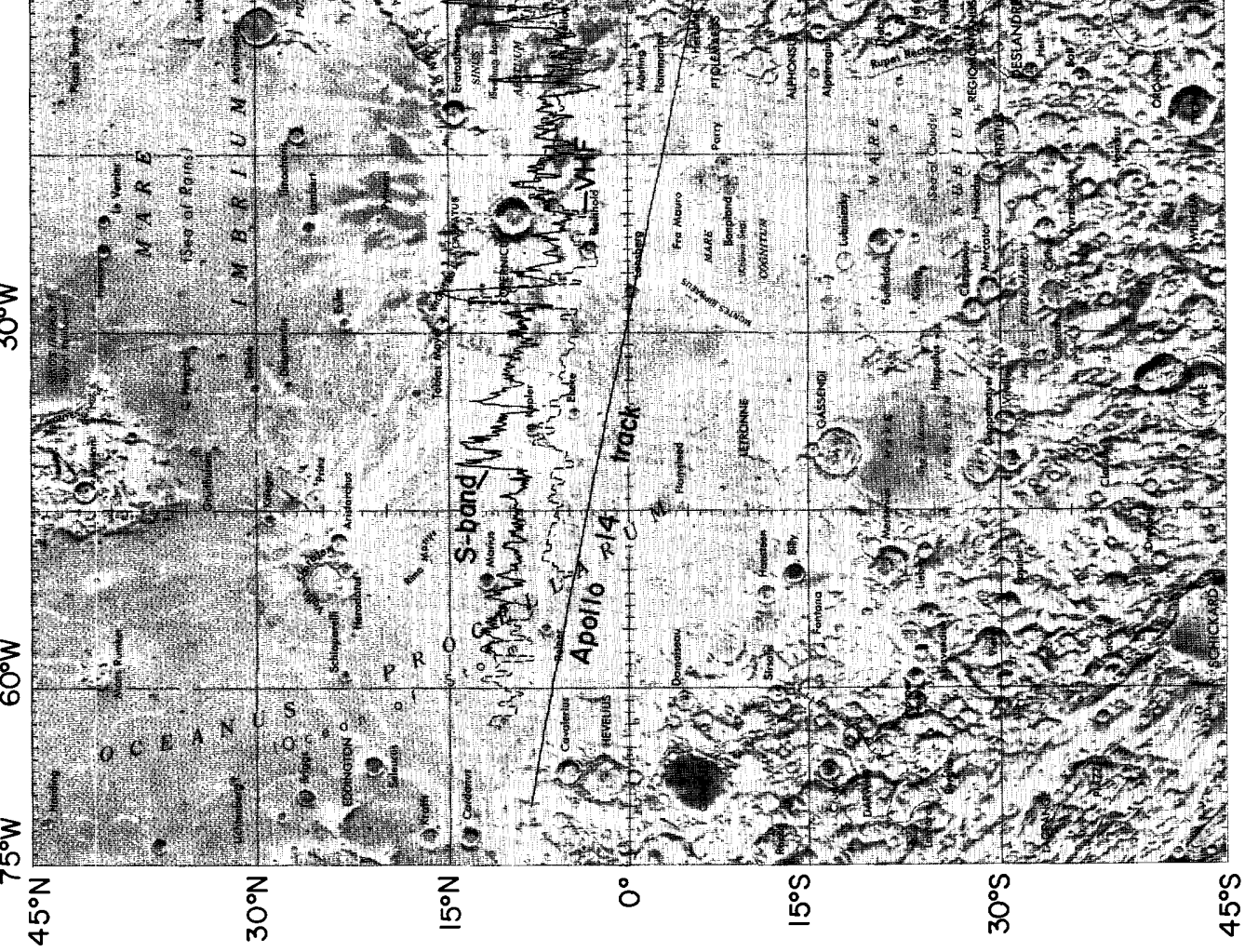

\%

क्ष

국

의 흐

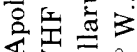

政

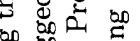

of

क

过苋菏

응

क

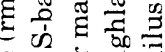

语

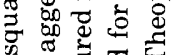

.

ฐ

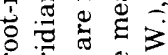

ช

क 8 क⿺

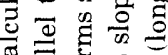

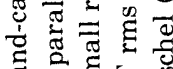

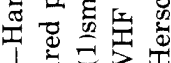

1.

จิ ซूँ

글 
岁

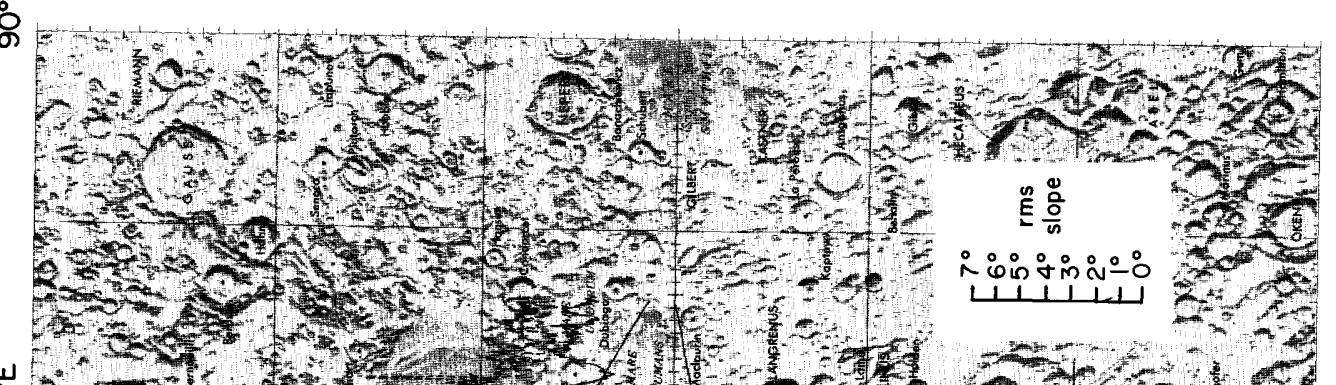

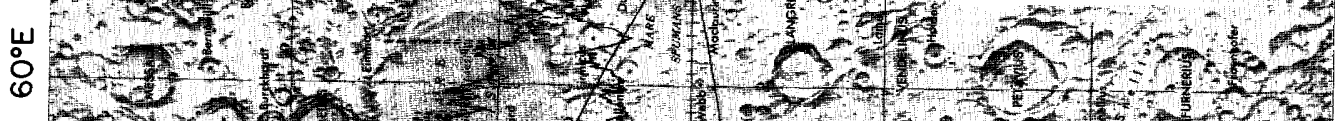

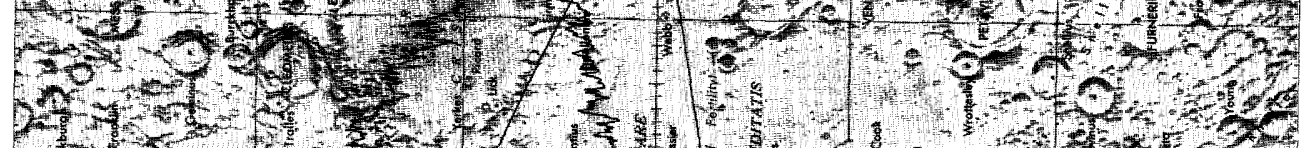

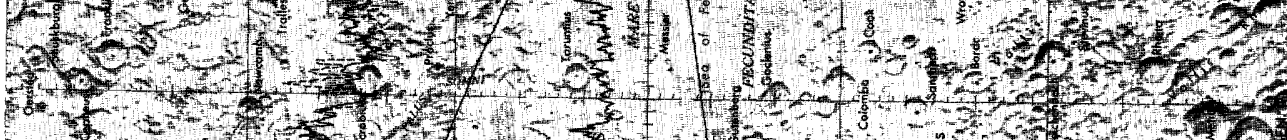

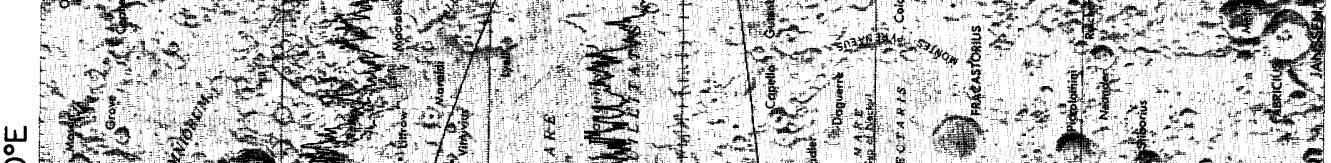

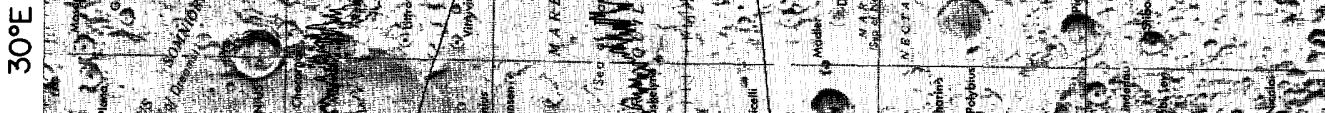

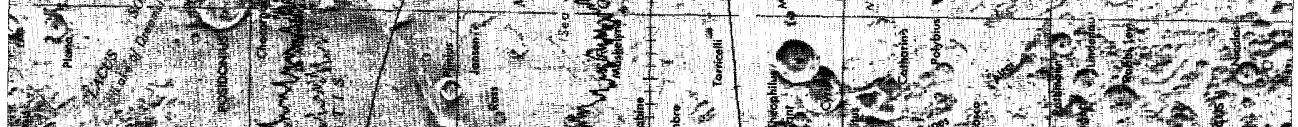

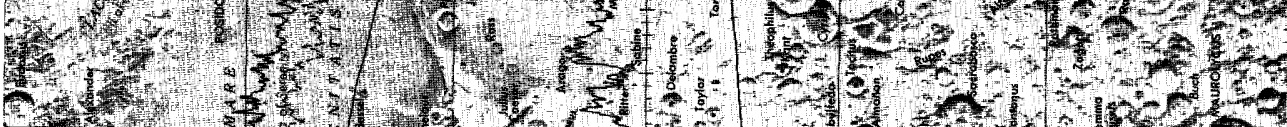

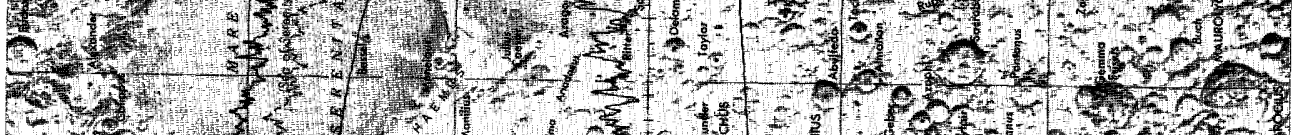

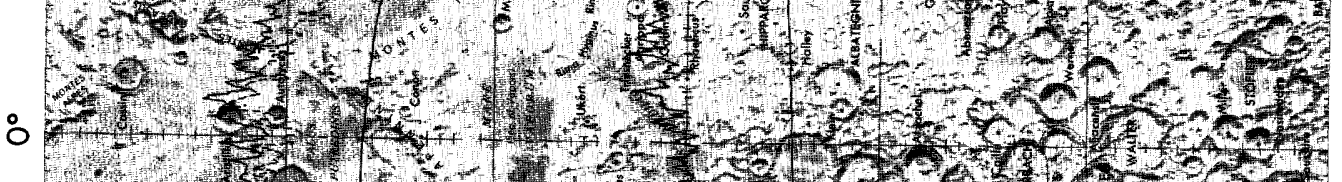

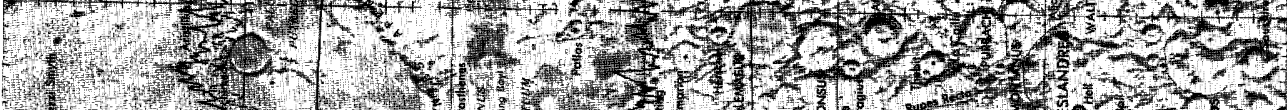

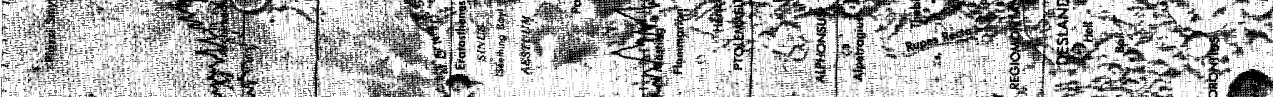

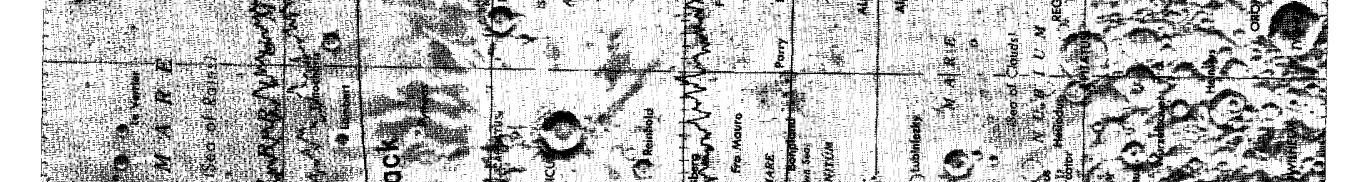

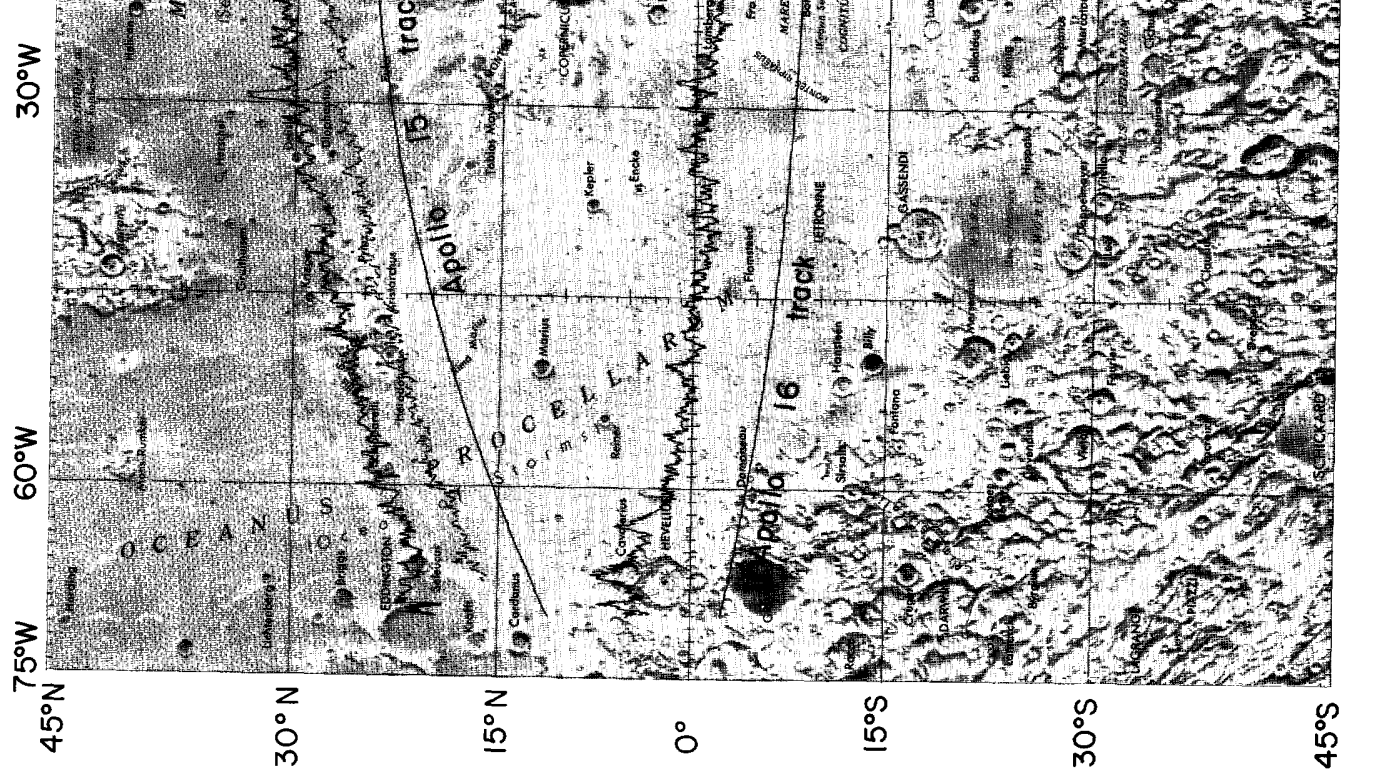

范

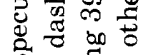

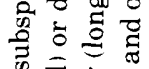

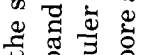

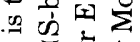

恼

东示范

贾

可

穷

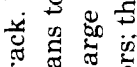

$=7$

ส

एँ

응

के 옹

홍

है

过

শ

त्ञ

今

蛋

용

임

ฮี छ

10.

范 क्ᄋ क

द.

ऽ 0

bo है

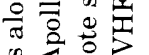

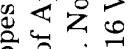

का

कह क्षँ के के

음

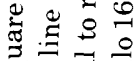

훈 똥

๘

可 है

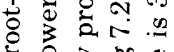

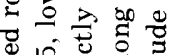

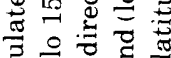

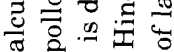

这医

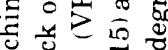

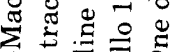

훙ㅇㅇㅇ

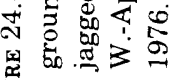


small over maria. The change is most marked for the VHF radar, which samples at greater slope lengths than the S-band. Large rms slopes are measured where the ground track crosses craters such as Lansberg (long $26.5^{\circ} \mathrm{W}$., fig. 23), LaLande (long $8.5^{\circ} \mathrm{W}$., fig. 23), Herschel (long $2^{\circ} \mathrm{W}$., fig. 23), Gaudibert (long $38^{\circ} \mathrm{E}$., fig. 23), Euler (Apollo 15, long $29.2^{\circ} \mathrm{W}$., fig. 24), and Hind (Apollo 16, long 7.3 ${ }^{\circ}$ E., fig. 24). Detailed comparisons of bistatic-radar roughness estimates with visual impressions of roughness shown on Lunar Orbiter IV images and Apollo mapping camera photographs have shown there is a good correlation between the two (Moore and others, 1975, 1976). Visually smooth mare surfaces have relatively small S-band and VHF rms slopes. Visually rough craters and highlands have relatively large S-band and VHF rms slopes. With the exception of the Apollo 16 results (Moore and others, 1976), VHF rms slopes in upland terrain are commonly equal to the S-band rms slopes and locally exceed them. In contrast, VHF rms slopes for the maria are less than the S-band rms slopes and are locally one-half the S-band rms slopes. Areally small and subtle changes in roughness are measured by the radar. On the flanks of the crater Theophilus, sharp decreases in rms slopes coincide with smooth patches in an otherwise rough ejecta blanket (Moore and others, 1975). Southwest of Kepler near Maestlin R (long 41.5 ${ }^{\circ}$ W., fig. 23, Moore and others, 1975), the S-band radar measured the change in crater density on the maria as the track crossed more heavily cratered terrain on one side of a scarp to less heavily cratered terrain on the other side of the scarp.

\section{CORRELATION WITH GEOLOGIC: MAP UNITS}

Because lunar photogeologic map units are defined using topography as one of several criteria (Wilhelms, 1970, 1972a; Shoemaker and Hackman, 1962), bistatic-radar rms slopes should be systematically related to geologic map units. This is the case (Moore and others, 1975,1976 ). The systematic relation between radar roughness and geologic map units is shown in a general way in figure 25 where average handcalculated S-band and VHF rms slopes for selected geologic map units along the Apollo 14 and 15 ground tracks are compared. Mare materials have small rms slopes for both radars, and S-band rms slopes are significantly larger than VHF rms slopes. Highland geologic map units have larger average rms slopes for. both radars, and average VHF rms slopes may equal or exceed the average S-band $\mathrm{rms}$ slopes. Similar results are obtained for the craters, which in this case (fig. 25) correspond to Copernican craters of Apollo 14. Frequency distributions of S-band and VHF rms slopes for individual resolution cells within geologic map units (see for example Moore and others, 1975) indicate that the distribution of roughness of lunar surfaces shown in the radar data resembles the distribution of the major terrain units seen through telescopes and on photographs.

Albedo (Pohn and Wildey, 1970) is also used as a criterion for geologic map units (Wilhelms, 1970, 1972a; Shoemaker and Hackman, 1962). As seen in figure 26, albedo and rms slopes, which are two independent variables, are directly correlated (see also Moore and others, 1976). Dark, smooth mare surfaces have both low average albedos and small average S-band rms slopes. Highland and crater units tend to have high average albedos and large average S-band rms slopes. Here again, the combined use of albedo and rms slopes would produce a map that resembles the Moon as viewed visually.

\section{CORRELATION WITH INFRARED ECLIPSE TEMPERATURES}

Comparison of average machine-calculated S-band rms slopes with average infrared eclipse temperatures

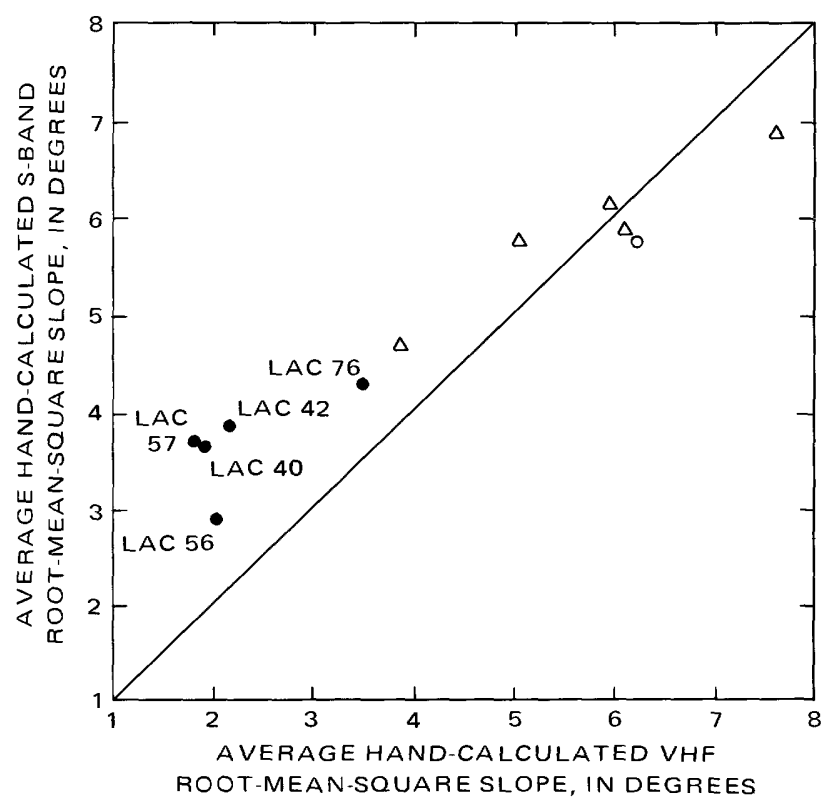

Figure 25.-Comparison of average hand-calculated S-band and VHF rms slopes for selected geologic map units along Apollo 14 and 15 bistatic-radar tracks. Points represent averages taken from Moore and others (1976) where number in sample is greater than 50. Mare materials (filled circles) plot at lower left, highland units (triangles) occur at upper right, and crater units (open circles) at upper right. LAC (Lunar Astronautical Chart) numbers indicate 1:1,000,000-scale geologic map in which mare material occurs (Carr, 1965, 1966; McCauley 1967; Hackman, 1962; Eggleton, 1965). Straight line is loci of points with equal S-band and VHF rms slopes. 


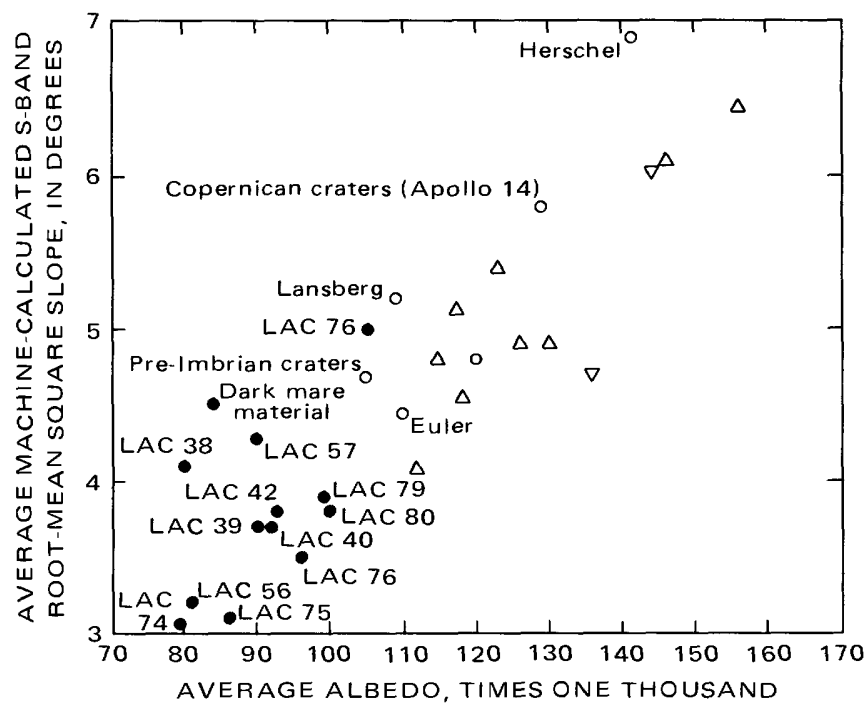

FIGURE 26.-Comparison of average machine-calculated S-brand rms slopes and albedos for selected geologic map units along Apollo 14, 15, and 16 bistatic-radar tracks. Points represent averages taken from Moore and others (1976) where number in sample is greater than 50 (except for points representing craters Herschel, Lansberg, and Euler, which have fewer than 50). Mare materials (filled circles) plot at lower left (except mare material in Montes Riphaeus region, Apollo 14), highland (triangles) and crater (open circles) units at upper right. LAC numbers indicate geologic maps in which map unit occurs (Moore, 1965, 1967; Carr, 1965, 1966; McCauley, 1967, 1973, Marshall, 1963; Hackman, 1962; Eggleton, 1965; Elston, 1972; Hodges, 1973). (Average albedos of geologic units obtained from map in Pohn and Wildey, 1970.)

(Shorthill, 1973) for selected geologic map units (fig. 27) shows an inverse relation and suggests a third variable that could be used to subdivide the Moon into surface types using remotely sensed data. Frequency distributions of infrared eclipse temperatures of some mare materials are characterized by tails or anomalously high frequencies of high temperatures (Moore and others, 1975) which are related to bright craters. Such is the case for mare material in the Hevelius and Kepler quadrangles (McCauley, 1967; Hackman, 1962). Removal of the anomalies reduces the average scaled infrared eclipse temperatures in the Hevelius and Kepler quadrangles to about 120 and $118^{2}$. Mare materials sampled in the Seleucus and Aristarchus quadrangles (Moore, 1965, 1967) do not have these large "tails," and their position in figure 27 would be affected to only a small degree by the "tails." Thus, the mare materials in these areas have anomalously high infrared eclipse temperatures that separate them from the other maria sampled. Remote measurements may also be used to subdivide maria (Moore and others, 1975), and one such example using S-band bistatic-

${ }^{2}$ Units are scaled values using the equation of Shorthill ( 1973 ): see also p. B61, equation 8. radar and scaled infrared eclipse temperatures is illustrated in figure 27 by the widely separated positions of mare materials which are warm and smooth and highland materials which are cool and rough. Anomalous conditions such as mare material in the Riphaeus Mountains region (Eggleton, 1965) can be recognized. Mare material in that region sampled by Apollo 14 is rough and cool compared to mare material sampled there by Apollo 16 which is smooth and warm.

\section{SLOPE-PROBABILITY DISTRIBUTIONS}

Three types of slope-probability distributions are obtained from the radar echoes: (1) normal, (2) tailed, and (3) complex. The normal distributions are reasonably close to gaussian curves. Tailed distributions have fewer slopes at small slope angles and more slopes at large slope angles than a gaussian distribution. Complex distributions have two or more modes and cannot be fitted by a gaussian curve. An example of a normal distribution is the highlands near Vitruvius (lat $18.8^{\circ}$ N., long $32.0^{\circ}$ E.) where a gaussian curve produces a

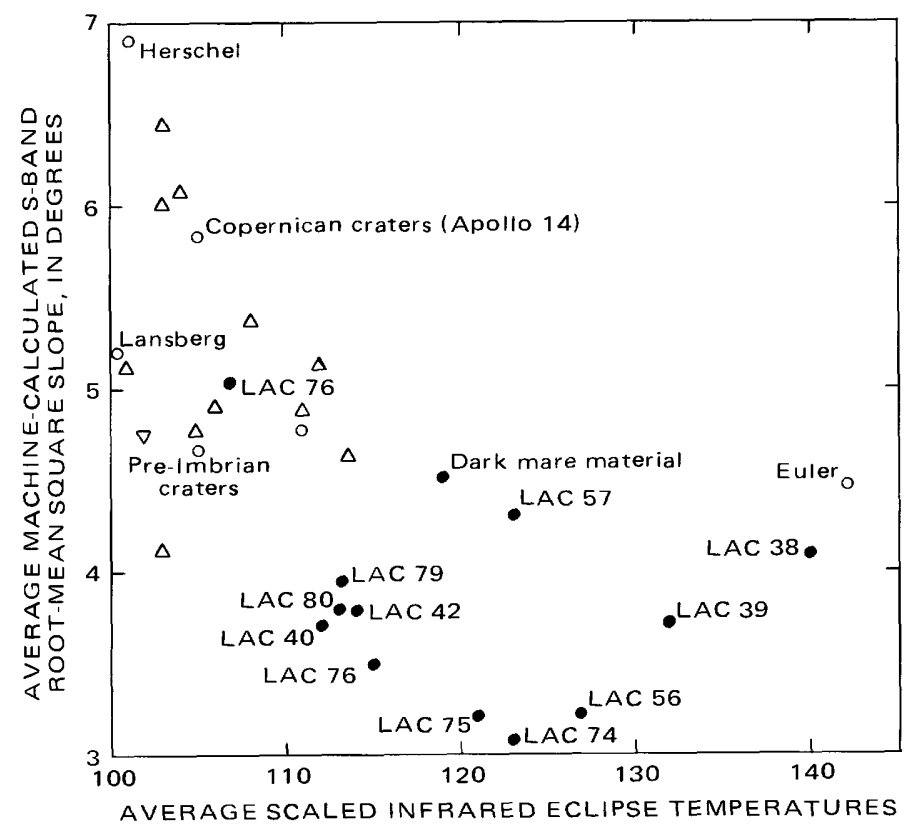

Figure 27.-Comparison of average machine-calculated S-band rms slopes and average infrared eclipse temperatures for selected geologic map units along Apollo 14, 15, and 16 bistatic-radar tracks. Points represent averages taken from Moore and others (1976) where number in sample is greater than 50 (except points representing Herschel, Lansberg, and Euler, which have fewer than 50). LAC numbers indicate geologic maps in which mare units occur (see figs. 25 and 26). Mare materials (filled circles) plot at lower right (except mare material in Montes Riphaeus region, Apollo 14); highland (triangles) and crater (open circles) units plot at upper left except for Euler, which has anomalously high average infrared eclipse temperatures. 
good fit to the S-band radar results (fig. 28). The cumulative distribution is approximately a gaussian curve for the VHF radar, although the histogram shows minor departures (fig. 28). Mare surfaces at lat $23.8^{\circ} \mathrm{N}$., long $26^{\circ} \mathrm{W}$., are examples of tailed distributions. The tail or excess of slopes above the gaussian curve at large slope angles is less strong for the S-band radar than that of the VHF radar in Mare Imbrium (fig. 29). Distributions are complex in the highlands near Glaisher (lat $11.4^{\circ} \mathrm{N}$., long $52^{\circ} \mathrm{E}$.). Although the S-band distribution is approximately normal, the VHF distribution is clearly complex (fig. 30). The data available have not been completely analyzed, but it appears at this time that mare surfaces have tailed distri-

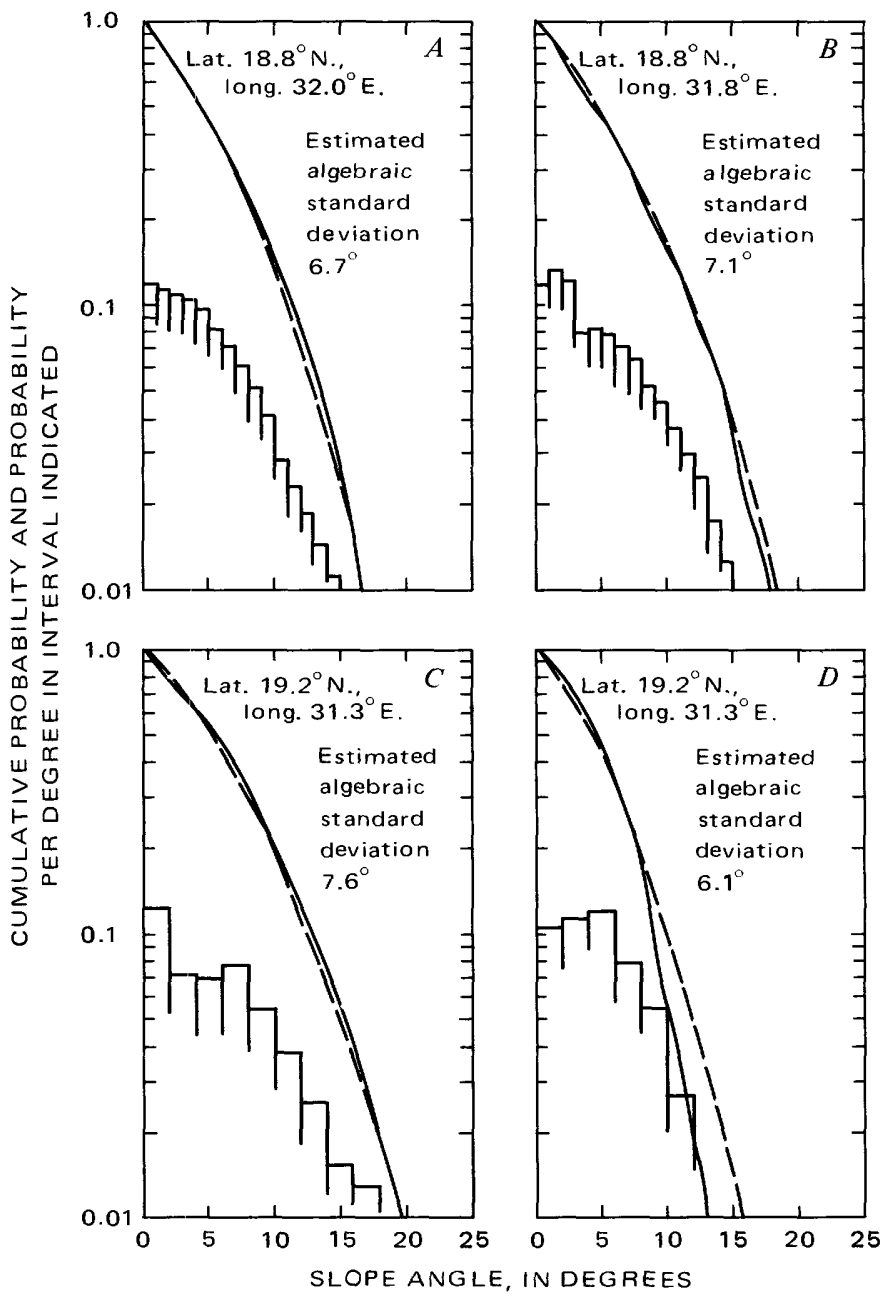

FIGURE 28.-Bistatic-radar and photogrammetry slope-probability distributions of the normal type for $A, 13-\mathrm{cm}$ (S-band) radar, $B$, $116-\mathrm{cm}$ (VHF radar), and $C, 25-\mathrm{m}$ slope length. Photogrammetry distribution at $202 \mathrm{~m}, D$, is not the normal type. Solid line is actual cumulative distribution; dashed line is cumulative gaussian distribution. Histogram shown with solid lines. Sampled area is highlands near crater Vitruvius. Radar data courtesy of G. L. Tyler Stanford University.

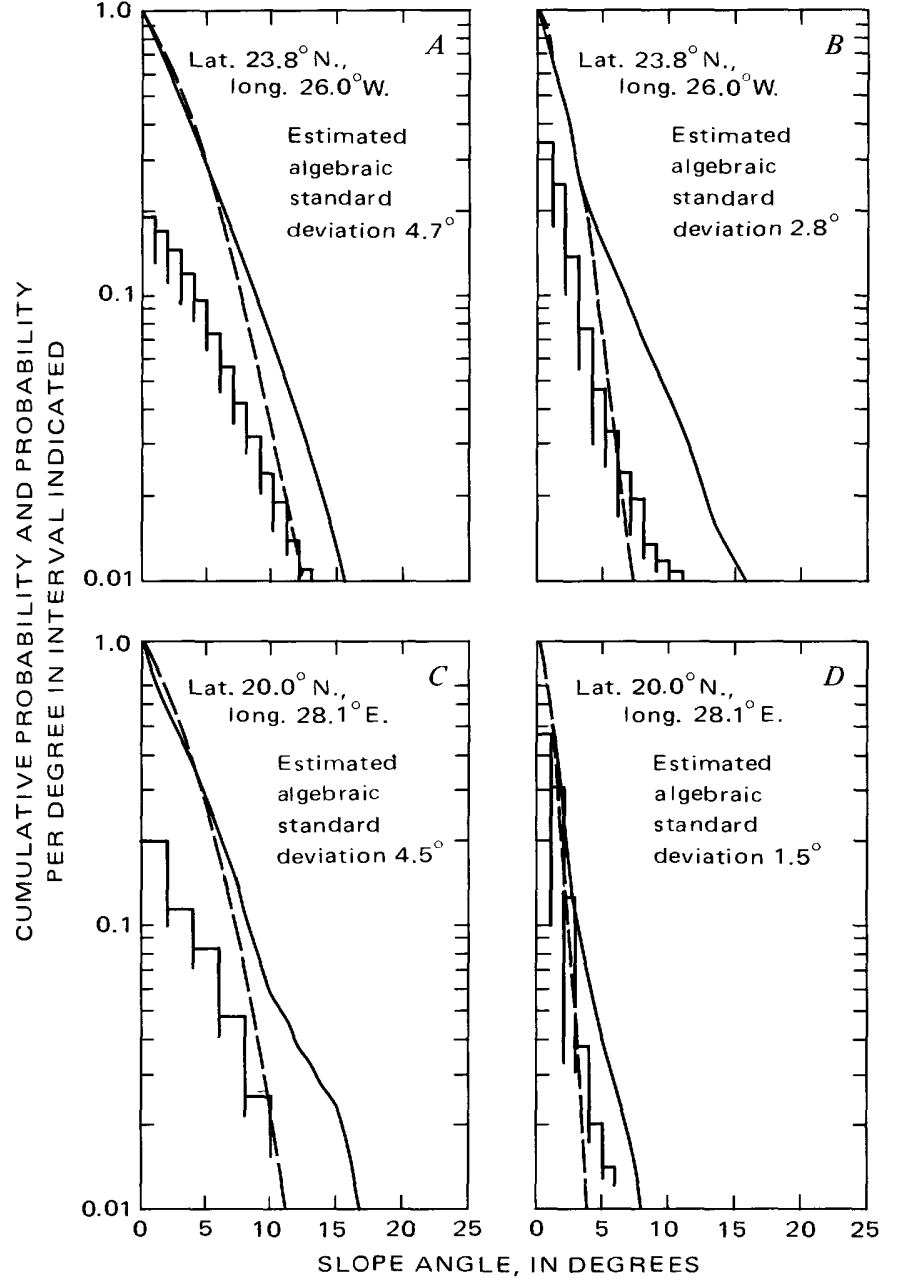

FIGURE 29.-Bistatic-radar and photogrammetry slope-probability distributions of the tailed typed for $A, 13-\mathrm{cm}$ (S-band) radar, $B$, $116-\mathrm{cm}$ (VHF) radar, $C, 25-\mathrm{m}$ slope length, and $D, 200-\mathrm{m}$ slope length. Solid line is actual cumulative distribution; dashed line is cumulative gaussian distribution. Histogram shown with solid lines. Actual distribution has more slopes at large slope angles than gaussian distribution. Area sampled by radar is mare material in Mare Imbrium. Area sampled by photogrammetry is mare material in Mare Serenitatis. Radar data courtesy of G. L. Tyler, Stanford University.

butions whereas highland surfaces may be normal, tailed, or complex.

The forms of the slope-probability distributions obtained by the radar are similar to those obtained independently using photogrammetric techniques in the same terrain type, and the algebraic standard deviations are generally about the same for both techniques (figs. 28, 29, and 30; Moore and others, 1976). Slope-probability distributions of experimentally cratered surfaces also exhibit parallels with those obtained by the radar (Moore and others, 1974, 1975, 1976). Thus, the radar technique for obtaining slopeprobability distributions and characterizing lunar surfaces is a valuable tool for future lunar exploration. 


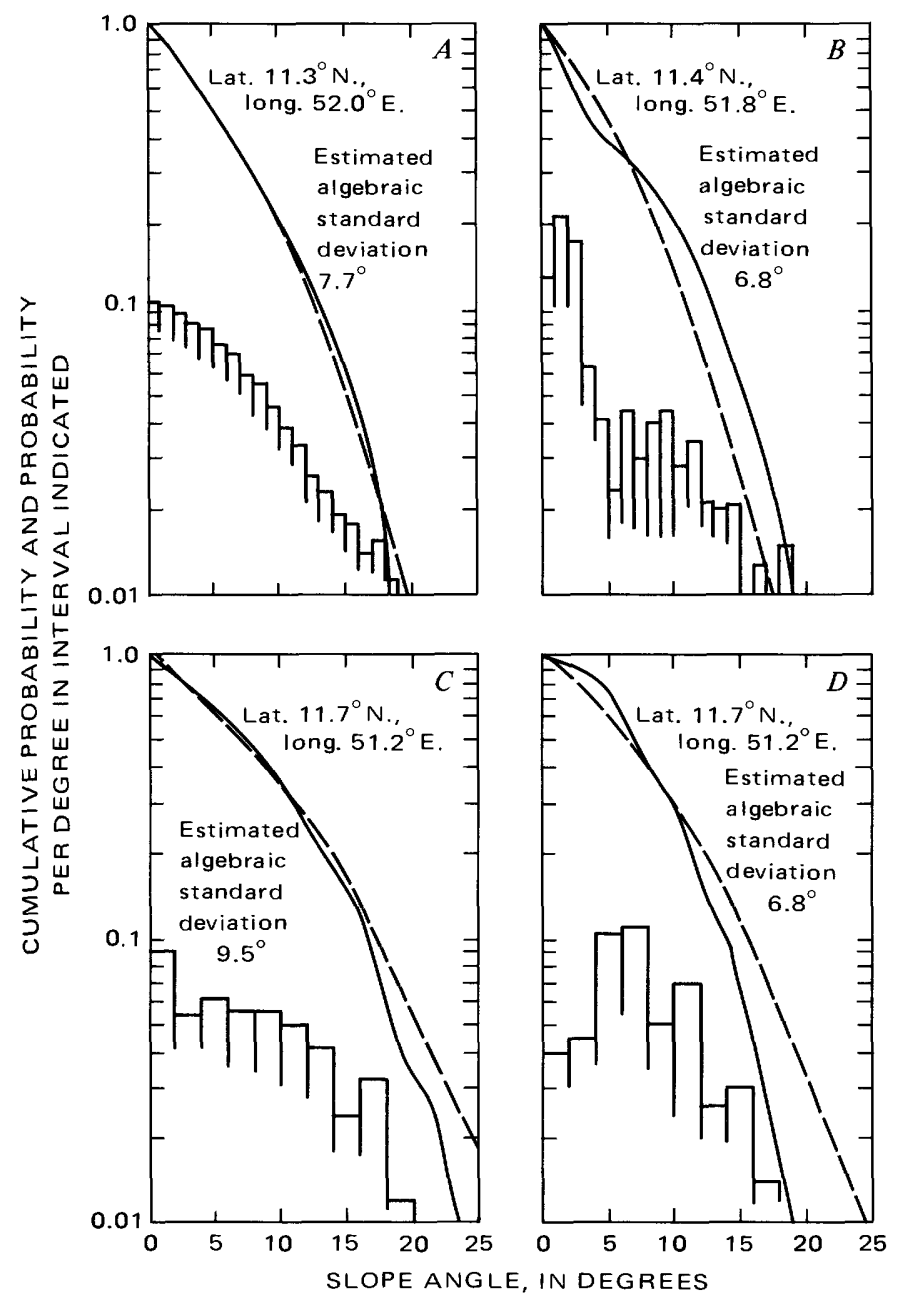

FiguRe 30.-Bistatic-radar and photogrammetry slope-probability distribution of the complex type for $A, 13-\mathrm{cm}$ (S-band) radar, $B$, $116-\mathrm{cm}$ (VHF) radar, $C, 25-\mathrm{m}$ slope length, and $D, 202-\mathrm{m}$ slope length. Solid line is actual cumulative distribution; dashed line is cumulative gaussian distribution. Histogram shown with solid lines. Sampled area is highlands near crater Glaisher. Note modes in histogram for 116-cm radar and photogrammetric distributions. Radar data courtesy of G. L. Tyler, Stanford University.

\section{DISCUSSION}

Although the bistatic-radar experiment was a success, three unresolved problems should be noted: (1) machine-calculated rms slopes are uniformly smaller than algebraic standard deviations estimated from the slope-probability distributions, ${ }^{3}(2)$ in the analysis of the echo spectra for slope-probability distributions, slope angles larger than $20^{\circ}$ are excluded, and (3) VHF rms slopes sometimes exceed S-band rms slopes. The machine-calculated rms slopes are about $1.5^{\circ}$ smaller

\footnotetext{
${ }^{3}$ Algebraic standard deviations are estimated as that slope angle corresponding to a cumulative probability of 0.316 for slopes equal to and greater than that slope angle.
}

than the algebraic standard deviations (table 9, fig. 31 ). This difference may result because the surface is assumed to be gaussian and well behaved in the machine-calculated rms slopes (Tyler and others, 1973), and signal-noise is treated differently in the two methods.

The exclusion of slope angles larger than $20^{\circ}$ is not serious for mare surfaces and relatively smooth highlands. For rough highlands and craters, this exclusion is significant. For example, the crater Euler has an algebraic standard deviation of about $19^{\circ}$ for an adirectional slope probability distribution for the surface

TABLE 9.-Comparison of machine-calculated rms slopes, handcalculated rms, and algebraic standard deviations $(\sigma)$ estimated from slope-probability distributions

\begin{tabular}{|c|c|c|c|c|c|c|c|}
\hline \multirow{2}{*}{\multicolumn{2}{|c|}{ Type of surface and location }} & \multicolumn{3}{|c|}{ S-band radar } & \multicolumn{3}{|c|}{ VHF radar } \\
\hline & & Machine & Hand & $\sigma$ & Machine & Hand & $\sigma$ \\
\hline Mare & $20.4^{\circ} \mathrm{N} ., 26.0^{\circ} \mathbf{E}$ & 3.70 & 3.51 & 4.6 & 2.38 & 1.84 & 3.4 \\
\hline Mar & $12.8^{\circ} \mathrm{N} ., 26.0^{\circ} \mathrm{W}$ & -3.73 & 3.80 & 4.7 & 1.60 & 1.43 & 2.8 \\
\hline Highland & $9.5^{\circ} \mathrm{N},, 55.9^{\circ} \mathrm{E}$ & -5.67 & $\ldots$ & 8.5 & 5.92 & $-\ldots-$ & 6.7 \\
\hline Highland & $11.4^{\circ} \mathrm{N} ., 52.0^{\circ} \mathrm{E}$ & -5.67 & & 7.7 & 4.94 & $-\ldots$. & 6.8 \\
\hline Highland & $13.9^{\circ} \mathrm{N} ., 46.0^{\circ} \mathrm{E}$ & -4.59 & & 7.1 & 5.4 & & 6.1 \\
\hline Highland & $14.7^{\circ}$ N., $44.0^{\circ} \mathrm{E}$ & 4.70 & $-\ldots$ & 6.3 & 4.57 & & 5.9 \\
\hline Highland & $18.8^{\circ} \mathrm{N}, 3^{1} .8^{\circ} \mathrm{E}$. & 4.65 & & 6.7 & 4.37 & 5.12 & 7.1 \\
\hline
\end{tabular}

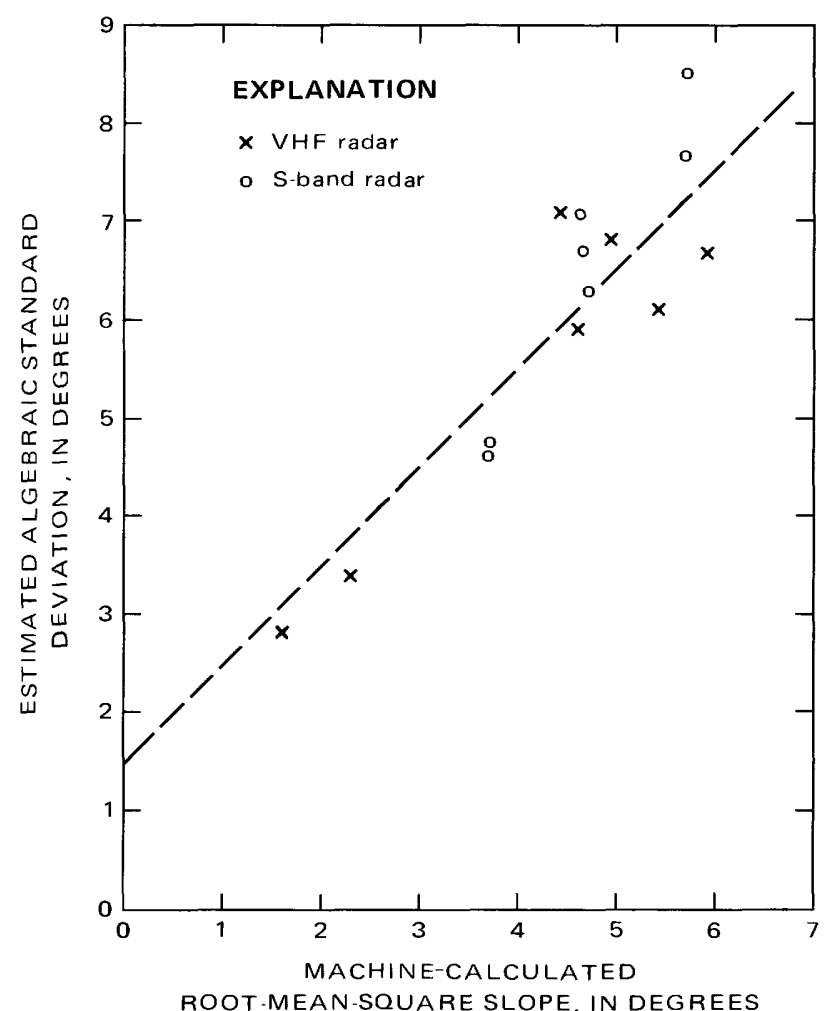

FiguRE 31.-Comparison of algebraic standard deviations estimated from slope-probability distributions measured by radar- and machine-calculated rms slopes. Estimated algebraic standard deviations are larger than rms slopes for both S-band and VHF frequencies. Radar data courtesy of G. L. Tyler, Stanford University. 
within the rim at a scale length of $24 \mathrm{~m}$. If the crater interior were sampled to give unidirectional slopes, the algebraic standard deviation would be $12^{\circ}$ instead of $19^{\circ}$. Thus, S-band rms slopes for Euler, which reach $5.6^{\circ}$ (machine calculated) and $7.1^{\circ}$ (hand calculated), are too low.

VHF rms slopes that exceed S-band rms slopes would not be expected. Clearly, roughness increases with decreasing scale length. However, if the two radars act as a filter and measure roughness contributions between two different scale-length increments, such a result is possible.

Despite some minor inconsistencies, the bistaticradar results are very good: (1) The roughness estimates agree with the visual and photographic evidence for the Moon and are consistent with the geologic map units, (2) the combination of radar roughness, albedo, and infrared eclipse temperatures could be used to produce maps of the Moon which would, in general, resemble the distribution of the major terrain types, (3) the results on slope-probability distributions obtained by the radar are in general agreement with those obtained using photographs and photogrammetric techniques.

\section{EARTH-BASED RESULTS}

\section{REFLECTION OF SOLAR RADIATION WITH WAVELENTH FROM $0.3 \mu \mathrm{M}$ TO $2.2 \mu \mathrm{M}$ By Gerald G. Schaber}

The methods of photometry, polarimetry, colorimetry, and spectral reflectivity have been applied to reflected lunar light since early in the present century to obtain data on the physical and chemical composition of the lunar surface. The four techniques for optical characterization of the Moon will be summarized with reference to its major geologic significance in this section. Each of these techniques complimented one another and provided the basis for the resurgence since the Apollo missions of interest in high-resolution spectral reflectivity variations as they relate to chemical composition of the Moon. They form a useful basis for extrapolation of the Apollo results to other areas of the Moon and for discovering lunar areas that have properties unlike those sampled by Apollo.

\section{PHOTOMETRY AND POLARIZATION OF SUNLIGHT}

Earth-based photometric and polarimetric investigations of the Moon proved to be extremely accurate in predicting the fine-scale physical properties of the lunar surface before the first close-up observations by the Luna 9 and Surveyor I spacecraft in February and June 1966 (Dollfus, 1962; Hapke, 1963; Hapke and Van Horn, 1963). The Moon was found to scatter light in a unique manner, and it could be characterized by four distinct photometric properties: (1) a visual albedo that is uniformly low, ranging from 5 percent to 18 percent; (2) a sharp maximum of visual albedo at or near full Moon (zero phase); (3) a strong dependence between visual albedo and lunar phase, which is nearly independent of location on the lunar disk or type of terrain on the lunar surface; and (4) polarization of visible reflected light varying from (a) zero at full (b) to maximum negative polarization of 1.2 percent at a phase angle of $11^{\circ}$ (c) to zero again at a phase angle of $23^{\circ}$ where the plane of polarization suddenly rotates, and $(\mathrm{d})$ then reaching a broad maximum near $110^{\circ}$ (Hapke, 1964).

These photometric properties were early recognized to be grossly different from most of the common terrestrial materials (summarized by Fessenkov, 1962, and Markov, 1962; Hapke, 1963; Hapke and Van Horn, 1963; Pellicori, 1969; Dollfus and others, 1971). Although basaltic powders and dark volcanic ash and slag were among these lunar materials suggested, no firm conclusions about the composition and nature of the minerals involved could be determined (fig. 32) (Dollfus, 1962). Taken collectively, the photometric and polarization properties of the Moon were correctly interpreted to result from a uniform covering of the lunar surface by dust or ash-like material with up to 90 percent voids into which light from any direction could penetrate. The surface particles were suggested to be mostly opaque with fairly rough surfaces and an average grain size of $10 \mu \mathrm{m}$, capable of absorbing 70 percent or more of the light incident on them. This porous, dark opaque layer need not be thick because of the very small penetration of sunlight.

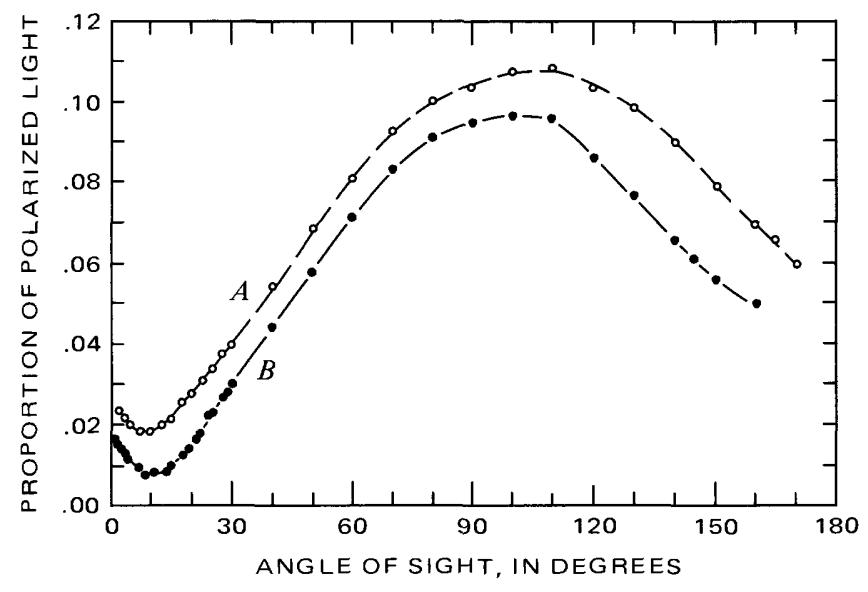

FIgURE 32.-Polarization of light of the Moon and of some mixtures of volcanic ashes (from Dollfus, 1962, after Lyot, 1929). A, Mixture of volcanic ashes with an albedo of $0.13 ; B$, mean curve for the Moon. 
One of the main difficulties with duplicating the lunar photometric curves lay in the fact that pulverization of even the darkest terrestrial rocks results in a powder that has a relatively high albedo (Salisbury, 1970; Adams, 1967; Minnaert, 1969). Consequently, it was difficult to explain the low albedo of the lunar surface, interpreted by photometric and polarization studies to be covered with fine material.

Pulverized terrestrial silicate rocks have a high albedo because of the relatively low absorption coefficient of silicate minerals, which allows progressively more light to pass successfully through some part of a grain, as particle size is reduced, to be scattered back to the viewer (Salisbury, 1970). The only terrestrial materials which have high absorption coefficients, and thus decreased albedo with pulverization, are oxides, sulfides, and native metals. Opaque minerals such as magnetite and ilmenite are present in terrestrial rocks, but not in the proportions necessary to cause decreasing albedo with decreasing particle size.

After the samples were returned by Apollo, the lunar surface material was known to be a complex, multicomponent system consisting of rocks of several major compositions, high concentrations of iron-titanium oxides, brown-red to black (including green and orange) glasses and agglutinates, and possibly metalrich opaque grain coatings. The effects of the high iron-titanium glasses and metal-rich grain coatings on the observed lunar albedo have been the primary subject of debate.

The production of glass at the lunar surface is among the explanations offered to account for the lunar surface darkening process (Conel and Nash, 1970; Adams and McCord, 1971a, b). It was theorized that while crushed lunar rock has a relatively high albedo, glass produced by impact melting of the same rock is quite dark; thus as more and more dark glass is churned into or deposited upon light-colored sediments, they darken with time. This postulate can be rejected because true glasses of lunar composition, created in the laboratory, have an albedo much higher than that of lunar soil and thus mixing of this material with pulverized lunar crystalline rocks would not appreciably darken lunar soil (Hapke and others, 1973).

Partial devitrification could make lunar glasses more absorbing (darker) by crystallization of opaque inclusions rich in iron and titanium (Hapke and others, 1973; Nash and Conel, 1973). The degree of devitrification, however, is a complex function of rate of cooling and composition of a glass (Cassidy and Hapke, 1975). Although black glass spherules at the lunar surface do often show extensive devitrification it is not known exactly what processes are involved. Presumably, fresh glass within a thick ejecta blanket would cool slowly enough to devitrify and would later be brought up to the surface by impact cratering. The degree of devitrification observed could then depend on the local conditions related to subsequent excavation of material by impacts. In conflict with this view, devitrified laboratory glasses have absorption bands characteristic of ilmenite, which are not visible in lunar fines and which would have to be masked during the course of lunar soil darkening (Cassidy and Hapke, 1975). Furthermore, the idea that subsurface sediments contain large amounts of darkened devitrified grains working their way upward is not supported by examination of core samples. These observations lead to the resurrection of an earlier suggestion (Gold, 1955; Hapke, 1966, 1970; Gold and others, 1970; Hapke and others, 1970) that darkened lunar fines have been coated by lightabsorbing thin films produced by micrometeorite vaporization or solar wind sputter-vaporization and deposition. Chemical etching of dark lunar soil removes material at grain surfaces and restores the soil to a condition of high reflectivity, characteristic of crushed lunar basalt, thus strengthening the theory of darkening by a coating process (Hapke and others, 1970; Gold and others, 1970). The amount of additional iron-rich material added to the lunar fines was quantified by heating lunar fines (10084) and pulverized crystalline rock (10017) in an oxygen atmosphere to $100^{\circ} \mathrm{C}$ on the thermogravimetric balance (Cassidy and Hapke, 1975). The weight of the fines increased 2 percent, and the weight of the rock powder increased 1 percent. Calculations showed that if all metallic $\mathrm{Fe}$ and $\mathrm{Fe}^{+2}$ in the samples were oxidized to $\mathrm{Fe}^{+3}$, both weight increases would have been about 1 percent; thus, the excess weight increase of the fines could be explained by oxidation of submicroscopic metallic iron in vapordeposited films on grain surfaces. The argument has been strengthened by measurements of overall enrichments of iron at the grain surfaces of smoothed lunar fines, compared to the bulk composition of the grain samples; the degree of iron enrichment was found to be correlated with the visual albedo of the fines (Gold and others, 1974). Unpublished data on the magnetic character of the thin iron-rich films on lunar fines indicate that the films contain more than 10 percent iron as superparamagnetic particles smaller than 30A (Cassidy and Hapke, 1975). Such materials could thus account for a large part of the lunar darkening effect by causing strong visible absorptions. The presence of large concentrations of superparamagnetic iron in the grain coatings could also be a major factor in creating the variable natural remanent magnetization observed on the old, more mature, lunar breccia terranes (see section on "Lunar Magnetism").

In another proposed mechanism for alteration and 
darkening of the lunar regolith (Housley and others, $1973,1974)$, solar wind protons are embedded in the surfaces of lunar grains which are subsequently melted by micrometeroid impact, thus darkening the grain surfaces. This process has not yet been verified experimentally.

\section{COLOR}

An even more rewarding approach to analysis of reflected lunar light has been to observe its behavior as a function of wavelength and spectral energy distribution of the reflected sunlight (McCord and Adams, 1973). This is, in short, observation of lunar color differences, distinct from albedo in that, for the latter, the reflected light is analyzed relative to the source light for its intensity at one or more wavelengths.

Investigation of lunar surface color variations in the visible and near infrared have been of considerable scientific interest since early in this century. Beginning with the quantitative visual observations of Wilsing and Scheiner (1921) in 1908-1910, it was recognized that the lunar highlands were redder than the lunar maria. When the first lunar spectrally filtered photographs were reported by Miethe and Seegert (1911) and Wood (1912), additional unique spectral regions such as the Aristarchus plateau (Wood's Spot) were recognized. These early lunar photographic studies were soon followed by those of Miethe and Seegert (1914) and Barabashov (1924). Wright (1929) was the first to obtain high-quality spectrally filtered composite photographs of the Moon. He utilized six filters in the ultraviolet, violet, green, orange, red, and extreme red. The use of spectrally filtered composite photographs stresses differences in color and subdues differences in albedo between reflecting areas.

In recent years Barabashov (1953), Scott (1964) and Whitaker (1972, 1973, and in Kuiper, 1965) have produced improved definition, enhanced color-difference photographs of the Moon (fig. 33). These photographic studies of lunar color have all shown the same major color anomalies: the relative redness of central Serenitatis compared with Tranquillitatis, the blue area in Mare Imbrium, and others. However, the disadvantages of the photographic method for color analysis are that it is not rigorously quantitative and is weakly dependent on albedo variations, phase angle, and the exposure characteristics of the film. In some cases, these variables can be misinterpreted as color differences.

It was early recognized that, although the color image method was most useful to obtain data on the size, shape, and boundary sharpness of lunar color regions, more quantitative data would be needed. Quan- titative methods were soon reported, and for the most part, they verified nearly all of the lunar color regions first described from the photographic image data. Techniques applied to this task included (1) photographic spectrophotometry, (2) photographic spectroscopy, (3) photoelectric photometry, and more recently (4) four-color multi-spectral scanning techniques and (5) vidicon imaging photometry. A detailed historical account of the early investigations is reported by McCord (1968).

\section{SPECTRAL REFLECTIVITY}

The major goals of those attempting to quantify lunar spectral reflectivity were to determine (1) the shape of the reflectivity curves over large spectral range; (2) the magnitude of lunar color contrasts, (3) the time dependence, if any, of the color contrasts, and (4) the effect of albedo and surface morphology on color contrasts.

Determination of the shape of the spectral reflectivity curve required measurements made at several wavelengths and over an extended spectral range. The methods of spectroscopy and multifilter photometry were utilized for this purpose (fig. 34). Workers using these techniques found that at least some lunar spectral reflectivity curves contain flexures which were interpreted as absorption and emission features associated with specific minerals and rock types (Adams, 1967, 1968, Adams and Filice, 1967, Aronson and others, 1967).

The magnitude of the color contrasts seems to depend on the size of the spectral interval considered and the areas of the lunar surface observed (fig. 35). Although the degree of color variations reported in earlier works (McCord, 1968) showed some discrepancy, recent high-resolution ( 0.1 to 0.3 percent) measurements indicate that the spectral reflectivity differences, measured with respect to a standard area in Mare Serenitatis (fig. 34A), are most frequently under 5 percent, and differences of 10 percent are common (McCord, 1969). In specific areas, differences reach above 20 percent, and the maximum difference from the most red area to the most blue is about 60 percent.

The verification of a time dependence of lunar color contrasts was to be an important aspect of spectral reflectivity investigations, especially in large-scale mapping programs. Lunar spectral reflectance differences of the order of 2 to 3 percent have been measured for phase angles of $0^{\circ}$ and $35^{\circ}$ (McCord, 1968). The variation between phase angles of $35^{\circ}$ to $90^{\circ}$ are generally around 1 percent. Color index observations (Gehrels and others, 1964) were the first to show clearly that the Moon exhibits a slight reddening with phase angle and 


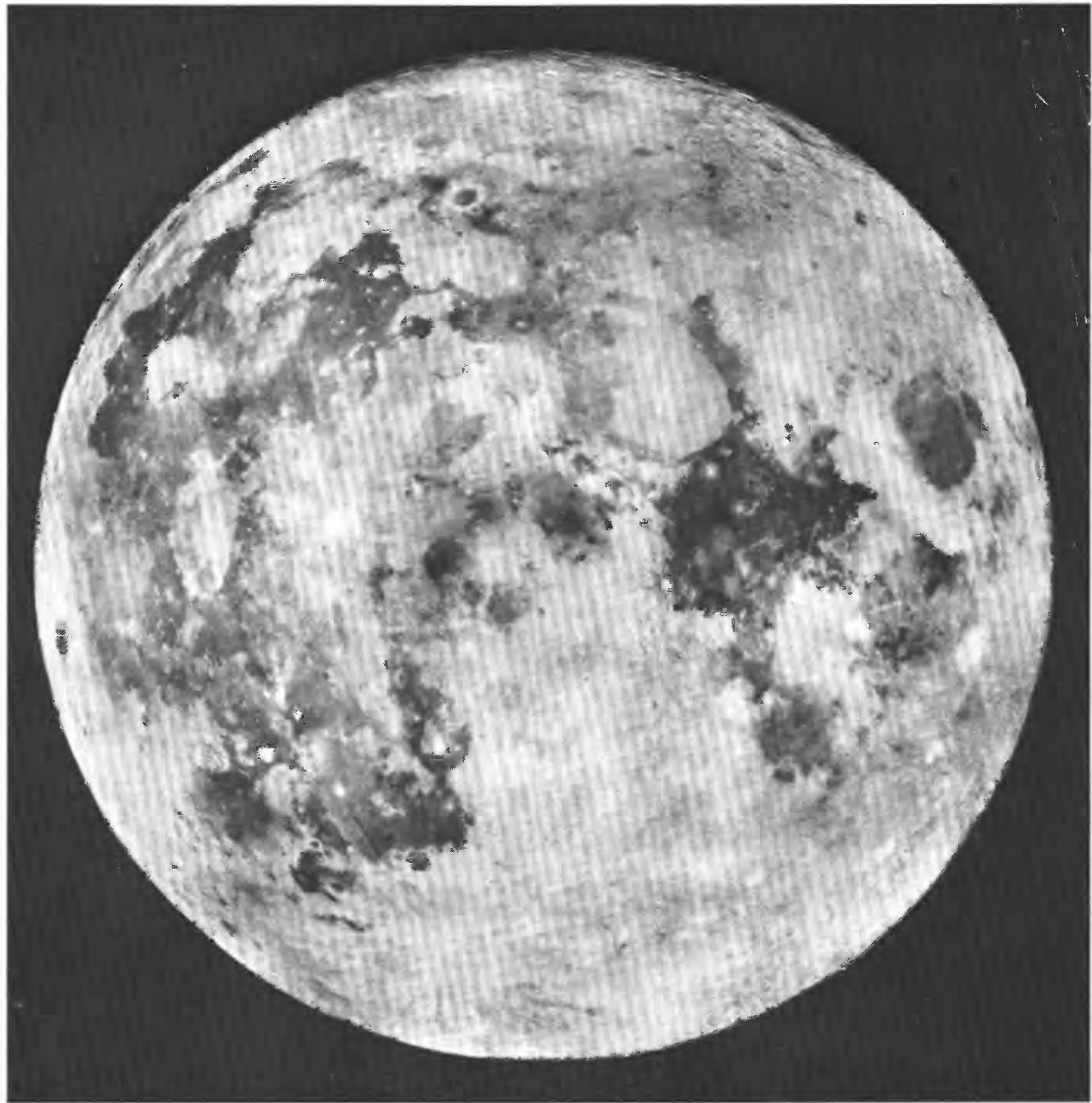

FIGURE 33.-Composite color-difference photograph of the Moon. Spectral bands used were $0.37 \mu \mathrm{m}$ and $0.61 \mu \mathrm{m}$. Light is red, dark is blue. Diameter of Moon is $3,476 \mathrm{~km}$. Photograph courtesy of E. A. Whitaker, Lunar and Planetary Laboratories, University of Arizona, Tucson, Arizona.

that the lunar brightness increases significantly within $5^{\circ}$ of full Moon ("opposition effect").

The dependence of lunar color on albedo has been reported by almost all workers, each observing a general reddening of the lunar surface with increased albedo. Radlova $(1941,1943)$ reported that darker lunar regions exhibit a wide range of colors, while the lighter regions, in general, are characterized by reddish tints. Fresh craters are very important exceptions to this rule, however (Radlova, 1943; McCord and others, 1972). The few exceptions to the reddening effect have important geologic significance and will be discussed later in this paper. The reddening law seems to hold more strongly in the maria than in the uplands or for 

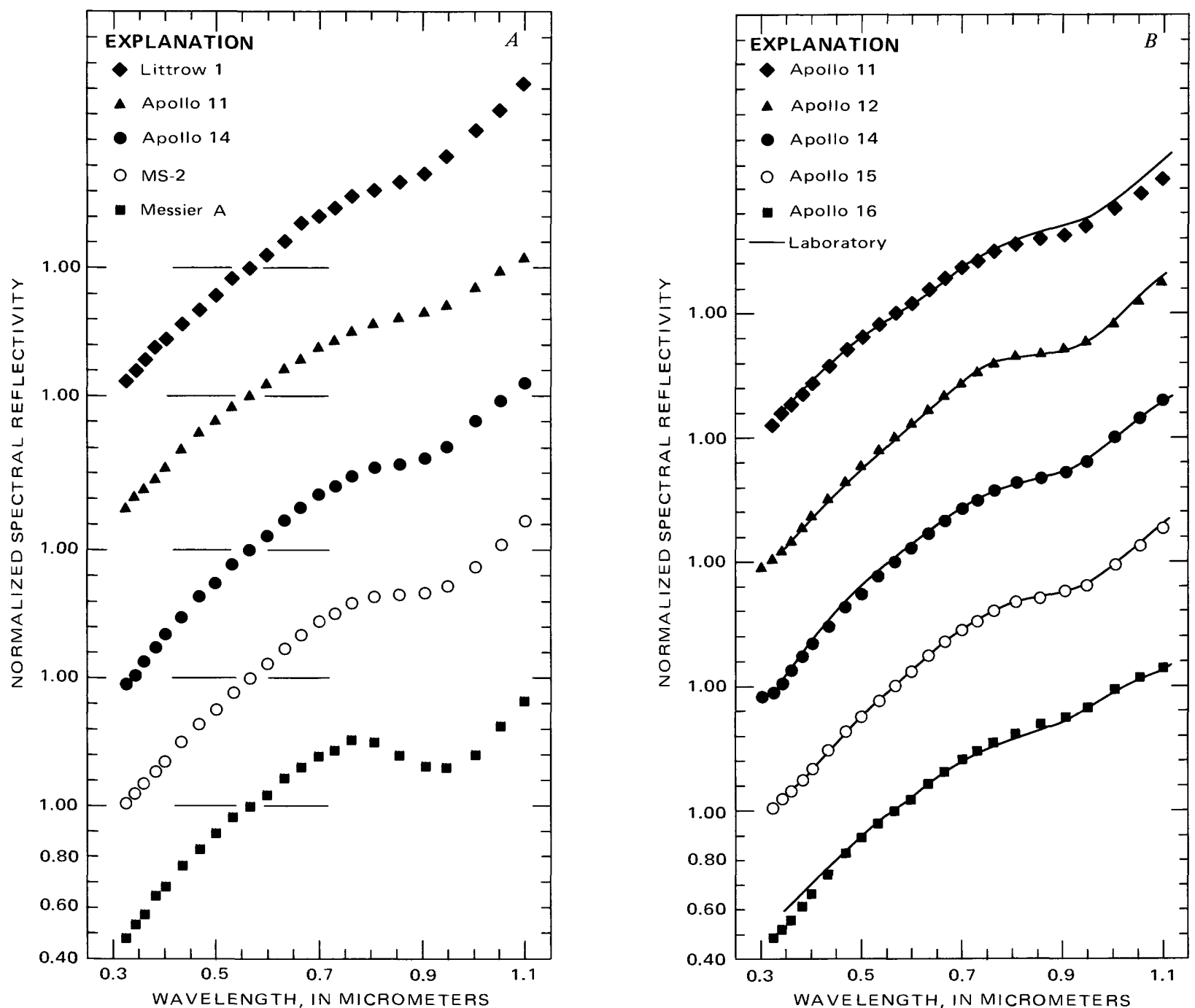

Figure 34.-A, Normalized spectral reflectivity for selected lunar surfaces: Littrow, Apollo 11 area, Apollo 14, MS-2 or standard area in Mare Serenitatis used to obtain relative spectral reflectances (see figs. 37 and 38), and area of Messier A. B, Comparison of normalized reflectances of Apollo landing sites measured through telescopes (data points) with normalized reflectances of regolith samples from Apollo landing sites measured in the laboratory (solid lines). Lunar surface resolution is 10-20 km (after McCord and Adams, 1973).

bright craters, and the slope of the linear dependence of color on brightness varies with the lunar region studied (McCord, 1968).

The dependence of lunar differential color on morphology has been generally discussed in terms of maria, uplands, and bright craters. Upland regions have been shown to appear uniform in color and in the shape of the spectral curve in contrast to the maria regions, which exhibit large color differences and a variety of spectral curve slopes (fig. 35; McCord, 1969). The younger, bright craters of both maria and uplands are some of the most highly colored features of the lunar surface (fig. 36).

The lunar multispectral photography experiment (S-158) was flown in lunar orbit aboard Apollo 12 (1) to record subtle color differences at two to four orders of magnitude better areal resolution than achieved from Earth and (2) to obtain information on the scale of surface compositional and mineralogical heterogeneity (Goetz and others, 1971). Four Hasselblad cameras (80-mm lenses) with Wratten filters $(0.35 \mu \mathrm{m}$ to 0.85 $\mu \mathrm{m})$ and plus-X type black and white film were used to take 142 photographic frames, primarily over lunar highland terrain ( 80 percent of frames). Aside from the color differences attributed to the blocky ejecta of several fresh craters observed, the lunar highlands were found to be extremely uniform in color, indicating small surface compositional variation. Computer color-ratio techniques were applied to the multispectral photography, but limited photometric resolution of 

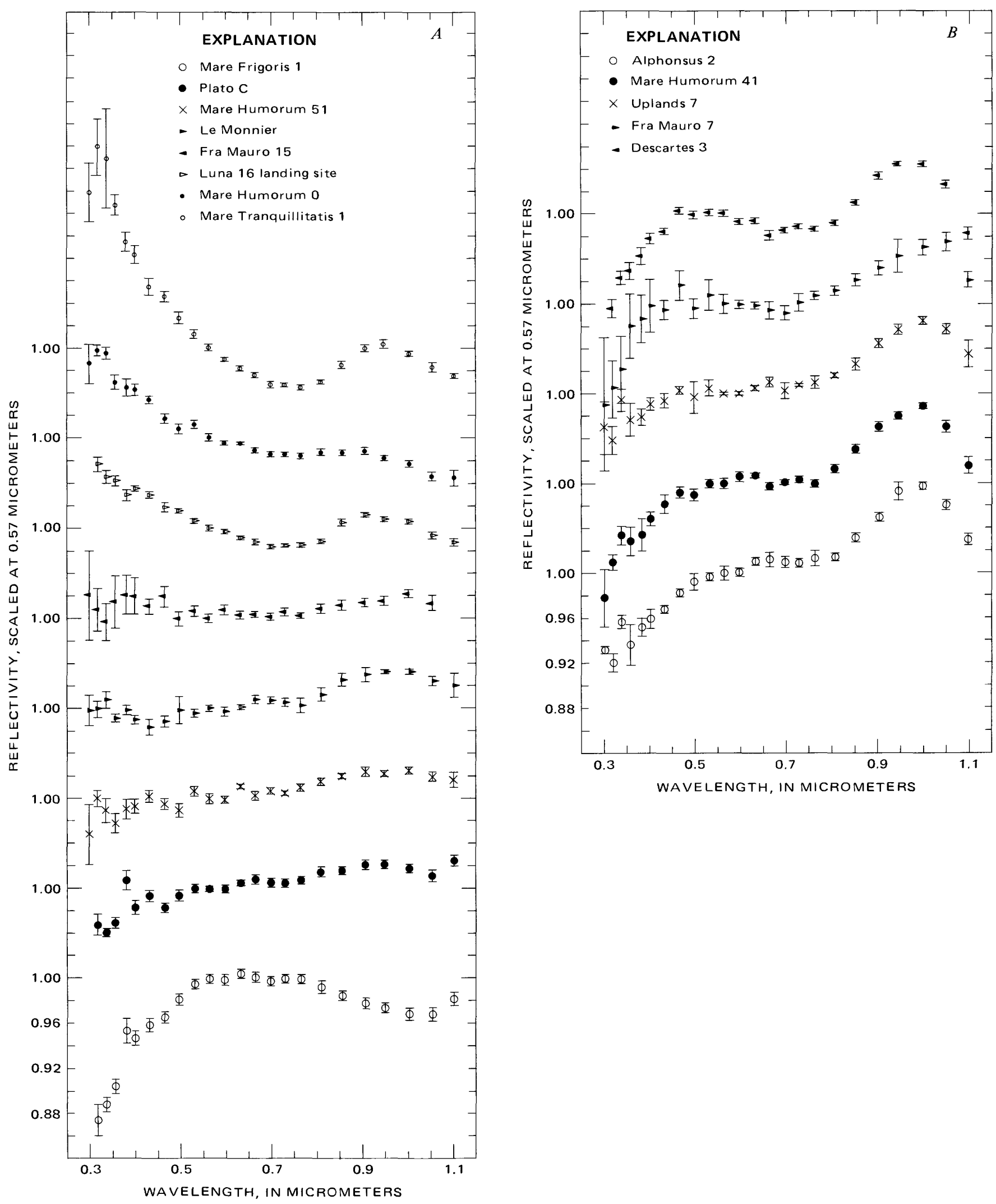

FIgURE 35.--Relative spectral reflectivity of lunar maria, $A$, and highlands, $B$. Curves are ratios of spectral reflectance at $10-20 \mathrm{~km}$ resolution for area indicated and standard area of Mare Serenitatis (MS-2 in fig. 34). Vertical bars represent range of values within one sigma confidence level. Although the Moon has a reddish color, areas with curves sloping to left are termed "red" and areas with curves sloping to right are termed "blue" (after McCord and Adams, 1973). 

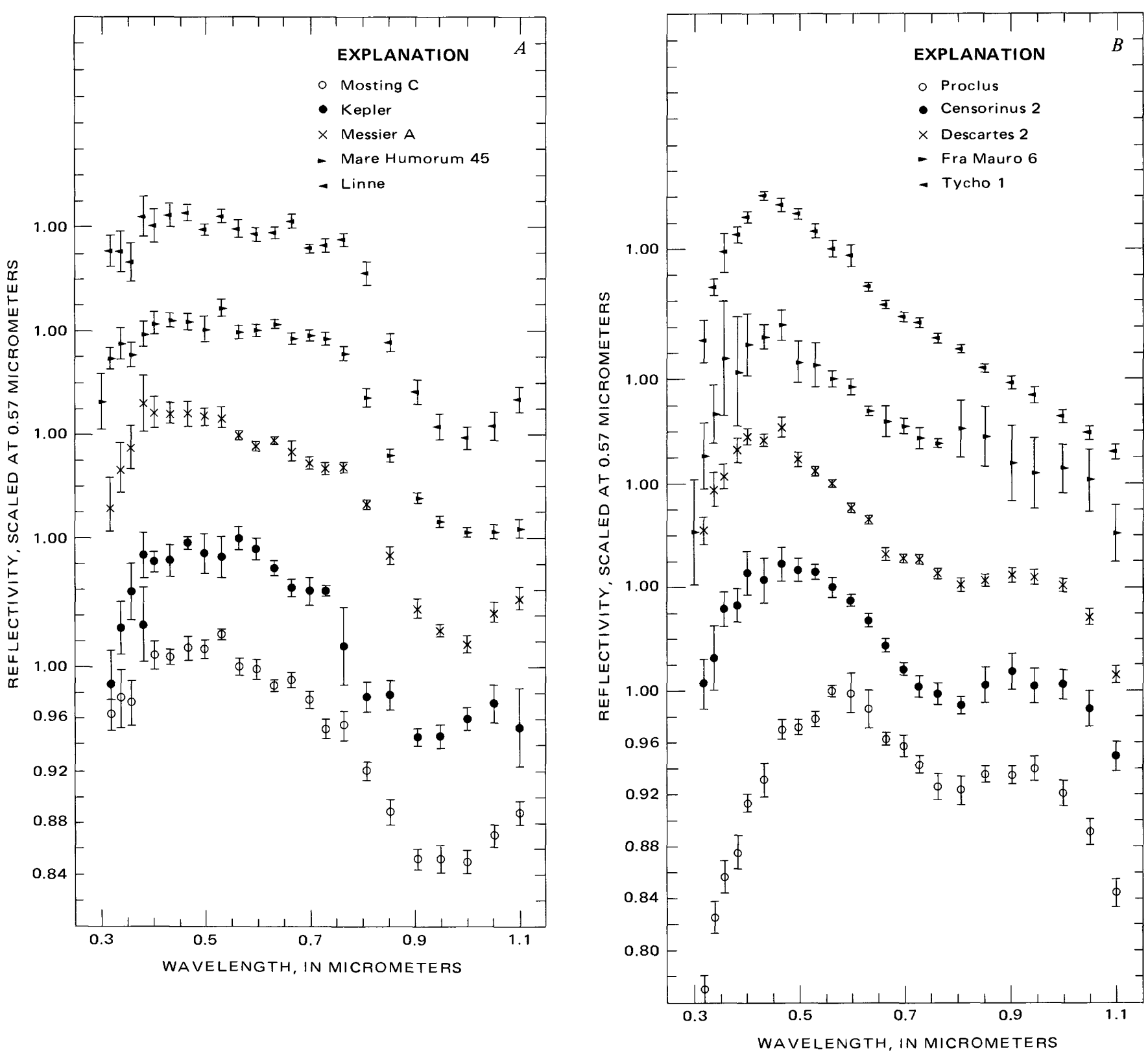

Figure 36.-Relative spectral reflectivity of bright craters in maria, $A$, and highlands, $B$. Both types of craters would appear to be relatively "blue" when measured with spectral bands near $1.0 \mu \mathrm{m}$ and $0.4 \mu \mathrm{m}$. Form of relative reflectances of craters in maria is distinct from those in highlands (after McCord and Adams, 1973). Vertical bars represent range of values within one sigma confidence level.

the film emulsions and a number of systematic errors innate to photographic spectral observations impaired results (Goetz and others, 1971).

Apollo 17 lunar module pilot Harrison Schmitt (1974) made direct orbital visual observations (near zero phase) of lunar color of both mare and upland in the Mare Serenitatis-Mare Crisium region. He reported unanticipated clarity of the color hues ranging from blue-tan to brown and orange to brown. Lucchitta and Schmitt (1974) discussed the presence of orange and red features observed and photographed in the Sulpicius Gallus Formation during the Apollo 17 mis- sion and found that these colored materials occurred only within the confines of the dark mantle deposits.

\section{SPECTRAL RESPONSE AND CHEMICAL COMPOSITION}

The importance of remote quantitative spectral reflectivity measurements lies in the uniqueness of visible and near-infrared diffuse spectra of pyroxenes and other common rock-forming minerals and the extent to which telescopic spectra can be used to determine mineralogy of the Moon and other planetary bodies. Laboratory studies of the reflection spectra of 
igneous rocks (Adams and Filice, 1967; Hunt and Salisbury, 1970; Adams and McCord, 1972; Adams, 1974; Charette and others, 1974) have shown that the diffuse reflectance spectra are related to mineralogy and chemical composition (fig. 37). Electron absorption bands, present in the diffuse spectra of most minerals and their powders, were found to be produced by transition elements, notably iron and titanium, in various valence and coordination states. These band frequencies are sensitive to distortion of transition metal d-orbital shells by neighboring atoms and because metal-oxygen distances differ for most minerals, the frequencies of the absorption bands can be used to identify minerals that exhibit them (McCord and

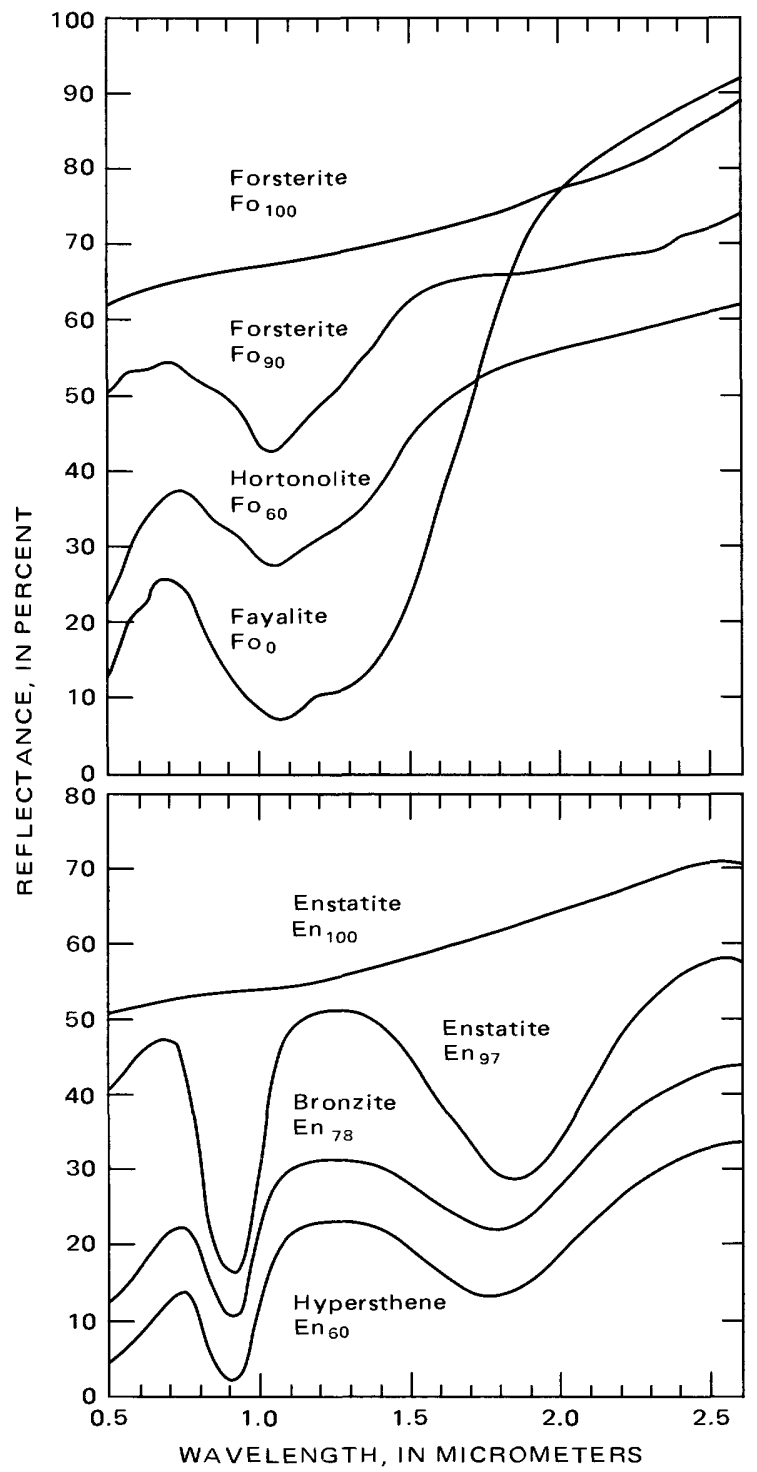

FIgURE 37.-Spectral reflectance of several common silicate minerals (after Adams, 1968.) Curves separated for clarity.
Johnson, 1970). The primary basis for the interpretation of absorption bands in the spectra of silicate rocks and minerals between $0.3 \mu \mathrm{m}$ and $2.5 \mu \mathrm{m}$ was developed through the application of crystal field theory to mineralogy (Burns, 1965; White and Keester, 1966). Transmission spectra of oriented single crystals, using polarized light, led to later refinements in band assignment (Bancroft and Burns, 1967; White and Keester, 1967; Burns, 1970).

Adams $(1967,1968)$ presented evidence that the 1.0 $\mu \mathrm{m}$ absorption band in telescopic spectra of the Moon may indicate the presence of basaltic material; more specifically, $\mathrm{Fe}^{+2}$ residing in olivine or an iron- and calcium-bearing pyroxene or both. The wavelength position of $\mathrm{Fe}^{+2}$ absorption in pyroxene near $0.95 \mu \mathrm{m}$ is a sensitive measure of the iron and calcium content of the pyroxene (Adams, 1974) (fig. 38). The symmetry of this band can be used to detect the presence of olivine.

The construction of high-resolution double-beam filter photometers in the years just before the Apollo missions (McCord, 1968; McCord and Johnson, 1969) permitted high-quality measurements $(0.1$ to 0.3 percent) of lunar spectral reflectivity $(0.4 \mu \mathrm{m}$ to $1.0 \mu \mathrm{m})$ for the first time (fig. 34). These spectra, normalized to a standard region in Mare Serenitatis (long $21.4^{\circ} \mathrm{E}$. lat $18.7^{\circ} \mathrm{N}$.), showed clear spectral differences between maria, highlands, and fresh crater materials (figs. 35, 36). These classes of spectrum shapes were later (McCord and others, 1972) referred to as spectral types. The studies by McCord (1968) and McCord and Johnson (1969) confirmed the earlier suggestion by Adams (1968) that absorption features evident on lunar spectral curves are similar to those found for

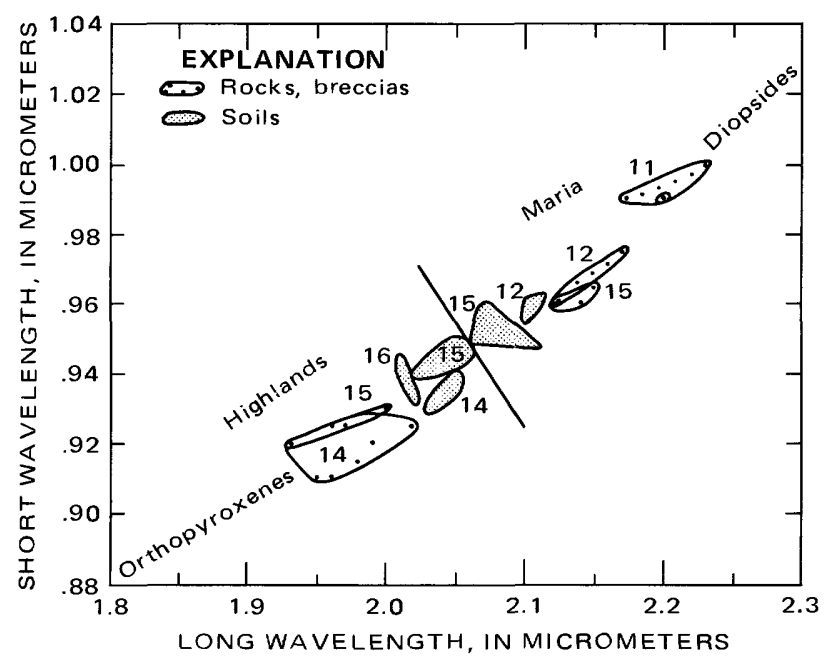

FIGURE 38.-Position of short-wavelength absorption band plotted against position of long-wavelength band for various Apollo samples (after McCord and Adams, 1973). Numbers indicate number of Apollo Mission. 
common terrestrial ferrosilicates within the infrared band (centered at $1.0 \mu \mathrm{m}$ ) corresponding to the $\mathrm{Fe}^{+2}$ absorption band found in the laboratory curves (Adams and Filice, 1967).

Spectral reflectivity analysis of the Apollo samples showed that the telescopic lunar spectral curves matched those of the actual lunar materials (fig. 34; McCord and Adams, 1973), thus strengthening the previous contention that remote compositional mapping was possible by the reflectivity technique (Adams and Jones, 1970; McCord and Johnson, 1970; Adams and McCord, 1970; Conel and Nash, 1970) (fig. 34). It was realized after return of the Apollo samples that the low abundance of trivalent ions, especially of $\mathrm{Fe}^{+3}$, allowed the $\mathrm{Fe}^{+2}$ bands to be well resolved in Earth-based lunar spectra (Adams and McCord, 1972).

Investigation of the relation between telescopic spectra and laboratory spectra of Apollo 11 and Apollo 12 samples suggested that the highlands spectra are consistent with an anorthositic gabbro composition, and that bright craters in both mare and highlands expose materials that are relatively crystalline compared with their backgrounds, which are richer in dark glass (Adams and McCord, 1972). Bright craters and rays in the maria were reported to darken in place by meteoritic impact-induced vitrification and mixing with the surrounding material, whereas highland bright craters and rays possibly darken through regional contamination by iron- and titanium-rich mare material. McCord and others (1972) suggested that the major compositional differences across the near side of the Moon are effectively restricted to the uplands, and that most other variations in the spectral curves are a function of the degree of aging within the major types of material.

Samples returned by Apollo have shown that the proportion of glassy agglutinates in the surface material increases with age as measured by particle tracks and with maturity as measured by the grain-size distribution. Similar conclusions were reached in laboratory studies of lunar surface materials which showed that agglutinates strongly affect the reflection spectrum by reducing the strength of absorption bands and increasing the slope of the curve continuum (Adams and McCord, 1973; Charette and Adams, 1975). The depth of the pyroxene absorption band for soils of equivalent maturity is affected by the amount of pyroxene present (Pieters and others, 1975). Rhodes and others (1975) reported that as the lunar soils become richer in agglutinates, they increase in ferromagnesian elements ( $\mathrm{Fe}, \mathrm{Ti}, \mathrm{Mn}$ ) and decrease in plagioclase components $(\mathrm{Al}, \mathrm{Ca})$, indicating fractionation of the major elements. The mechanism of this fractionation process is not well known at present and should be the subject of future laboratory research.

The discovery of abundant titanium, iron, and dark glass in the Apollo samples has encouraged several workers to consider the effect of these materials on laboratory and telescopic spectra. Investigations of the effect of titanium and iron on the color of natural lunar glass and synthetic glass showed that it was possible, by vitrification, to produce silicate materials with enhanced red reflectance (blue absorption) without the presence of ferric iron oxide (Conel, 1970). Conel considered the possible causes of coloration in the redbrown lunar glass to be (1) electronic transitions in $\mathrm{Ti}^{+3}$ ions, and possibly $\mathrm{Fe}^{+2}$, and (2) coloration arising from absorption by submicroscopic metallic spheres dispersed in the glass. Adams and McCord (1970) suggested that the strong ultraviolet and blue absorption in lunar glass is caused by the high content of iron and titanium that was derived from ilmenite through melting, probably by impact with the crystalline rock. They suggested that the decrease in reflectance from crystalline rock to glass-rich rock or soil can be explained by more efficient use of the available metal ions as light absorbers.

The existence of the thin, opaque, iron-rich coatings on the lunar soil grains poses a special difficulty in obtaining usable spectral reflectivity data. The thin grain coatings, besides being very light absorbent, would mask absorption bands characteristic of the uncoated lunar materials and thus could cause misinterpretation of remotely sensed spectral data and other geochemical observations (Cassidy and Hapke, 1975). The enrichment of heavier elements such as iron in the lunar grain coatings is attributed by Cassidy and Hapke to a fractionation of heavy and light elements during the coating process or processes. The fivefold enrichment of metallic iron in lunar fines over lunar basalts is taken then as evidence of such a fractionation process. Such a fractionation could also account for the observed isotopic fractionation in lunar soil, in which the heavier isotope always appears to be enriched relative to the lighter one (Epstein and Taylor, 1971; Clayton and others, 1974).

The existence of a limited variety of rock types (basalt and anorthositic-gabbro) on the lunar surface definitely simplifies the problem of geochemical mapping of the Moon by spectral reflectivity methods. On the other hand, the complex multicomponent system of opaque and nonopaque glass, iron-rich grain coatings, and abundant opaque oxides of iron and titanium tends to complicate matters by masking the introduction of diverse absorption effects. In the years since the landing of Apollo 17, these factors have received considerable attention (Nash and Conel, 1973; Pieters and others, 1974; Charette and others, 1974; Adams and 
others, 1974; Adams, 1974; Pieters and others, 1975).

Nash and Conel (1974) have shown that with construction of ternary plots of (a) reflectance at $0.55 \mu \mathrm{m}$, (b) band depth ${ }^{4}$ at $0.9 \mu \mathrm{m}$, and (c) red-to-blue ratios $(0.7 \mu \mathrm{m}-0.4 \mu \mathrm{m})$ with suitably calibrated curves, one can estimate mineral concentrations on a quantitative basis from spectral reflectivity data on unknown rock materials. They suggest that complicating factors to this technique include (1) the abundance of additional components not included in the calibration mixture such as olivine and glass and their degree of opaqueness; (2) the albedo and band depth variations of the component mineral species as functions of their particle size and bulk porosity of the mixture, and (3) the composition of the pyroxene, which affects the mean position and depth of the absorption band near $0.9 \mu \mathrm{m}$. Details on the effects of glasses and ilmenite on lunar and planetary spectral reflectances are summarized as follows (Nash and Conel, 1974):

Devitrified glass mixed with crystalline material reduces the albedo and overall spectral reflectance in the range $0.3-2.0 \mu \mathrm{m}$ and broadens, flattens and shifts absorption bands due to $\mathrm{Fe}^{+2}$, originally in pyroxene, plagioclase, and olivine (fig. 39).

Nonopaque glass causes relatively deep absorption band structures that distort or overwhelm bands from crystalline material. The albedo effect will be proportional to the glass content. The nonopaque glass will cause maximum band distortion but minimum darkening of material.

Opaque glass causes shallow absorption bands with little distortion effect on crystalline bands, but albedo depression will be large relative to glass content (similar to ilmenite effect).

Ilmenite has a diluting effect disproportionate to its concentration in mixtures with nonopaque minerals, tending to reduce strongly the overall albedo and the absorption band depth for the mixture (Nash and Conel, 1974).

Special applications of spectral reflectivity data to lunar geochemistry have included the detection of $\mathrm{TiO}_{2}$ content in bulk lunar soil (Charette and others, 1974; fig. 40). This technique makes use of the slope of lunar-sample-calibrated spectral curves between 0.402 and $0.564 \mu \mathrm{m}$ which is primarily affected by the iron and titanium absorptions in the lunar agglutinates and glasses. Finely disseminated metallic iron in the agglutinates also may have a major effect in this spectral region (Adams and McCord, 1973).

Before the Apollo 17 mission, the visible and nearinfrared spectrum of a $10-\mathrm{km}$-diameter area of dark mantling material $50 \mathrm{~km}$ northwest of the landing site

'Band depth is the fractional depth to bottom of band from assumed background being equal to straight line through shoulders of band (Nash and Conel. 1973).

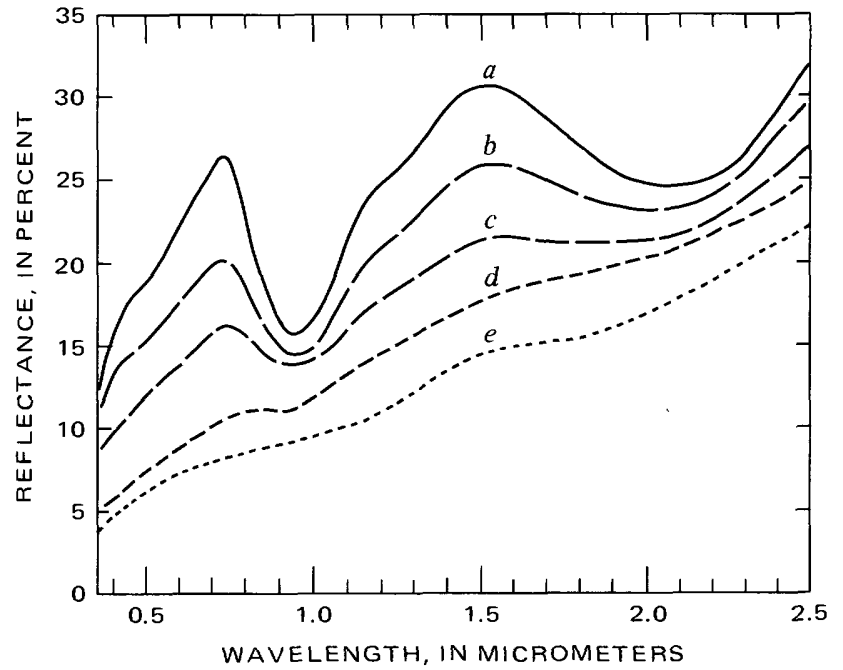

FigURE 39.-Spectral reflectivity of ( $a$ ) whole-rock powder, Apollo 12 sample 12063, 79; (b) rock powder plus 20 percent glass; (c) rock powder plus 55 percent glass; (d) Apollo 12 surface fines, sample 12070,111 , and $(e)$ whole-rock glass made from sample 12063,79 (after McCord and Adams, 1973).

was measured using a filter-photometer-equipped telescope (Pieters and others, 1973). The reflectance spectra for the dark mantle near the Apollo 17 site and at least four other lunar areas were found to be distinguishable from the spectra of nearly 200 other measured lunar areas. The lunar dark mantle areas have relative spectral reflectivity curves which are very blue in the visible region and relatively bright in the infrared (Pieters and others, 1973).

The spectral reflectances of samples of the orange glass and black soils from the Apollo 17 site were found to match Earth-based spectra of the dark mantle in the Taurus-Littrow region obtained by digital vidicon methods (Pieters and others, 1974; Adams and others, 1974). The dark mantle appears to be well developed northwest of the actual landing site but is much diluted in the immediate landing site region by mature mare regolith, probably by secondary crater materials (Lucchitta, 1977).

The orange glass spectrum, characteristic of an ironand titanium-rich glass, has a broad absorption band feature near $1.1 \mu \mathrm{m}$ due to $\mathrm{Fe}^{+2}$ on octahedral lattice sites and a weak band near $0.5 \mu \mathrm{m}$ arising from $\mathrm{Ti}^{+3}$. The similarity of the Apollo 17 orange glass (74220) and black soil (74001) is consistent with the interpretation that the black glass is the devitrified equivalent of the orange glass and that both materials probably originated in a volcanic fire fountain (Heiken and McKay, 1974). The green glass spheres found at the Apollo 15 site are very similar in morphology to that of the orange glass but are more ultramafic and have a unique spectra (Adams and others, 1974). 


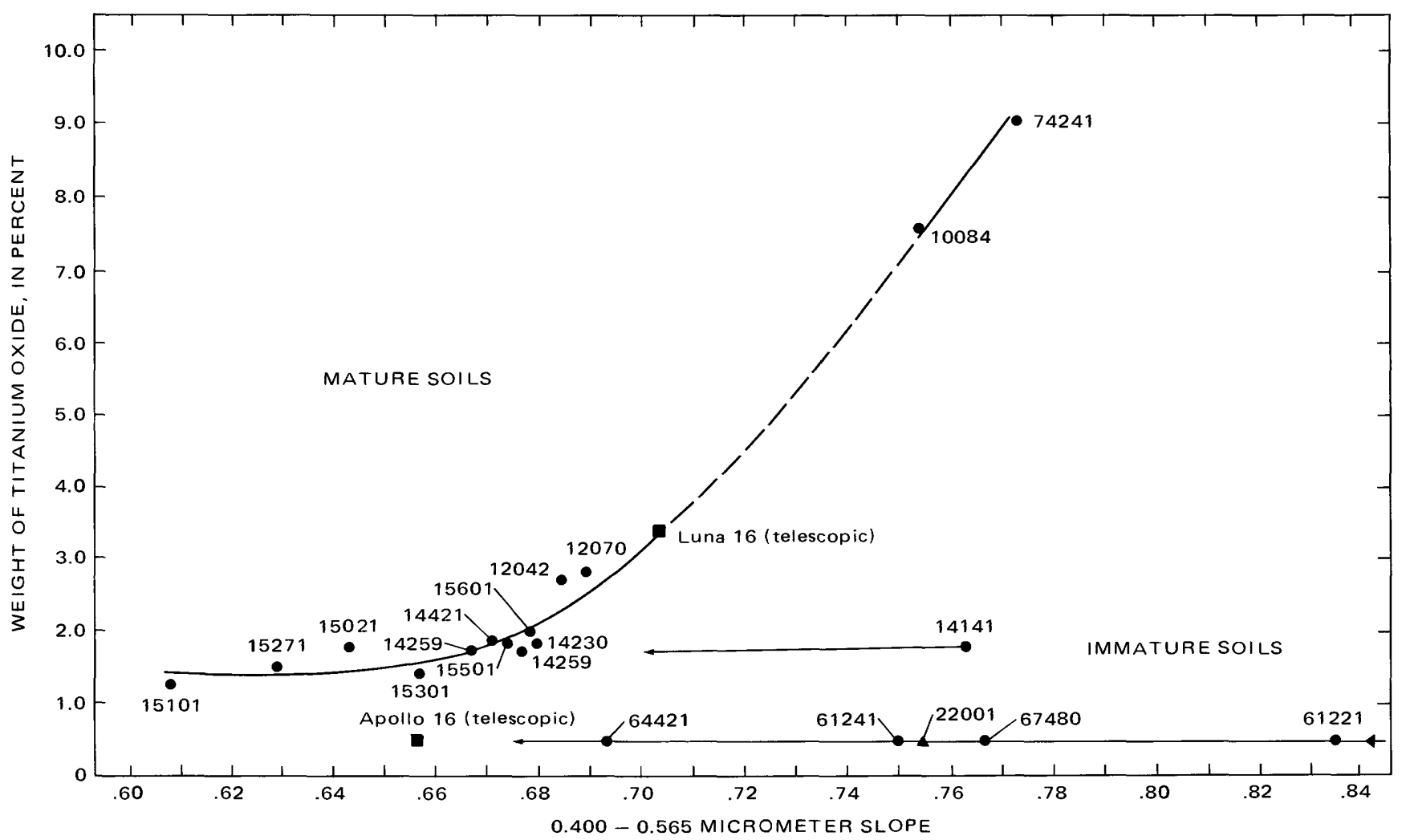

FIGURE 40.-Percentage of titanium oxide in the bulk lunar soils as a function of $0.400 \mu \mathrm{m}-0.565 \mu \mathrm{m}$ slope. Arrows indicate probable evolution of immature soils into mature soils as a function of agglutinate content and hence of time (after Charette and others, 1974).

Mare Serenitatis, Mare Humorum, and the Aristarchus plateau region have been subjects of recent investigations utilizing remotely sensed data such as spectral reflectivity, photographic color differences, Earth-based radar reflectivity $(3.8-\mathrm{cm}$ and $70-\mathrm{cm}$ wavelengths), Apollo bistatic-radar echoes, photogeologic mapping, and infrared eclipse temperature data (Thompson and others, 1973; Pieters and others, 1975; Zisk and others, 1977). The multispectral approach in defining the nature and extent of geologic and geochemical surface units is well developed in these studies. The Aristarchus plateau region is somewhat enigmatic because of its unusual response: It has a low albedo combined with low infrared eclipse temperatures, an extremely red color, and low reflectivities to $3.8-\mathrm{cm}$ and $70-\mathrm{cm}$ Earth-based radar. Zisk and others (1977) attribute these responses to the presence of a titanium-rich material (at least $10 \mathrm{~m}$ deep) that is relatively rock-free, and probably relatively large amounts of orange glass exposed at the surface, similar to that found at the Apollo 17 site.

\section{COMMENTS}

The potential is high for extending high-resolution (areas smaller than $10 \mathrm{~km}$ diameter) spectral reflectiv- ity mapping to the entire Earth-facing hemisphere of the Moon. This remote-sensing technique is perhaps unique in that the spectral definition of regional geologic units on the lunar surface can be done from Earth, unlike other geochemically related measurements such as X-ray fluorescence, gamma-ray spectrometry, or alpha-particle spectrometry that require lunar orbital platforms.

There is an obvious need, however, for more extensive laboratory research to support the conclusions made from the spectral reflectance data. Areas of research should include (1) further definition of the electron charge transfers involving titanium and iron; (2) continued investigation into the effects of mixtures of lunar materials on spectral reflectance; and (3) categorization and quantification of spectral signatures resulting from masking and shifting of absorption bands by opaque grain coatings and various types of lunar glass materials.

Future geologic applications of Earth-based lunar spectral reflectivity methods should include (1) recognition and areal mapping of spectrally unique lunar materials such as crystalline rocks exposed by young craters; dark mantle deposits containing green, orange, or black glass; (2) detailed investigations of various light plains deposits with regard to possible 
variations in chemical, mineral, or glass components (3) detection of mineralogical, chemical and glass variations radially away from craters of diverse ages for the purpose of recognizing stratigraphically unique materials excavated by the crater; (4) correlation of Earth-based radar reflectivity anomalies with unique spectral reflectivity signatures such as that of the Imbrium flows (Schaber and others, 1975); (5) analysis of extremely red lunar features such as the Gruithuisen domes (lat $35^{\circ} \mathrm{N}$., long $40^{\circ} \mathrm{W}$.); and (6) continued spectral mapping of the lunar maria surface units.

Earth-based spectral measurements of the lunar surface will provide the only significant new data on lunar chemistry in the near future until they are bolstered by high-resolution instruments aboard future spacecraft.

\section{REFLECTION OF RADAR WAVES FROM EARTH-BASED STATIONS}

\section{By Gerald G. Schaber and H. J. Moore}

Starting with the earliest lunar radio-echoes produced in 1946 (DeWitt and Stodola, 1949), the Moon has been the subject of extensive studies by Earthbased radar utilizing a wide range of wavelengths. Excellent summaries of the history of lunar radar observations and early interpretations are given by Evans (1962) and Evans and Hagfors (1971).

It was early recognized that the Moon behaved like a specular reflector in a small region centered at the center of the visible disk but exhibited rapid fading of echoes due to limb dark scattering away from this region. Early analyses of the subearth specular returns from the Moon were extremely successful in predicting the lunar radius, relative dielectric constant, and roughness of the center of the lunar disk (Evans and Pettengill, 1963). These predictions were subsequently confirmed by Surveyor and Apollo data.

The echoes from the Moon could not be completely described as reflections from a gently undulating surface. Instead, two components were postulated: a quasi-specular echo arising from the gently undulating surface, and a diffuse echo arising from scattering by small-scale roughness. These components of the lunar radar echoes became evident by measuring echo polarizations. The strongest echo component is called the polarized component and has the polarization expected for a specular reflector. The second, weaker component is called the depolarized component and is polarized in the opposite sense. In theory, the quasispecular echo comes from a small region of the center of the lunar disk and makes no contribution to the depolarized echo, whereas diffuse scattering originating from practically all the lunar disk contributes to the polarized echo and is the chief mechanism producing the depolarized echoes (Thompson and others, 1970; Thompson and Zisk, 1972). Attention will be given primarily to the depolarized echoes because they are a measure of fine-scale roughness and other properties. Depolarized echoes originate from most of the Earthfacing regions of the Moon.

Diffuse scattering is generally thought to be caused by single and multiple scattering of radar echoes by rocks on the surface and within the upper few meters of the regolith (Hagfors, 1967; Burns, 1969; Pollack and Whitehill, 1972). This interpretation of the diffuse component was strengthened by the discovery of anomalously enhanced, incoherent radar echoes from the region of the crater Tycho (Pettengill and Thompson, 1968). Other factors, which will be discussed below, are also involved.

\section{RADAR MAPS}

Maps of back-scattered polarized and depolarized echoes from the Moon have been made for wavelengths of $3.8 \mathrm{~cm}$ (Zisk and others, 1974), $23 \mathrm{~cm}$ (Hagfors and others, 1968), $70 \mathrm{~cm}$ (Thompson, 1974; Thompson and Dyce, 1966), $75 \mathrm{~cm}$ (Ponsonby and others, 1972), 185 $\mathrm{cm}$ (Ponsonby and others, 1972) and $7.5 \mathrm{~m}$ (Thompson, 1970). The maps are prepared using echo delay and doppler as a means of locating the scattering regions on the lunar disk (Thompson, 1974; Thompson and Dyce, 1966; Lincoln Laboratory, 1968; Pettengill and others, 1974). With this technique lunar radar maps have been prepared with resolution cells about $2 \times 2 \mathrm{~km}$ and $10 \times 10 \mathrm{~km}$ for $3.8-\mathrm{cm}$ and $70-\mathrm{cm}$ wavelengths, respectively. Much lower resolution radar maps have been made for other wavelengths. Geologic investigations of lunar backscatter have been almost exclusively concerned with the $3.8 \mathrm{~cm}$ (fig. 41) and $70 \mathrm{~cm}$ (fig. 42) delay-doppler radar maps owing to their superior resolution.

\section{ECHOES AND LUNAR FEATURES}

In a general sense, there are three kinds of depolarized echoes: (1) average ones, (2) positive anomalies or echoes that are much stronger than average, and (3) negative anomalies or echoes that are much weaker than average. Depolarized echoes from the highlands are generally stronger than those from the maria, but this is clearly not the case everywhere. The general tendencies, as well as exceptions, are shown in figure 43 where polarized echoes have been plotted against average depolarized echoes from selected terrain types with $3.8-\mathrm{cm}$ and $70-\mathrm{cm}$ radar along the Apollo bistatic-radar subspecular tracks (figs. 44, 45). Superimposed on the average backscatter of both the highlands and the maria are positive 
anomalies, generally corresponding to craters such as Euler (fig. 45; $29^{\circ}$ W., Apollo 15), Theophilus (fig. 44; $26^{\circ}$ E., Apollo 14), Lansberg (fig. 44; $26.5^{\circ}$ W., Apollo 14 ), and some very small craters (near $48^{\circ} \mathrm{W}$. and $52^{\circ}$ W., Apollo 14; fig. 44) not visible in the accompanying illustrations. A negative anomaly is represented by dark mare material at the edge of Mare Serenitatis (fig. 45; $27^{\circ}$ E., Apollo 15).

The variables producing the depolarized echoes have never been completely separated in a suitable experiment. In radar theory, there are five factors that may cause a positive anomalous depolarized echo: (1) an increase in the number of rocks wavelength size and larger in the upper meter or so of the regolith, (2) an increase in the dielectric constant of a normally rough or blocky surface, (3) an increase in the electromagnetic absorption in the upper meter or so of the regolith, (4) to a variable extent, a slope that tilts the surface toward the Earth-based radar, and (5) an increase in fine-scale roughness. All the factors may contribute to the resulting echoes either singly or in various combinations, and there is evidence for each.

Evidence for 3.8- and 70-cm depolarized echo enhancements due to an increase in concentrations of blocks has been found by correlating strong echoes with high infrared eclipse temperatures and visually blocky surfaces shown in high-resolution images and photographs (Thompson and others, 1974; Zisk and Moore, 1972). Depolarized echoes from craters decrease with (1) increasing age of the craters, (2) decreasing concentrations of resolvable blocks seen in images, and (3) decrease in infrared eclipse temperatures, which also decrease with the decrease in concentrations of blocks. These results are also consistent with an increase in the dielectric constant of the surface. On the other hand, relative dielectric constants for the lunar highlands (about 2.8) and maria (about 3.2) estimated during the Apollo and Explorer 35 bistatic-radar experiments (Tyler, 1968; Howard and Tyler, 1972b) are reversed in magnitude compared to the expected values from the magnitudes of highland and mare depolarized echoes, a finding in conflict with the second factor (increase of the dielectric constant of a normally rough or blocky surface) if the uplands and maria are, in fact, normally rough and blocky. Evidence for echo enhancements due to slopes tilted toward the Earthbased radar is clear because Earth-facing slopes within craters have larger depolarized echoes than slopes facing in the opposite or perpendicular directions (Moore and others, 1975; Moore and Zisk, 1973). This may be seen in figures 41 and 42 as well as figures 44 and 45 , where the strong depolarized echo peaks from the crater Lansberg (26.5 W., Apollo 14$)$ and Euler $\left(29^{\circ}\right.$ W., Apollo 15) are displaced to the west side of the craters.
A similar conclusion is reached when echoes from the flanks of craters such as Delisle and Diophantus (Moore and others, 1975) are considered. Here, slopes of crater flanks facing the Earth have stronger depolarized echoes than those facing the opposite direction. Relatively strong echoes from the highlands, in contrast with the maria, are consistent with surface tilt because the bistatic-radar experiment (Howard and Tyler, 1972a, 1972b) and photographs (Moore and others, 1975, 1976) show that the highlands are significantly rougher at scale lengths of 30 to $250 \mathrm{~m}$ than the maria. Highlands could therefore have a relatively large fraction of area of Earth-facing slopes as viewed by the radar. Evidence for echo enhancements due to small-scale roughness is found at the Apollo 17 landing site, where smooth-looking level surfaces have weaker depolarized echoes than rougher-looking level surfaces (Moore and Zisk, 1973).

The notion that the weaker echoes result from electromagnetic absorption has received considerable attention. Pollack and Whitehill (1972), in developing a physical model of lunar radar multiple scattering, suggested that the most important factor affecting the differences in radar back scattering between mare and highlands may be the radar absorption length in rocks and soil within the two regions, which is possibly related to the ilmenite content. The absorption length of a material is defined as the distance over which an electromagnetic wave must travel in the material before being attenuated to $1 / e$ ( 36.8 percent) of its initial intensity. A decrease of absorption length for a normally rough and blocky regolith reduces the amount of backscattered depolarized echoes because fewer blocks are encountered by the shallow penetrating radar signals than by the deeply penetrating radar signals. Pollack and Whitehill (1972) suggest than an increase in absorption length of a factor of only 3.5 would be required to produce a change of a factor of 5 in the depolarized lunar radar return observed between maria and highlands. Schaber and others $(1970,1975)$ have reported that the surface of Mare Imbrium contains some of the most distinct red-blue color boundaries and lowest depolarized $70-\mathrm{cm}$ radar backscatter variations on the near side of the Moon. The weakest levels (less than 50 percent of the average power returned from the basin floor) of both $3.8-\mathrm{cm}$ and $70-\mathrm{cm}$ backscatter within Imbrium are confined to Imbrian and Eratosthenian mare surfaces of the blue spectral type. Variations in radar return are well correlated with individually mapped lava flow units of youngest Eratosthenian age whose source was traced to a fissure vent in the southwestern edge of the basin (Schaber, 1973). The frequency distribution of the $70-\mathrm{cm}$ polarized and depolarized radar echoes for five mare 

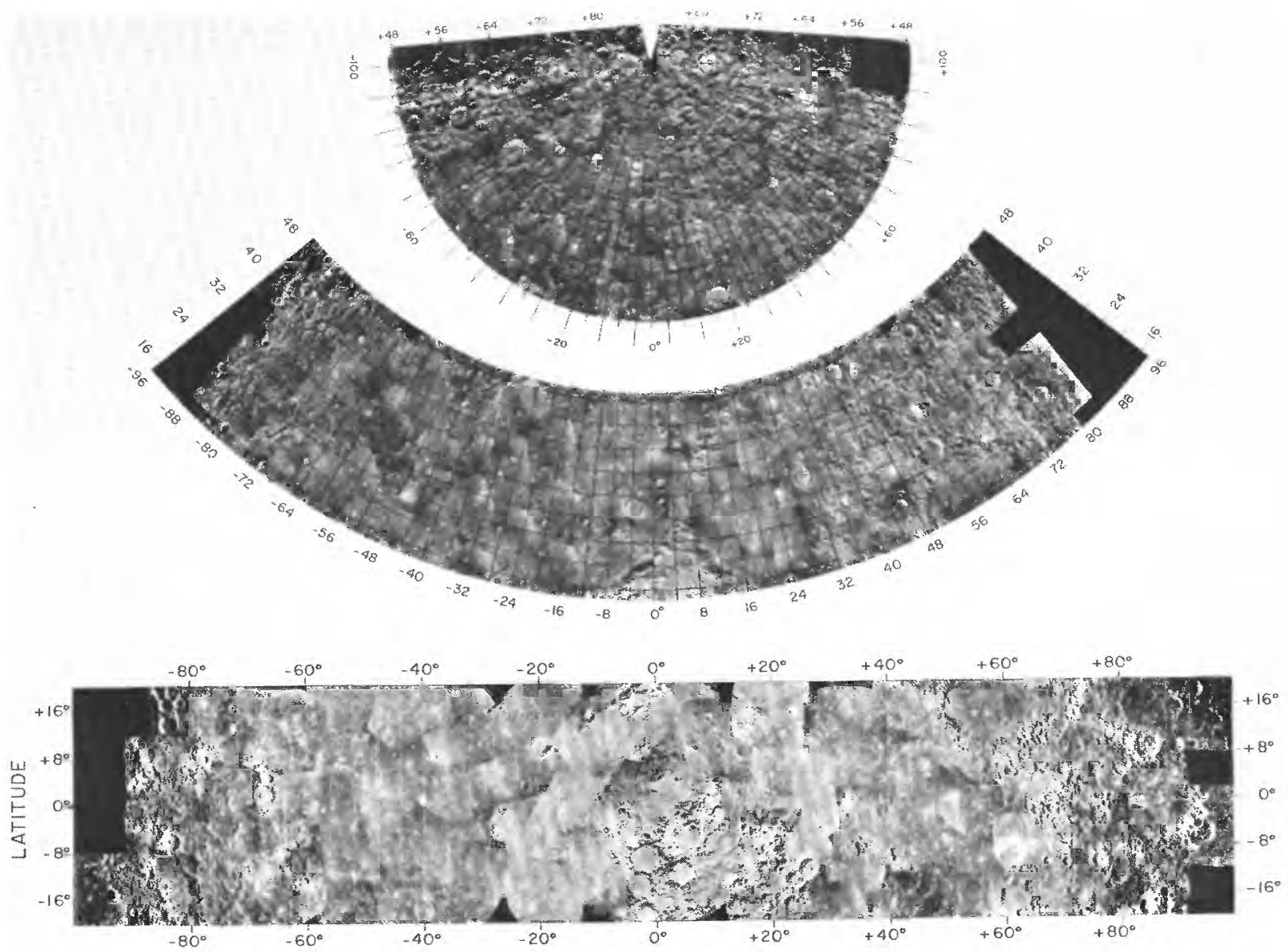

LONGITUDE

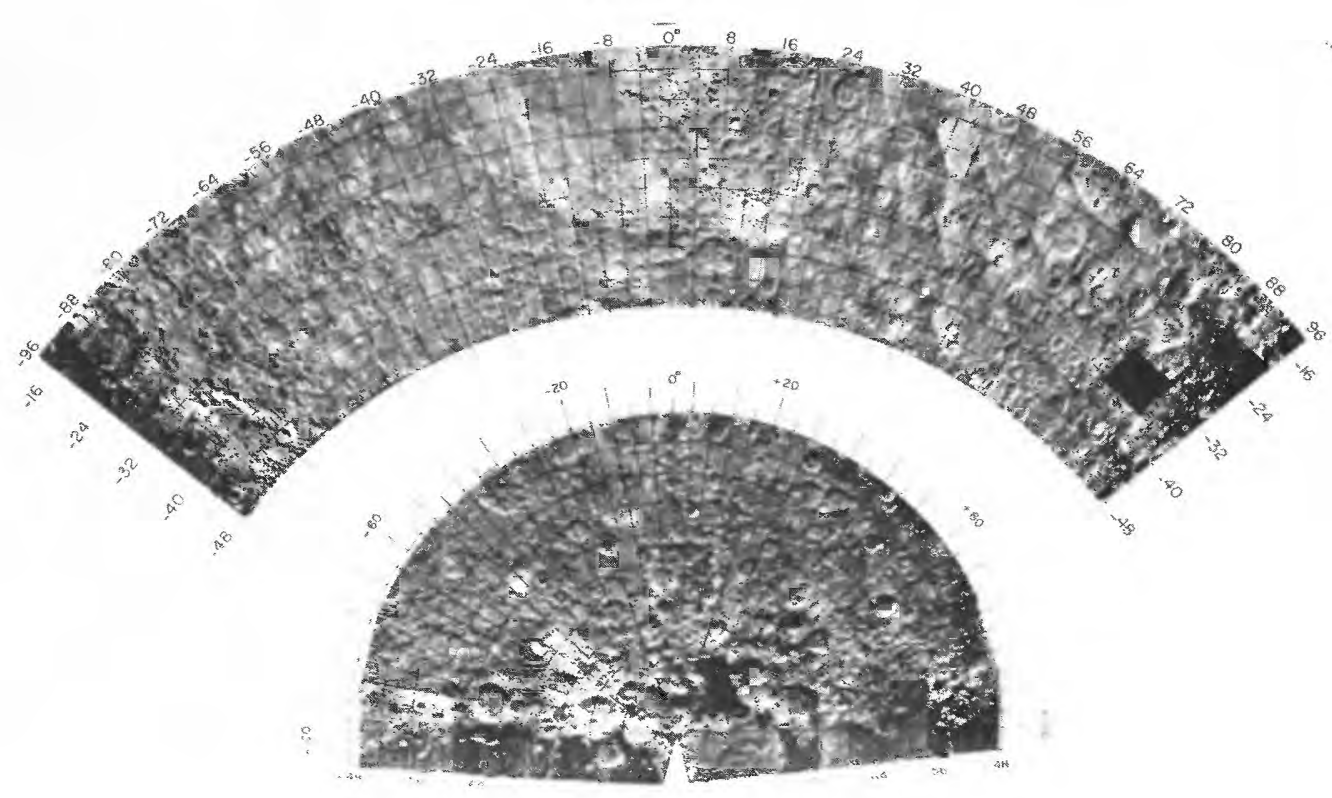

Figure 41--Radar maps of the Moon at 3.8-cm wavelength. One degree of 

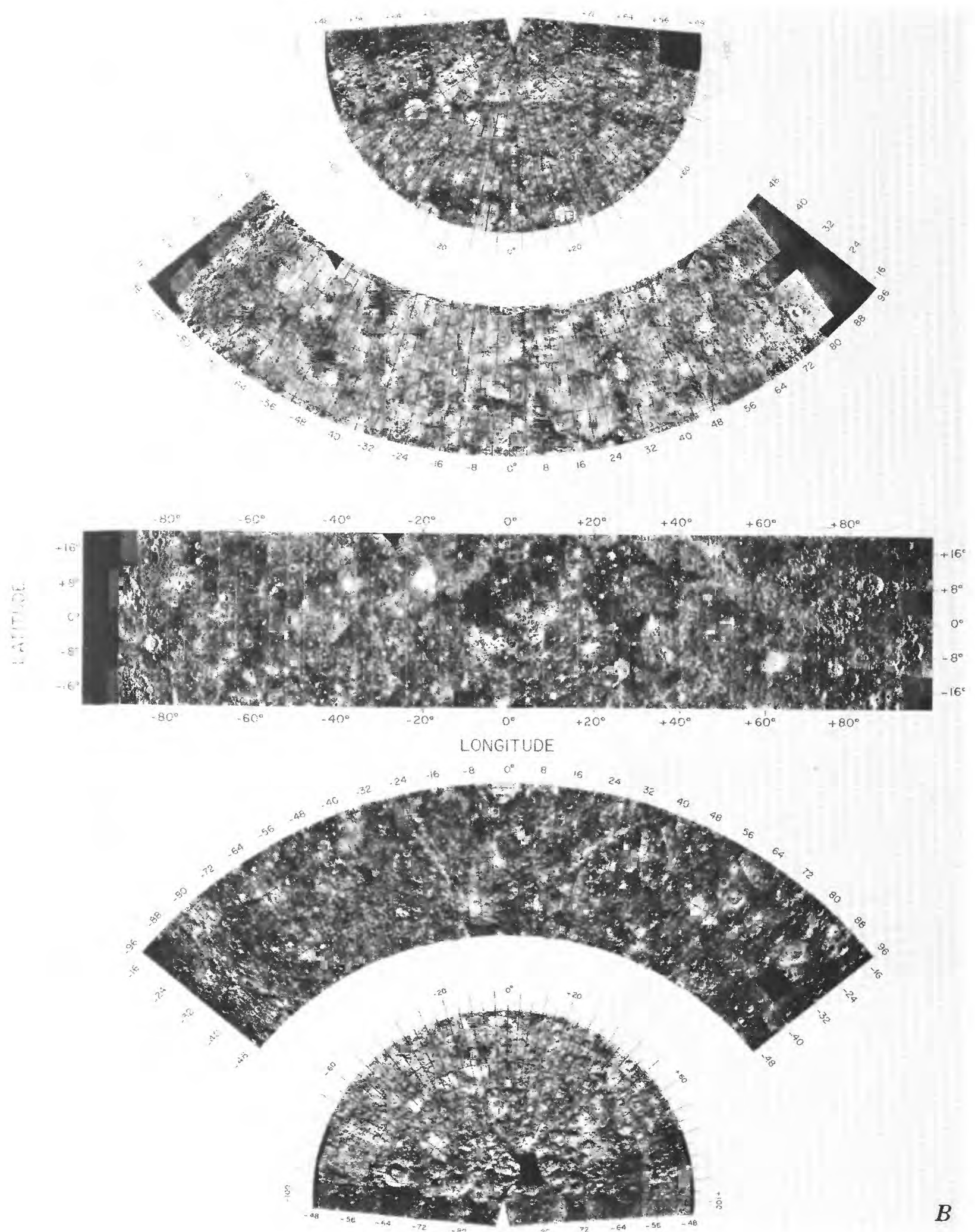

$A$, polarized echoes. $B$, depolarized echoes (courtesy of S. H. Zisk). latitude is $30 \mathrm{~km}$. 


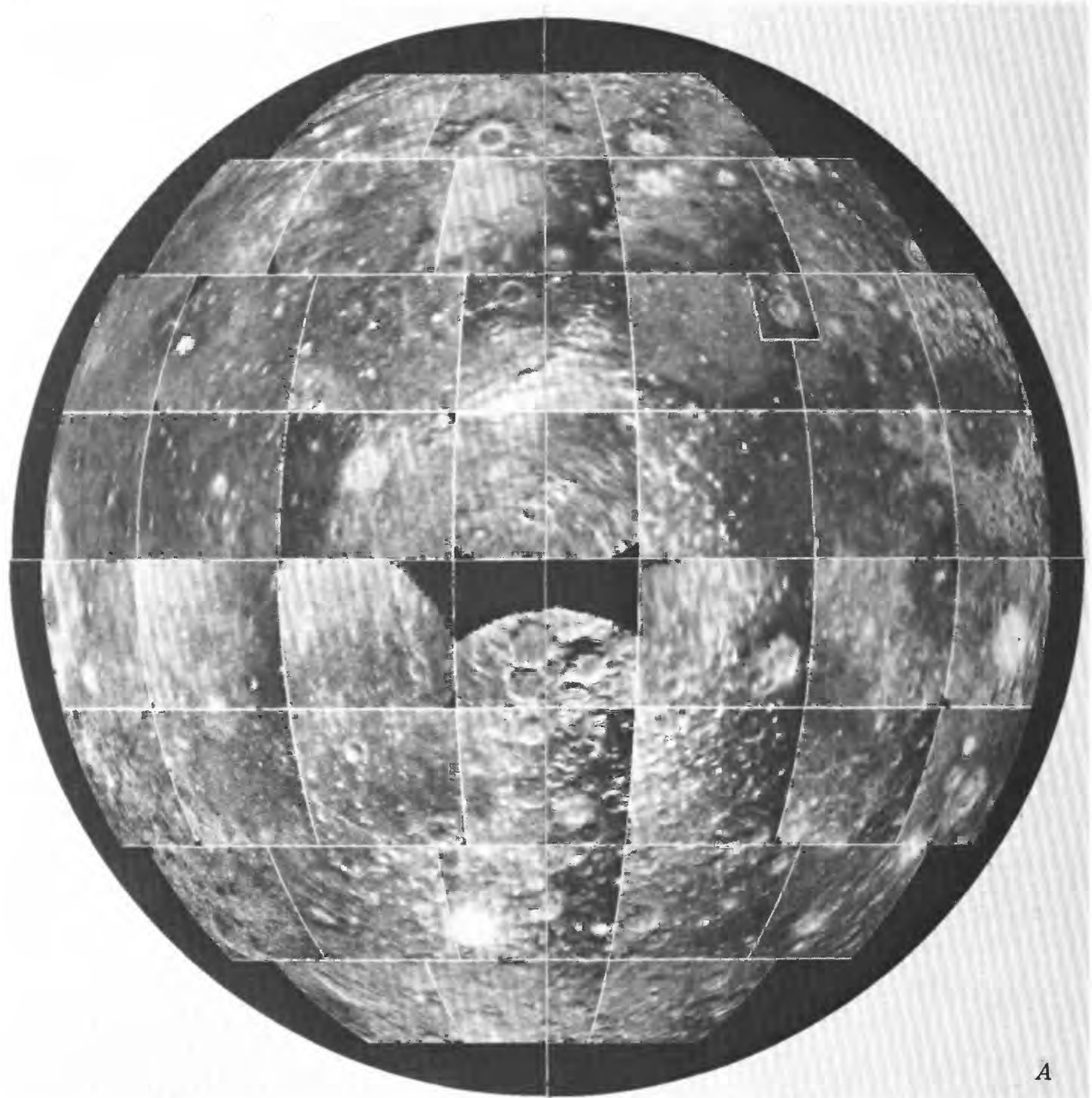

Figure 42.- Radar maps of the Moon at 70-cm wavelength. $A$, polarized of Moon is

surfaces (one red, four blue) within the Imbrium basin indicate that echo strengths decrease generally from the earliest Imbrian surfaces to the youngest Erathosthenian surfaces. This effect within Mare Imbrium was attributed to absorption resulting from increased amounts of the mineral ilmenite and other anomalies associated with deposition of the blue mare materials. Although somewhat speculative, it has been suggested that $70-\mathrm{cm}$ depolarized radar echo strengths vary inversely with $\mathrm{TiO}_{2}$ content and that the radar maps can be utilized for geochemical mapping of the maria in the same manner as spectral reflectivity (Charette and others, 1974).

A second type of lunar surface that returns very weak radar signals are the so-called lunar "black spots" (see for example, Pieters and others, 1973). The 


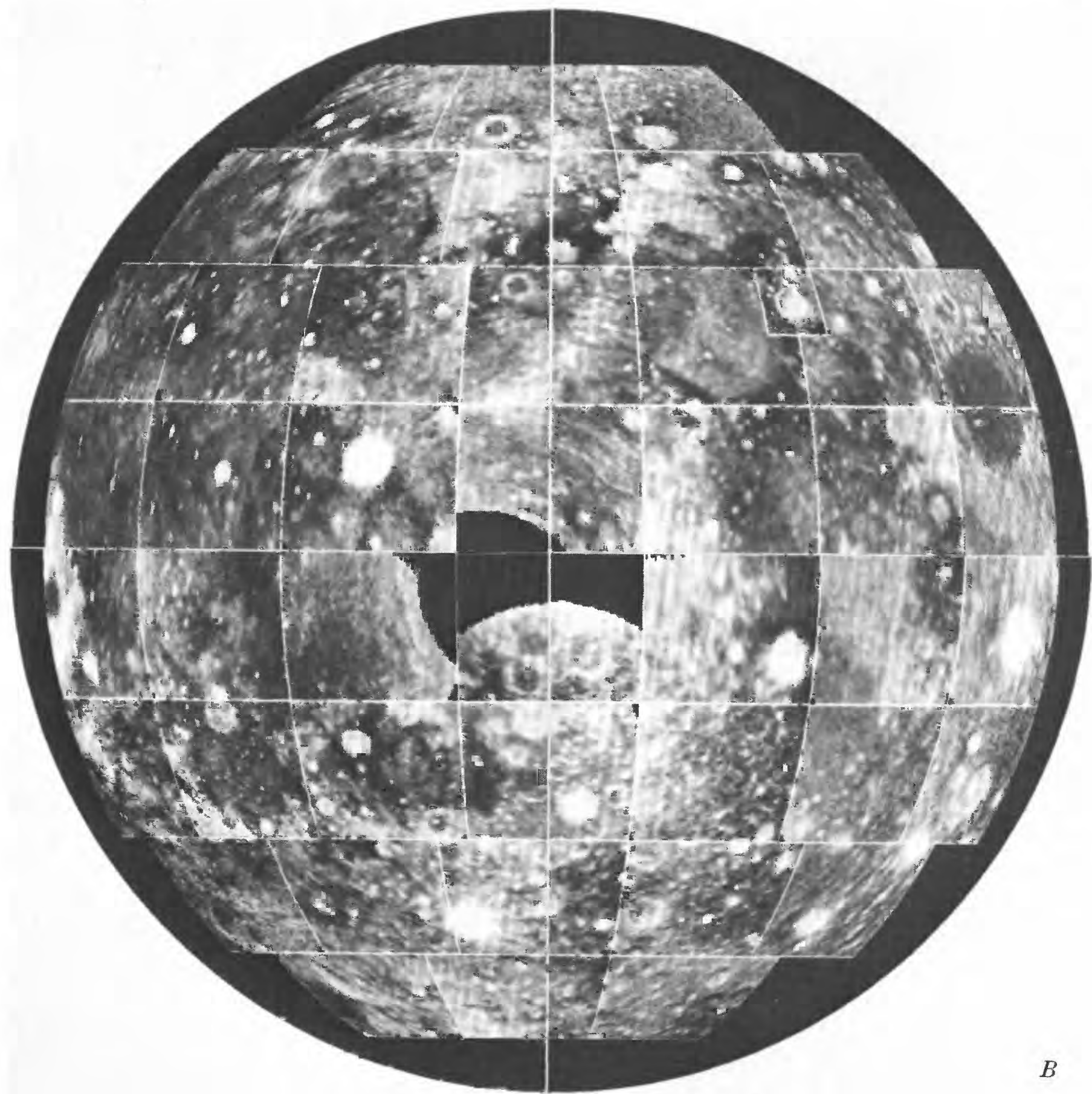

echoes. $B$, depolarized echoes (courtesy of T. W. Thompson). Diameter $3,476 \mathrm{~km}$.

black spots, which include the Apollo 17 site, have spectral reflectances and radar reflectivities indicating relatively rock free surfaces, a very low ratio of crystalline to amorphous (glass) material, and high concentrations of iron and titanium in the amorphous phase. Data collected during the Apollo 17 mission verified the high iron ( 18 percent $\mathrm{FeO}$ in basalt; 15 percent $\mathrm{FeO}$ in soil) and titanium (13 percent $\mathrm{TiO}_{2}$ in basalt; 8 per- cent $\mathrm{TiO}_{2}$ in soil) and a reduced population of surface rocks relative to other landing sites on maria. The regolith at the Apollo 17 site consisted primarily of powdered high-titanium subfloor basalt material (42-67 percent) with subordinate amounts of high-titanium orange glass and its devitrified equivalent (black glass beads) (12-22 percent), and aluminous massif components (21-36 percent) (Rhodes and others, 1974). 

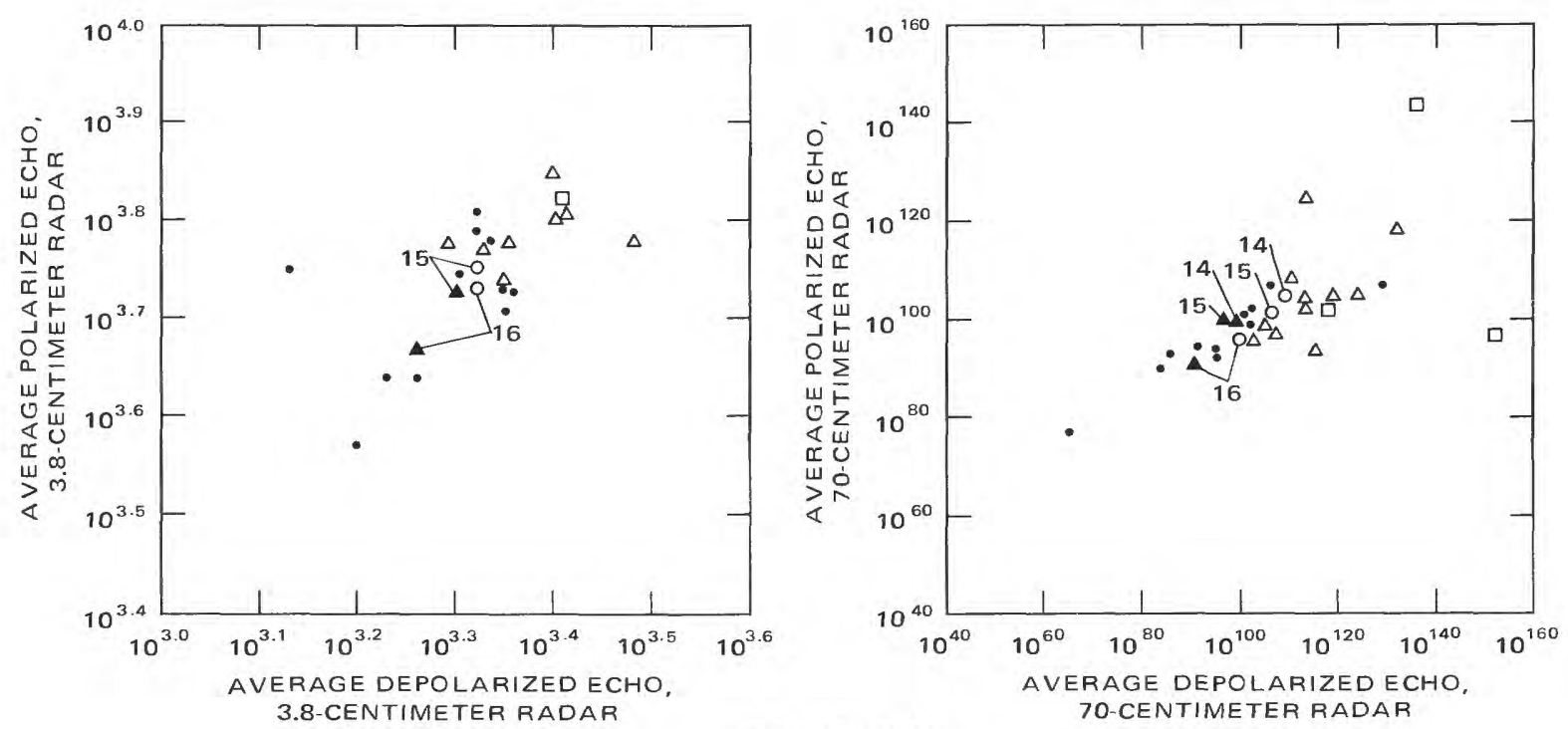

\section{EXPLANATION}

- Average echoes along bistatic-radar tracks

of Apollo 14, 15, and 16

- Average echoes from maria

- Average echoes from selected mare areas

$\triangle \quad$ Average echoes from selected highland areas

$\square \quad$ Average echoes chiefly from large craters

Figure 43.-Polarized and depolarized echoes for 3.8-cm radar along the Apollo 15 and 16 bistatic-radar tracks and 70-cm radar along Apollo 14, 15, and 16 bistatic-radar tracks.

Another lunar black spot, the Aristarchus plateau in Oceanus Procellarum (lat $25^{\circ} \mathrm{N}$., long $50^{\circ} \mathrm{W}$.), has low radar reflectivity, low albedo, a very reddish color, and low infrared eclipse temperatures; this combination of characteristics is consistent with large amounts of titanium and rather large amounts of orange glass (Zisk and others, 1977).

\section{LABORATORY STUDIES}

Measurements of electrical properties of Earth materials and lunar samples illustrate some of the factors that can affect radar echoes. Absorption lengths in powders tend to decrease with increasing density because both the loss tangent and permittivity increase with density (Campbell and Ulrich, 1969). In a large variety of rock types, there is little or no correlation of absorption length with silica content, and for powders there is no correlation of permitivity, loss tangent, and absorption length with chemical composition (Campbell and Ulrich, 1969). Measurements of electrical properties at $10 \mathrm{MHz}$ on samples returned by Apollo 14, 16, and 17 are consistent with the postulate that weak echoes result from decreased absorption due to high titanium content. Apollo 17 soils have a higher density (1.3 times), a larger dielectric constant (1.3 times), and a larger loss tangent (3.3 times) than those of Apollo 14 and 16 (Sill, W. R., oral commun., 1974).
The result is that the absorption length of the hightitanium regolith of Apollo 17 (8 percent $\mathrm{TiO}_{2}$ ) should be smaller than that of the low-titanium regolith of Apollo 14 (2 percent) and 16 (1 percent). If the regolith in question is normally rough and blocky, weaker echoes should result because of the smaller penetration of the radar in the titanium-rich regolith (Burns, 1969).

\section{DISCLSSION}

Geological observations, theory, and laboratory studies show that at least five variables can affect the depolarized echo strengths from the Moon: (1) variations in concentrations of rocks and blocks in the upper regolith, (2) variations in dielectric constants of normally rough and blocky surfaces, (3) changes in electromagnetic absorption, (4) directions of large-scale surface tilts, and (5) changes in small-scale roughness. In many cases, photographic evidence indicates a more predominant role for different variables than do laboratory studies on returned lunar samples. The degree to which these variables can be separated from one another without the benefit of photographs or samples of the backscattering area is unclear.

Radar maps, despite an inability to separate the variables, can be important in characterizing planetary surfaces and mapping variations of planetary surfaces. Lunar experience would greatly enhance the value of 
แั

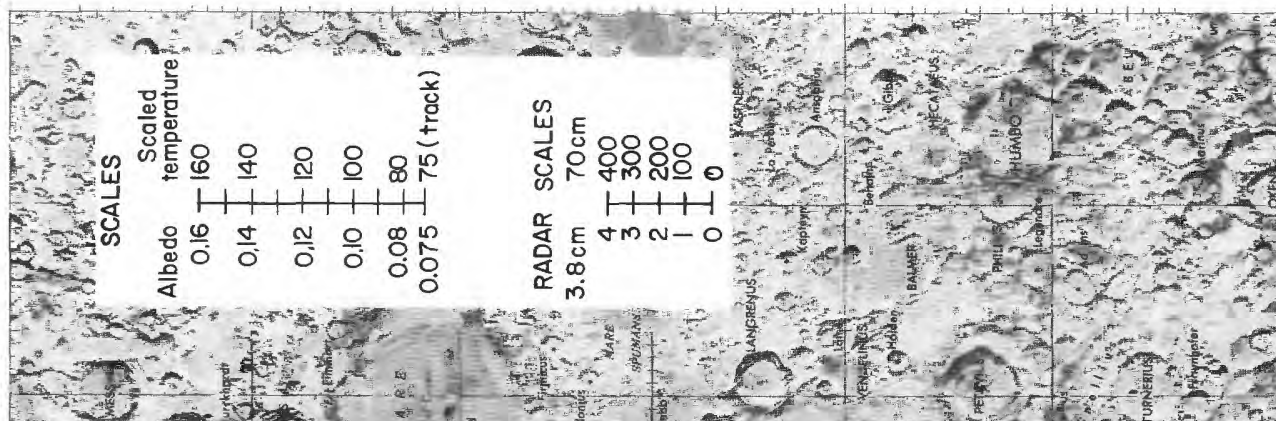

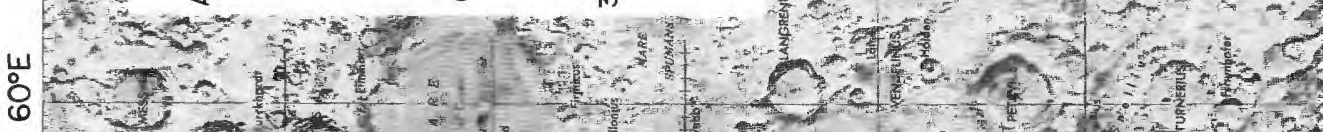

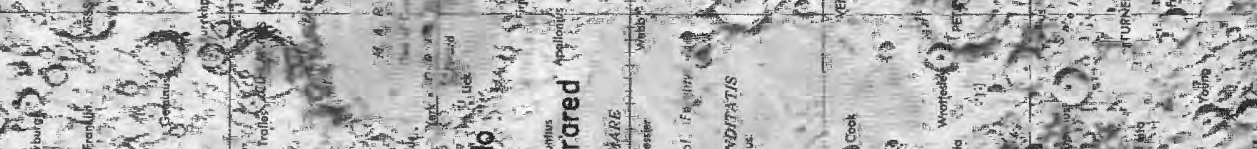

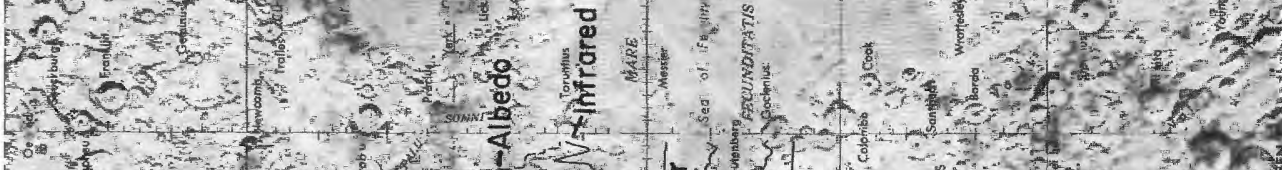

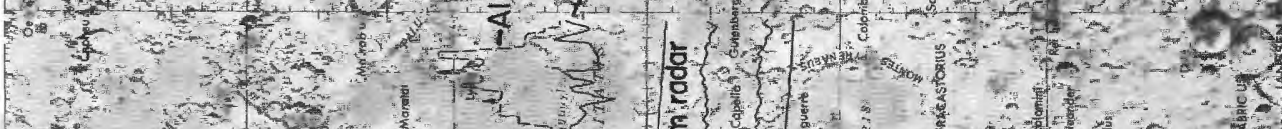

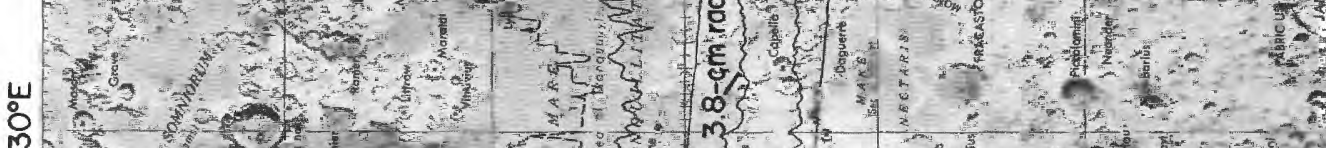

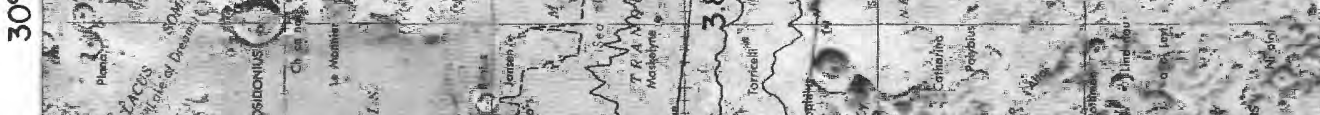

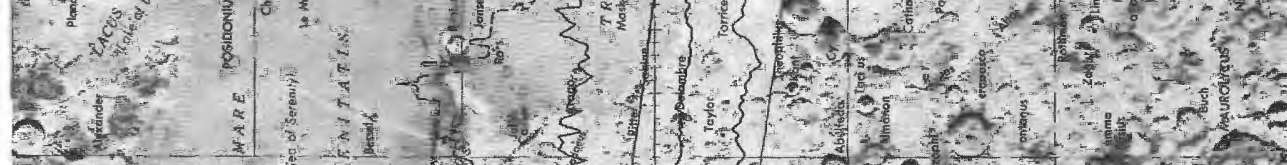

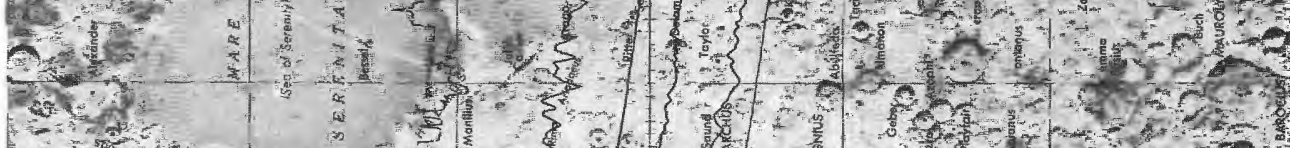

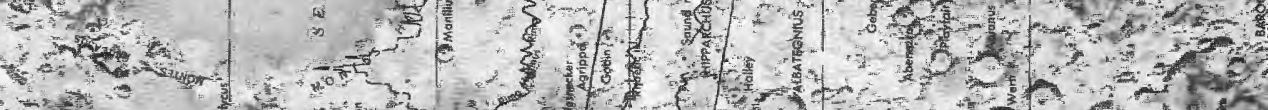

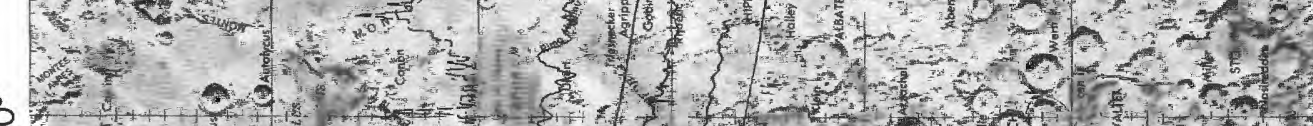

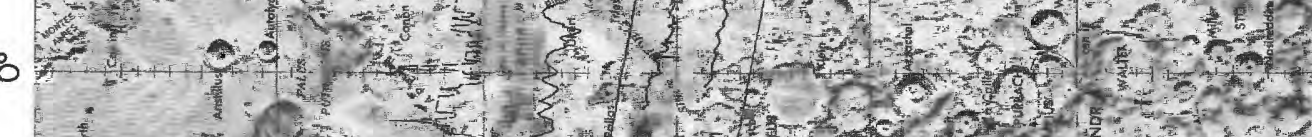

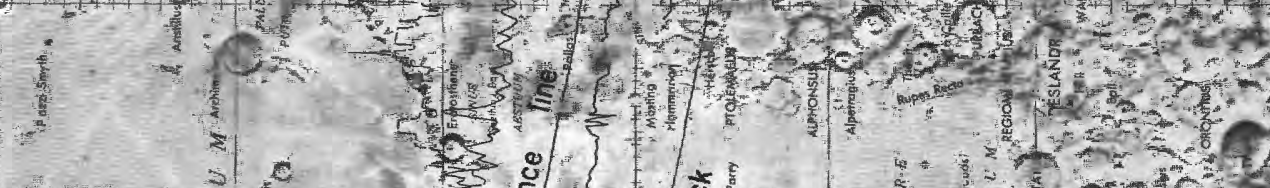

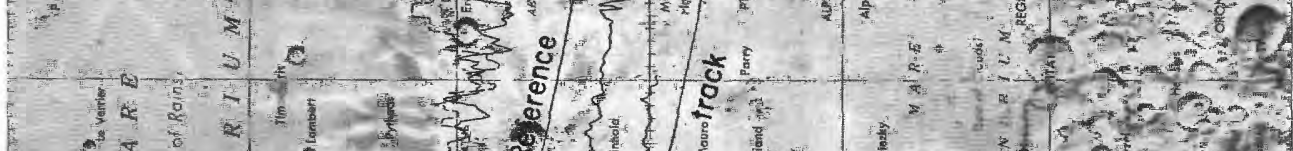

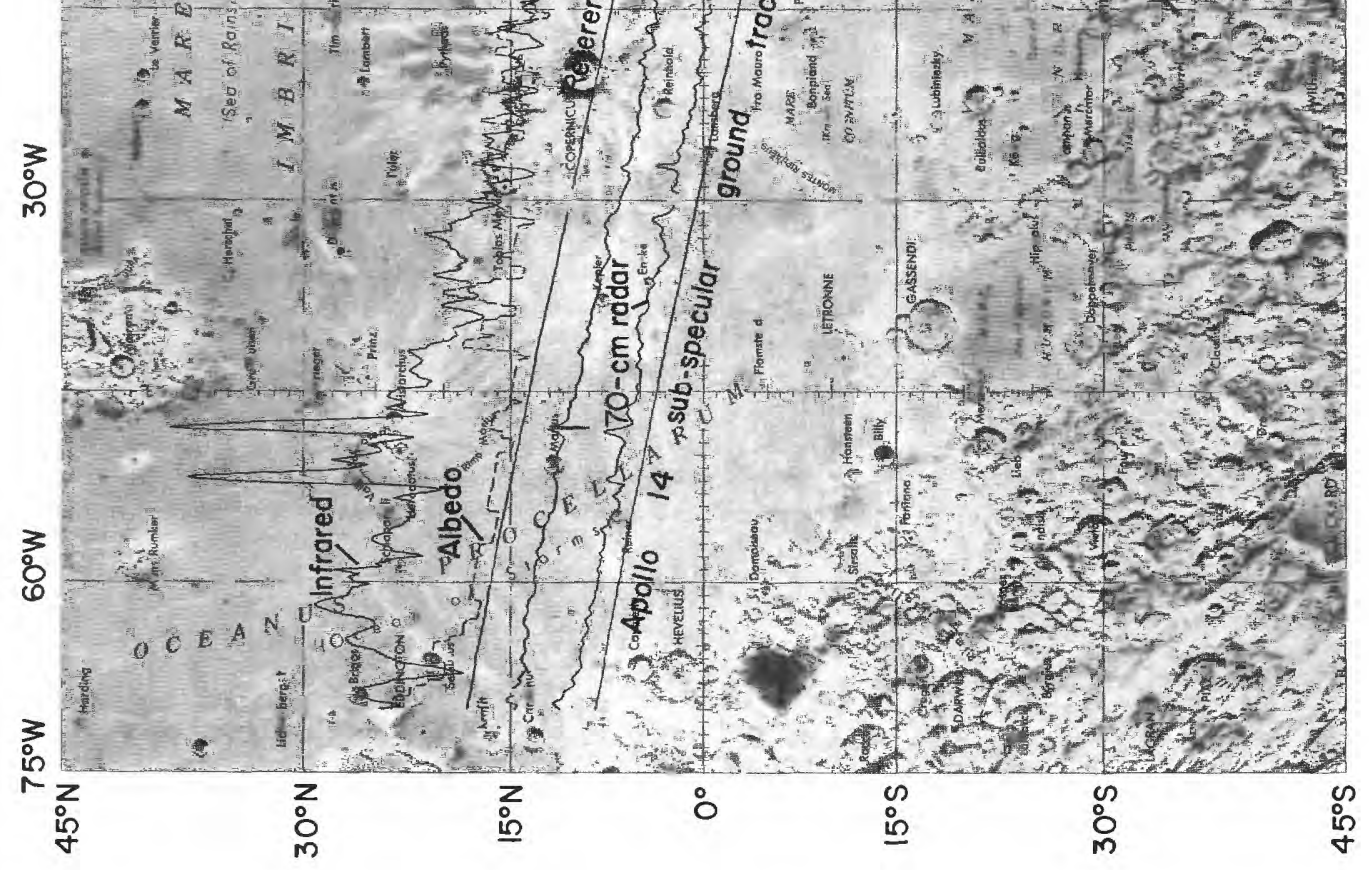


岁

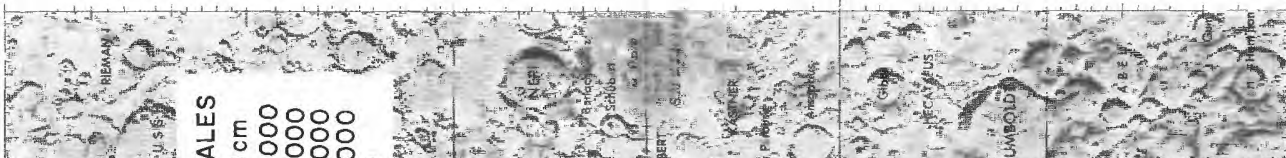

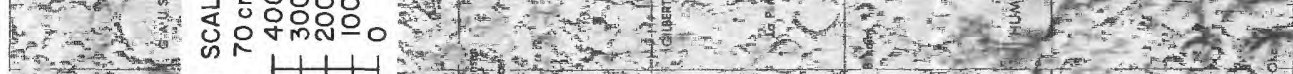

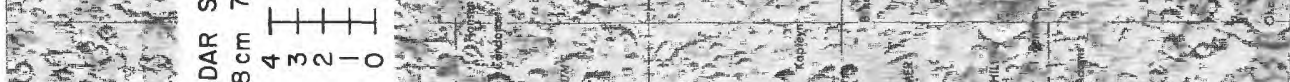

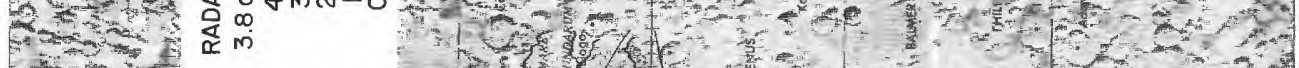
(3)

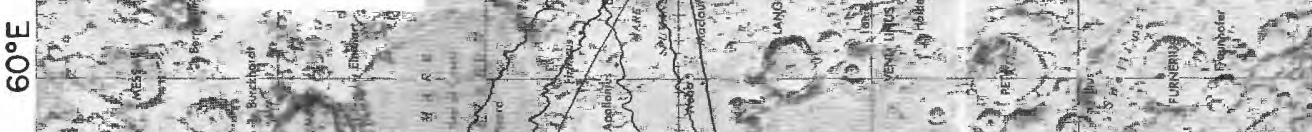

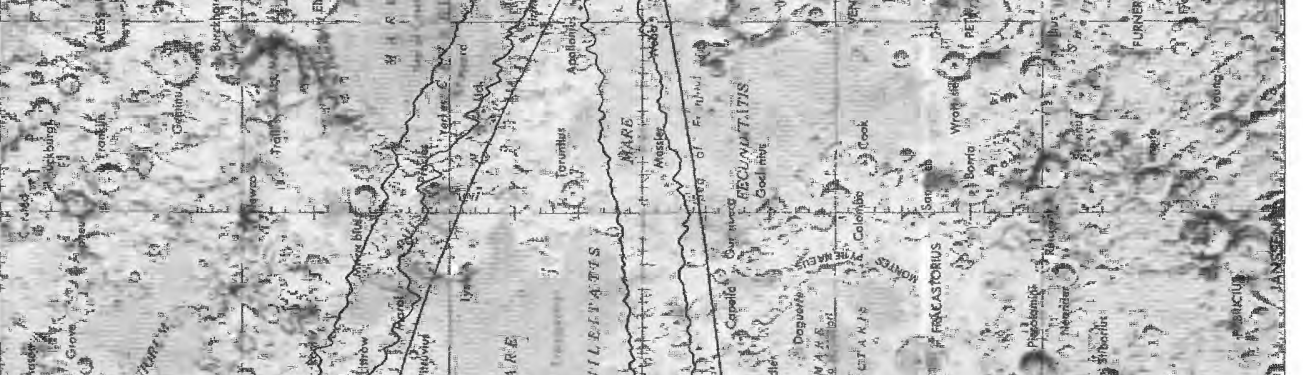
$x-5$
0

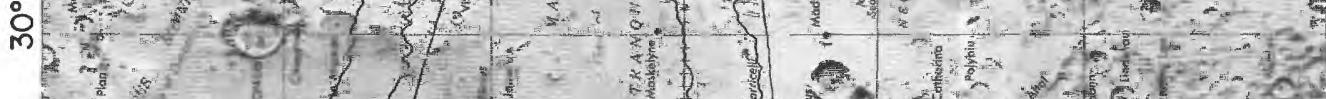

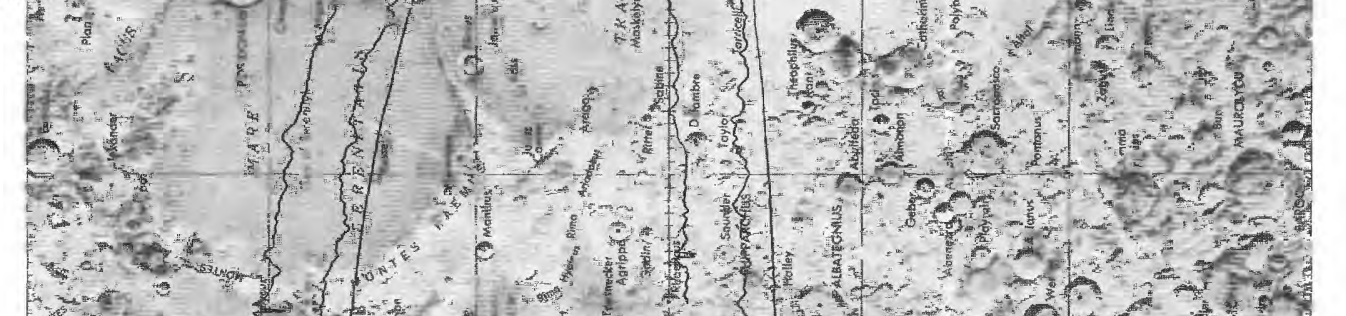

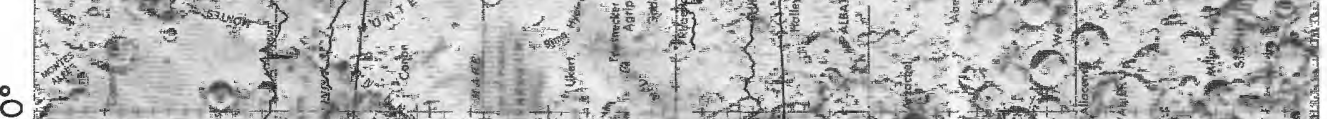

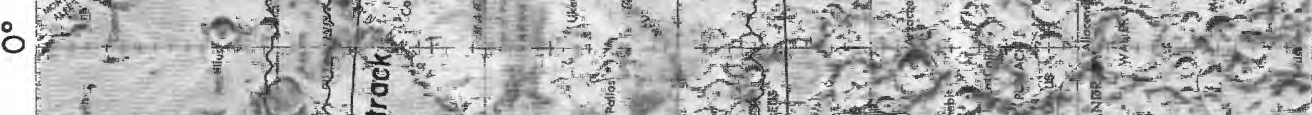

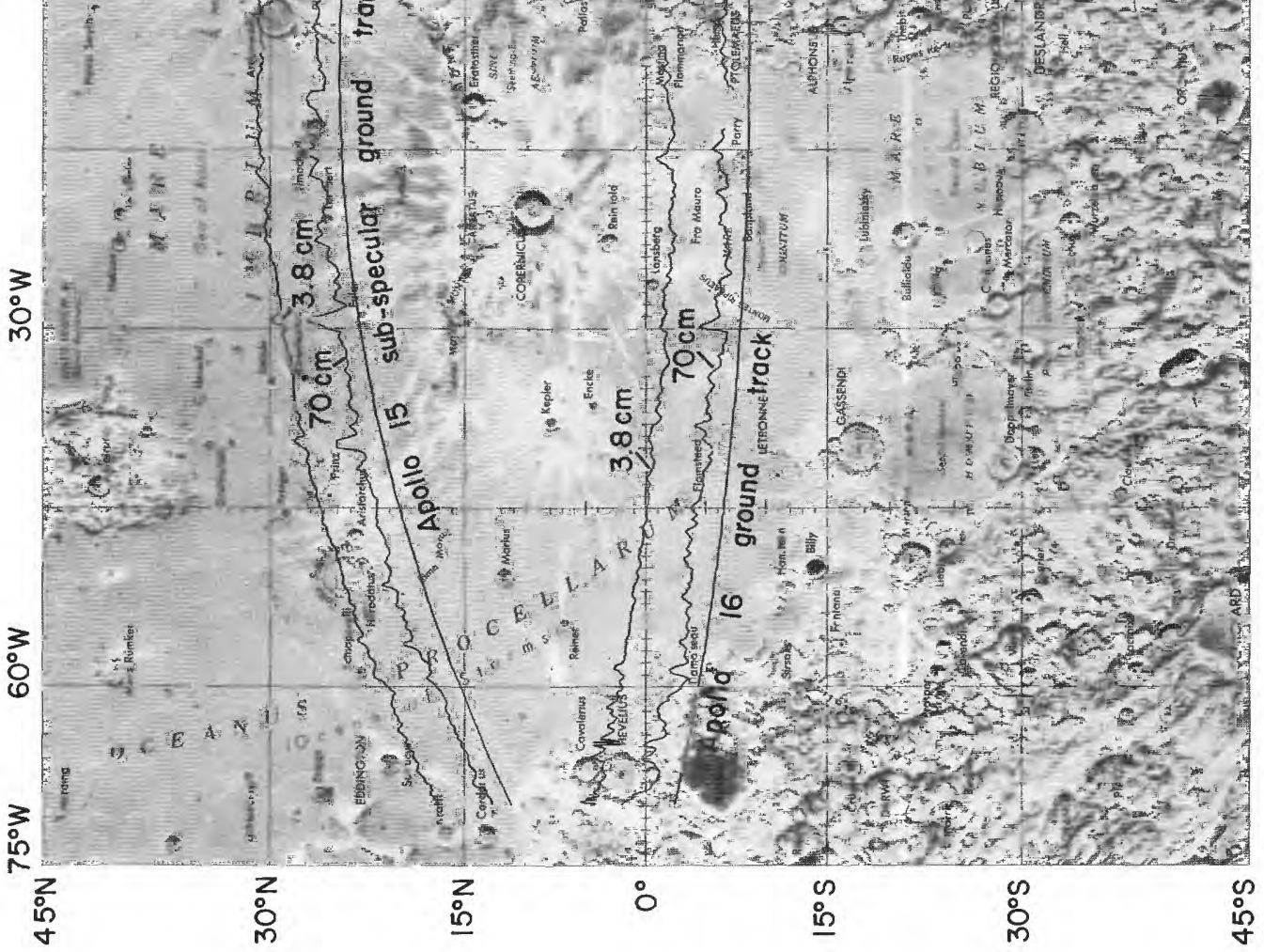


the maps, as would more photographs, images of backscattering areas, and samples from the areas.

On the Moon, weak depolarized echoes are of special interest, and much needs to be done to understand them. There are three distinct occurrences of weak depolarized echoes: (1) lunar black spots or dark mantled areas, (2) local and regional relatively blue mare surfaces, and (3) halos surrounding certain large craters that extend to one or more crater diameters. The reasons for this last occurence have not yet been addressed in the radar literature.

A primary unanswered question is how deep the radar signals penetrate the regolith before being backscattered. For example, are the $70-\mathrm{cm}$ radar waves penetrating the mare regoliths into the fractured substrate basalt. If they are, where is the major absorption taking place.

\section{INFRARED ECLIPSE TEMPERATURES}

\section{By H. J. Moore}

The thermal response of the lunar surface has been measured from the Earth during eclipses during which the average surface cools from the full-Moon temperature of about $400^{\circ} \mathrm{K}$ to about $150^{\circ} \mathrm{K}$. Eclipse temperature measurements used here were obtained during the penumbral phase of the lunar eclipse of December 19, 1964, in the wavelength band of 10-12 $\mu \mathrm{m}$ (Shorthill, 1973, 1970; Saari and others, 1966; Saari and Shorthill, 1963, 1966a; Shorthill and Saari, 1965a). A resolution of 10 arc seconds was achieved, corresponding to roughly $17 \mathrm{~km}$ at the sub-Earth point. The positions of the scans on the Moon were determined by associating small features with observed anomalies. The positions of eclipse temperatures and their magnitudes have been correlated with root-mean-square slopes from the Apollo bistatic-radar experiment subspecular tracks and their magnitudes (Moore and others, 1975; 1976).

Lunar temperatures are calculated assuming the Moon is a blackbody radiator of its planetary heat (Pettit, 1961; Sinton, 1962a). In order to compare eclipse temperature measurements of different areas of the Moon on an equal basis, they were normalized to the average behavior of the highlands (Shorthill, 1970, 1973). The normalization is corrected for the decrease in temperature toward the limbs caused by the initial full-Moon temperature distribution, the asymmetry in the cooling time caused by the passage of the Earth's shadow across the disk, and differences of cooling times between successive observation scans.

A "flattened Moon" quantity, $\Delta F M$, results from the normalization. It is given by

$$
\Delta F M=\frac{T_{\text {obs }}-T_{\text {base }}}{T_{\text {full Moon }}},
$$

where $T_{\text {obs }}$ is the observed eclipsed temperature, $T_{\text {base }}$ is the expected localized background temperature, and $T_{\text {full Moon }}$ is the localized full Moon temperature. For some presentations and analyses, scaled values, $I R$, are used (T. W. Thompson, written commun., 1975; Moore and others, 1975):

$$
I R=100+1000 \Delta F M .
$$

Scaled infrared eclipse temperatures for the lunar near side are shown in figure 46.

\section{ECLIPSE TEMPERATLRES AND LUNAR FEATURES}

Average values of observed infrared eclipse temperatures for geologic map units along the Apollo photographic tracks and bistatic-radar tracks show a general inverse correlation with albedo (figs. 44,47 ), with the exception of bright young craters (Moore and others, 1976). The general inverse correlation is most marked in Oceanus Procellarum along the Apollo bistatic-radar ground tracks near $50^{\circ} \mathrm{W}$. where albedos are low and scaled eclipse temperatures are high (figs. $44,47)$. The areal distribution of infrared eclipse temperatures is particularly well shown in figure 46 . In contrast with Oceanus Procellarum, infrared eclipse temperatures of highland regions along the Apollo 14 and 16 bistatic-radar tracks are relatively low and albedos are high (figs. 44, 47), and for the highland area adjacent to the southwest edge of Mare Crisium $\left(55^{\circ} \mathrm{E}\right.$, Apollo 15), infrared eclipse temperatures are low and albedos are high (fig. 47). Superimposed on this general correlation are strong peaks where both infrared eclipse temperatures and albedos may be high. The spikes of high eclipse temperatures and albedos usually correlate with craters, particularly fresh ones which may be large (more than $10 \mathrm{~km}$ ) or small (a few kilometers). The strongest infrared eclipse temperature spikes along the Apollo 14 bistatic-radar track (fig. 44) correspond to small, very fresh craters near Suess $\left(48^{\circ} \mathrm{W}\right.$.) and Reiner A $\left(51.5^{\circ} \mathrm{W}\right.$.). Another high eclipse-temperature spike corresponds to LaLande $\left(39^{\circ}\right.$ W., fig. 44). Striking examples of high infrared eclipse temperatures also occur along the Apollo 15 and 16 bistatic-radar tracks (fig. 47). Along the Apollo 15 bistatic-radar ground tracks, the crater Euler $\left(29^{\circ} \mathrm{W}\right.$.), the crater Vitruvius $\left(35^{\circ} \mathrm{E}\right.$.), and the Tycho ray that passes through Bessel ( $18^{\circ} \mathrm{E}$.) have both a high eclipse temperature and a high albedo. Other spikes are commonly related to small craters and their ejecta. A small crater near Capella ( $36^{\circ}$ E., Apollo 16 track) has high 


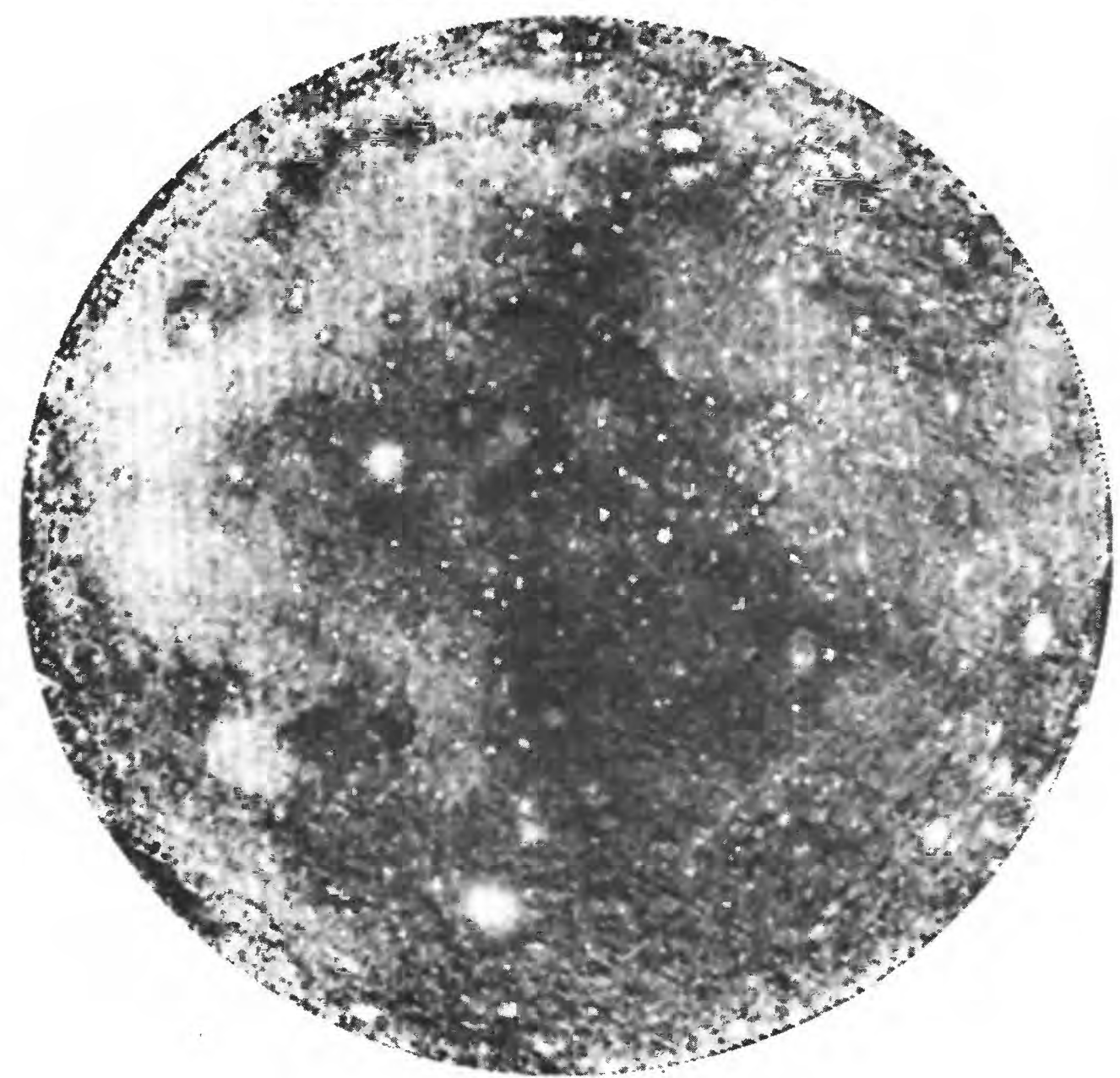

FigURE 46.-Scaled infrared eclipse temperatures of lunar near side. Bright areas are relatively warm, dark areas are relatively cool. Note high temperatures in Oceanus Procellarum, Mare Frigoris, and northwestern Mare Imbrium (outer part of upper left quandrant). Bright circular area in lower left is Mare Humorum. Very bright circular areas are young craters such as Tycho, Aristarchus, Copernicus, and Langrenus. Dark areas are relatively cool highlands. Measured at $11 \mu \mathrm{m}$. (Image courtesy of R. W. Shorthill, University of Utah Research Institute and T. W. Thompson, Jet Propulsion Laboratory, California Institute Technology. Data from eclipse temperature observations of J. M. Saari and R. W. Shorthill, December 19, 1964.) Diameter of Moon is $3,476 \mathrm{~km}$.

eclipse temperatures and albedos, as does another small crater in Parry ( $16^{\circ}$ W., Apollo 16 track, fig. 47).

These relations are shown in a quantitative way in figure 48 , where average values of scaled eclipse temperatures for geologic map units are inversely related to average albedos (see also Moore and others, 1975, 1976). Western maria (points $38,39,56,57$, and 75 in fig. 48) are generally warm and may exceed the average temperatures for the crater Euler and its ejecta. Two points are plotted for mare material in the Montes Riphaeus region (76) which represent the average values along the Apollo 14 track (lower eclipse temperature) and along the Apollo 16 track (higher eclipse temperature); their separation indicates local variations in the maria. Another notable variation is that high infrared eclipse temperatures generally coincide with the Imbrian flows of western Imbrium (Schaber and others, 1975), and lower ones coincide with eastern Imbrium (fig. 48; variation indicated by arrows from point 40).

As with the terrestrial radar echoes, there are three general classes of infrared eclipse tempeatures: (1) average ones, (2) anomalously high ones or hot spots (Saari and Shorthill, 1966b; Shorthill and Saari, $1965 \mathrm{a}, \mathrm{b})$, and (3) anomalously low ones or cold spots. The crater Euler in figures 47 and 48, where average values for the crater and its ejecta have been plotted, is a hot spot. Peak scaled values of the infrared eclipse temperatures within the crater are near 174 (fig. 47). Eclipse temperatures for the ejecta and insides of other 
:

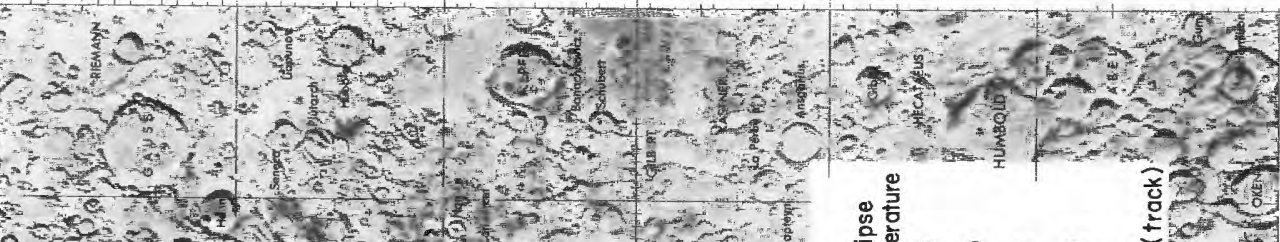

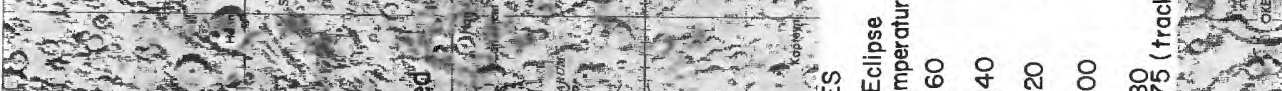

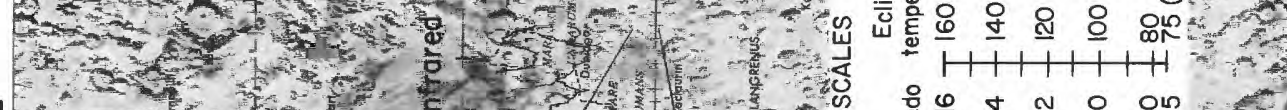

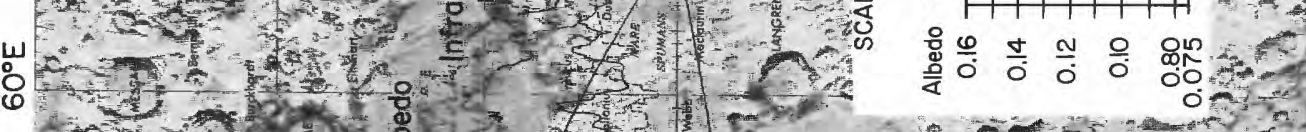

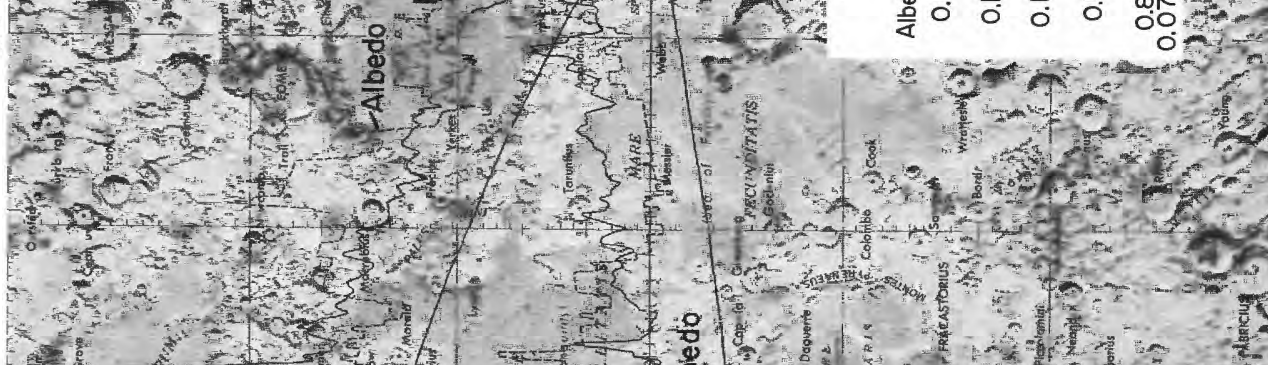

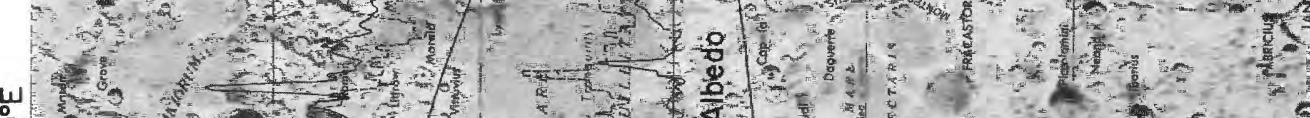

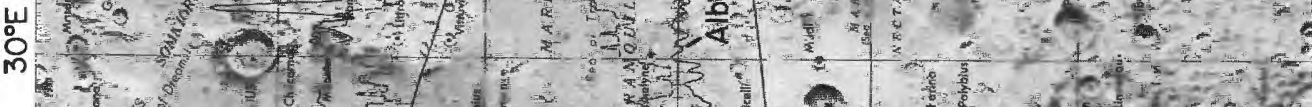

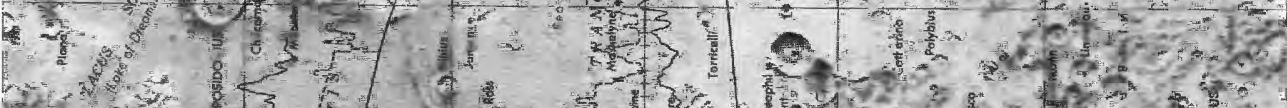

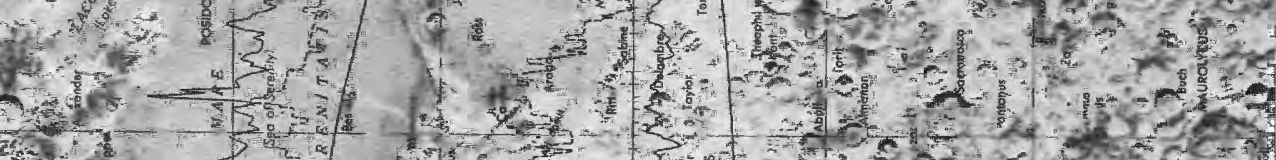

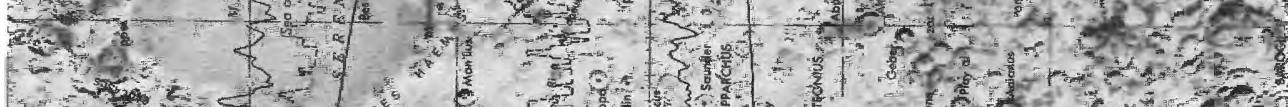

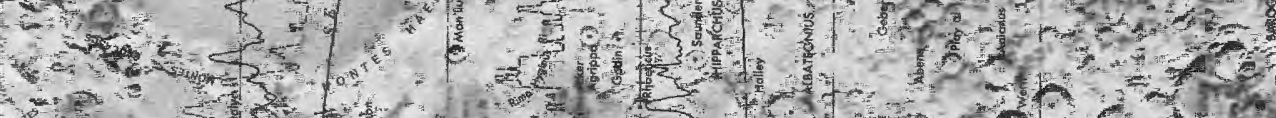

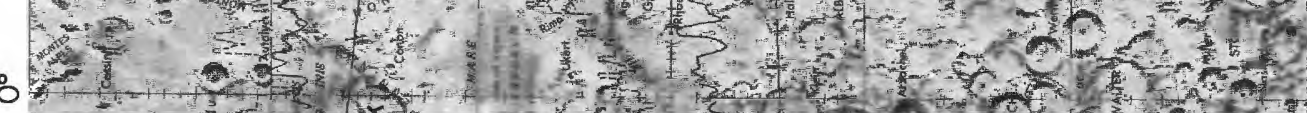
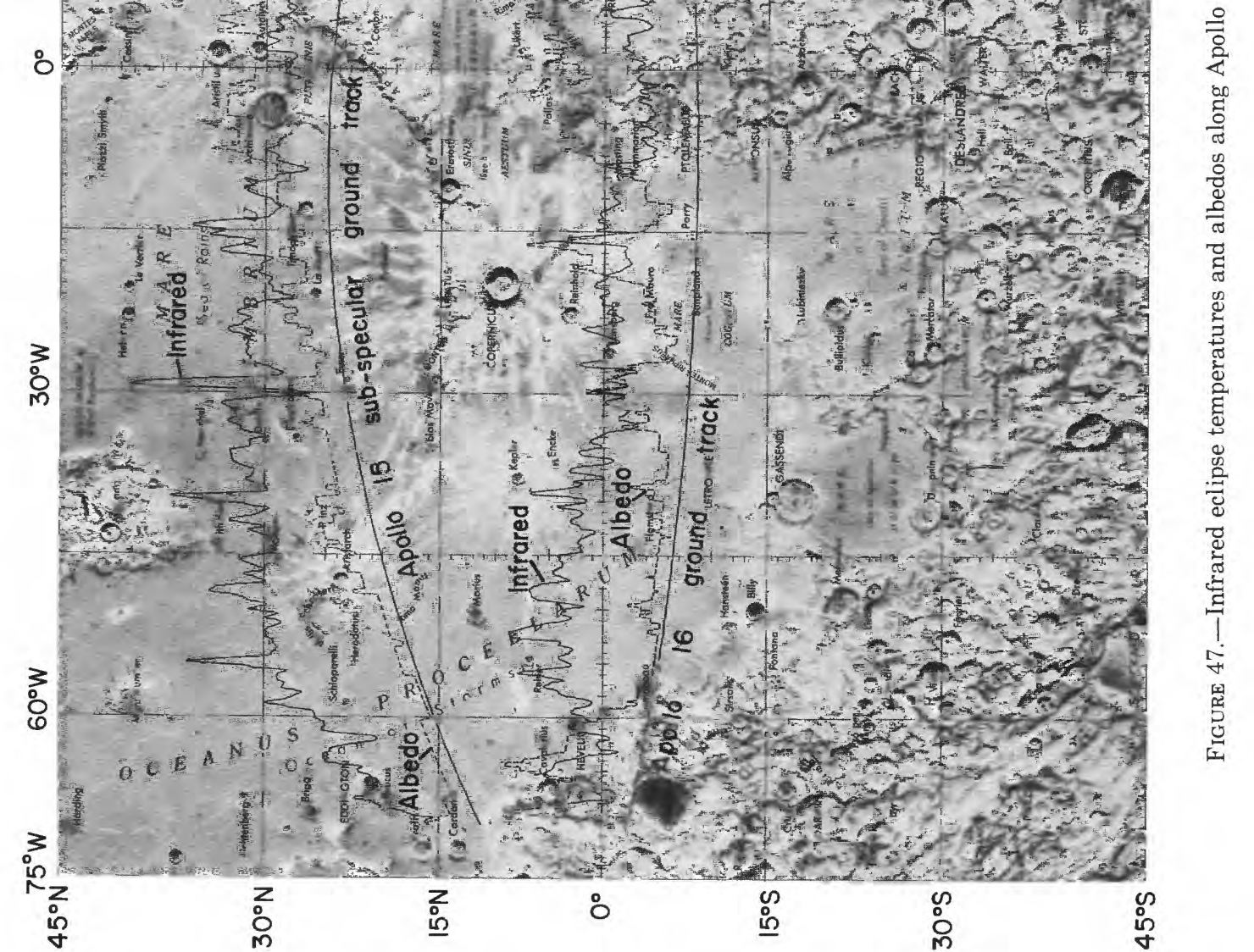


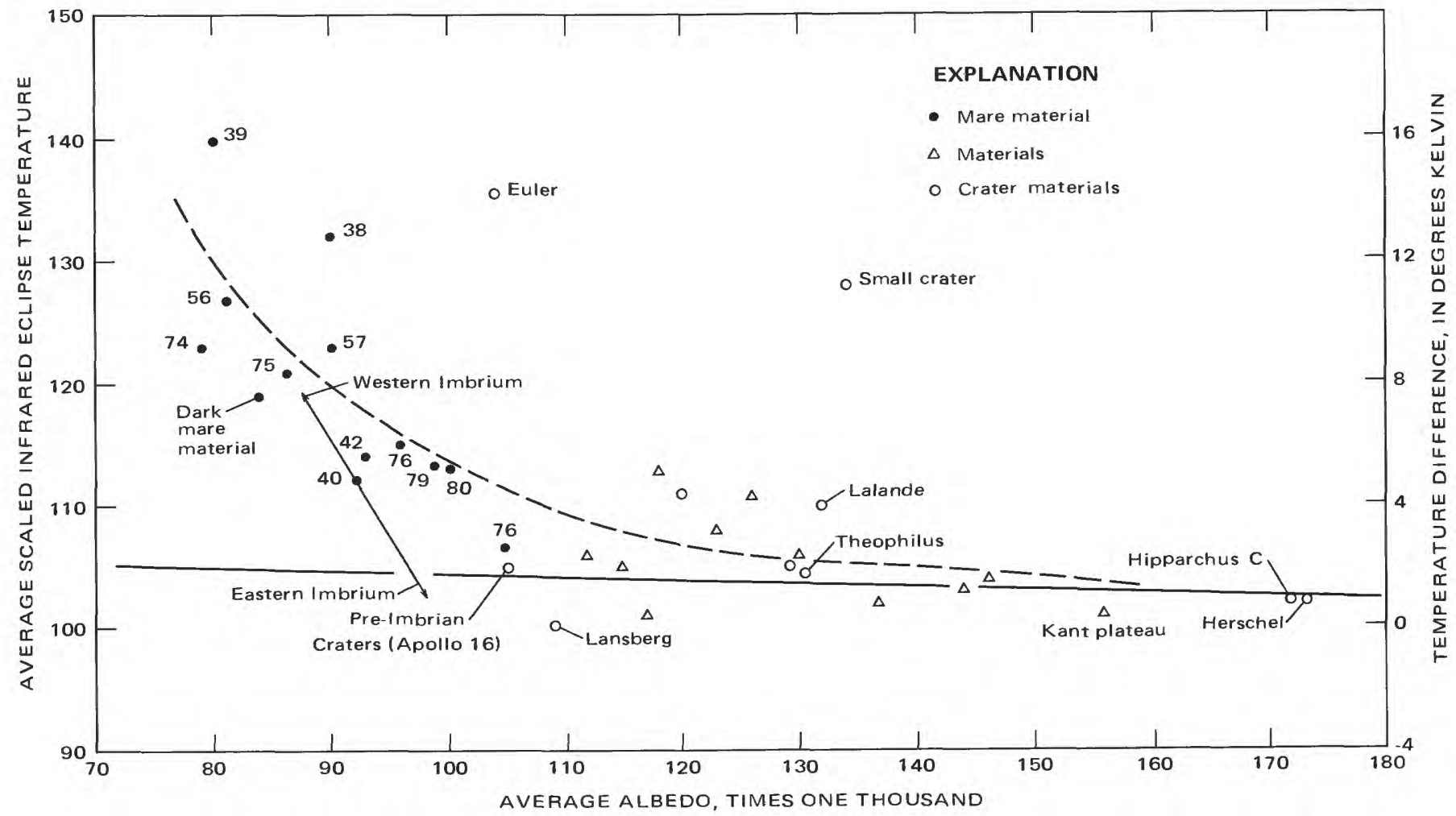

FigURE 48.-Average infrared eclipse temperatures and average albedos of maria, highlands, and selected craters along Apollo 14, 15, and 16 bistatic-radar ground tracks. Numbers by data points for maria indicate maps in the LAC series (table 10) in which they are located. Solid line indicates scaled-eclipse temperatures that can be ascribed to initial temperatures resulting from albedo for materials with identical emissivities, thermal conductivities, densities, and specific heats. Note inverse relation between average scaled infrared eclipse temperatures and albedos (indicated by dashed line); maria are generally warmer than highlands. Euler and small crater (lat $5.8^{\circ} \mathrm{S}$., long $36^{\circ} \mathrm{E}$.) are hot spots with unusually high eclipse temperatures. Average temperatures for craters and ejecta of LaLande, Theophilus, Herschel, and Hipparchus C are low compared to Euler and small crater. Lansberg and pre-Imbrian craters of Apolla 16 have low average eclipse temperatures.

large craters along the Apollo bistatic-radar tracks (Lansberg, fig. 44; $26.5^{\circ} \mathrm{W}$.; Theophilus, fig. $44,27^{\circ} \mathrm{E}$; and Herschel, fig. $44,3^{\circ}$ W.) are not hot spots (except the central peak of Theophilus which is a hot spot). Selected hot spots in the "Apollo zone" of the lunar near side are listed in table 10 .

The Aristarchus-Montes Harbinger region, a cold spot, is especially noteworthy because of the combination of a low albedo and low infrared eclipse temperature, suggesting that unusual materials are present on the surface there (Zisk and others, 1977).

\section{CALSES OF HIGH INFRARED ECLIPSE TEMPERATURES}

Initial temperature differences resulting from albedo differences (Saari and Shorthill, 1967, 1972) of materials with the same emissivities and thermal inertias can only be maintained to a minor degree during an eclipse. Initial temperatures of materials are related to their albedos by the equation

$$
T_{o}=T_{b b}(1-A)^{1 / 4}
$$

where $T_{o}$ is the initial temperature, $T_{b b}$ is the brightness temperature corresponding to zero albedo $\left(T_{b b}=\right.$ $408.6^{\circ} \mathrm{K}$ ), and $A$ is the albedo (Saari and Shorthill, 1972 , p. 171, eq. 3). The final temperature can be calculated from

$$
T_{f / T_{o}}=0.457-0.32 \log _{10} \frac{\epsilon \sigma T_{0}{ }^{3} t_{0}^{1 / 2}}{(10 K \rho c)^{1 / 2}},
$$

where $\epsilon$ is the emissivity, $\sigma$ is the Stefan-Boltzman constant, $t_{0}$ is the time, $K$ is the thermal conductivity, $\rho$ is the density, and $c$ is the specific heat (Saari and Shorthill, 1963, p. 133). Solutions for the equations, where $\epsilon, t_{o}, K, \rho$, and $c$ are taken as constant and $T_{f}=$ $150^{\circ}$ for $T_{0}=391.8^{\circ} \mathrm{K}$, are tabulated below:

$\begin{array}{ccc}\text { Albedo } & T_{t_{s}} & T_{t} \\ 0.180 & 388.8 & 149.8^{\circ} \mathrm{K} \\ 0.155 & 391.8 & 150.0^{\circ} \mathrm{K} \\ 0.070 & 401.2 & 150.6^{\circ} \mathrm{K}\end{array}$

Thus, albedo alone will account for only about $1^{\circ} \mathrm{K}$ of the temperature difference in figure 48 . 
TABLE 10.-List of selected craters and areas in "Apollo zone" with relatively high eclipse temperatures for general area

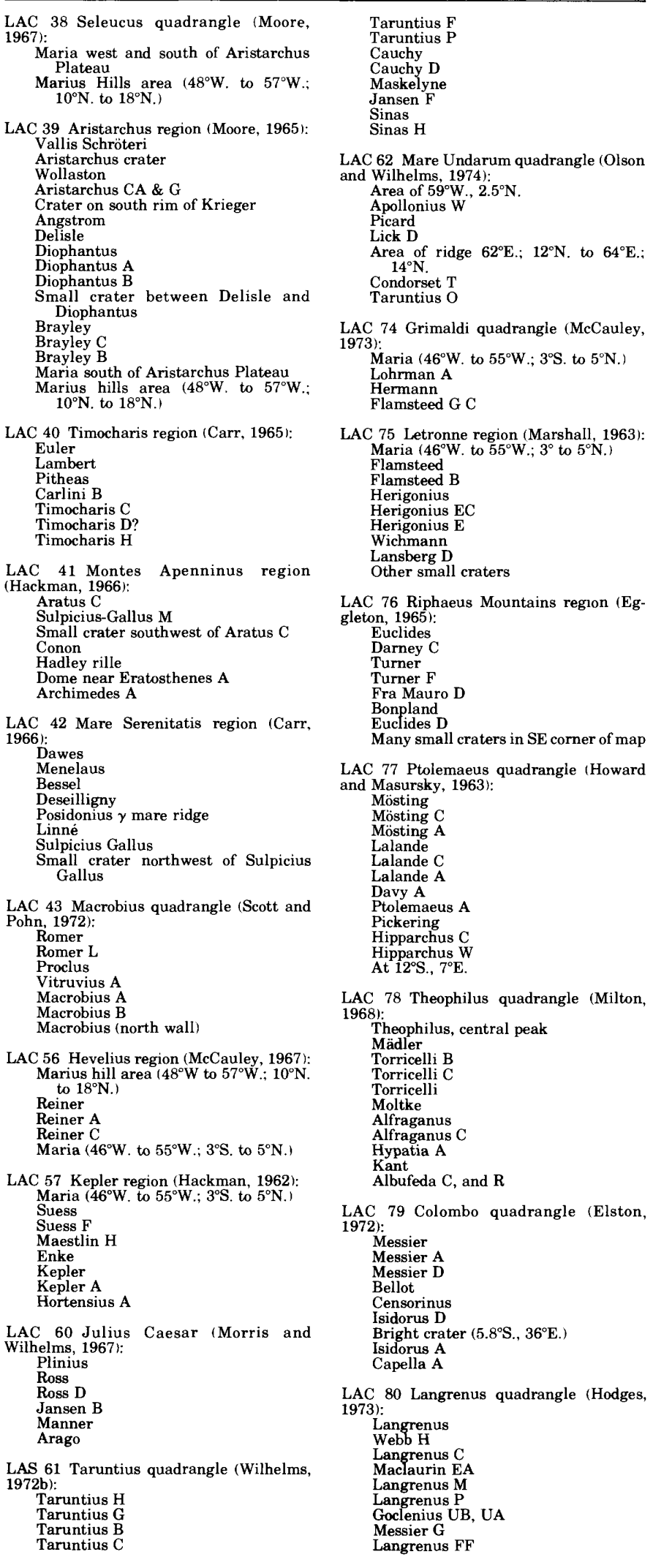

Localized high temperature anomalies, or hot spots, are believed to result from an excess of bare rocks on the lunar surface (Roelof, 1968; Winter, 1970; Allen, 1971). The surface rocks must be about $10 \mathrm{~cm}$ or more in diameter, and the number of rocks per unit area must be larger than that observed by Surveyors 1 and 3 (Thompson and others, 1974). A particularly good example of a lunar hot spot is the crater Tycho (Sinton, $1962 \mathrm{~b})$. Tycho can be accounted for with a model of 0.3 $\mathrm{mm}$ of dust over bare rocks-in contrast to the thick dust required for Tycho's surroundings. Geologic observations support the hypothesis that rocks on the surface are responsible for the high infrared eclipse temperatures (Thompson and others, 1974).

Measurements of thermal conductivities and specific heats of returned lunar samples show that they are both functions of temperature (Cremers and Hsia, 1973, 1974; Hemingway and others, 1973). Conductivity differences of fines returned by Apollo from maria (Cremers and Hsia, 1973) and Apollo 16 highlands (Cremers and Hsia, 1974) would produce the differences in infrared eclipse temperature that are observed. Furthermore, the product of density and specific heat could account for the observed eclipse temperature differences. Cremers and Hsia (1974) indicate that the differences of thermal properties of lunar and terrestrial fines are most probably caused by differences in typical particle size and shape.

\section{DISCUSSION}

Perhaps the most significant observation of the infrared eclipse temperatures is the high temperatures observed in Oceanus Procellarum and western Mare Imbrium. The distribution of these high temperatures is very similar to the distribution of young mare plains (Boyce, 1976). If one postulates a coincidence of relatively coarse grained regolith with abundant blocks because of a youthful surface with a thin regolith-as is the case for young fresh craters-then Oceanus Procellarum is indeed young, and the flows in western Mare Imbrium are also young by these criteria.

\section{A BASIS FOR EXTRAPOLATION}

As the last Apollo mission was preparing to leave the vicinity of the Moon, the Apollo 17 crew said that Apollo was just the beginning. Someday we may return to the lunar surface. Until then, the scientific community is charged with the responsibility of assimilating existing lunar data and extrapolating Apollo, Surveyor, Luna, and Lunakod surface results to other parts of the Moon using remote sensing and measurements to discover targets for future lunar explora- 
tion which will produce the highest scientific yields. The remote sensing and measurements described here could form the basis for extrapolation of lunar surface results, but supplemental measurements from both Earth and spacecraft in lunar orbit would enhance the validity of the extrapolations.

Although data from the surface and from remote sensing are only partly assimilated, the basis for extrapolation can be illustrated with selected examples of unresolved problems that require lunar rock samples and surface data. Indeed, it is not possible to resolve many lunar and planetary problems without carefully collected and documented samples and subsequent isotopic, chemical, and petrologic analyses. Five general extrapolations will be discussed:

1. Duration of volcanic activity on the Moon.

2. Early cratering history of the Moon before 3.84 b.y. ago.

3. Lunar multiringed basins and the provenance of lunar highland samples.

4. Regional and local chemical variations.

5. Variation of physical properties and roughness of lunar surface.

\section{DURATION OF VOLCANIC ACTIVITY}

Remote sensing and measurements indicate that volcanic flows continued to form well beyond the time indicated by samples returned by the Apollo and Luna missions. There are four lines of evidence for this. First, relative ages of the Imbrium flows and Oceanus Procellarum maria are younger than the mare of Apollo 12, where basalts are as young as 3.15 b.y. The best estimate from relative age determinations indicate that basalt continued to flow at least as recently as 2.5 b.y. ago. Second, the remarkable geographic coincidence between mare surfaces with young relative ages and mare surfaces with high infrared eclipse temperatures lends strong support to the youth of the Imbrium flows and maria in Oceanus Procellarum. High infrared eclipse temperatures indicate that the regoliths of these areas are blocky and relatively coarse grained. Such a result is consistent with relatively young volcanic flows overlain by relatively thin and immature regolith. Third, stratigraphic evidence for the youth of the Imbrium flows and some of the maria in Oceanus Procellarum is compelling. The Imbrium flows are unusual, their crisp well-preserved morphology showing that they have not been extensively degraded and eroded by micrometeoroid bombardment (Schaber, 1973). Nearby, mare units are superposed on the ejecta of Euler and Delisle (Wilhelms, 1980). North and west of the Aristarchus plateau in Oceanus Procellarum, youthful volcanic rampart maars are present (Moore, 1971a; Pike, 1980), and flows are superposed on older flows around the plateau as well as on relatively small craters (Wilhelms, 1980). Fourth, Surveyor I surface data (Shoemaker and others, 1969b) and craters seen in Lunar Orbiter images show that the regolith in the Flamsteed area of Oceanus Procellarum is relatively thin (Oberbeck and Quaide, 1967) and the area is unusually blocky compared to maria with older relative ages. Thus, a good target for future lunar surface exploration should be somewhere in Oceanus Procellarum or western Mare Imbrium where the preponderance of data measured remotely indicate there are young volcanic flows. Locating such sites precisely must await more careful and detailed studies.

\section{EARLY CRATERING HISTORY BEFORE 3.84 B.Y. AGO}

Although the elucidation of the broad timing of the early cratering and basin-forming period represents a major accomplishment of the Apollo program, many of the details are unresolved. Geologic evidence shows that the Moon has a population of multiring basins in the steady state, or at least close to it (Howard and others, 1974). The interval of time over which basins formed, the existence or absence of predecessors, and the origin of the bodies producing them are unknown-indeed, the bodies producing them could have come from the Moon itself or elsewhere. The relatively small interval represented by metamorphic ages of rocks collected during Apollo from the highlands is only a few hundred million years or so and could represent a large number of big events or one event (G. J. Wasserburg, oral commun., 1976). Photogeologic evidence and theoretical evidence for the widespread distribution of ejecta from both the Orientale and Imbrium basins (Moore and others, 1974; O'Keefe and Ahrens, 1976; McGetchin and others, 1973) or even pervasive distribution (Chao and others, 1973, 1975) also indicate that ejecta from one or several basin events may have been sampled by the Apollo missions at any one or all of the highland sites. On the other hand, Reed and Wolfe (1975) offer an excellent argument for the presence of ejecta from a nearby southern Serenitatis basin some $300 \mathrm{~km}$ across at the Apollo 17 site. Relative ages of highland plains and crater frequency distributions yield strong evidence for two major moonwide events and vestiges of earlier ones.

In keeping with the common practice used in the study of complicated mineral deposits on Earth, areas where geologic relations appear to be least complicated are examined before proceeding to the complex area of the deposit itself. Thus, the Orientale basin is a likely candidate for future lunar exploration in order to clarify the early cratering history of the Moon. There, 
the morphology of all the geologic map units is remarkably well preserved and interpretable (Moore and others, 1974; Scott and others, 1977). Large massifs protrude above the basin floor, and blocks from outcrops in the massifs have moved downslope where they are easily accessible to landed spacecraft. Similar relations occur on the steep inward-facing slopes of the basin outer rim or Montes Cordillera. The ejecta units beyond the Cordillera rim are crisply preserved. Everywhere fresh craters with a wide range of sizes penetrate the regolith and have exhumed material from depth.

Populations of craters in the lunar highlands, from $30 \mathrm{~km}$ to $1 \mathrm{~km}$ across, have always been an important lunar problem. Were they produced by debris from space or by debris ejected from the lunar basins? Photogeologic evidence lends strong support for the notion that many of them, if not most, were produced by ejecta from the lunar basins (Wilhelms, 1980). Secondary craters from Imbrium have been systematically mapped in the near-side highlands (Eggleton, in Ulrich and Muehlberger, 1980), where they cover a substantial area. Secondary craters from Orientale have been described and systematically mapped in the vicinity of the basin (Scott and McCauley, 1977), but efforts to locate them elsewhere on the Moon are confined to limited regions (Wilhelms, 1980). Degraded secondary craters from the Nectaris basin abound on its southwest to southeast flank (Stuart-Alexander and Wilhelms, 1975). In general, existing maps of secondary craters do not exceed more than one to three basin diameters from the centers of the basins from which the secondary projectiles originated; yet, ejecta from the basins may have traveled to the antipodes of the basins (Moore and others, 1974); photogeologic evidence indicates that fluting and furrowing near Mare Ingenii at the antipode of the Imbrium basin were due to the impact of ejecta from Imbrium. At Ingenii, furrows and ridges are alined along radials from the antipode of Imbrium. Characteristically, they are well developed on crater walls with directions of slopes parallel to the radials, but furrows and ridges on walls with slopes at right angles to the radials are either absent or parallel to the radials and contours. Furrows and ridges are not confined to crater walls. They also occur on level but irregular terrain and crater flanks where they are again subparallel to Imbrium antipode radials. Furrowed terrain is present at the antipode of Orientale just north of Mare Marginis, but evidence is weaker than for Imbrium because existing photographic coverage and Lunar Orbiter images are rather poor.

Geologic mapping with the goal of identifying basin secondaries is far from complete. To our knowledge the only way to resolve the problem of the role of secondary cratering in the lunar highlands is by more photogeologic studies of the Moon.

Good arguments for a dominant population of secondary craters were initiated by Shoemaker (1965) for smaller craters and adopted for large secondary craters from basins by Oberbeck (1975), who incorporated data from Mars and Mercury in his argument.

Such impact cratering may also have occurred at a fine scale (several hundred meters and less) according to natural vagaries and variations in the basinforming events. Thus, secondary impact cratering at the fine scale could have been responsible for resetting the crater-age clocks in local areas but not in others (Boyce and others, 1974). Whether or not the resetting of the crater-age clocks was due chiefly to a process resulting in net deposition of basin ejecta or to impact erosion and extensive mixing of substrate materials can best be resolved with lunar samples from a basin such as Orientale collected along azimuths from the basin center at progressively larger distances from the basin rim.

\section{LUNAR MULTIRINGED BASINS AND THE PROVENANCE OF LUNAR HIGHLAND SAMPLES}

Five major lunar questions and a host of others are unanswered:

1. What are the stratigraphic relations in the lunar highlands?

2. How deep did the lunar basins excavate?

3. Was there a strong lunar magnetic field early in lunar history?

4. Is the layering of the lunar mantle and crust in the far-side highlands the same as that in the central lunar near side?

5. Did the highland crust compensate isostatically during the period of basin formation or later?

The problem of resolving the stratigraphic complexity of the highlands representing the early history of the Moon during the period of extensive basin formation is formidable if the state of lunar affairs at that time was as complicated as viewed by some workers. Clearly any one basin, say Orientale or Imbrium, could have ejected debris to any point on the Moon (Moore and others, 1974). Photogeologic evidence for Imbrium ejecta reaching all of the Apollo sites is strongest, but Orientale ejecta could also have reached these sites. If a single event were responsible for all the highland rocks collected, the small range in metamorphic ages would represent partial resetting of the radiometric clocks and experimental error.

The provenance of some rocks collected at the Apollo 15 site is not entirely clear. Rocks such as 15415 , 
15455 , and 15362 could represent Imbrium ejecta or Orientale ejecta. The basis for saying so is the frequency distribution for craters measured in the Montes Apenninus just southeast of the Apollo 15 site (Neukum and others, 1975a). This crater frequency distribution for craters smaller than $8 \mathrm{~km}$ is remarkably close to those of the Orientale ejecta and unlike those of the Fra Mauro Formation (Boyce and others, 1974). Although Orientale ejecta may be present at the Apollo 14 site, photogeologic evidence shows that the radial facies textures of Imbrium ejecta were not destroyed by the possible dynamic deposition of Orientale ejecta. With a steady-state distribution of lunar basins, some ejecta from the many lunar basins could have been transported from one side of the Moon and back again, possibly a number of times. The result would be a "proto-regolith" many kilometers thick that is penetrated by only the largest lunar basins (see also Short and Forman, 1972). In this model, the small range in metamorphic ages would represent a number of basin events close together in time.

Despite the potential complications, the basin exhibiting both the least morphologic degradation of its features and a large size should be a prime target for exploration in future years. The Orientale basin is such a basin, perhaps the only one. Its ejecta can be confidently recognized, and also the crater probably excavated material from beneath a thick "protoregolith."

The depths from which certain lunar highland samples have come are problematical, because of a lack of knowledge of basin shape during the formation stages. Here the only test of depth can come from returned samples in conjunction with data on the layering of the Moon. Good geologic arguments for the source of the rocks being ejected from a mare-filled basin centered in southeast Mare Serenitatis have been put forth (Reed and Wolfe, 1975). In these arguments, the Apollo 17 massifs are interpreted to be the rim and are entirely composed of ejecta from deep within the Serenitatis basin. Large depths of excavation by basin-forming events are consistent with anorthite-aluminous enstatite-forsterite-aluminous spinel assemblages in samples returned from the Apollo 17 lunar highlands (Bence and McGee, 1976). If these assemblages represent equilibrium assemblages, pressures of 3 to 7.5 kbar are indicated, and inferred depths of excavation are 60 to $150 \mathrm{~km}$. Gravity data might provide constraints on basin size when coupled with suitable topographic measurements. For this purpose, Orientale must be studied and far-side basins should be studied because gravity data for Orientale are incomplete and those for other far-side basins are far from satisfactory. Independent measures of anomalies do not agree as to magnitude, shape, and even location. If the problem of isostatic compensation can ever be resolved, both quality topographic maps and surface or low orbiting satellite gravimetry will be required.

\section{REGIONAL AND LOCAL CHEMICAL VARIATIONS}

Although major strides in understanding regional and local chemical variations were made by the Apollo orbital geochemical experiments, the coverage obtained is confined to mostly equatorial strips, or bands, related to the orbital tracks of Apollo 15 and 16. Thus, the moonwide distributions of the $\mathrm{Al} / \mathrm{Si}$ and $\mathrm{Mg} / \mathrm{Si}$ ratios and of iron, titanium, magnesium, thorium, uranium, and potassium are essentially unknown. Additionally, the orbital geochemical experiments generally do not have the resolution necessary for unraveling complex geology in certain regions.

Spectral reflectance data measured from both the Earth and orbiting spacecraft offer great promise in obtaining information on the composition of the Moon with the resolutions required for careful geologic analyses. From Earth, resolutions near $20-40 \mathrm{~km}$ have been achieved. From lunar orbit, resolutions at least a hundredfold better should be achievable. Of particular interest are the relatively young fresh craters that have excavated materials from depth, exposing them in the near-rim ejecta and within the crater. Two particularly good examples are the craters Linné and Aristarchus, which have excavated mare and highland materials respectively. Indeed, Earth-based telescopic measurements of the relative reflectance of materials brought to the surface by the lunar crater Linne is the same as the relative reflectances, determined in the laboratory, of crushed basalt collected at the Apollo 12 site. This shows that Linne is a very young crater that has chiefly, if not entirely, excavated mare basalt. Earth-based telescopic measurements of the relative reflectances of materials brought to the surface by the lunar crater Aristarchus are practically the same as the relative reflectances of fresh Cone crater ejecta from the Apollo 14 site some $1,000 \mathrm{~km}$ away (see McCord and Adams, 1973). This fact, when combined with the anomalous radioactivity for both the vicinity of Aristarchus and the Apollo 14 site, suggests that similar materials are present in both places. Geologic interpretation leads to the conclusion that both the Apollo 14 site and Aristarchus contain KREEP-rich Imbrium ejecta. At Aristarchus, the importance of high resolution of the spectral reflectance data (less than 30 $\mathrm{km}$ ) is critical. Aristarchus is surrounded by mare basalts to the east and south and other volcanic materials on the Aristarchus Plateau to the northwest. Unlike the averaged Apollo orbital geochemical data 
which do not resolve the necessary detail, the spectral reflectance data have supplied the necessary detail for unraveling the sequence of layers of materials (Zisk and others, 1977).

Spectral reflectances could also provide evidence for relative ages of some surfaces. A particularly important goal would be a detailed study of Oceanus Procellarum to see if the regoliths there are relatively young compared to maria elsewhere, particularly at the Apollo landing sites. An example of such a correlation is revealed by the Reiner Gamma area which has a telescopic relative reflectance indicating it contains exposures of fresh mare basalt. Here, geologic interpretation requires at least two hypotheses: (1) Reiner Gamma is a young event exposing fresh rock or (2) the maria of Oceanus Procellarum are relatively young.

More examples could be cited but would be beyond the scope of this paper. The examples illustrate the importance of high-resolution data, the ways in which such data can be used to establish the types of lunar materials at a given locality, and ways to establish the layering of the Moon.

\section{VARIATION OF PHYSICAL PROPERTIES AND ROUGHNESS OF LUNAR SURFACE}

Variations of physical properties and roughness of the lunar surface can be detected using several remote measurement techniques: (1) analyses of quasispecular radar echoes, (2) analyses of diffusely scattered radar echoes, (3) analyses of the thermal response under a variety of insolation conditions, (4) analyses of spectral reflectances at short wavelengths, (5) light polarization properties, and 6) high-resolution stereoscopic images. Systematic collection and analyses of data using these techniques are far from complete. The three Apollo bistatic-radar tracks cover only a limited part of the Moon, and supplemental coverage by Explorer 35 is sparse. Although the quasispecular part of Apollo bistatic-radar echoes has been studied in detail, the diffuse part has not, and it is this part of the echo that can be used to estimate rock populations and regolith thickness. Three kinds of geologically interesting units have never been adequately sampled by the radar: (1) fresh lunar craters such as Aristarchus, (2) lunar dark spots such as the annulus of Mare Serenitatis, and (3) unusually hued areas such as the Aristarchus plateau. Although data are incomplete, extrapolation of the bistatic-radar results indicate the following:

1. The uppermost lunar regolith is remarkably uniform with a dielectric constant near 3.0.

2 . Locally, the lunar surface is layered with a thin regolith overlying a denser layer.

3 . Highland rms slopes are near $5^{\circ}$ to $7^{\circ}$ for radar wavelengths of 13 and $116 \mathrm{~cm}$, and those of the maria are $2^{\circ}$ to $4^{\circ}$ for the shorter (S-band) wavelength and $1^{\circ}$ to $2^{\circ}$ for the longer (VHF) wavelength.

4. Forms of slope-probability distributions vary with terrain.

The results above are consistent with other data. Mechanical properties measured on the lunar surface (Costes, 1973) indicate a uniform lunar surface. Crater morphology shows that regolith thicknesses vary from place to place (Oberbeck and Quaide, 1968). Photogrammetry yields slope probability distributions that are compatible in form with those of the radar and show that the highlands are, in fact, rougher than maria.

Maps of diffuse polarized and depolarized echoes from terrestrial radar provide data for the entire lunar near side. The echo strengths have not yet been unambiguously interpreted. Although the role of blocks and fragments and slopes tilted toward the Earth are well established, those two variables cannot be separated everywhere, and the effects of other variables are poorly understood. Despite the uncertainties, the diffuse reflectivities of the lunar surface do provide a basis for extrapolation and another variable for tests of similarity. The usefulness of these variables is severely hampered by the fact that the subsets of the Earthbased data for the 3.8 and $70 \mathrm{~cm}$ radars are improperly correlated, which results in mismatched echo strengths at the mutual boundaries of the data subsets.

The most complete and hence most useful data set describing the thermal response of the lunar near side are the infrared eclipse temperatures measured from Earth. Unlike the terrestrial radar data, there are no subsets of data with mismatched boundaries. Interpretations of the high infrared eclipse temperature are ambiguous. Large blocks and fragments could be responsible for the high eclipse temperatures, and simple increases in grain size above the average could produce the effect. In reality, both and possibly more variables are involved. Nevertheless, infrared eclipse temperatures can be used for extrapolation.

The application of spectral reflectances have not been completely explored, nor is coverage of the lunar surface complete. Of particular interest are the contrasting relative reflectances of the different areas. The region of Reiner Gamma in Oceanus Procellarum must contain little glass and large amounts of crushed basalt. Highland craters such as Proclus expose fresh materials from beneath the surface. Other areas have old mature regoliths. Complete data on spectral reflectances could be very valuable in looking for future exploration sites. 


\section{REFERENCES CITED}

Adams, J.B., 1967, Lunar surface composition and particle size: Implications from laboratory and lunar spectral reflectance data: Jour. Geophys. Research, v. 72, p. 5717-5720.

1968, Lunar and martian surface: Petrologic significance of absorption bands in the near-infrared: Science, v. 159, p. 14531455.

-1974, Visible and near-infrared diffuse reflectance spectra of pyroxenes as applied to remote sensing of solid objects in the solar system: Jour. Geophys. Research, v. 79. p. 4829-4836

Adams, J. B., and Filice, A. L., 1967, Spectral reflectance 0.4 to 2.0 microns of silicate rock powders: Jour. Geophys. Research, v. 72, p. 5705-5715.

Adams, J. B., and Jones, R. L., 1970, Spectral reflectivity of lunar samples: Science, v. 167, p. 737-739.

Adams, J. B., and McCord, T. B., 1970, Remote sensing of lunar surface mineralogy: Implications from visible and near-infrared reflectivity of Apollo 11 samples: Proc. Apollo 11 Lunar Sci. Conf., Geochim. et Cosmochim. Acta, Suppl. 1, v. 3, p. 1937 1945.

1971a, Alteration of lunar optical properties: Age and composition effects: Science, v. 171, p. 567-571.

1971b, Optical properties of mineral separates, glass and anorthositic fragments from Apollo mare samples: Proc. Second Lunar Sci. Conf., Geochim. et Cosmochim. Acta, Supp. 2, v. 3, p. 2183-2195.

-1972, Electronic spectra of pyroxenes and interpretation of telescopic spectral reflectivity curves of the Moon: Proc. Third Lunar Sci. Conf., Geochim. et Cosmochim. Acta, Supp. 3, v. 3, p. 3021-3034.

1973, Vitrification darkening in the lunar highlands and identification of Descartes material at the Apollo 16 site: Proc. Fourth Lunar Sci. Conf., Geochim. et Cosmochim. Acta, Supp. 4, v. 1, p. 163-177.

Adams, J. B., Pieters, Carle, and McCord, J. B., 1974, Orange glass: Evidence for regional deposits of pyroclastic origin on the Moon: Proc. Fifth Lunar Sci. Conf., Geochim. et Cosmochim. Acta, Supp. 5, v. 1. p. 171-187.

Adler, I., Trombka, J. I, Gerard, J., Schmadebeck, R., Lowman, P., Blodgett, H., Yin, L., Eller, E., Lamothe, R., Gorenstein, P., Bjorkholm, P., Harris, B., and Gursky, H., 1972a, X-ray Fluorescence Experiment, in Apollo 15 preliminary science report: Natl. Aeronautics Space Admin. Spec. Pub. NASA SP-289, p. 17 (1)-17 (17).

Adler, I., Trombka, J. I, Gerard, J., Lowman, P., Schmadebeck, R., Blodgett, H., Eller, E., Yin, L., Lamothe, R., Osswald, G., Gorenstein, P., Bjorkholm, P., Gursky, H., and Harris, B., Golub, L., and Harnden, F. R., Jr., 1972b, X-ray Fluorescence Experiment, in Apollo 16 preliminary science report: Natl. Aeronautics Space Admin. Spec. Pub. NASA SP-315, p. 19(1)-19(14).

Adler, I., Trombka, J. I., Gerard, J., Schmadebeck, R., Lowman, P., Blodgett, H., Yin, L., Eller, E., Lamothe, R., Gorenstein, P., Bjorkholm, P., Harris, B., and Gursky, H., 1972c, Apollo 15 X-ray Fluorescence Experiment: Greenbelt, Md., Goddard Space Flight Center, Preprint X-641-72-57, 37 p.

Adler, I., Trombka, J. I, Gerard, J., Lowman, P., Schmadebeck, R., Blodgett, H., Eller, E., Y in, L., Lamothe, R., Gorenstein, P., and Bjorkholm, P., 1972d, Apollo 15 Geochemical X-ray Fluorescence Experiment: Preliminary Report: Science, v. 175, p. 436440.

Adler, I., Trombka, J. I., Gerard, J., Lowman, P., Schmadebeck, R., Blodgett, H., Eller, E., Yin, L., Lamothe, R., Osswald, G., Gorenstein, P., Bjorkholm, P., Gursky, H., and Harris, B., 1972e,
Apollo 16 Geochemical X-ray Fluorescence Experiment: Preliminary report: Science, v. 177 , p. 256-259.

Adler, I., Trombka, J. I., Schmadebeck, R., Lowman, P., Blodgett, H., Yin, L., Eller, E., Podwysocki, M. H., Weidner, J. R., Bickel, A. L., Lum, R. K. L., Gerard, J., Gorenstein, P., Bjorkholm, P., and Harris, B., 1973, Results of Apollo 15 and 16 X-ray Experiment: Proc. Fourth Lunar Sci. Conf., Geochim. et Cosmochim. Acta, Supp. 4, v. 3, p. $2783-2791$.

Aeronautical Chart and Information Center, 1971, Apollo 14 Lunar photography Indexes: Prepared by the Aeronautical Chart and Information Center, U.S. Air Force, for Natl. Aeronautics Space Admin. (photography indexes compiled by the Manned Spacecraft Center, Mapping Sciences Branch, Houston, Tex.), 3 sheets.

1972, Apollo 15 lunar photography index maps: prepared by the Aeronautical Chart and Information Center, U.S. Air Force, for the Natl. Aeronautics Space Admin., 10 sheets.

Allen, D. A., 1971, Infrared studies of the lunar terrain, I: The background Moon: The Moon, v. 2, p. 320-337.

Ananda, Mohan, 1975, Farside lunar gravity from a mass point model [abs.]: Proc. Sixth Lunar Sci. Conf., Geochim. et Cosmochim. Acta, Supp. 6, Part I, p. 9-11.

Andre, C. G., Hallam, M. E., Clark, P. E., Podwysocki, M. H., Weidner, J. R., and Adler, I., 1975, Synthesis of remote sensing data from the Tranquillitatis/Serenitatis area [abs.], in Abstracts of papers submitted to the Sixth Lunar Science Conference: Houston, Tex., Lunar Sci. Inst., p. 15-17.

Arnold, J. R., Metzger, A. E., Peterson, L. E., and Trombka, J. I., 1972a, Gamma-Ray Spectrometer Experiment, in Apollo 15 preliminary science report, pt. 16: Natl. Aeronautics Space Admin. Spec. Pub. NASA SP-289, p. 16(1)-16 (6).

Arnold, J. R., Metzger, A. E., Peterson, L. E., Reedy, R. C., and Trombka, J. I., 1972b, Gamma-Ray Spectrometer Experiment, in Apollo 16 preliminary science report, pt. 18: Natl. Aeronautics Space Admin. Spec. Pub. NASA SP-315, p. 18(1)-18(8).

Aronson, J. R., Emslie, A. G., Allen, R. V., and McLinden, H. G., 1967, Studies of the middle-and-far-infrared spectra of mineral surfaces for application in remote composition of the Moon and planets: Jour. Geophys. Research, v. 72, p. 687-703.

Arvidson, R., Crozaz, G., Drozd, R. J., Hohenberg, C. M., and Morgan, C. J., 1975, Cosmic ray exposure ages of features and events at the Apollo landing site: The Moon, v. 13, p. 259-276.

Bancroft, C. M., and Burns, R. G., 1967, Interpretation of the electronic spectra of iron in pyroxenes: Am. Mineralogist, v. 52, p. 1278-1287.

Barabashov, N. P., 1924, Spectrophotometric investigations of the lunar surface: Astron. Zhur., v. 1, p. 44-57. 1953, On color contrasts of the lunar surface: Priroda, v. 42, p. $88-90$.

Bence, A. R., and McGee, J., 1976, Significance of the assemblage anorthite-aluminous enstatite-fosterite-aluminous spinel in the lunar highlands [abs.]: Geol. Soc. America Ann. Mtg., Denver, Colo., 8 Nov-11 Nov 1976, Proc., p. 772.

Boyce, J. M., 1975, Chronology of the major flow units in the western nearside maria, in Conference on origins of mare basalts and their implications for lunar evolution: Houston, Tex., Lunar Sci. Inst., p. 11-14.

1976, Relative ages of flow units in the lunar nearside maria, in Abstracts of papers submitted to the Seventh Lunar Science Conference: Houston, Tex., Lunar Sci. Inst., p. 85-87.

Boyce, J. M., and Dial, A. L., 1973, Relative ages of some nearside mare units based on Apollo 17 metric photographs, in Apollo 17 preliminary science report: Natl. Aeronaut. Space Admin. Spec. Pub. 330, p. 29-26 to $29-28$. 
1975, Relative ages of flow units in Mare Imbrium and Sinus Iridum: Proc. Sixth Lunar Sci. Conf., Geochim. et Cosmochim. Acta, Supp. 6, v. 3, p. 2585-2595.

Boyce, J. M., Dial, A. L., and Soderblom, L. A., 1974, Ages of the lunar nearside light plains and maria: Proc. Fifth Lunar Sci. Conf., Geochim. et Cosmochim. Acta, Supp. 5, v. 1, p. 11-23.

-1975, A summary of relative ages of lunar nearside and farside plains, U.S. Geol. Survey Interagency Report Astrogeology-66, $26 \mathrm{p}$.

Burns, A. A., 1969, Diffuse component of lunar radar echoes: Jour. Geophys. Research, v. 74, p. 6553-6566.

Burns, R. G., 1965, Electronic spectra of silicate minerals: Application of crystal field theory to aspects of geochemistry: Univ. California, Berkeley, Ph.D. thesis, 293 p.

1970, Mineralogical applications of crystal-field theory: London, Cambridge Univ. Press, 224 p.

Campbell, M.J., and Ulrichs, J., 1969, Electrical properties of rocks and their significance for lunar radar observations, Jour. Geophys. Research, v. 74, p. 5867-5881.

Carr, M. H., 1965, Geologic map of the Mare Timocharis region of the Moon: U.S. Geol. Survey Misc. Geol. Inv. Map I-462 (LAC 40), scale 1:1,000,000.

1966, Geologic map of the Mare Serenitatis region of the Moon: U.S. Geol. Survery Misc. Geol. Inv. Map I-489 (LAC 42), scale 1:1,000,000.

Cassidy, W. A., and Hapke, B. W., 1975, Effects of darkening processes on surfaces of airless bodies: Icarus, v. 25, p. 371-383.

Chao, E. C. T., Hodges, C. A., Boyce, J. M., and Soderblom, L. A., 1975, Origin of lunar light plains: U.S. Geol. Survey Jour. Research, v. 3 , no. 4 , p. 379-392.

Chao, E. C. T., Soderblom, L. A., Boyce, J. M., Wilhelms, D. E., and Hodges, C. A., 1973, Lunar light plains deposits (Cayley Formation)-A reinterpretation of origin [abs.], in Abstracts submitted to the Fourth Lunar Science Conference: Houston, Tex., Lunar Sci. Inst., p. 127-128.

Charette, M. P., and Adams, J. B., 1975, Agglutinates as indicators of lunar soil maturity: Proc. Sixth Lunar Sci. Conf., Geochim. et Coshochim. Acta, Supp. 6, v. 2, p. 2281-2289.

Charette, M. P., McCord, T. B., Pieters, Carle, and Adams, J. B., 1974, Application of remote spectral reflectance measurements to lunar geology: Classification and determination of titanium content of lunar soils: Jour. Geophys. Research, v. 79, p. 16051613.

Cisowski, S., Fuller, M. D., Rose, M. E., and Wasilewski, P. J., 1972, Magnetic effects of experimental shocking of lunar soil: Proc. Fourth Lunar Sci. Conf., Geochim. et Cosmochim. Acta, Supp. 4, v. 3, p. 3003-3017.

Clayton, R. N., Mayeda, T. K., and Hurd, J. M., 1974, Loss of O, Si, S, and $\mathrm{K}$ from the lunar regolith [abs.], in Abstracts submitted to the Fifth Lunar Science Conference: Houston, Tex., Lunar Sci. Inst. p. 129-131.

Coleman, P. J., Lichtenstein, B. R., Russell, C. T., Schubert, G., and Sharp, L. R., 1972, The Particles and Fields Subsatellite Magnetometer Experiment, in Apollo 16 Preliminary Science Report: Natl. Aeronautics Space Admin. Spec. Pub. 315, p. 23-1 to 23-13.

Coleman, P. J., Jr., Schubert, G., Russell, C. T., and Sharp, L. R., 1971, The Particles and Fields Subsatellite Magnetometer Experiment, in Apollo 15 Preliminary Science Peport: Natl. Aeronautics Space Admin. Spec. Pub. 289, p. 22-1 to 22-9.

Collinson, D. W., Runcorn, S. K., and Stephenson, A., 1975, On changes in the ancient lunar magnetic field intensity [abs.], in Abstracts submitted to the Sixth Lunar Science Conference: Houston, Tex., Lunar Sci. Inst., p. 158-160.
Collinson, D. W., Runcom, S. K., Stephenson, A., and Manson, A. J., 1972, Magnetic properties of Apollo 14 rocks and fines: Proc. Third Lunar Sci. Conf., Geochim. et Cosmochim. Acta, Supp. 3, v. 3, p. 2343-2361.

Conel, J. E., 1970, Coloring of synthetic and natural lunar glass by titanium and iron, Part A, Section VI, Lunar and planetary sciences_Space Science Division: Pasadena, California Inst. Technology Space Programs Summary 37-62, v. III, Jet Propulsion Lab., p. 26-31.

Conel, J. E., and Nash, D. B., 1970, Spectral reflectance and albedo of Apollo 11 lunar samples: Effects of irradiation and vitrification and comparison with telescopic observations: Proc. Apollo 11 Lunar Sci. Conf., Geochim. et Cosmochim. Acta, Supp. 1, v. 3, p. 2013-2023.

Cook, M. L., and Mortensen, K. S., 1967, Impact cratering in granular materials: Jour. Appl. Physics, v. 38, p. 5125-5128.

Costes, N. C., 1973, Regional variations in physical and mechanical properties of lunar surface regolith [abs.], in Abstracts submitted to the Fourth Lunar Science Conference: Houston, Tex., Lunar Sci. Inst., p. 159-161.

Cremers, C. J., and Hsia, H. S., 1973, Thermal conductivity and diffusivity of Apollo 15 fines at low density, Proc. Fourth Lunar Sci. Conf., Geochim. et Cosmochim. Acta, supp. 4, v. 4, p. 24592464.

1974, Thermal conductivity of Apollo 16 lunar fines: Proc. Fifth Lunar Sci. Conf., Geochim. et Cosmochim. Acta, Supp. 5, v. 3, p. 2703-2708.

Crozaz, G., Drozd, R. J., Hohenberg, C. M., Morgan, C. J., Ralston, C., Walker, R., and Yuhas, D., 1974, Lunar surface dynamics: Some general conclusions and new results from Apollo 16 and 17: Proc. Fifth Lunar Sci. Conf., Geochim. et Cosmochim. Acta, Supp. 5, p. 2475-2499.

Defense Mapping Agency, Aerospace Center, 1972, Apollo Mission 16 lunar photography index maps: prepared and published by Defense Mapping Agency, Aerospace Center, St. Louis, Mo., for the Natl. Aeronautics Space Admin. (photography indexes compiled by Manned Spacecraft Center, Mapping Sci. Branch, Houston, Tex.), 6 sheets.

1973, Apollo Mission 17 lunar photography index maps: prepared and published by the Defense Mapping Agency Aerospace Center, St. Louis, Mo., for the Natl. Aeronautics Space Admin., 8 sheets.

Dennis, J. G., 1971, Ries structure, southern Germany-A review: Jour. Geophys. Research, v. 76, p. 5394-5406.

DeWitt, J. H., and Stodola, E. K., 1949, Detection of radio signals reflected from the Moon: Proc. Inst. Radio Eng., v. 37, p. 229.

Doell, R. R., Grommé, C. S., Thorpe, A. N., and Senftle, F. E., 1970, Magnetic studies of Apollo 11 lunar samples: Proc. Apollo 11 Conf., Geochim. et Cosmochim. Acta, Supp. 1, v. 34, p. 2097 2120.

Dolginov, Sh. Sh., Eroshenko, E. G., Zhuzgov, L. N., and Pushkov, N. V., 1966, Measurements of the magnetic field in the vicinity of the Moon by the artificial satellite Luna 10: Dokl. Akad. Nauk SSSR, v. 170 , p. 574-577.

Dollfus, A., 1962, The polarization of moonlight, in Kopal, Zdenek ed., Physics and astronomy of the Moon: New York, Academic Press, p. 131-159.

Dollfus, A., Bowell, E., and Titulaer, C., 1971, Polarimetric properties of the lunar surface and its interpretation, Part IITerrestrial samples in orange light: Astronomy and Astrophysics, v. 10 , p. $450-466$.

Duennebier, F. K., Dorman, J., Lammlein, D., Latham, G., and Nakamura, Y., 1975, Meteroid flux from passive seismic experiment data: Proc. Sixth Lunar Sci. Conf., Geochim. et Cos- 
mochim. Acta, Supp. 6, v. 2, p. 2417-2426.

Duennebier, F. K., Watkins, J. S., and Kovach, R. L., 1974, Results from the Lunar Surface Profiling Experiment: Abs. Fifth Lunar Sci. Conf., Johnson Spacecraft Center, Houston, Tex., March $18-22,1974$, p. 183.

Dunn, J., Fisher, R. M., Fuller, M. D., Lally, S., Rose, M. E., Schwerer, F. L., and Wasilewski, P. J., 1972, Shock remanent magnetization of lunar soil [abs.], in Abstracts submitted to the Fourth Lunar Science Conference: Houston, Tex., Lunar Sci. Inst., p. 194-195.

Dyal, P. C., Parkin, C. W., and Sonnett, C. P., 1970, Lunar Surface Magnetometer Experiment, in Apollo 12 Preliminary Science Report: Natl. Aeronautics Space Admin. Spec. Pub. 235, p. 55-73.

Dyal, P. C, Parkin, C. W., Colburn, D. S., and Schubert, G., 1972, Lunar Surface Magnetometer Experiment: Apollo 16 Prelim. Sci. Rept., Natl. Aeronautics Space Admin. Spec. Pub. 315, p. 11-1 to 11-14.

Eggleton, R. E., 1965, Geologic map of the Riphaeus Mountains region of the Moon: U.S. Geol. Survey Misc. Geol. Inv. Map I-458 (LAC 76), scale $1: 1,000,000$.

Eggleton, R. E., and Schaber, G. G., 1972, Cayley Formation interpreted as basin ejecta, in Apollo 16 preliminary science report: Natl. Aeronautics Space Admin. Spec. Pub. 315, p. 29-7 to 29-16.

Elston, D. P., 1972, Geologic map of the Colombo quadrangle of the Moon: U.S. Geol. Survey Misc. Geol. Inc. Map I-714 (LAC 79), scale $1: 1,000,000$.

Epstein, S., and Taylor, H. P., Jr., 1971, $\mathrm{O}^{18} / \mathrm{O}^{16}, \mathrm{Si}^{30} / \mathrm{Si}^{28 .} \mathrm{D} / \mathrm{H}$, and $\mathrm{C}^{13} / \mathrm{C}^{12}$ ratios in lunar samples: Proc. Second Lunar Sci. Conf., Geochim. et Cosmochim. Acta, Supp. 2, v. 2, p. 1421-1441.

Evans, J. V., 1962, Radio echo studies of the Moon, in Kopal, Zdeněk, ed., Physics and astronomy of the Moon: New York, Academic Press, p. 429-479.

Evans, J. V., and Hagfors, T., 1971, Radar studies of the Moon, in Advances in astronomy and astrophysics: New York, Academic Press, p. 29-105.

Evans, J. V., and Pettengill, G. H., 1963, The scattering behavior of the Moon at wavelengths of $3.6,68$, and 784 centimetres: Jour. Geophys. Research, v. 68, p. 423-447.

Ferrari, A. J., 1975, Lunar gravity: The farside map: Science, v. 188, p. $1297-1300$.

Fessenkov, V. G., 1962, Photometry of the Moon, in Kopal, Zdeněk, ed., Physics and astronomy of the Moon: New York, Academic Press, p. 99-128.

Fuller, M. D., 1974, Lunar magnetism: Rev. Geophysics and Space Physics, v. 12, p. 23-70.

Gault, D. E., 1970, Saturation and equilibrium conditions for impact cratering on the lunar surface: Criteria and implications: Radio Sci. v. 5 , no. 12 , p. $273-291$.

Gehrels, T., Coffeen, T., and Owings, D., 1964, Wavelength dependence of polarization-III. The lunar surface: Astron. Jour., v. 69 , p. $826-852$.

Goetz, A. F. H., Billingsley, F. C., Head, J. W., McCord, T. B., and Yost, E., 1971, Apollo 12 multispectral photography experiment: Proc. Second Lunar Sci. Conf., Geochim. et Cosmochim. Acta, Supp. 2, v. 3, p. 2301-2310.

Gold, T., 1955, The lunar surface: Monthly Notes Royal Astron. Soc., v. 115 , p. $585-604$.

Gold, T., Bilson, E., and Baron, R. L., 1974, Observations of iron-rich coating on lunar grains and relation to low albedo: Proc. Fifth Lunar Sci. Conf., Geochim. et Cosmochim. Acta, Supp. 5, v. 3, p. 2413-2422.

Gold, T., Campbell, M. J., and O'Leary, B. T., 1970, Optical and high-frequency electrical properties of the lunar sample: Science, v. 167, p. 707-709.
Gosé, W. A., Pearce, G. W., Strangway, D. W., and Larson, E. E., 1972 , On the applicability of lunar breccias for paleomagnetic interpretations: The Moon, v. 5, p. 156-169.

Greeley, R., 1970, Terrestrial analogs to lunar dimple (drainage) craters: The Moon, v. 1, p. 237-252.

Griscom, D. L., Friebele, E. J., and Marquardt, C. L., 1972, Evidence for a ubiquitous, sub-microscopic "magnetite-like" constituent in lunar soils: Proc. Fourth Lunar Science Conf., Geochim. et Cosmochim. Acta, Supp. 4, v. 3, p. 2709-2727.

Grudewicz, E. B., 1974, Lunar upland and plains relative age determination and their bearing on the provenance of the Cayley Formation [abs.], in Abstracts submitted to the Fifth Lunar Science Conference: Houston, Tex., Lunar Sci. Inst., p. 568-570.

Hackman, R. J., 1962, Geologic map and sections of the Kepler region of the Moon: U.S. Geol. Survey Misc. Geol. Inv. Map I-355 (LAC 57), scale $1: 1,000,000$.

1966, Geologic map of the Montes Apenninus region of the Moon: U.S. Geol. Survey Misc. Geol. Inv. Map I-463 (LAC 41), scale $1: 1,000,000$.

Hagfors, T., 1967, A study of the depolarization of lunar radar echoes: Radio Sci., v. 2, p. 445-465.

Hagfors, T., Namii, B., and Stone, K., 1968, Aperture synthesis in radar astronomy and some applications to lunar and planetary studies: Radio Sci., v. 3, p. 491-509.

Hallam, M. E., Andre, C. G., Clark, P. E., Podwysocki, M. H., and Weidner, J. R., 1974, Statistical analysis of Al/Si intensity ratios as a lunar geologic mapping technique [abs.], in Abstracts of papers submitted to the Sixth Lunar Science Conference: Houston, Tex., Lunar Sci. Inst., p. 327-329.

Hallam, M. E., Andre, C. G., and Weidner, J. R., 1975, Al/Si intensities of crater materials and the depths of Tranquillitatis and Serenitatis basalts [abs.]: Meteoritics, v. 10, p. 409.

Hapke, B. W., 1963, A theoretical photometric function for the lunar surface: Jour. Geophys. Research, v. 68, p. 4571-4586. 1964, Photometric and other laboratory studies relating to the lunar surface, in Salisbury, J. W., and Glaser, P. E., eds., The lunar surface layer-materials and characteristics: New York, Academic Press, p. 323-334.

1966, Optical properties of the Moon's surface, in Hess, W., Menzel, D., and O'Keefe, J., eds., The nature of the lunar surface: Baltimore, Md., Johns Hopkins Univ. Press, p. 141-153. -1970 , Inferences from the optical properties of the Moon concerning the nature and evolution of the lunar surface: Radio Sci., v. 5 , p. $293-299$.

Hapke, B. W., Cassidy, W. A., and Wells, E. N., 1973, Chemical, magnetic and optical characterizations of glasses produced by simulated lunar surface processes: Trans. Am. Geophys. Union, v. 54, p. 356.

Hapke, B. W., Cohen, A. J., Cassidy, W. A., and Wells, E. N., 1970, Solar radiation effects on the optical properties of Apollo 11 samples: Proc. Apollo 11 Lunar Sci. Conf., Geochim. et Cosmochim. Acta, Supp. 1, v. 3, p. 2199-2212.

Hapke, B. W., and Van Horn, H., 1963, Photometric studies of complex surfaces with applications to the Moon: Jour. Geophys. Research, v. 68 , p. $4545-4570$.

Hartmann, W. K., and Wood, C. A., 1971, Moon-Origin and evolution of multi-ring basins: The Moon, v. 3, p. 3-78.

Head, J. W., 1974, Orientale multi-ringed basin interior and implications for the petrogenesis of lunar highland samples: The Moon, v. 11 , p. $327-356$.

-1976, Lunar volcanism in space and time: Rev. Geophysics Space Physics, v. 14, p. 265-300.

Heiken, G. H., and McKay, D. S., 1974, Petrology of Apollo 17 soils: Proc. Fifth Lunar Sci. Conf., Geochim. et Cosmochim. Acta, Supp. 5, v. 1, p. 843-860.

Helsley, C. E., 1970, Magnetic properties of Lunar 10022, 10069, 
10084, and 10085 samples: Proc. Apollo 11 Lunar Sci. Conf., Geochim. et Cosmochim. Acta, Supp. 1, v. 3, p. 2213-2219.

Hemingway, B. S., Robie, R. A., and Wilson, W. H., 1973, Specific heats of lunar soils, basalt, and breccias from the Apollo 14, 15, and 16 landing sites, between $90^{\circ}$ and $350^{\circ} \mathrm{K}$ : Proc. Fourth Lunar Sci. Conf., Geochim. et Cosmochim. Acta, Supp. 4, v. 3, p. 24812487.

Hodges, C. A., 1973, Geologic map of the Langrenus quadrangle of the Moon: U.S. Geol. Survey Misc. Geol. Inv. Map I-714 (LAC 80 ), scale $1: 1,000,000$

Hoffman, K. A., and Banerjee, S. K., 1975, Magnetic "zig-zag" behavior in lunar rocks: Earth and Planetary Sci. Letters, v. 25, p. 331-337.

Holt, H. E., 1974, Geologic map of the Purbach quadrangle of the Moon: U.S. Geol. Survey Misc. Geol. Inv. Map I-822, (LAC 95), scale $1: 1,000,000$.

Horn, P., Jessberger, E. K., Kirsten, T., and Richter, H., 1975, ${ }^{39} \mathrm{Ar} /$ ${ }^{40} \mathrm{Ar}$ dating of lunar rocks: Effects of grain size and neutron irradiation: Proc. Sixth Lunar Sci. Conf., Geochim. et Cosmochim. Acta, Supp. 6, v. 2, p. 1563-1591.

Housley, R. M., Cirlin, E.H., Paton, N. E. and Goldberg, I. B., 1974, Solar wind and micrometeorite alteration of the lunar regolith: Proc. Fifth Lunar Sci. Conf., Geochim. et Cosmochim. Acta., Supp. 5, v. 3, p. 2623-2642.

Housley, R. M., Grant, R. W., and Paton, N. E., 1973, Origin and characteristics and excess $\mathrm{Fe}$ metal in lunar glass welded aggregates: Proc. Fourth Lunar Sci. Conf., Geochim. et Cosmochim. Acta, Supp. 4, v. 3, p. 2737-2749.

Howard, H. T, and Tyler, G. L., 1971, Bistatic-radar investigations, in Apollo 14 preliminary science report: Natl. Aeronautics Space Admin. Spec. Pub. NASA SP-272, p. 257-266.

-1972a, Bistatic-radar investigation, in Apollo 15 preliminary science report: Natl. Aeronautics Space Admin. Spec. Pub. NASA SP-289, p. 23-1 to 23-10.

1972b, Bistatic-radar investigation, in Apollo 16 preliminary science report: Natl. Aeronautics Space Admin. Spec. Pub. NASA SP-315, p. 25-1 to 25-13.

Howard, K. A., 1973, Avalanche mode of motion-Implication from lunar samples: Science, v. 180, p. 1052-1055.

Howard, K. A., Carr, M. H., and Muehlberger, W. R. 1973, Basalt stratigraphy of southern Mare Serenitatis, in Apollo 17 preliminary science report: Natl. Aeronautics Space Admin. Spec. Pub. NASA SP-330, p. 29(1)-29(12).

Howard, K. A., and Masursky, Harold, 1968, Geologic map of the Ptolemaeus quadrangle of the Moon: U.S. Geol. Survey Misc. Geol. Inv. Map I-566 (LAC 77, RLC-13), scale 1 : 1,000,000.

Howard, K. A., Wilhelms, D. E., and Scott, D. H., 1974, Lunar basin formation and highland stratigraphy: Rev. Geophysics Space Physics, v. 12, no. 3, p. 309-327.

Hubbard, J. J., and Minear, J. W., 1975, A physical and chemical model of early lunar history: Proc. Sixth Lunar Sci. Conf., Geochim. et Cosmochim. Acta, Supp. 6, v. 1, p. 1057-1085.

Hunt, G. R., and Salisbury, J. W., 1970, Visible and near-infrared spectra of minerals and rocks, 1, Silicate minerals: Modern Geology, v. 1, p. 283-300.

Hutcheon, I. D., Macdougall, D., and Stevenson, J., 1974, Apollo 17 particle track studies-surface residence times and fission track ages for orange glass and large boulders: Proc. 5th Lunar Sci. Conf., Geochim. et Cosmochim. Acta, Supp. 5, v. 3, p. 2597-2608.

Innes, M. J. S., 1961, The use of gravity methods to study the underground structure and impact energy of meteorite craters: Jour. Geophys. Research, v. 66, p. 2225-2239.

Kaula, W. M., 1975, The gravity and shape of the Moon: EOS, Trans. Am. Geophys. Union, v. 56, p. 309-316.

Kirsten, T., Horn, P., and Kiko, J., 1973, ${ }^{39} \mathrm{Ar}-{ }^{40} \mathrm{Ar}$ dating and rare gas analysis of Apollo 16 rocks and soils: Proc. Fourth Lunar Sci.
Conf., Geochim. et Cosmochim. Acta, Supp. 4, v. 2, p. 1757-1784.

Kovach, R. L., Watkins, J. S., and Landers, T., 1971, Active Seismic Experiment, in Apollo 14 preliminary science report: Natl. Aeronautics Space Admin. Spec. Pub. NASA SP-272, p. 163174.

Kovach, R. L., Watkins, J. S., and Talwani, P., 1972, Active Seismic Experiment, in Apollo 16 preliminary science report: Natl. Aeronautics Space Admin. Spec. Pub. NASA SP-315, p. 10(1)10(14).

Kuiper, G. P., 1965, Interpretation of Ranger VII records, in Ranger VII, pt. 2: Experimenters' analysis and interpretation: Pasadena, Calif., Jet Propulsion Laboratory, California Inst. Technology Tech. Rept. 32-700, p. 9-73.

Leich, D. A., Kahl, S. B., Kirschbaum, A.R., Niemeyer, S., and Phinney, D., 1975, Rare gas studies on Boulder 1, Station 2, Apollo 17 [abs], in Abstracts submitted to the Sixth Lunar Science Conference: Houston, Tex., Lunar Sci. Inst., p. 501-503.

Lin, R. P., Anderson, K. A., Goldstein, B., Gose, W. A, Hubbard, N. J., McCoy, J. E., Schaber, G. G., and Srnka, L. F. J., 1975a, Proposal to measure the lunar surface magnetic fields using the electron scattering method: Space Sciences Lab., Univ. California, Berkeley, UCBSSL No. 581/74, 216 p.

Lin, R. P., McGuire, R. E., Howe, H. C., and Anderson, K. A., 1975b, Mapping of lunar surface remanent magnetic fields by electron scattering: Proc. Sixth Lunar Sci. Conf., Geochim. et Cosmochim. Acta, Supp. 6, v. 3, p. 2971-2973.

Lincoln Laboratory, 1968, Radar studies of the Moon, vols. I and II; Lexington, Mass., Lincoln Laboratory, Mass. Inst. Technology, $125 \mathrm{p}$.

Lucchitta, B. K., 1977, Tycho, secondary crater clusters and the origin of the Apollo 17 light mantle: Icarus, v. 30, p. 80-96.

Lucchitta, B. K., and Sanchez, A. G., 1975, Crater studies in the Apollo 17 region: Proc. Sixth Lunar Sci. Conf., Geochim. et Cosmochim. Acta, Supp. 6, v. 3, p. 2427-2441.

Lucchitta, B. K., and Schmitt, H. H., 1974, Orange glass in the Sulpicius Gallus Formation at the southwestern edge of Mare Serenitatis: Proc. Fifth Lunar Sci. Conf., Geochim. et Cosmochim. Acta, Supp. 5, v. 1, p. 223-234.

Lugmair, G. W., Scheinin, N. B., and Marti, K., 1975, Sm-Nd age and history of Apollo 17 basalt 75075: Evidence for early differentiation of the lunar exterior: Proc. Sixth Lunar Sci. Conf., Geochim. et Cosmochim. Acta, Supp. 6, v. 2, p. 1419-1429.

Lyot, B., 1929, Research on the polarization of light from planets and some terrestrial substances: Ann. Obs. Paris, v. 8, pt. I, 161 p.; translated 1964; Natl. Aeronautics Space Admin. Tech. Translation F-187, 144 p.

McCauley, J. F., 1967, Geologic map of the Hevelius region of the Moon: U.S. Geol. Survey Misc. Geol. Inv. Map I-491 (LAC 56), scale 1:1,000,000.

1973, Geologic map of the Grimaldi quadrangle of the Moon: U.S. Geol. Survey Misc. Geol. Inv. Map I-740 (LAC-74), scale 1:1,000,000

McCord, T. B., 1968, Color differences on the lunar surface: Pasadena, California Inst. of Technology, Ph.D. thesis, $181 \mathrm{p}$. 1969 , Color differences on the lunar surface: Jour. Geophys. Research, v. 74, p. 3131-3142.

McCord, T. B., and Adams, J. B, 1973, Progress in remote optical analysis of luanr surface composition: The Moon, v. 7, p. 453474.

McCord, T. B., Charette, M.P., Johnson, T. V., Lebofsky, L. A., and Pieters, Carle, 1972, Spectrophotometry ( 0.3 to 1.1 microns) of visited and proposed Apollo lunar landings sites: The Moon, v. 4, p. $52-89$.

McCord, T. B., and Johnson, T. V., 1969, Relative spectral reflectivity (0.4 to 1.0 microns) of selected areas of the lunar surface: Jour. Geophys. Research, v. 74, p. 4395-4401. 
1970 , Lunar spectral reflectivity ( 0.30 to 2.50 microns) and implications for remote mineralogical analysis: Science, v. 169, p. 855-858.

McCoy, J. E., Anderson, K. A., Lin, R. P., Howe, H. C., and McGuire, R. E., 1975, Lunar remanent magnetic field mapping from orbital observation of mirrored electrons: The Moon, v. 14, p. 35-47.

McGetchin, T. R., Settle, Mark, and Head, J. W., 1973, Radial thickness variation in impact crater ejecta: Implications for lunar basin deposits: Earth Planetary Sci. Letters, v. 20, p. 226-236.

McKee, L.L., Bird, R. S., and Schwirzke, F., 1974, Self-generated magnetic fields associated with a laser-produced plasma: Phys. Rev. Part A, v. 9, p. 1305-1311.

Marcus, A.H., 1970, Comparison of equilibrium size distributions for lunar craters: Jour. Geophys. Research, v. 75 , no. 26, p. $4977-$ 4984.

Markov, A. V., 1962, The physical properties of the lunar surface, in The Moon-A Russian view: Univ. Chicago Press, p. 123-156.

Marshall, C. H., 1963, Geologic map and sections of the Letronne region of the Moon: U.S. Geol. Survey Misc. Geol. Inv. Map I-385 (LAC 75), scale 1:1,000,000.

Marti, K., Lightner, B. D., and Osborn, T. W., 1973, Krypton and xenon in some lunar samples and the age of North Ray Crater: Proc. Fourth Lunar Sci. Conf., Geochim. et Cosmochim. Acta, Supp. 4, v. 2, p. 2037-2048.

Metzger, A. E., Trombka, J. I., Reedy, R. C., and Arnold, J. R., 1974, Element concentrations from lunar orbital gamma-ray measurements: Proc. Fifth Lunar Sci. Conf., Geochim. et Cosmochim. Acta, Supp. 5, v. 2, p. 1067-1078.

Miethe, A., and Seegert, B., 1911, On qualitative differences of light reflected by various parts of the Moon's surface: Astron. Nachrichten, v. 188, no. 4489, p. 9-12; no. 4502, p. 239-246; no. 4510, p. 371-374.

-1914, Qualitative differences in the light reflected from various parts of the Moon: Astron. Nachrichten, v. 198, no. 4736, p. 121-124.

Milton, D. J., 1968, Geologic map of the Theophilus quadrangle of the Moon: U.S. Geol. Survey Misc. Geol. Inv. Map I-546 (LAC-78), scale $1: 1,000,000$.

Minnaert, M. G. J., 1969, The effect of pulverization on the albedo of lunar rocks, Icarus, v. 11, p. 332-337.

Moore, H. J., 1964, Density of small craters on the lunar surface, in Astrogeologic studies annual progress report, August 24, 1962_July 1, 1963, pt. D: U.S. Geol. Survey open-file report, p. 34-51.

1965, Geologic map of the Aristarchus region of the Moon: U.S. Geol. Survey Misc. Geol. Inv. Map I-465 (LAC 39), scale 1:1,000,000.

1967, Geologic Map of the Seleucus quadrangle of the Moon: U.S. Geol. Survey Misc. Geol. Inv. Map I-527 (LAC 38), scale 1:1,000,000.

1968, Ranger VIII and gravity scaling of lunar craters: Science, v. 159 , p. $333-334$.

1971a, Geologic interpretation of lunar data: Earth Sci. Rev., v. 7 , p. $5-33$.

- 1971b, Craters produced by missile impacts: Jour. Geophys. Research, v. 76 , p. $5750-5755$.

1976, Missile impact craters (White Sands Missile Range, New Mexico) and applications to lunar research: U.S. Geol. Survey Prof. Paper 812-B, 47 p.

Moore, H. J., Hodges, C. A., and Scott, D. H., 1974, Multiringed basins-Illustrated by Orientale and associated features: Proc. Fifth Lunar Sci. Conf., Geochim. et Cosmochim. Acta, Supp. 5, v. 1, p. $71-100$.

Moore, H. J., Lugn, R. V, and Newman, E. B., 1974, Some morphometric properties of experimentally cratered surfaces: U.S. Geol. Survey Jour. Research, v. 2, p. 279-388.
Moore, H. J., and Schaber, G. G., 1975, An estimate of the yield strength of the Imbrium flows: Proc. Sixth Lunar Science Conf., Geochim. et Cosmochim. Acta, Supp. 6, v. 1, p. 101-118.

Moore, H. J., and Tyler, G. L., 1974, Comparison between photogrammetric and bistatic radar slope-frequency distributions, in Apollo 17 preliminary science report, pt. C: Natl. Aeronautics Space Admin. Spec. Pub. NASA SP-330, p. 33(17)-33(26).

Moore, H. J., Tyler, G. L., Boyce, J. M, Shorthill, R. W., Thompson, T. W., Walker, A. S., Wilhelms, D. E., Wu, S.S.C., and Zisk, S. H., 1975, Correlation of photogeology and remote sensing data along the Apollo 14 bistatic-radar ground track, Part I-A working compendium: U.S. Geol. Survey Interagency Report Astrogeology 75 (Open-File Rept. 75-284), 88 p.

1976, Correlation of photogeology and remote sensing data along the Apollo 14, 15, 16 bistatic-radar ground track, Part II-A working compendium: U.S. Geol. Survey Interagency Rept. Astrogeology 80, (Open-File Rept. 76-298), 101 p.

Moore, H. J., and Zisk, S. H., 1973, Calibration of radar data from Apollo 17 and other mission results, in Apollo 17 preliminary science report: Natl. Aeronautics Space Admin. Spec. Pub. NASA SP-330, part B, p. 33(10)-33(17).

Morris, E. C., and Wilhelms, D. E., 1967, Geologic map of the Julius Caesar quadrangle of the Moon: U.S. Geol. Survey Misc. Geol. Inv. Map I-510 (LAC 60), scale 1:1,000,000.

Morrison, D. A., McKay, D. S., Moore, H. J., and Heiken, G. H., 1972, Microcraters on lunar rocks, in Criswell, D. R., ed., Proc. Third Lunar Sci. Conf., Geochim. et Cosmochim. Acta, Supp. 3, v. 3, p. 2767-2791.

Morrison, R. H., and Oberbeck, V. R., 1975, Geomorphology of crater and basin deposits-Emplacement of the Fra Mauro Formation: Proc. Sixth Lunar Sci. Conf., Geochim. et Cosmochim. Acta, Supp. 6, v. 3, p. 2503-2530.

Muehlberger, W. R., Batson, R. M., Freeman, V. L., Hait, M. H., Holt, H. E., Howard, K. A., Jackson, E. D., Larson, K. B., Reed, V. S., Rennilson, J. A., Scott, D. H., Sutton, R. L., Stuart-Alexander, D. E., Swann, G. A, Trask, N. J., Ulrich, G. E., Wilshire, H. G., and Wolfe, E. W., 1973, Preliminary geologic analysis of the Apollo 17 site, in Apollo 17 preliminary science report: Natl. Aeronautics Space Admin. Spec. Pub. 330, p. 6-1 to 6-91.

Muller, P. M., and Sjogren, W. L., 1968, Lunar mass concentrations: Science, v. 161 , no. 3842 , p. $680-684$.

Nagata, T., Fisher, R. M., Schwerer, F. C., Fuller, M. D., and Dunn, J. R., 1971, Magnetic properties and remanent magnetization of Apollo 12 lunar materials and Apollo 11 lunar microbreccias: Proc. Second Lunar Sci. Conf., Geochim. et Cosmochim. Acta, Supp. 2, v. 3, p. 2461-2471.

-1972, Rock magnetism of Apollo 14 and 15 materials: Proc. Third Lunar Sci. Conf., Geochim. et Cosmochim. Acta, Supp. 3, v. 3 , p. $2423-2447$.

-1973, Magnetic properties and natural remanent magnetization of Apollo 15 and 16 lunar materials: Proc. Fourth Lunar Sci. Conf., Geochim. et Cosmochim. Acta, Supp. 4, v. 3, p. 3019-3043. 1975, Basic magnetic properties of Apollo 17 basaltic and anorthositic materials [abs.], in Abstracts submitted to the Sixth Lunar Science Conference: Houston, Tex., Lunar Sci. Inst., p. 584-586.

Nagata, T., Ishikawa, Y., Kinoshita, H., Kono, M., Syono, Y., and Fisher, R. M., 1970, Magnetic properties and natural remanent magnetization of lunar samples: Proc. Apollo 11 Lunar Sci. Conf., Geochim. et Cosmochim. Acta, Supp. 1, v. 3, p. 2325- 2340.

Nagata, T., Sugiura, N., Fisher, R. M., Schwerer, F. C., Fuller, M. D., and Dunn, J. R., 1974, Magnetic properties of Apollo 11-17 lunar materials with special reference to effects of meteorite impact: Proc. Fifth Lunar Sci. Conf., Geochim. et Cosmochim. Acta, Supp. 5, v. 3, p. 2827-2839.

Nakamura, Y., Latham, G., Lammlein, D., Ewing, Maurice, Duen- 
nebier, F. K., and Dorman, J., 1974, Deep lunar interior inferred from recent seismic data: Geophys. Research Letters, v. 1, p. 137-140

Nash, D. B., and Conel, J. E., 1973, Vitrication darkening of rock powders: Implications for optical properties of the lunar surface: The Moon, v. 8, p. 346-364.

-1974 , Spectral reflectance systematics for mixtures of powdered hypersthene, laboradorite, and ilmenite: Jour. Geophys. Research, v. 79, p. 1615-1621.

National Space Science Data Center, 1969, Lunar Orbiter photographic data: Greenbelt, Md., Goddard Space Flight Center, Data User's Note NSSDC 69-05, 37 p. and plates.

-1971a, Apollo 14 lunar photography: Greenbelt, Md.. Goddard Spaceflight Center, Data User's Note NSSDC 71-16a, 25 p.

1971b, Apollo 14 photography: Greenbelt, Md., Goddard Spaceflight Center, Data User's Note NSSDC 71-16b, 139 p.

1971c, Apollo 14 photographic catalog: Greenbelt, Md., Goddard Spaceflight Center, Data User's Note NSSDC 71-16c, 375 p.

1972, Apollo 15 Lunar photography: Greenbelt, Md., Goddard Spaceflight Center, Data User's Note NSSDC 72-07, 33 p., 2 appendices.

___ 1973, Apollo 16 lunar photography: Greenbelt, Md., Goddard Spaceflight Center, Data User's Note NSSDC 73-01, 47 p., 2 appendices.

1974, Apollo 17 lunar photography: Greenbelt, Md., Goddard Spaceflight Center, Data User's Note NSSDC, 74-08, 59 p., 2 appendices.

Nettleton, L. L., 1940, Geophysical prospecting for oil: New York, McGraw-Hill, $444 \mathrm{p}$.

Neukum, G., König, B., and Arkani-Hamed, J., 1975a, Study of lunar impact crater size-distributions: The Moon, v. 12 , no. 2, p. $201-$ 230.

Neukum, G., König, B., Fechtig, H., and Storzer, D., 1975b, Crater ing in the Earth-Moon system: Consequences for age determination by crater counting: Proc. Lunar Sci. Conf. 6th, Geochim. et Cosmochim. Acta, Supp. 6, v. 3, p. 2597-2620.

Nyquist, L. E., Bonsal, B. M, and Wiesmann, H., 1975, Rb-Sr ages and initial ${ }^{87} \mathrm{Sr}{ }^{86} \mathrm{Sr}$ for Apollo 17 basalts and KREEP basalt 15386: Proc. Sixth Lunar Sci. Conf., Geochim. et Cosmochim. Acta, Supp. 6, v. 2, p. 1445-1465.

Oberbeck, V. R., 1970, Laboratory simulation of impact cratering with high explosives: Natl. Aeronautics Space Admin. Tech. Mem. NASA TM-X-62010, $56 \mathrm{p}$.

__ 1975, The role of ballistic erosion and sedimentation in lunar stratigraphy: Rev. Geophysics Space Physics, v. 13, no. 2, p. 337-362.

Oberbeck, V. R., Hörz, F., Morrison, R. H., Quaide, W. L, and Gault, D. E., 1975, The origin of lunar smooth-plains: The Moon, v. 12, no. 1, p. $19-54$.

Oberbeck, V. R., Morrison, R. H., and Wedekin, John, 1972, Lunar secondary craters, in Apollo 16 preliminary science report: Natl. Aeronautics Space Admin. Spec. Pub. NASA SP-315, p. 29(51)-29(56)

Oberbeck, V. R., and Quaide, W. L., 1967, Estimated thickness of a fragmental surface layer of Oceanus Procellarum: Jour. Geophys. Research, v. 72, p. 4697-4704.

1968, Genetic implications of lunar regolith thickness variations: Icarus, v. 9, p. 446-465.

O'Keefe, J. D., and Ahrens, T. J., 1976, Distribution of initial impact ejecta, in Abstracts submitted to the Seventh Lunar Science Conference: Houston, Tex., Lunar Sci. Inst., p. 648-650.

Olson, A. B., and Wilhelms, D. E., 1974, Geologic map of the Mare Undarum quadrangle of the Moon: U.S. Geol. Survey Misc. Geol. Inv. Map I-837 (LAC 62), scale 1: 1,000,000.

Papanastassiou, D. A., and Wasserburg, G. J., 1970, Rb-Sr ages of lunar rocks from the Sea of Tranquillity: Earth Planetary Sci. Letters, v. 8 , p. 1-19.

-1971a, Lunar chronology and evolution from $\mathrm{Rb}-\mathrm{Sr}$ studies of Apollo 11 and 12 samples: Earth Planetary Sci. Letters, v. 11, no. 37 , p. $37-62$.

$-1971 \mathrm{~b}$, The Rb-Sr ages of igneous rocks from the Apollo 14 mission and the ages of the Fra Mauro Formation: Earth Planetary Sci. Letters, v. 12, p. 36-48.

1972, The Rb-Sr age of a crystalline rock from Apollo 16: Earth Planetary Sci. Letters, v. 16, p. 289-298

$-1973, \mathrm{Rb}-\mathrm{Sr}$ ages and initial strontium in basalts from Apollo 15: Earth Planetary Sci. Letters, v. 17, p. 324-337.

$-1975, \mathrm{Rb}-\mathrm{Sr}$ study of a lunar dunite and evidence for early lunar differentiates: Proc. Sixth Lunar Sci. Conf., Geochim. et Cosmochim. Acta, Supp. 6, v. 2, p. 1478-1489.

Parker, M. N., and Tyler, G. L., 1973, Bistatic-radar estimation of surface-slope probability distributions with applications to the Moon: Radio Sci., v. 8, p. 177-184.

Pearce, G. W., Gose, W. A., and Strangway, D. W., 1973, Magnetic studies of Apollo 15 and 16 lunar samples: Proc. Fourth Lunar Science Conf., Geochim. et Cosmochim. Acta, Supp. 4, v. 3, p. 3045-3076.

Pearce, G. W., Strangway, D. W., and Gose, W. A., 1972, Remanent magnetization of the lunar surface: Proc. Second Lunar Sci. Conf., Geochim. et Cosmochim. Acta, Supp. 2, v. 3, p. 2449-2464. -1974, Magnetic properties of Apollo samples and implications for regolith formation: Proc. Fifth Lunar Sci. Conf., Geochim. et Cosmochim. Acta, Supp. 5, v. 3, p. 2815-2826.

Pellicori, S. F., 1969, Polarization-albedo relationship for selected lunar regions: Nature, v. 221, p. 162.

Pettengill, G. H., and Thompson, T. W., 1968, A radar study of the lunar crater Tycho at $3.8 \mathrm{~cm}$ and $70 \mathrm{~cm}$ wavelengths: Icarus, v. 8 , p. $457-471$.

Pettengill, G. H., Zisk, S. H., and Thompson, T. W., 1974, The mapping of lunar radar scattering characteristics: The Moon, v. 10 , p. 3-16.

Pettit, Edison, 1961, Planetary temperature measurements, in Kuiper, G. P., and Middlehurst, B. M., eds., The solar system, planets and satellites, v. III, chap. 10: Univ. Chicago Press, p. $400-428$

Pieters, Carle, Head, J. W., McCord, T. B., Adams, J. B., and Zisk, S. H., 1975, Geochemical and geological units of Mare Humorum: Definition using remote sensing and lunar sample information: Proc. Sixth Lunar Sci. Conf., Geochim. et Cosmochim. Acta, Supp. 6, v. 3, p. 2689-2710.

Pieters, Carle, McCord, T. B., Charette, M. P., and Adams, J. B., 1974, Lunar surfaces: Identification of the dark mantling material in the Apollo 17 soil samples: Science, v. 183, p. 1191-1194.

Pieters, Carle, McCord, T. B., Zisk, S. H., and Adams, J. B., 1973, Lunar black spots and the nature of the Apollo 17 landing area: Jour. Geophys. Research, v. 78, p. 5867-5875.

Pike, R. J., 1974, Depth/diameter relations of fresh lunar craters; Revision from spacecraft data: Geophys. Research Lett., v. 1, no. 7, p. 291-294.

- 1980, Geometric interpretation of lunar craters: U.S. Geol. Survey Professional Paper 1046-C (in press).

Podwysocki, M. H., Weidner, J. R., Andre, C. G., Bickel, A. L., Lum, R. S., Adler, I., and Trombka, J. I., 1974, The application of trend surface analysis to a portion of the Apollo $15 \mathrm{X}$-ray fluorescence data: Proc. Fifth Lunar Sci. Conf., Geochim. et Cosmochim. Acta, Supp. 5, v. 3, p. 3017-3024

Pohl, J., and Angenheister, G., 1969, Anomalien des Erdmagnetifeldes und Magnetisierung der Gesteine im Nordlinger Ries: Geol. Bavarica, v. 61, p. 327-336.

Pohn, H. A., and Wildey, R. L., 1970, A photoelectric-photographic study of the normal albedo of the Moon: U.S. Geol. Survey Prof. 
Paper 599-E, $20 \mathrm{p}$

Pollack, J. B., and Whitehill, Laird, 1972, A multiple-scattering model of the diffuse component of lunar radar echoes: Jour. Geophys. Research, v. 77, no. 23, p. 4289-4303.

Ponsonby, J. E. B., Morrison, I., Birks, A. R., and Landon, J. K., 1972, Radar images of the Moon at 75 and $185 \mathrm{~cm}$ wavelengths: The Moon, v. 5, p. 286-293.

Quaide, W. L., and Oberbeck, V. R., 1968, Thickness determinations of the lunar surface layer from lunar impact craters: Jour. Geophys. Research, v. 73 , no. 16 , p. 5244-5270.

- 1969, Geology of the Apollo landing sites: Earth Sci. Rev., v. 5, p. $255-278$.

Radlova, L. N., 1941, Visual colorimetry of the Moon, Uchenyye Zapiski: Leningrad State Univ., no. 82, p. 99-129 (in Russian). 1943, Photographic colorimetry of the Moon: Astron. Zhur., v. 20, p. 1-13 (in Russian with English summary).

Reed, V. S., and Wolfe, E. W., 1975, Origin of the Taurus-Littrow massifs: Proc. Sixth Lunar Sci. Conf., Geochim. et Cosmochim. Acta, Supp. 6, v. 3, p. 2443-2461.

Regan, R. D., and Hinze, W. J., 1975, Gravity and magnetic investigations of Meteor Crater, Arizona: Jour. Geophys. Research, v. 80 , p. $776-788$.

Rhodes, J. M., Adams, J. B., Charette, M. B., and Rogers, K. V., 1975, The chemistry of agglutinate fractions in lunar soils: Lunar Science VI, Lunar Sci. Inst., Houston, Tex., p. 665-666.

Roberson, F. I., and Kaula, W. M., 1972, Apollo 15 laser altimeter, in Apollo 15 preliminary science report: Natl. Aeronautics Space Admin. Spec. Pub. NASA SP-289, p. 25(48)-25(50).

Roelof, E. C., 1968, Thermal behavior of rocks on the lunar surface: Icarus, v. 8, p. 138-159.

Rowan, L.C., 1971, Geologic map of the Rupes Altai quadrangle of the Moon: U.S. Geol. Survey Misc. Geol. Inv. Map I-690 (LAC 96 ), scale $1: 1,000,000$.

Runcorn, S. K., 1975, An ancient lunar magnetic dipole field: Nature, v. 253, p. $701-703$.

Runcorn, S. K., Collinson, D. W., O'Reilly, W., Battey, M. H., Stephenson, A., Jones, J. M, Manson, A. J., and Readman, P.W., 1970, Magnetic properties of Apollo 11 lunar samples: Geochim. et Cosmochim. Acta, Supp. 1, v. 34, p. 2369-2398.

Runcorn, S. K., Collinson, D. W., O'Reilly, W., Stephenson, A., Battey, M. H., Manson, A. J., and Readman, P. W., 1971, Magnetic properties of Apollo 12 lunar samples: Proc. Royal Soc. London, Ser. A., v. 325, p. 157-174.

Russell, C. T., Coleman, P. J., Lichtenstein, B. R., Schubert, G., and Sharp, L. R., 1974, Apollo 15 and 16 subsatellite magnetometer measurements of the lunar magnetic field: Proc. 16th plenary meeting of COSPAR Akademie-Velga, Berlin, Space Research, v. 14 , p. $629-634$.

Russell, C. T., Coleman, P. J., Jr., Fleming, B. K., Hilburn, L., Lichtenstein, B. R., and Schubert, G., 1975, Low altitude lunar magnetic field observations, in Abstracts submitted to the Sixth Lunar Science Conference: Houston, Tex., Lunar Sci. Inst., p. 695.

Saari, J. M., and Shorthill, R. W., 1963, Isotherms of crater regions on the illuminated and eclipsed Moon: Icarus, v. 2, p. 115-136. -1965 , Thermal anomalies on the totally eclipsed Moon of December 19, 1964: Nature, v. 205, p. 964-965.

-1966a, Isotherms in the equatorial region of the totally eclipsed Moon: Boeing Sci. Research Laboratories Doc. D1-820530,3 p., 1 chart.

1966b, Hot spots on the Moon: Sky and Telescope, v. 31, no. 6, p. $3-7$.

1967, Isothermal and isophotic atlas of the Moon-contours through a lunation: Natl. Aeronautics Space Admin. Contractor Report NASA CR-855, 186 p.
1972, The sunlit lunar surface I, albedo studies and full Moon temperature distribution: The Moon, v. 5, p. 161-178.

Saari, J. M., Shorthill, R. W., and Deaton, T. K., 1966, Infrared and visible images of the eclipsed Moon of December 19, 1964: Icarus, v. 5, p. 635-659.

Salisbury, J. W., 1970, Albedo of lunar soil: Icarus, v. 13, p. 509-512. Schaber, G. G., 1973, Lava flows in Mare Imbrium: Geologic evaluation from Apollo orbital photography: Proc. Fourth Lunar Sci. Conf., Geochim. et Cosmochim. Acta, Supp. 4, v. 1, p. 73-92.

Schaber, G.G., Eggleton, R. E., and Thompson, T. W., 1970, Lunar radar mapping correlation between radar reflectivity and stratigraphy in northwestern Mare Imbrium: Nature, v. 226, no. 5252 , p. $1236-1239$.

Schaber, G. G., Thompson, T. W., and Zisk, S. H., 1975, Lava flows in Mare Imbrium: An evaluation of anomalously low Earth-based radar reflectivity: The Moon, v. 13, p. 395-423.

Schmitt, H. H., 1974, Lunar mare color provinces as observed on Apollo 17: Geology, v. 2, p. 55-56.

Schultz, P. H., and Gault, D. E., 1974, Seismic effects from major basin formation on the Moon and Mercury: Natl. Aeronautics Space Admin. NASA TM, S-62, 388, 39 p.

Scott, D. H., Diaz, J. M., and Watkins, J. A., 1975, The geologic evaluation and regional synthesis of metric and panoramic photographs: Proc. Sixth Lunar Sci. Conf., Geochim. et Cosmochim. Acta, Supp. 6, v. 3, p. 2531-2540.

Scott, D. H., McCauley, J. F., and West, M. N., 1977, Geologic map of the west side of the Moon: U. S. Geol. Survey Misc. Inv. Map I- 1034 , scale $1: 5,000,000$.

Scott, D. H., and Pohn, H. A. 1972, Geologic map of the Macrobius quadrangle of the Moon: U.S. Geol. Survey Misc. Geol. Inv. Map I-799 (LAC 43), scale $1: 1,000,000$.

1974, The geologic significance of some lunar gravity anomalies: Proc. Fifth Lunar Conf., Geochim. et Cosmochim. Acta, Supp. 5, v. 3, p. 3025-3036.

Scott, N. W., 1964, Color on the Moon: Nature, v. 204, p. 1075-1076.

Shoemaker, E. M., 1965, Preliminary analysis of the fine structure of the lunar surface in Mare Cognitum, in Ranger VII, Part II, Experimenters' analyses and interpretations: Pasadena, California Inst. Technology Jet Propulsion Lab. Tech. Rept. 32-700, p. 75-134.

1970, Origin of fragmental debris on the lunar surface and the history of the bombardment of the Moon: paper presented at I Seminaris de Geologia Lunar, Univ. Barcelona, May 1970.

Shoemaker, E. M., Batson, R. M, Holt, H. E., Morris, E. C., Rennilson, J. J., and Whitaker, E. A., 1969a, Observations of the lunar regolith and the Earth from the television camera on Surveyor 7: Jour. Geophys. Research, v. 74, no. 25, p. 6081-6119.

Shoemaker, E. M., and Hackman, R. J., 1962, Stratigraphic basis for a lunar time scale, in Kopal, Zdeněk, and Mikhailov, Z. K., eds., The Moon: New York, Academic Press, p. 289-300.

Shoemaker, E. M, Hait, M. H., Swann, G. A., Schleicher, D. L, Dahlem, D. H., Schaber, G. G., and Sutton, R. L., 1970, Lunar regolith at Tranquillity Base: Science, v. 167, no. 3918, p. 452455 .

Shoemaker, E. M., Morris, E. C., Batson, R. M., Holt, H. E. Larson, K. B., Montgomery, D. R., Rennilson, J. J., and Whitaker, E. A., $1969 \mathrm{~b}$, Television observations from Surveyor, in Surveyor program results: Natl. Aeronautics Space Admin. Spec. Pub. NASA SP-184, p. 19-128.

Short, N.M., and Forman, M. L., 1972, Thickness of impact crater ejecta on the lunar surface: Modern Geology, v. 3, p. 69-91.

Shorthill, R.W., 1970, "Infrared Moon": A review: Jour. Spacecraft and Rockets, v. 7, p. 385-397.

1973 , Infrared atlas charts of the eclipsed Moon: The Moon, v. 7, p. $22-45$. 
Shorthill, R. W., and Saari, J. M., 1965a, Nonuniform cooling of the eclipsed Moon: A listing of thirty prominent anomalies: Science, v. 150 , p. $210-212$.

1965b, Recent results of lunar eclipse measurements showing hot spots: Advances in Astronaut. Sci., v. 20, p. 545-556.

Silver, L. T., 1971, U-Th-Pb isotopic system in Apollo 11 and Apollo 12 regolithic materials and a possible age for the Copernican event [abs.]: Trans. American Geophys. Union, v. 52, no. 7, p. 534.

Sinton, W. M, 1962a, Temperatures on the lunar surface; in Kopal, Zdeněk, ed., Physics and astronomy of the Moon: New York, Academic Press, p. 407-428.

$-1962 b$, Eclipse temperatures of the lunar crater Tycho, in Kopal, Zdeněk, and Mikhailov, Z. K., eds. The Moon: New York, Academic Press, p. 469-471.

Sjogren, W. L., 1974, Lunar gravity at $100 \mathrm{~km}$ altitude: Proc. Fifth Lunar Sci. Conf., Geochim. et Cosmochim. Acta, Supp. 5, Plate 1.

Sjogren, W. L., Gottlieb, P., Muller, P. M., and Wollenhaupt, W. R., 1972a, Lunar gravity via Apollo 14 doppler radio tracking: Science, v. 175 , no. 4018 , p. $165-168$.

Sjogren, W. L., Muller, P. M., and Wollenhaupt, W. R., 1972b, Apollo 15 gravity analysis from the S-band transponder experiment: The Moon, v. 4, p. 411-418.

Sjogren, W. L., Wimberly, R. N., and Wollenhaupt, W. R., 1974a, Lunar gravity: Apollo 17: The Moon, v. 11, p. 41-52.

Sjogren, W. L., Wollenhaupt, W. R., and Wimberly, R. N., 1974b, Lunar gravity via the Apollo 15 and 16 subsatellite: The Moon, v. 9, p. 115-129.

1974c, Lunar gravity: Apollo 16, The Moon, v. 11, p. 35-40.

Soderblom, L. A., 1970a, A model for small-impact erosion applied to the lunar surface: Jour. Geophys. Research, v. 75, no. 14, p. 2655-2661.

1970b, The distribution and ages of regional lithologies in the lunar maria: Calif. Inst. Technology, Pasadena, Ph. D. thesis, $139 \mathrm{p}$.

Soderblom, L. A., and Boyce, J. M., 1972, Relative ages of some nearside and farside terra plains based on Apollo 16 metric photography, in Apollo 16 preliminary science report, pt. A: Natl. Aeronautics Space Admin. Spec. Pub. NASA SP-315, p. 29(3)29(5).

Soderblom, L.A., and Lebofsky, L. A., 1972, Technique for rapid determination of relative ages of lunar areas from orbital photography: Jour. Geophys. Research, v. 77, p. 279-296.

Sonett, C. P., Colburn, D. S., Currie, R. G, and Mihalov, J. D., 1967, The geomagnetic tail: Topology, reconnection and interaction with the Moon, in Carovillano, R. L., McCaly, J. F., and Radoski, H. F., eds. Physics of the magnetosphere: Dordrecht, Netherlands, D. Reidel, p. 461-484.

Sonnett, C. P., Colburn, D. S., Dyal, P., Parkin, C. W., Swith, B. F., Schubert, G., and Schwartz, K., 1971, Lunar electrical conductivity profile: Nature, v. 230, p. 359-362.

Srnka, L. J., Criswell, D. R., and Wollenhaupt, W. R., 1975, Lunar topography and limb compression source regions: The Moon, v. 14, p. 59-69.

Stamper, J. A., Papadopoulos, K., Sudan, R. N., Dean, S. O., and McLean, E. A., 1971, Spontaneous magnetic fields in laserproduced plasmas: Phys. Rev. Lett., v. 26, p. 1012-1015.

Strangway, D. W., Larsson, E. E., and Pearce, G. W., 1970, Magnetic studies of lunar samples-Breccia and fines: Proc. Apollo 11 Lunar Sci. Conf., Geochim. et Cosmochim. Acta, Supp. 1, v. 3, p. 2435-2451.

Strangway, D. W., Rylaarsdam, J. C., and Annan, A. P., 1975a, Lunar magnetic anomalies, in Abstracts submitted to the Sixth Lunar Science Conference: Houston, Tex., Lunar Sci. Inst., p. 789. -1975b, Magnetic anomalies near Van de Graaff Crater: Proc. 6th Lunar Sci. Conf., Geochim. et Cosmochim. Acta, Supp. 6, p. 2975-2984.

Stuart-Alexander, D. E., and Wilhelms, D. E., 1975, The Nectarian System, a new lunar time-stratigraphic unit: U. S. Geol. Survey Jour. Research, v. 3, p. 53-58.

Swann, G. A., Bailey, N. G., Batson, R. M., Eggleton, R. E., and others, 1971, Preliminary geologic investigations of Apollo 14 landing site, in Apollo 14 preliminary science reports: Natl. Aeronautics Space Admin. Spec. Pub. NASA SP-272, p. 39-85.

Swann, G. A., and Reed, V. S., 1974, A method for estimating the absolute ages of small Copernican craters and its application to the determination of Copernican meteorite flux, in Proc. Fifth Lunar Sci. Conf., Geochim. et Cosmochim. Acta, Supp. 5, v. 1, p. 151-158.

Tera, F., Papanastassiou, D. A., and Wasserburg, G. J., 1974, Isotopic evidence for a terminal lunar cataclysm: Earth Planetary Sci. Letters, v. 22, p. 1-21.

Thompson, T. W., 1970, Map of lunar radar reflectivity at $7.5 \mathrm{~m}$ wavelength: Icarus, v. 13, p. 363-370.

- 1974, Atlas of lunar radar maps at $70 \mathrm{~cm}$ wavelenth: The Moon, v. 10, p. 51-85.

Thompson, T. W., and Dyce, R. B., 1966, Mapping of lunar radar reflectivity at 70 centimeters: Jour. Geophys. Research, v. 71, p. 4843-4853.

Thompson, T. W., Howard, K. A., Shorthill, R. W., Tyler, G. L., Zisk, S. H., Whitaker, E. A., Schaber, G. G., and Moore, H. J., 1973, Remote sensing of Mare Serenitatis, in Apollo 17 preliminary science report: Natl. Aeronautics Space Admin. Spec. Pub. NASA SP-330, Part A, p. 33(3)-33(10).

Thompson, T. W., Masursky, Harold, Shorthill, R. W., Tyler, G. L, and Zisk, S. H., 1974, A comparison of infrared, radar, and geologic mapping of lunar craters: The Moon, v. 10, p. 87-117.

Thompson, T. W., Pollack, J. B., Campbell, M. J., and O'Leary, B. T., 1970, Radar maps of the Moon at $70 \mathrm{~cm}$ wavelength: Radio Sci., v. 5 , p. 253-262.

Thompson, T. W., and Zisk, S. H., 1972, Radar mapping of lunar surface roughness, in Lucas, John, ed., Progress in astronautics and aeronautics: Cambridge, Mass., M.I.T. Press, v. 28, p. 83117.

Tidman, D. A., 1974, Strong magnetic fields produced by composition discontinuities in laser-produced plasmas, Phys. Rev. Letters, v. 32 , p. $1179-1181$.

Tidman, D. A., and Shanny, R. A., 1974, Field-generating thermal instability in laser-heated plasmas: Physics of Fluids, v. 17, p. 1207-1210.

Trask, N. J., 1966, Size and spatial distribution of craters estimated from the Ranger photographs, in Ranger VIII and IX, Part II, Experimenters' analyses and interpretations: Pasadena, Calif. Inst. Technology Jet Propulsion Lab. Tech. Rept. 32-800, p. 252-264.

-1971, Geologic comparison of mare materials in the lunar equatorial belt, including Apollo 11 and 12 landing sites: U.S. Geol. Survey Prof. Paper 750-D, p. D138-D144.

Trombka, J. I., Arnold, J. R., Reedy, R. C., Peterson, L. E., and Metzger, A. E., 1973, Some correlations between measurements by the Apollo gamma-ray spectrometer and other lunar observations: Proc. Fourth Lunar Sci. Conf., Geochim. et Cosmochim. Acta, Supp. 4, v. 3, p. 2847-2853.

Turner, G., and Cadogan, P. H., 1975, The history of lunar bombardment inferred from ${ }^{40} \mathrm{Ar}-{ }^{39} \mathrm{Ar}$ dating of highland rocks: Proc. Sixth Lunar Sci., Conf. Geochim. et Cosmochim. Acta, Supp. 6, v. 2, p. 1509-1538.

Tyler, G. L., 1968, Oblique-scattering radar reflectivity of the lunar surface: Preliminary results from Explorer 35: Jour. Geophys. 
Research, v. 73 , p. $7608-7620$.

Tyler, G. L., and Howard, H. T., 1973, Dual-frequency bistatic-radar investigations of the Moon with Apollos 14 and 15: Jour. Geophys. Research, v. 78, p. 4852-4874.

Tyler, G. L., Howard, H. T., and Dow, G. R., 1973, Stanford Apollo Bistatic-Radar Experiment (S-170): National Space Science Data Center description: Stanford, Calif., Stanford Electronics Laboratories, Center for Radar Astronomy, Radioscience Laboratory Tech. Rept. 3282-1 (SU-SEL-72-006), 83 p.

Tyler, G. L., Simpson, R. A., and Moore, H. J., 1971, Lunar slope distributions: Comparison of bistatic-radar and photographic results: Jour. Geophys. Research, v. 76, p. 2790-2795.

Ulrich, G. E., and Muehlberger, W. E., ed., 1980, Geology of the Apollo 16 area, central lunar highlands: U.S. Geol. Survey Prof. Paper 1048 (in press).

Ulrich, G. E., and Saunders, R. S., 1968, Advanced system traverse research project report with a section on problems for geologic investigations of the Orientale region of the Moon: U.S. Geol. Survey open-file rept. Astrogeology-7, $11 \mathrm{p}$.

Urey, Harold, and Runcorn, S. K., 1973, A new theory on lunar magnetism: Science, v. 180 , p. 636-638.

Warren, N., and Anderson, O. L., 1972, Applications to lunar geophysical models of the velocity-density properties of lunar rocks, glasses, and artificial glasses: Proc. Third Lunar Sci. Conf., Geochim. et Cosmochim. Acta, Supp. 3. v. 3, p. 2587-2598.

Wasilewski, P. J., 1974, Magnetic remanence mechanisms in iron and iron-nickel alloys, metallographic recognition criteria and implications for lunar sample research: The Moon, v. 9, p. 335354.

Wasserburg, G. J., and Papanastassiou, D. A., 1971, Age of an Apollo 15 mare basalt: Lunar crust and mantle evolution: Earth Planetary Sci. Lett., v. 13, p. 97-104.

Whitaker, E. A., 1972, Color contrasts in Mare Nubium and the southern Oceanus Procellarum, in Apollo 16 Preliminary Science Report: Natl. Aeronautics Space Admin. Spec. Pub. NASA SP-315, p. 29-104 to 29-105.

-1973, Lunar color boundaries and their relationship to topographic features: A preliminary survey: The Moon, v. 4, p. 348355.

White, W. B., and Keester, K. L., 1966, Optical absorption spectra of iron in the rock-forming silicates: Am. Mineralogist, v. 51, p. 774-791.

-1967, Selection rules and assignments for the spectra of ferrous iron in pyroxenes: Am. Mineralogist, v. 52, p. 1508-1514.

Wilhelms, D. E, 1970, Summary of lunar stratigraphy-Telescopic observations: U.S. Geol. Survey Prof. Paper 599-F, 47 p.

1972a, Geologic mapping of the second planet: U.S. Geol. Survey Interagency Rept. Astrogeology 55, $36 \mathrm{p}$. -1972b, Geologic map of the Taruntius quadrangle of the Moon: U.S. Geol. Survey Misc. Geol. Inv. Map I-722 (LAC-61), scale $1: 1,000,000$.

1980 , Stratigraphy of part of the lunar nearside: U.S. Geological Survey Prof. Paper. 1046-A (in press).

Wilhelms, D. E., and El-Baz, Farouk, 1975, Geologic map of the east region of the Moon: U.S. Geol. Survey Misc. Inv. Map I-948, scale $1: 5,000,000$.

Wilhelms, D. E., and McCauley, J. F., 1971, Geologic map of the near side of the Moon: U.S. Geol. Survey Misc. Geol. Inv. Map I-703, scale $1: 5,000,000$.

Wilsing, I., and Scheiner, I., 1921, Spectrophotometric measurements on rocks on the Moon, Mars, and Jupiter: Pub. Astrophys. Observatory Potsdam, v. 24, p. 3-25.

Winter, D. F., 1970, The infrared Moon: Data interpretations and implications: Radio Sci., v. 5, p. 229-240.

Wolfe, E. W., Lucchitta, B. K., Reed, V. S., Ulrich, G. E., and Sanchez, A. G., 1975, Geology of the Taurus-Littrow valley floor: Proc. Sixth Lunar Sci. Conf., Geochim. et Cosmochim. Acta, Supp. 6, v. 3, p. 2463-2482.

Wood, R. W., 1912, Selective absorption of light on the Moon's surface and lunar petrography: Astrophys. Jour., v. 36, p. 75-84.

Wright, W. H., 1929, The Moon as photographed by light of different colors: Astron. Soc. Pacific Pub., v. 41, p. 125-132.

Young, R. A., 1975, Mare crater size frequency distributions: Implications for relative surfaces ages and regolith development, in Abstracts submitted to the Sixth Lunar Science Conference: Houston, Tex., Lunar Sci. Inst., p. 890-892.

Zisk, S. H., Hodges, C. A., Moore, H. J., Shorthill, R. W., Thompson, T. W., Whitaker, E. A., and Wilhelms, D. E., 1977, The Aristarchus-Harbinger region of the Moon: Surface geology and history from recent remote-sensing observations: The Moon, v. 17, p. 59-99.

Zisk, S. H., Hodges, C. A., Whitaker, E. A., Moore, H. J., Shorthill, R. W., Thompson, T. W., and Wilhelms, D. E., 1975, An examination of the Aristarchus area by remote sensing measurements, in Abstracts of papers submitted to Sixth Lunar Science Conference: Houston, Tex., Lunar Sci. Inst., Part II, p. 896-897.

Zisk, S. H., and Moore, H. J., 1972, Calibration of radar data from Apollo 16 results, in Apollo 16 preliminary science report: Natl. Aeronautics Space Admin. Spec. Pub. SP-315, p. 29-110 to 29 113.

Zisk, S. H., Pettengill, G. H., and Catura, G. W., 1974, 3.8-cm radar atlas of the Moon: The Moon, v. 10, p. 17-50.

Zook, H. A., 1975, The state of meteoric material on the Moon: Proc. Sixth Lunar Sci. Conf., Geochim. et Cosmochim. Acta, Supp. 6, v. 2, p. $1653-1672$. 